\title{
Causes and consequences of lipid overload in skeletal muscle, liver and heart
}

Citation for published version (APA):

Bilet, L. (2015). Causes and consequences of lipid overload in skeletal muscle, liver and heart. [Doctoral Thesis, Maastricht University]. Maastricht University. https://doi.org/10.26481/dis.20150702lb

Document status and date:

Published: 01/01/2015

DOI:

10.26481/dis.20150702lb

Document Version:

Publisher's PDF, also known as Version of record

\section{Please check the document version of this publication:}

- A submitted manuscript is the version of the article upon submission and before peer-review. There can be important differences between the submitted version and the official published version of record.

People interested in the research are advised to contact the author for the final version of the publication, or visit the DOI to the publisher's website.

- The final author version and the galley proof are versions of the publication after peer review.

- The final published version features the final layout of the paper including the volume, issue and page numbers.

Link to publication

\footnotetext{
General rights rights.

- You may freely distribute the URL identifying the publication in the public portal. please follow below link for the End User Agreement:

www.umlib.nl/taverne-license

Take down policy

If you believe that this document breaches copyright please contact us at:

repository@maastrichtuniversity.nl

providing details and we will investigate your claim.
}

Copyright and moral rights for the publications made accessible in the public portal are retained by the authors and/or other copyright owners and it is a condition of accessing publications that users recognise and abide by the legal requirements associated with these

- Users may download and print one copy of any publication from the public portal for the purpose of private study or research.

- You may not further distribute the material or use it for any profit-making activity or commercial gain

If the publication is distributed under the terms of Article $25 \mathrm{fa}$ of the Dutch Copyright Act, indicated by the "Taverne" license above, 


\section{CAUSES \\ AND CONSEQUENCES \\ OF LIPID OVERLOAD \\ IN SKELETAL MUSCLE, \\ LIVER AND HEART}

LENA BILET

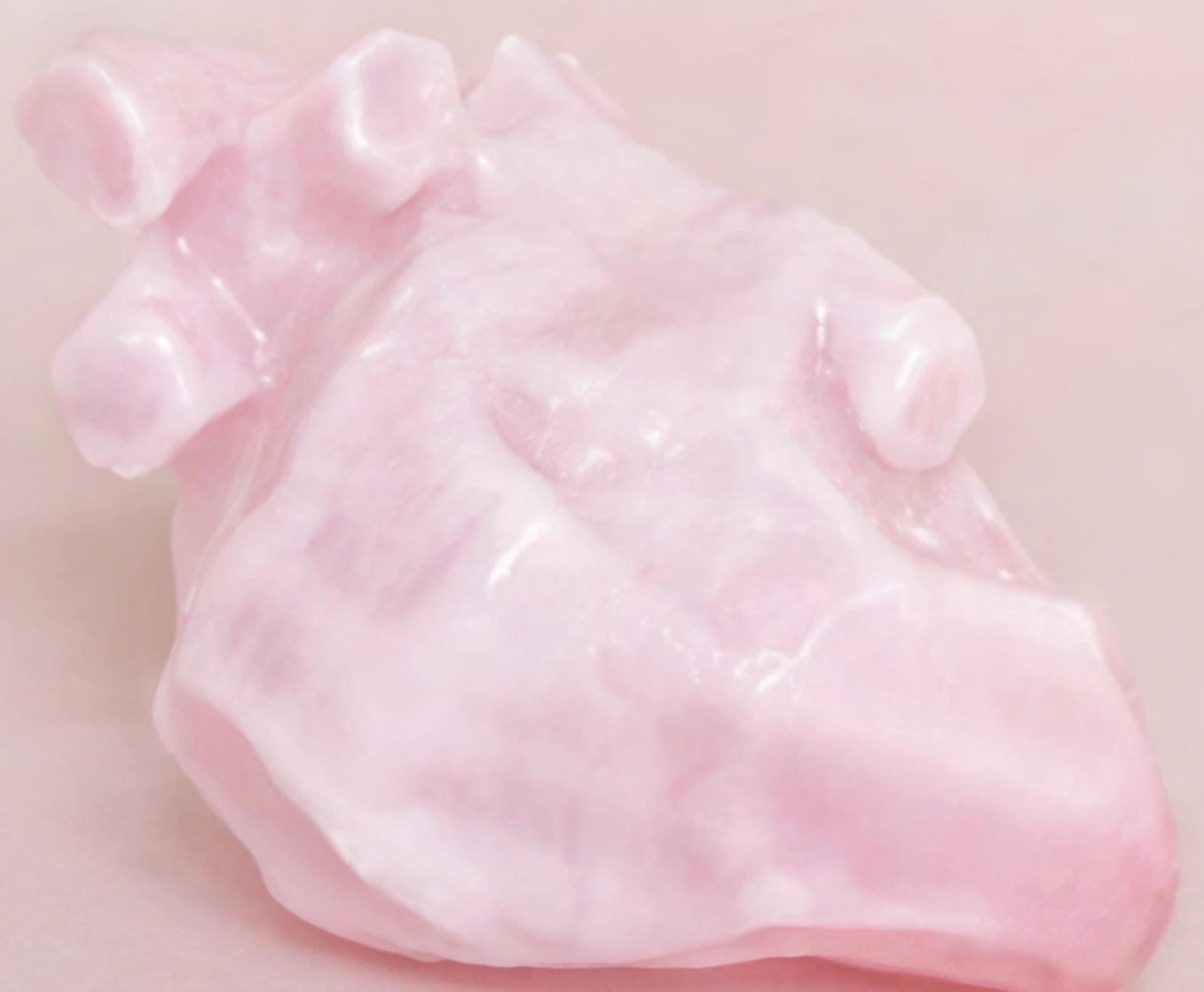


Causes and consequences of lipid overload in skeletal muscle, liver and heart 
The studies presented in this thesis were performed within NUTRIM School of Nutrition and Translational Research in Metabolism, which participates in the Graduate School VLAG (Food Technology, Agrobiotechnology, Nutrition and Health Sciences), accredited by the Royal Netherlands Academy of Arts and Sciences.
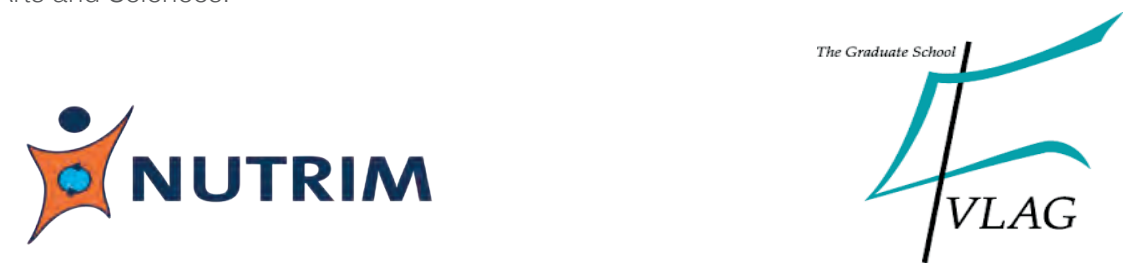

The research described in this thesis was supported by a $\mathrm{VICl}$ (grant 918.96.618) for innovative research from the Netherlands Organization for Scientific Research (NWO).

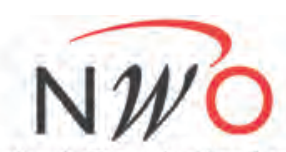

Netherlands Organisation for Scientific Research

Financial support by Unilever and the Dutch Heart Foundation for the publication of this thesis is gratefully acknowledged.
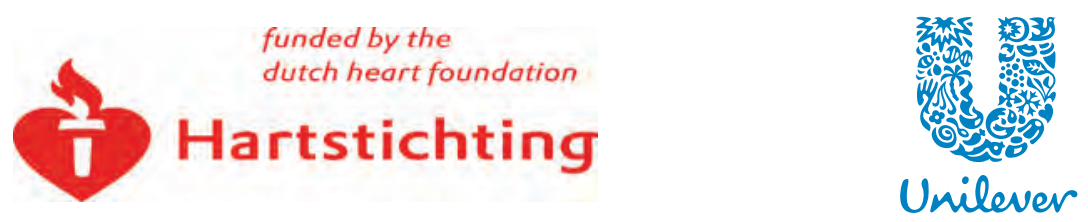

(C) Copyright Lena Bilet, Maastricht 2015

Photos and cover design: Ayfa van Oeteren

Layout: Lena Bilet

Printed by: Gilde print, Enschede

ISBN: 978-94-6233-010-8 


\section{Causes and consequences of lipid overload in skeletal muscle, liver and heart}

\section{Proefschrift}

ter verkrijging van de graad van doctor aan de Universiteit Maastricht, op gezag van de Rector Magnificus, Prof. dr. L.L.G. Soete volgens het besluit van het College van Decanen, in het openbaar te verdedigen op donderdag 2 juli 2015 om 14.00 uur

door

Lena Bilet 


\section{Promotores}

Prof. dr. P. Schrauwen

Prof. dr. M.K.C. Hesselink

\section{Co-promotor}

Dr. V.B. Schrauwen-Hinderling

\section{Beoordelingscommissie}

Prof. dr. ir. R. P. Mensink (voorzitter, Maastricht University Medical Center+)

Prof. dr. C. Schalkwijk (Maastricht University Medical Center+)

Prof. dr. ir. A. Kersten (Wageningen University \& Research Center)

Prof. dr. J. Eckel (German Diabetes Center Dusseldorf)

Dr. G. Plasqui (Maastricht University Medical Center+) 
Omne trium perfectum. 


\section{TABLE OF \\ 8 Chapter 1 \\ CONTENTS \\ 18 Chapter 2}

38 Chapter 3

58 Chapter 4

72 Chapter 5

100 Chapter 6

124 Chapter 7

142 Chapter 8

164 Chapter 9 
Introduction

Exercise-induced modulation of cardiac lipid content in healthy lean young men

Acute exercise does not decrease liver fat in men with overweight or NAFLD

Differential effects of exercise on IMCL content in the fasted and fed state

Treatment with Acipimox fails to improve insulin sensitivity and may impair cardiac function in non-insulin dependent type 2 diabetes mellitus

The effect of one-legged lowered physical activity on insulin sensitivity and lipid and glucose metabolism

The novel biomarker for insulin resistance alpha-hydroxybutyrate is not responsive to lifestyle changes affecting liver fat or insulin sensitivity

General discussion

Appendices 
L.Bilet 
CHAPTER

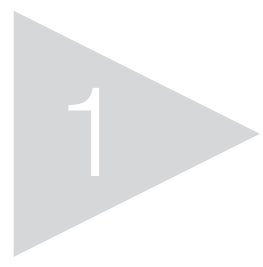

Introduction 


\section{OBESITY AND ITS COMORBIDITIES - A GROWING PROBLEM}

The World Health Organization (WHO) is defining overweight and obesity as "abnormal or excessive fat accumulation that presents a risk to health". Further they describe obesity as a result of an imbalance between calories consumed and calories expended resulting in an energy imbalance. Energy imbalance is caused by overnutrition [1] and physical inactivity. Obesity was recognized as a medical risk factor [2] already by the ancient Greeks with Hippocrates writing; "Corpulence is not a disease itself, but the harbinger of others" [3]. Today we know that obesity is associated with several chronic conditions, such as type 2 diabetes, cardiovascular disease and cancer. The prevalence of obesity has nearly doubled between 1980 and 2015, and the prevalence of obesity-related conditions is likely to increase as obesity continues to rise in the next few decades. At present, a least 2.8 million people die each year as a result of being overweight or obese (WHO report March 2013).

\section{ECTOPIC FAT ACCUMULATION}

Obesity is the major risk factor for insulin resistance, and $80 \%$ of all type 2 diabetic patients are overweight or obese. While obesity is characterized by an excessive accumulation of fat in the body, it is specifically the accumulation of fat within peripheral tissues, such as skeletal muscle, liver, and heart (called steatosis or ectopic fat accumulation), which is associated with the development of insulin resistance [4-11]. An excessive accumulation of these lipids in the cytoplasm of the cells of these organs may lead to cellular dysfunction or cell death, a phenomenon known as lipotoxicity [12-14]. It has been suggested that ectopic fat accumulation is the mechanistic link between obesity and chronic diseases such as type 2 diabetes and cardiovascular disease [15-17]. To better understand this relationship, it is important to study lipid accumulation in non-adipose tissue. The traditional way of measuring lipid content (especially in skeletal muscle) is to assess the amount of triglycerides in a biopsy. Non-invasive in vivo techniques, such as Proton Magnetic Resonance Spectroscopy ( ${ }^{1} \mathrm{H}-\mathrm{MRS}$ ), have recently become available to enable measurements of lipid accumulation in humans not only in skeletal muscle, but also in heart, liver and pancreas. Indeed, studies have shown that increased 
intramuscular triglyceride accumulation is associated with skeletal muscle insulin resistance $[18,19]$. Similarly, fat accumulation in the liver is an independent marker of metabolic dysfunction, such as insulin resistance and dyslipidaemia, and an independent predictor of type 2 diabetes; whereas obese persons with normal liver fat content appear to be resistant to developing obesity-related metabolic complications [20-22]. Finally, excess fat accumulation in the heart is a hallmark of obesity and type 2 diabetes and is associated with left ventricular dysfunction and premature death $[23,24]$. However, despite the well-known detrimental effects of ectopic fat accumulation, it is not completely understood why fat accumulates in non-adipose tissues and how this is regulated.

\section{LIPOTOXICITY AND ECTOPIC FAT ACCUMULATION}

The metabolic function of adipose tissue is to store fat, acting as a buffer by taking up dietary fat that enters the circulation [1, 25]. Those free fatty acids (FFA) are stored as triglycerides in adipocytes and serve as a source of energy during fasting conditions. However, the "adipose tissue expandability" or "lipid overflow" hypothesis $[26,27]$, states that there is a failure in the capacity for appropriate adipose tissue expansion in obesity. This failure leads to an increased fatty acid flux (meal derived or endogenous fatty acids) away from rather than into adipose tissue resulting in an inappropriate storage of fat in non-adipose tissue. In the insulin sensitive state, insulin is a potent inhibitor of lipolysis [28] and restrains the release of FFA from the adipocyte by inhibiting the lipases involved. However, in type 2 diabetics, the ability of insulin to inhibit lipolysis and maintain plasma FFA concentration low is markedly impaired [28]. This leads to a sustained elevated plasma FFA level. Chronically elevated plasma FFA levels, in turn, have been suggested to cause insulin resistance in muscle and liver [29-31], and these FFA-induced disturbances are referred to as lipotoxicity [31]. Therefore, ectopic fat accumulation has been considered the key feature distinguishing between metabolically healthy and metabolically abnormal subjects. With increased FFA influx, these non-adipose tissues will be challenged to promote fat oxidation. Recent evidence, however, suggests that oxidative capacity in these tissues is hampered in insulin resistance and diabetes [32, 33]. Indeed, impaired fat oxidative capacity in type 2 diabetic patients has been suggested as an underlying factor for ectopic fat accumulation [34, 35]. Therefore, compromised mitochondrial function may play an important role in the accumulation of fatty 
acids at ectopic sites, subsequently leading to steatosis, cardiomyopathy and hepatic and skeletal muscle insulin resistance. Although it has been recognized that the ectopic triglyceride accumulation per se is not always detrimental and can be adaptive, what happens to the fatty acids within non-adipose tissues is what determines the risk for developing insulin resistance. Within the cell, fatty acids can either be oxidized or directed towards storage. It is suggested that it is the accumulation of lipid intermediates of intramyocellular lipid (IMCL) content, such as diacylglycerol (DAG), ceramides and fatty acyl-CoAs, rather than triglyceride per se that impedes cellular insulin signalling [36, 37]. Interestingly, partitioning more fatty acids toward triglyceride synthesis within muscle reduced the accumulation of fatty acid metabolites and therefore supports the hypothesis above that it is the accumulation of these lipid intermediates and not IMCL per se that is causing insulin resistance. This concept has its roots in the "athletes' paradox" [38] because endurance-trained athletes are exquisitely insulin sensitive yet their intramuscular triglyceride content matches or even exceeds that of diabetic subjects [39]. The "athletes' paradox" was the first indication that ectopic fat accumulation per se is not a bad thing.

\section{OUTLINE OF THESIS}

The studies in this thesis mainly focus on the role of FFA in ectopic lipid accumulation and how this is linked to lipotoxicity. Environmental factors such as consumption of high-fat and/or energy-dense diets combined with a low physical activity level are the main causes of obesity. It is also well established that obesity predisposes individuals to accumulation of excessive fat in non-adipose tissues such as the heart, the liver and the skeletal muscle, eventually leading to the development of type 2 diabetes. However, why lipids accumulate in these tissues, and the role of FFA, is presently unknown.

Performing prolonged acute exercise in the fasted state is a model to physiologically elevate plasma FFAs. We therefore investigated the effect of exercise-induced elevation of plasma FFAs on ectopic fat accumulation in various tissues. In chapter 2 the effect of exercise-induced elevation of plasma FFAs on cardiac lipid content, cardiac function and cardiac energy status was investigated. In chapter $\mathbf{3}$ we investigated the effect of acute exercise on hepatic lipid accumulation and hepatic energy metabolism. Chapter $\mathbf{4}$ describes our investigation of the effect of acute 
exercise on skeletal muscle lipid content. In chapter $\mathbf{5}$ we aimed to reverse the effects of elevated plasma FFA levels by inhibition of peripheral lipolysis with a nicotinic acid analogue (Acipimox). We hypothesized that this would lead to reduction in ectopic fat accumulation and thereby improve organ function and subsequently improve the metabolic profile in type 2 diabetic patients.

Although plasma FFA levels, as pointed out above, play an important role in ectopic lipid accumulation and in the development of insulin resistance, mitochondrial dysfunction is also suggested to be an important determinant of ectopic lipid accumulation. Therefore, in chapter $\mathbf{6}$, we tried to unravel the relationship between mitochondrial function, ectopic lipid accumulation and insulin resistance. To this end we applied a model in which muscle mitochondrial function was changed in only one leg, leaving the other leg unaffected, thereby allowing the direct comparison within one individual - of the local effect of altered mitochondrial function on muscle lipid accumulation and insulin sensitivity. We applied the model of unilateral lower limb suspension (ULLS), mimicking inactivity in one leg of a subject, while using the other leg of the same individual as an active control.

Alpha-hydroxybutyrate has been recognized as a novel biomarker for progressive insulin resistance. In chapter $\mathbf{7}$ we used samples obtained from a variety of studies in well phenotyped subjects to examine if alpha-hydroxybutyrate could also be a useful marker to detect early changes in insulin sensitivity in future studies.

Finally, in chapter $\mathbf{8}$ the results of the present thesis are discussed in broader perspective. 


\section{REFERENCES}

1. Frayn KN. Adipose tissue as a buffer for daily lipid flux. Diabetologia. 2002;45(9):1201-10.

2. Haslam D. Obesity: a medical history. Obes Rev. 2007;8 Suppl 1:31-6.

3. Haslam DW, James WP. Obesity. Lancet. 2005;366(9492):1197-209.

4. Unger $\mathrm{RH}$. Lipotoxicity in the pathogenesis of obesity-dependent NIDDM. Genetic and clinical implications. Diabetes. 1995;44(8):863-70.

5. Boden G. Obesity, insulin resistance and free fatty acids. Curr Opin Endocrinol Diabetes Obes. 2011;18(2):139-43.

6. Boden G, Lebed B, Schatz M, Homko C, Lemieux S. Effects of acute changes of plasma free fatty acids on intramyocellular fat content and insulin resistance in healthy subjects. Diabetes. 2001;50(7):1612-7.

7. Badin PM, Louche K, Mairal A, Liebisch G, Schmitz G, Rustan AC, Smith SR, Langin D, Moro C. Altered skeletal muscle lipase expression and activity contribute to insulin resistance in humans. Diabetes. 2011;60(6):1734-42.

8. Felber JP, Ferrannini E, Golay A, Meyer HU, Theibaud D, Curchod B, Maeder E, Jequier E, DeFronzo RA. Role of lipid oxidation in pathogenesis of insulin resistance of obesity and type II diabetes. Diabetes. 1987;36(11):1341-50.

9. Krssak M, Roden M. The role of lipid accumulation in liver and muscle for insulin resistance and type 2 diabetes mellitus in humans. Rev Endocr Metab Disord. 2004;5(2):127-34.

10. Perseghin G, Scifo P, De Cobelli F, Pagliato E, Battezzati A, Arcelloni C, Vanzulli A, Testolin G, Pozza G, Del Maschio A, Luzi L. Intramyocellular triglyceride content is a determinant of in vivo insulin resistance in humans: a ${ }^{1} \mathrm{H}-{ }^{13} \mathrm{C}$ nuclear magnetic resonance spectroscopy assessment in offspring of type 2 diabetic parents. Diabetes. 1999;48(8):1600-6.

11. Unger RH, Orci L. Lipotoxic diseases of nonadipose tissues in obesity. Int $\mathrm{J}$ Obes Relat Metab Disord. 2000;24 Suppl 4:S28-32.

12. Unger $\mathrm{RH}$, Orci L. Diseases of liporegulation: new perspective on obesity and related disorders. FASEB J. 2001;15(2):312-21.

13. Schaffer JE. Lipotoxicity: when tissues overeat. Curr Opin Lipidol. 2003;14(3):281-7.

14. van Herpen NA, Schrauwen-Hinderling VB. Lipid accumulation in nonadipose tissue and lipotoxicity. Physiol Behav. 2008;94(2):231-41.

15. Despres JP. Body fat distribution and risk of cardiovascular disease: an update. Circulation. 2012;126(10):1301-13.

16. Shimabukuro M. Cardiac adiposity and global cardiometabolic risk: new concept and clinical implication. Circulation journal : official journal of the Japanese Circulation Society. 2009;73(1):27-34.

17. Shulman Gl. Ectopic fat in insulin resistance, dyslipidemia, and cardiometabolic disease. The New England journal of medicine. 
2014;371(12):1131-41.

18. Goodpaster BH, Theriault R, Watkins SC, Kelley DE. Intramuscular lipid content is increased in obesity and decreased by weight loss. Metabolism. 2000;49(4):467-72.

19. Pan DA, Lillioja S, Kriketos AD, Milner MR, Baur LA, Bogardus C, Jenkins $A B$, Storlien LH. Skeletal muscle triglyceride levels are inversely related to insulin action. Diabetes. 1997;46(6):983-8.

20. Fabbrini E, Mohammed BS, Magkos F, Korenblat KM, Patterson BW, Klein S. Alterations in adipose tissue and hepatic lipid kinetics in obese men and women with nonalcoholic fatty liver disease. Gastroenterology. 2008;134(2):424-31.

21. Korenblat KM, Fabbrini E, Mohammed BS, Klein S. Liver, muscle, and adipose tissue insulin action is directly related to intrahepatic triglyceride content in obese subjects. Gastroenterology. 2008;134(5):1369-75.

22. Deivanayagam S, Mohammed BS, Vitola BE, Naguib GH, Keshen TH, Kirk EP, Klein S. Nonalcoholic fatty liver disease is associated with hepatic and skeletal muscle insulin resistance in overweight adolescents. Am J Clin Nutr. 2008;88(2):257-62.

23. Iozzo P. Myocardial, perivascular, and epicardial fat. Diabetes Care. 2011;34 Suppl 2:S371-9.

24. Haemmerle G, Lass A, Zimmermann R, Gorkiewicz G, Meyer C, Rozman J, Heldmaier G, Maier R, TheussI C, Eder S, Kratky D, Wagner EF, Klingenspor M, Hoefler G, Zechner R. Defective lipolysis and altered energy metabolism in mice lacking adipose triglyceride lipase. Science. 2006;312(5774):7347.

25. Lewis GF, Carpentier A, Adeli K, Giacca A. Disordered fat storage and mobilization in the pathogenesis of insulin resistance and type 2 diabetes. Endocr Rev. 2002;23(2):201-29.

26. Unger $\mathrm{RH}$. Lipid overload and overflow: metabolic trauma and the metabolic syndrome. Trends Endocrinol Metab. 2003;14(9):398-403.

27. Groop LC, Bonadonna RC, DelPrato S, Ratheiser K, Zyck K, Ferrannini E, DeFronzo RA. Glucose and free fatty acid metabolism in non-insulindependent diabetes mellitus. Evidence for multiple sites of insulin resistance. The Journal of clinical investigation. 1989;84(1):205-13.

28. Boden $\mathrm{G}$. Role of fatty acids in the pathogenesis of insulin resistance and NIDDM. Diabetes. 1997;46(1):3-10.

29. Boden G, Shulman GI. Free fatty acids in obesity and type 2 diabetes: defining their role in the development of insulin resistance and beta-cell dysfunction. Eur J Clin Invest. 2002;32 Suppl 3:14-23.

30. Bays H, Mandarino L, DeFronzo RA. Role of the adipocyte, free fatty acids, and ectopic fat in pathogenesis of type 2 diabetes mellitus: peroxisomal proliferator-activated receptor agonists provide a rational therapeutic 
approach. J Clin Endocrinol Metab. 2004;89(2):463-78.

31. Saltiel AR. New perspectives into the molecular pathogenesis and treatment of type 2 diabetes. Cell. 2001;104(4):517-29.

32. McGarry JD. What if Minkowski had been ageusic? An alternative angle on diabetes. Science. 1992;258(5083):766-70.

33. Kelley DE, Simoneau JA. Impaired free fatty acid utilization by skeletal muscle in non-insulin-dependent diabetes mellitus. The Journal of clinical investigation. 1994;94(6):2349-56.

34. Blaak EE, Wagenmakers AJ, Glatz JF, Wolffenbuttel BH, Kemerink GJ, Langenberg CJ, Heidendal GA, Saris WH. Plasma FFA utilization and fatty acid-binding protein content are diminished in type 2 diabetic muscle. Am J Physiol Endocrinol Metab. 2000;279(1):E146-54.

35. Kelley DE, Mandarino LJ. Fuel selection in human skeletal muscle in insulin resistance: a reexamination. Diabetes. 2000;49(5):677-83.

36. Shulman GI. Cellular mechanisms of insulin resistance. The Journal of clinical investigation. 2000;106(2):171-6.

37. Goodpaster BH, He J, Watkins S, Kelley DE. Skeletal muscle lipid content and insulin resistance: evidence for a paradox in endurance-trained athletes. J Clin Endocrinol Metab. 2001;86(12):5755-61.

38. van Loon LJ, Koopman R, Manders R, van der Weegen W, van Kranenburg GP, Keizer HA. Intramyocellular lipid content in type 2 diabetes patients compared with overweight sedentary men and highly trained endurance athletes. Am J Physiol Endocrinol Metab. 2004;287(3):E558-65. 
L.Bilet, T. van de Weijer, M.K.C. Hesselink, J.F.C. Glatz, H.J. Lamb, J. Wildberger, M.E. Kooi, P. Schrauwen, V.B. Schrauwen-Hinderling

Basic Research in Cardiology 2011 Mar; 106(2):307-315 


\section{CHAPTER}

\section{Exercise-induced modulation of}

cardiac lipid content in healthy lean young men 


\section{ABSTRACT}

Cardiac lipid accumulation is associated with decreased cardiac function and energy status (PCr/ATP). It has been suggested that elevated plasma fatty acid (FA) concentrations are responsible for cardiac lipid accumulation. Therefore, the aim of the present study was to investiagte if elevating plasma FA concentrations by exercise results in an increased cardiac lipid content, and if this influences cardiac function and energy status. Eleven male subjects (age: $25.4 \pm 1.1$ y, BMl: $23.6 \pm 0.8$ $\mathrm{kg} / \mathrm{m}^{2}$ ) performed a $2 \mathrm{~h}$ cycling protocol, once while staying fasted, and once while ingesing glucose, to create a state of high verus low plasma FA concentrations, respectively. Cardiac lipid content was measured by Proton Magnetic Resonance Spectroscopy ( $\left.{ }^{1} \mathrm{H}-\mathrm{MRS}\right)$ at baseline, directly after exercise and again $4 \mathrm{~h}$ post exercise, together with systolic function (by multi-slice cine-MRI) and cardiac energy status (by ${ }^{31} \mathrm{P}-\mathrm{MRS}$ ). Plasma FA concentrations were increased three-fold during exercise and nine-fold during recovery in the fasted state compared with the glucose-fed state $(p<0.01)$. Cardiac lipid content was elevated at the end of the fasted test day (from $0.26 \pm 0.04 \%$ to $0.44 \pm 0.04 \%, p=0.003$ ), while it did not change with glucose supplementation (from $0.32 \pm 0.03 \%$ to $0.26 \pm 0.05 \%$, $p=0.272$ ). Furthermore, PCr/ATP was decreased by $32 \%$ in the high plasma FA state compared with the low FA state $(n=6, P=0.014)$. However, in the high FA state, the ejection fraction $4 \mathrm{~h}$ post exercise was higher compared with the low FA state (63 $\pm 2 \%$ vs $59 \pm 2 \%, p=0.018$ ). Elevated plasma FA concentrations, induced by exercise in the fasted state, lead to increased cardiac lipid content but do not acutely hamper systolic function. Although the lower cardiac energy status is in line with a lipotoxic action of cardiac lipid content, a causal relationship cannot be proven. 


\section{INTRODUCTION}

Hospitalization for congestive heart failure is increasing world wide [20]. This increase is associated with the increasing prevalence of obesity $[10,6]$, which is an independent risk factor for the development of heart failure [11]. Obesity is associated with excessive storage of lipids (triglycerides) not only in adipose tissue but also in skeletal muscle, the liver and the heart. It has been suggested that lipid accumulation in cardiac tissue may have lipotoxic effects, thereby hampering cardiac function and predisposing to cardiomyopathy and heart failure. Cardiac lipotoxicity is well documented in both obese $[31,36]$ and lean animal models with exaggerated storage of fat in cardiac muscle induced by targeted over expression of genes involved in lipid delivery and synthesis in the myocardium [35,2,3,1,17], but direct evidence for cardiac lipotoxicity in humans is scarce. However, proton magnetic resonance spectroscopy ( ${ }^{1} \mathrm{H}-\mathrm{MRS}$ ) has recently been proven reliable for non-invasive in vivo investigation of cardiac tissue and enables human interventional studies $[29,32]$. Such studies have indicated that cardiac lipid accumulation is elevated in conditions of increased circulating fatty acid (FA) concentrations, such as obesity [5], a very low calorie diet [33] and fasting [18], and circulating FA concentrations were found to correlate with cardiac lipid content [5]. These data suggest that the cardiac uptake of FA is not tightly matched to oxidational needs but rather follows circulating FA concentrations. In addition, it has been shown that high plasma FA concentrations correlate negatively with the energy status of the heart [21], and the latter has a strong prognostic value in heart failure patients and might be an early marker of disturbed cardiac metabolism [16].

In that respect, it is interesting to examine the effect of acute exercise on cardiac lipid content and function. Acute exercise - when performed in the fasting state - is associated with a 3-fold elevation of plasma FA concentrations [22]. However, when acute exercise is performed while providing carbohydrate beverages, the increase in FA can be completely blunted. It could be hypothesized that cardiac lipid content will increase during exercise performed in the fasting state, due to elevated plasma FA concentrations. On the other hand, lipid content in skeletal muscle can be lowered by prolonged acute exercise [24] even despite high circulatory FA concentrations, due to increased fat oxidation to fuel physical activity. We have recently shown that prolonged endurance training decreased cardiac lipid content in parallel with improvements in cardiac function [23]. Thus, it can also be hypothesized that cardiac lipid content will decrease during exercise due to an increased oxidation of 
FA needed to meet the increased cardiac work. Therefore, comparing the effect of acute exercise with high versus low circulating FA concentrations will allow us to test the hypothesis that physiologically-induced elevation of plasma FA concentrations lead to an unrestricted uptake of FA in cardiac tissue, subsequent accumulation of intracardiac fat, and an ultimate reduction in cardiac function and cardiac energy status. To this end, we employed ${ }^{1} \mathrm{H}$-MRS to determine cardiac lipid content before and after exercise as well as four hours post exercise. MRI and ${ }^{31} \mathrm{P}-\mathrm{MRS}$ was employed four hours post exercise to determine cardiac function and cardiac energy status, respectively.

\section{MATERIALS AND METHODS}

\section{SUBJECTS}

Eleven healthy lean, untrained young men participated in this study. Subjects' characteristics are shown in table 1. None of the subjects participated in competitive sports and subjects with unstable weight ( $>3 \mathrm{~kg}$ change in preceding six months) were excluded from the study. The institutional medical ethical committee approved the study and written informed consent was obtained from all participants.

Table 1 Subjects' characteristics

\begin{tabular}{ll}
\hline Subjects' characteristics & Mean $\pm \mathrm{SE}$ \\
\hline Age, $\mathrm{yr}$ & $25.4 \pm 1.1$ \\
Height, $\mathrm{m}$ & $1.79 \pm 0.02$ \\
Weight, $\mathrm{kg}$ & $75.8 \pm 3.5$ \\
$\mathrm{BMl}, \mathrm{kg} / \mathrm{m}^{2}$ & $23.6 \pm 0.8$ \\
Fat $\%$ & $18.3 \pm 2.2$ \\
$\mathrm{VO}_{2} \mathrm{max} / \mathrm{kg}, \mathrm{ml} \times \mathrm{min}^{-1} \times \mathrm{kg}^{-1}$ & $38.5 \pm 15.6$ \\
\hline
\end{tabular}

Data are means \pm SD. BMI Body mass index.

\section{STUDY PROTOCOL}

Before the start of the study, body composition and maximal aerobic capacity was determined in all subjects. The experimental trial comprised two separate test days. Subjects refrained from physical activity two days prior to the test days. Furthermore, subjects were instructed to consume a standardized meal the 
evening prior to the test days and stay fasted from $10 \mathrm{pm}$ onwards. On the test days, subjects came to the laboratory at 7:00 am after an overnight fast. Cardiac lipid content was investigated by ${ }^{1} \mathrm{H}-\mathrm{MRS}$. After this, a teflon canula was inserted into an antecubital vein for sampling of blood. Immediately after taking the first blood sample, subjects ingested $1.4 \mathrm{~g} / \mathrm{kg}$ body weight of glucose (dissolved in water to a $20 \%$ solution and flavoured with $1 \mathrm{ml}$ lemon juice) or the same amount of water on the test day in fasted state. Next, subjects were guided to another lab where they started exercising at $50 \%$ of their maximal power output ( $t=0$ minute). The exercise period lasted for two hours and during exercise blood samples were taken and substrate oxidation was measured by indirect calorimetry for 15 minutes (Omnical, Maastricht, The Netherlands) every 30 minutes (at $t=30,60,90$ and 120 minutes). Immediately after cessation of the two hours of exercise, a second ${ }^{1} \mathrm{H}-\mathrm{MRS}$ measurement was performed. Subsequently, subjects bed-rested for three hours and a third ${ }^{1} \mathrm{H}-M R S$ scan together with additional measurements of ejection fraction (by CINE-MRI) and cardiac energy status (by ${ }^{31} \mathrm{P} \mathrm{MRS}$ ) were started four hours after exercise. During this post exercise period, blood samples were taken and substrate oxidation measured for 15 minutes every hour (at $t=180,240,300$ and 360 minutes). The experimental design is depicted in figure 1.

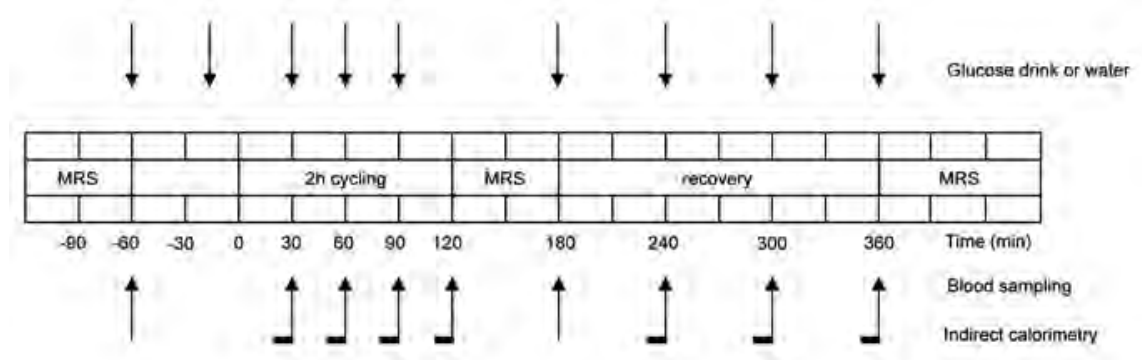

Figure 1 Experimental design of the study. All subjects performed the protocol two times, one time in the fasted state consuming water and one time with glucose supplementation. MRS cardiac magnetic resonance spectroscopy

The entire protocol was performed twice: once with the ingestion of glucose $(0.35 \mathrm{~g} /$ $\mathrm{kg}$ body weight at $\mathrm{t}=-15,30,60,90,180,240,300$ and 360) after the initial bolus of $1.4 \mathrm{~g} / \mathrm{kg}$ of body weight and once in the fasted state with ingestion of equal amounts of water. Both test days were separated by at least one week and were performed in random order. On a separate day a reference measurement of cardiac function without prior exercise was performed in the morning after an overnight fast. 


\section{MAXIMAL OXYGEN UPTAKE (WHOLE BODY OXIDATIVE CAPACITY)}

A routine incremental cycling test was used to determine maximal aerobic capacity as described previously [8]. Briefly, after a warming-up period of $5 \mathrm{~min}$, the intensity was increased every 2.5 min until exhaustion. Oxygen consumption was measured continuously throughout the test using indirect calorimetry (Omnical, Maastricht, The Netherlands) to determine $\mathrm{VO}_{2}$ max.

\section{HYDROSTATIC WEIGHING}

Hydrostatic weighing with simultaneous measurement of lung volume was used to determine body composition in the morning in the fasted state. The equation of Siri [28] was used to calculate fat percentage, fat mass and fat-free mass.

\section{BLOOD SAMPLE ANALYSES}

Blood samples were collected in EDTA-containing tubes and immediately centrifuged at high speed and frozen in liquid nitrogen and thereafter stored at $-80^{\circ} \mathrm{C}$ until assayed. Plasma fatty acids, triglycerides and glucose were measured with enzymatic assays automated on a Cobas Fara/Mira (FA: Wako Nefa C test kit; Wako Chemicals, Neuss, Germany) (glucose: hexokinase method; Roche, Basel, Switzerland) (triglycerides: ABX Pentra CP reagens, Horiba ABX Diagnostics, Montpellier, France) (glycerol: EnzytecTM glycerol kit, R-Biopharm, Germany).

\section{$\mathrm{MRI}$}

Cardiac CINE-MRI examinations were performed on a whole body MRI-scanner (Intera, 1.5 T, Philips Healthcare, Best, The Netherlands) as reported previously [32]. At the end of the test day, slices covering the whole left ventricle were acquired in 24 heart phases, to determine parameters of systolic function. During the other measurements, only four slices were acquired, which was sufficient to guide spectroscopy.

\section{IMAGE PROCESSING}

All images were analyzed quantitatively and ten images were examined for 
inter-observer reliability using dedicated software (CAAS, Pie Medical Imaging, Maastricht, The Netherlands) to determine end diastolic and end systolic volumes, left ventricular stroke volume, ejection fraction, cardiac output and cardiac index.

\section{${ }^{1} \mathrm{H}$ MRS}

Cardiac lipid content was determined in vivo by ${ }^{1} \mathrm{H}-\mathrm{MRS}$ as reported previous [23]. Respiratory gating and tracking was performed with a pencil beam navigator placed on the diaphragm [32]. Chemical shift selective (CHESS) water suppression was performed to acquire spectra of the lipid metabolites using a series of 32 spectra ( $n=2$ each), resulting in a total of 64 acquisitions. To acquire a reference spectrum of the unsuppressed water peak in the same volume of interest, the acquisition was repeated, with the CHESS pulse off resonance, using a series of 12 spectra ( $n=2$ each), resulting in a total of 24 acquisitions. From eleven subjects two had to be excluded from the cardiac lipid content analysis due to poor quality of spectra.

\section{${ }^{1}$ H-MRS SPECTRAL POST PROCESSING}

Post processing of the spectra was performed with the jMRUI software [7]. All ${ }^{1} \mathrm{H}$ MR spectroscopic data were fitted in the time domain. Manual phase correction was performed and subsequently all spectra with water suppression and without were averaged, resulting in one water-suppressed lipid spectrum originating from 128 averages and a non-suppressed spectrum from 24 averages for quantification of the water resonance. Myocardial lipid peaks were fitted by using the Advanced Magnetic Resonance (AMARES) fitting algorithm [34] within the jMRUI software [15] as reported earlier [32]. Cardiac lipid content is given as the percentage of the $\mathrm{CH}_{2}$ peak compared to the water resonance, uncorrected for T1 and T2 relaxation.

\section{${ }^{31} \mathrm{P}-\mathrm{MRS}$}

Single voxel cardiac ${ }^{31} \mathrm{P}-\mathrm{MRS}$ spectra were obtained from the left ventricle with subjects in the supine position as reported previously [9]. A $10 \mathrm{~cm}$ coil was fixed on the chest, at the level of the myocardium. Manual tuning and matching of the ${ }^{31} \mathrm{P}$-surface coil was performed to adjust for different coil loadings. ECG-triggered ISIS was used for localization to the left ventricle (TR=3.6 s, $n=192$ ). Spectroscopy and shimming volumes were planned on the transverse and sagittal scout images 
to include the entire left ventricle, while avoiding chest wall muscle and diaphragm muscle. A rest slab was placed over the chest muscle to minimize contamination from skeletal muscle.

\section{${ }^{31}$ P-MRS SPECTRAL POST PROCESSING}

${ }^{31}$ P-MRS was quantified with the dedicated software jMRUI. Signals were quantified in the time domain. Six Gaussian peaks were fitted using prior knowledge defining chemical shift. The ATP level in the ${ }^{31} \mathrm{P}-\mathrm{MRS}$ was corrected for the ATP contribution from blood and T1 corrected [4].

\section{STATISTICS}

Data are presented as mean \pm SE. A two-way ANOVA for repeated measures was performed to analyse data over time for cardiac lipid content, substrate oxidation and plasma values of FA, glucose, triglycerides and glycerol. Statistical differences in ejection fraction and PCr/ATP between the two conditions were determined by a paired student t-test. All statistics were performed using SPSS 16.0 for Mac and $\mathrm{P}<0.05$ was considered statistically significant.

\section{RESULTS}

\section{ENERGY EXPENDITURE AND SUBSTRATE OXIDATION}

No significant differences in energy expenditure between the glucose-fed and the fasted state were found neither during exercise nor post exercise (see table 2). During exercise, there was a significant time $(P<0.01)$ and treatment $(p<0.01)$ effect for respiratory quotient $(R Q)$, without a time ${ }^{\star}$ treatment interaction $(p=0.39)$ effect. $R Q$ was significantly lower at all time points in the fasted state compared with the glucose-fed state $(p<0.01)$ (see figure $2 a)$, reflecting lower carbohydrate oxidation in the fasted state, and $R Q$ decreased between $t=30$ and $t=90 \mathrm{~min}(p<0.05)$ in both conditions. In the post exercise period, a significant treatment effect $(p<0.01)$ was revealed, but no time $(p=0.88)$ or time*treatment $(p=0.10)$ effects were present. Also under resting conditions post exercise, $R Q$ was significantly lower in the fasted state compared with the glucose-fed state at all time points $(<0.01)$. 
During exercise, there was a significant time $(p<0.01)$ and treatment $(p<0.01)$ effect for both carbohydrate and fat oxidation, without a time*treatment interaction $(p=0.38$ and 0.27 , respectively) effect. As depicted in table 2 , carbohydrate oxidation was significantly lower at all time points in the fasted state compared with the glucose-fed state $(p<0.01)$, whereas fat oxidation was significantly higher at all time points in the fasted state compared with the glucose-fed state $(p<0.05)$. Both carbohydrate and fat oxidation increased between $t=30$ and $t=90(p<0.01)$. In the post exercise period the carbohydrate oxidation was significantly lower in the fasted state compared with the glucose-fed state at all time points $(p<0.01)$, whereas the fat oxidation was significantly higher in the fasted state compared with the glucose-fed state at all time points $(p<0.01)$. There was no time or time*treatment interaction effect for neither carbohydrate nor fat oxidation in the post exercise period $(P>0.05)$.

Table 2 Energy expenditure and fat and carbohydrate oxidation during and after exercise in glucose-fed and fasted state

\begin{tabular}{|c|c|c|c|c|c|c|c|}
\hline & \multirow[b]{2}{*}{$\begin{array}{l}\text { Time, } \\
\text { min }\end{array}$} & \multicolumn{3}{|c|}{ Glucose-fed } & \multicolumn{3}{|c|}{ Fasted } \\
\hline & & $\begin{array}{c}\mathrm{EE}, \\
\mathrm{kJ} / \mathrm{min}\end{array}$ & $\begin{array}{c}\text { Fat } \\
\text { oxidation, } \\
\mathrm{mg} / \mathrm{min}\end{array}$ & $\begin{array}{c}\text { CHO } \\
\text { oxidation, } \\
\mathrm{mg} / \mathrm{min}\end{array}$ & $\begin{array}{c}\mathrm{EE}, \\
\mathrm{kJ} / \mathrm{min}\end{array}$ & $\begin{array}{c}\text { Fat } \\
\text { oxidation, } \\
\text { mg/min }\end{array}$ & $\begin{array}{c}\text { CHO } \\
\text { oxidation, } \\
\text { mg/min }\end{array}$ \\
\hline \multirow{4}{*}{ Exercise } & 30 & $41.9 \pm 1.5$ & $313 \pm 31$ & $1871 \pm 80$ & $41.7 \pm 1.6$ & $476 \pm 83^{*}$ & $1451 \pm 151^{*}$ \\
\hline & 60 & $41.9 \pm 1.2$ & $398 \pm 27$ & $1659 \pm 73$ & $42.0 \pm 1.3$ & $530 \pm 31^{\#}$ & $1336 \pm 88^{\#}$ \\
\hline & 90 & $42.3 \pm 1.4$ & $469 \pm 27$ & $1503 \pm 67$ & $42.3 \pm 1.5$ & $635 \pm 16^{\#}$ & $1092 \pm 85^{\#}$ \\
\hline & 120 & $43.8 \pm 1.9$ & $467 \pm 3$ & $1606 \pm 137$ & $42.5 \pm 1.8$ & $665 \pm 22^{\#}$ & $1026 \pm 124^{\#}$ \\
\hline \multirow{3}{*}{$\begin{array}{l}\text { Post- } \\
\text { exercise }\end{array}$} & 240 & $5.3 \pm 0.2$ & $45 \pm 8$ & $226 \pm 19$ & $5.5 \pm 0.2$ & $95 \pm 7^{\#}$ & $109 \pm 11^{\#}$ \\
\hline & 300 & $5.4 \pm 0.2$ & $30 \pm 5$ & $267 \pm 17$ & $5.5 \pm 0.2$ & $103 \pm 5^{\#}$ & $93 \pm 11^{\#}$ \\
\hline & 360 & $5.4 \pm 0.2$ & $30 \pm 6$ & $269 \pm 18$ & $5.6 \pm 0.2$ & $104 \pm 6^{\#}$ & $92 \pm 11^{\#}$ \\
\hline
\end{tabular}

Data are mean \pm SE. EE energy expenditure, $\mathrm{CHO}$ carbohydrate. ${ }^{*} p<0.05$ and ${ }^{*} p<0.01$ compared with glucose-fed state.

\section{BLOOD PLASMA CONCENTRATIONS}

During exercise, there was a significant time $(P<0.01)$, treatment $(p<0.01)$ and time*treatment interaction $(p<0.01)$ effect for plasma FA concentrations. Except for baseline $(t=0)$ plasma FA concentrations were higher at all time points during exercise in the fasted state $(p<0.01)$ compared with the glucose-fed state (Fig. 2b). Plasma FA concentrations increased with time during exercise $(p<0.01)$, with this increase being more pronounced in the fasted state compared to the glucose-fed state. In the post exercise period, plasma FA concentrations were higher at all time points in the fasted state compared with the glucose-fed state $(p<0.001)$, but there 
was no time or time*treatment interaction effect.

During exercise, there was a significant time $(p<0.05)$, treatment $(p<0.01)$ and time*treatment interaction effect $(p<0.01)$ for plasma glucose concentrations. In the fasted state, plasma glucose concentrations decreased during exercise (Fig. 2c), whereas an increase was observed in the glucose-fed state. As a result, plasma glucose levels were lower in the fasted state compared with the glucose-fed state from time point $t=60$ min onwards $(p<0.05)$. In the post exercise period, plasma glucose concentrations were lower at all time points in the fasted state compared with the glucose-fed state $(p<0.01)$, and there was a time*treatment interaction $(p=0.046)$ effect, but there was no time $(p=0.085)$ effect.

a
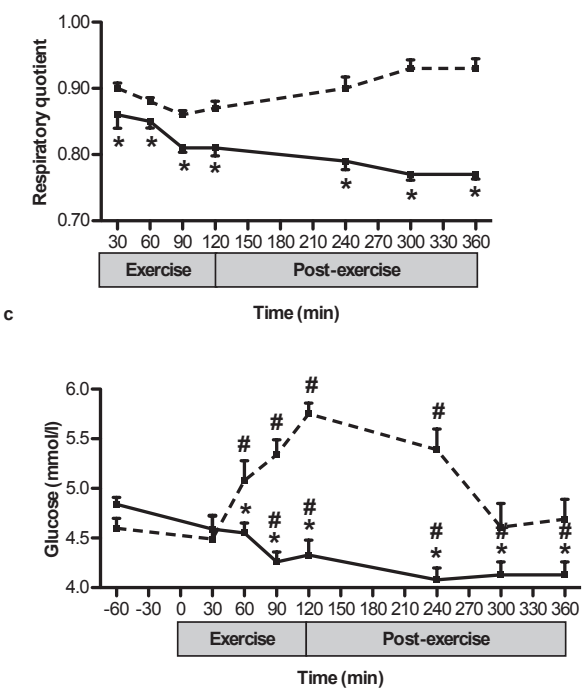

b
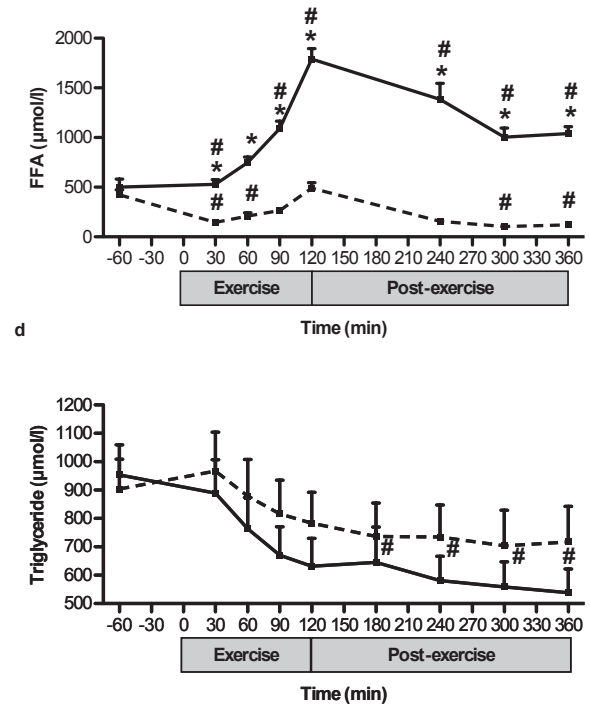

Figure 2 (a) Respiratory quotient during and after $2 \mathrm{~h}$ of cycling at $50 \%$ of maximal power output (Wmax) and plasma concentrations of (b) (free) fatty acids (FA), (c) glucose and (d) triglyceride (TG), with (dotted line) and without (solid line) glucose supplementation. For figure $2 a, b, c$ and $d:{ }^{*} P<0.01$ compared with glucose-supplemented condition. For figure $2 \mathrm{~b}, \mathrm{c}$ and $\mathrm{d}$ : ${ }^{\mathrm{P}} \mathrm{P}<0.05$ changes over time compared with baseline $(\mathrm{t}=-60)$. Data are means $\pm \mathrm{SE}$.

During exercise, there was no significant time $(p=0.16)$, treatment $(p=0.22)$ or time*treatment interaction $(p=0.87)$ effect for plasma triglyceride concentrations, whereas there was a tendency to lower plasma triglyceride concentrations post exercise in the fasted state compared with the glucose-fed state ( $p=0.069$, fig. $2 d)$. 
There were no time $(p=0.95)$ or time*treatment interaction $(p=0.99)$ effect for plasma triglyceride concentrations post exercise. Considering all time points of the test day, there is an overall time effect with triglyceride concentrations decreasing over time, being significantly different from baseline levels in the fasted condition from $t=120$ minutes onwards $(p>0.05)$.

There was a significant time $(p<0.01)$, treatment $(p<0.01)$ and time*treatment interaction $(p<0.01)$ effect for glycerol during exercise. Glycerol concentrations were higher in the fasted state, and increased during exercise, with a more pronounced increased in the fasted state (from $99 \pm 14 \mu \mathrm{mol} / \mathrm{l}$ to $620 \pm 31 \mu \mathrm{mol} / \mathrm{l}$ in the fasted state vs $91 \pm 9 \mu \mathrm{mol} / /$ to $219 \pm 27 \mu \mathrm{mol} / \mathrm{l}$ in the glucose-fed state). Post exercise glycerol was significantly higher in the fasted state compared with the glucose-fed state $(135 \pm 9 \mu \mathrm{mol} / \mathrm{l}$ vs $46 \pm 3 \mu \mathrm{mol} / \mathrm{l}$ at $\mathrm{t}=360)(p<0.01)$, but there was no time (0.11) or time*treatment interaction $(p=0.22)$ effect.

\section{CARDIAC LIPID CONTENT}

There was a significant treatment $(p=0.029)$ and time*treatment interaction $(p=0.009)$ effect for cardiac lipid content, but no time ( $p=0.242)$ effect. As depicted in figure 3, overall cardiac lipid content was higher at the end of the test day in the fasted state compared with the glucose-fed state, and cardiac lipid content increased after recovery from exercise in the fasted state $(p=0.003)$, whereas it did not change when glucose supplementation was given $(p=0.272)$. At baseline, there were no differences in cardiac lipid content between the two conditions $(p=0.239)$. Cardiac lipid content was also not different between the two conditions directly after exercise $(p=0.119)$. However, 4 hours post exercise cardiac lipid content was elevated by $41 \%$ in the fasted state compared with the glucose-fed state $(p=0.008)$.

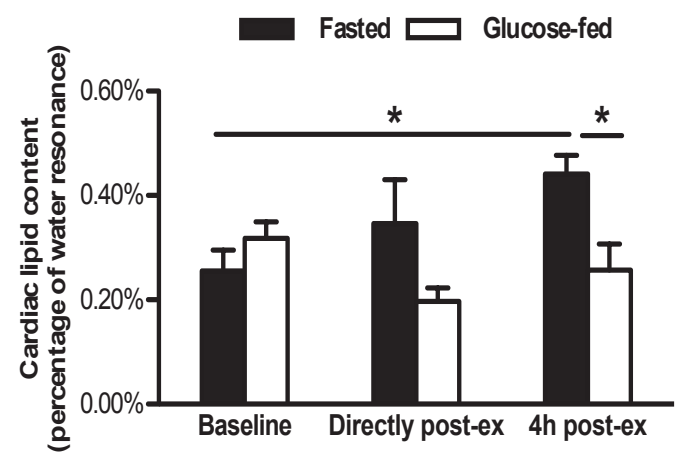

Figure 3 Cardiac lipid content at baseline, directly post exercise and $4 \mathrm{~h}$ post exercise. Cardiac lipid content is expressed as the relative intensity of the $\mathrm{CH}_{2}$ peak, compared to the unsuppressed water resonance. $n=9,{ }^{*} P<$ 0.01. Data are means \pm SE. 


\section{CARDIAC ENERGY STATUS AND FUNCTION}

In a subgroup of six subjects PCr/ATP was determined four hours post exercise. PCr/ATP was 32\% lower in the fasted state compared with the glucose-fed state $(p=0.014$, fig. 4). Ejection fraction ( $p=0.038$, fig. 5$)$, stroke volume $(115 \pm 6 \mathrm{ml}$ vs $107 \pm 4 \mathrm{ml}, \mathrm{p}=0.044)$, cardiac output $(7.2 \pm 0.5 \mathrm{l} / \mathrm{min}$ vs $6.0 \pm 0.2 \mathrm{l} / \mathrm{min}, \mathrm{p}=0.016)$ and cardiac index $\left(3.9 \pm 0.3 \mathrm{l} / \mathrm{min} / \mathrm{m}^{2}\right.$ vs $\left.3.3 \pm 0.2 \mathrm{l} / \mathrm{min} / \mathrm{m}^{2}, \mathrm{p}=0.016\right)$ were all significantly higher at $4 \mathrm{~h}$ of recovery in the fasted state compared with the glucosefed state. At $4 \mathrm{~h}$ of recovery, end diastolic $(182 \pm 8 \mathrm{ml}$ in the fasted state vs $180 \pm$ $8 \mathrm{ml}$ in the glucose-fed state, $\mathrm{p}=0.626)$ and end systolic $(68 \pm 4 \mathrm{ml}$ in the fasted state vs $73 \pm 5 \mathrm{ml}$ in the glucose-fed state, $p=0.179$ ) volumes were not significantly different between the fasted and glucose-fed state. A tendency to a higher heart rate during these measurements in the fasted state was found, compared with the glucose-fed state, however it did not reach statistical significance (63 $\pm 3 \mathrm{bpm}$ vs $58 \pm 3$ bpm, $\mathrm{p}=0.097$ ). Inter-observer variability of ejection fraction analysis was good with a coefficient of variation of $3.6 \pm 0.9 \%$.

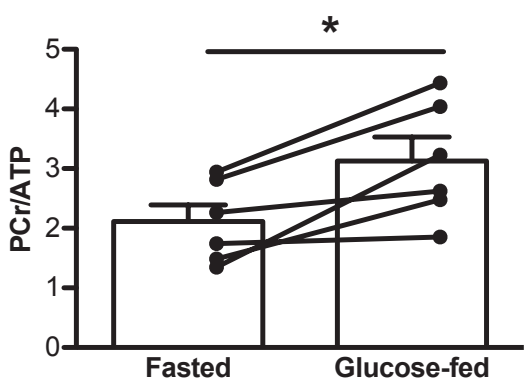

Figure 4 PCr/ATP ratio four hours post exercise, $n=6,{ }^{*} P=$ 0.014. Data are depicted both as individual and means \pm SE.

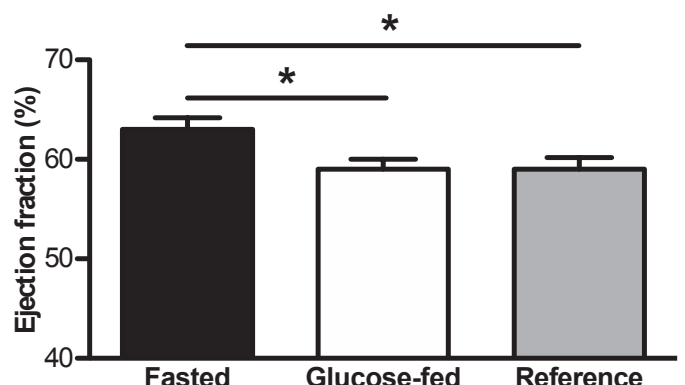

Figure 5 Left ventricular ejection fraction four hours post exercise, with (white bar) and without (black bar) glucose ingestion, compared with a reference (grey bar) measurement. ${ }^{*} P<0.05$. Data are means \pm SE.

To compare the values for cardiac function at $4 \mathrm{~h}$ of recovery to baseline reference values without prior exercise, we measured in the same subjects cardiac function after an overnight fast, on a separate day. 4h-recovery values for ejection fraction ( $p=0.026$, fig. 5), cardiac output $(7.2 \pm 0.5 \mathrm{ml}$ vs $5.8 \pm 0.3 \mathrm{ml}, \mathrm{n}=9, \mathrm{p}=0.015)$ and cardiac index $\left(3.7 \pm 0.3 \mathrm{l} / \mathrm{min} / \mathrm{m}^{2}\right.$ vs $\left.3.0 \pm 0.2 \mathrm{l} / \mathrm{min} / \mathrm{m}^{2}, \mathrm{n}=9, \mathrm{p}=0.007\right)$ were all significantly higher in the fasted state compared with the reference measurement, whereas the glucose-fed state did not differ from the reference measurement ( $p$ > 0.05). There was no difference in stroke volume between the reference measurement 
and the fasted $(p=0.933)$ or the glucose-fed $(p=0.241)$ states. Heart rate was significantly lower during the reference measurement compared with both the measurement in the fasted (52 \pm 4 bpm vs $62 \pm 4$ bpm, $n=9, p=0.001$ ) and glucosefed state (52 $\pm 4 \mathrm{bpm} 58 \pm 3 \mathrm{bpm}, \mathrm{n}=9, \mathrm{p}=0.013)$ at 4 hours of recovery.

\section{DISCUSSION}

The primary finding of the present study is that cardiac lipid content increases upon exercise-induced -i.e. physiological - elevation of plasma FA concentrations in healthy lean young men. Furthermore, we revealed that this increase in cardiac lipid content is paralleled by a lower cardiac energy status (lower PCr/ATP), but not by a lowered cardiac function. These results indicate that cardiac muscle is rather unrestricted in its uptake of circulating FA and that the validity of PCr/ATP ratio as a relevant marker of cardiac function can be debated under some circumstances.

There is an increasing prevalence of obesity worldwide and obesity is well known to be an independent risk factor for the development of heart failure. Obesity is associated with excessive storage of lipids (triglycerides) not only in adipose tissue, but also in non-adipose tissues, such as the heart. We show here for the first time that cardiac lipid content is increased upon exercise-induced elevation of plasma FA concentrations in healthy lean young men, and that blunting of the exerciseinduced increase in plasma FA concentrations completely prevents the increase in cardiac lipid content. This suggests that in healthy lean young men plasma FA concentration is an important determinant of cardiac lipid content, which in turn suggests that in this population uptake of FA in the heart largely depends on FA availability. This is in agreement with previous studies pointing at the importance of high FA concentrations as determinants of cardiac lipid content [5]. Increased cardiac lipid content is shown to be associated with obesity and diabetes $[32,5,26,30]$, conditions in which it is well known that plasma FA concentrations are high. Furthermore, fasting for more than 48 hours [18] or a very low calorie diet for more than three days [33], which both are characterised by elevated plasma FA concentrations, also resulted in increased cardiac lipid content. Although our results may suggest that elevated plasma FA concentrations may also underlie cardiac lipid accumulation and cardiac dysfunction in obesity and diabetes, it is important to note that major differences exist between obesity,insulin resistance and fasting. Thus, although both conditions are characterized by elevated plasma 
FA concentrations, plasma leptin and insulin levels are elevated in obesity, but markedly reduced upon fasting. It has recently been shown that under conditions of systemic insulin resistance the heart remains insulin sensitive [25], therefore chronic stimulation of multiple signaling processes in the myocardium by leptin and insulin may result in cardiac pathology.

Interestingly, our finding that elevated plasma FA lead to cardiac lipid accumulation are to some extent in accordance with observations in skeletal muscle. Thus, we have previously shown that during exercise, when peripheral lipolysis is stimulated to increase plasma FA availability for subsequent oxidation, a net accumulation of intramyocellular lipids occurred in non-exercising muscles of the upper arm, indicating that high circulatory FA concentrations also lead to unrestricted uptake of FA in skeletal muscle [24]. However, intramyocellular lipid content was reduced in the exercising muscles of the leg, suggesting that in this active muscle FA delivery was customized to FA oxidation. In that respect, it is surprising that in cardiac muscle, which heavily relies on FA for oxidation during exercise, the elevation of plasma FA lead to an increase rather than a decrease in cardiac lipid content. This suggests that the uptake of FA in cardiac muscle is less well tuned to the oxidative needs compared to skeletal muscle and that even under conditions of increased cardiac work, FA entering the heart are shuttled towards storage rather than to oxidation.

In parallel to the increased cardiac lipid content we also observed a lower cardiac energy status (lower PCr/ATP). Cardiac energy status has a strong prognostic value in heart failure patients and it has been suggested to be an early marker of disturbed cardiac metabolism [16]. In line with this, Scheuermann-Freestone et al. [21] found that the PCr/ATP ratios correlate negatively with plasma FA concentrations. Furthermore, a decreased PCr/ATP ratio has been found to be associated with diastolic dysfunction and diabetes [19]. As an explanation for this finding, it has been suggested that plasma FA increase the expression of mitochondrial uncoupling proteins in the heart, and these proteins can reduce the efficiency with which mitochondria can produce ATP, thereby resulting in altered PCr/ATP ratios [12]. Some care should be taken when interpreting PCr/ATP ratios as energy status, as the assumption that a decreased PCr/ATP ratio is reflecting a decreased $\mathrm{PCr} /$ $\mathrm{Cr}$ ratio can theoretically be biased by a decrease in total creatine concentration. In that context, other studies have shown that indeed creatine concentration in the failing heart is decreased $[27,13,14]$. In the current study, we cannot exclude 
that creatine depletion contributes to the lower PCr/ATP ratio found in the fasted condition. However, even though an increased cardiac lipid content was associated with a lower cardiac energy status in the present study, the systolic cardiac function was not negatively affected. The systolic cardiac function was determined by multi slice CINE-MRI, which is the gold standard for measuring systolic cardiac function. Together with myocardial spectroscopy this permits examinations of associations between myocardial triglyceride concentrations and cardiac function. Surprisingly, cardiac function was higher in the condition with high plasma FA concentrations and elevated cardiac lipid content compared with the glucose-fed state. Moreover, cardiac function in the fasted state was in fact elevated when compared with the reference condition. Increased concentrations of adrenaline and noradrenaline may be underlying the stronger contraction in that case. Alternatively, changes in peripheral resistance may occur with the current protocol, which may affect ejection fraction. Although the exact mechanism explaining the increased cardiac function in the high plasma FFA condition remains speculative, we can conclude that, if anything, the elevated plasma FA concentrations and concomitant cardiac lipid content did not negatively impact cardiac function. This shows that at least in this population PCr/ATP ratio is not a good marker of cardiac function under acute conditions of elevated FA.

In summary, in this study we revealed that elevated plasma FA concentrations, induced by prolonged exercise in the fasted state, increased storage of triglycerides in cardiac tissue but did not acutely hamper systolic function. Although the lower cardiac energy status is in line with a lipotoxic action of cardiac lipids, a causal relationship cannot be proven, and it cannot be excluded that acute prolonged exercise influences cardiac energy status and lipid content independently.

\section{ACKNOWLEDGEMENT}

Dr. M. Schär kindly provided the navigator software used for the ${ }^{1} \mathrm{H}-\mathrm{MRS}$ measurements.

Dr. P. Schrauwen is supported by a 'VICl' Research Grant for innovative research from the Netherlands Organization for Scientific Research (Grant 918.96.618). This research was supported by the Center for Translational Molecular Medicine and the Netherlands Heart Foundation, Dutch Diabetes Research Foundation and Dutch Kidney Foundation (PREDICCt). 


\section{REFERENCES}

1. Roger VL, Weston SA, Redfield MM, Hellermann-Homan JP, Killian J, Yawn BP, Jacobsen SJ. Trends in heart failure incidence and survival in a community-based population. JAMA. 2004;292(3):344-50.

2. Mokdad AH, Ford ES, Bowman BA, Dietz WH, Vinicor F, Bales VS, Marks JS. Prevalence of obesity, diabetes, and obesity-related health risk factors, 2001. Jama. 2003;289(1):76-9.

3. Kenchaiah S, Evans JC, Levy D, Wilson PW, Benjamin EJ, Larson MG, Kannel WB, Vasan RS. Obesity and the risk of heart failure. N Engl J Med. 2002;347(5):305-13.

4. Murphy NF, Maclntyre K, Stewart S, Hart CL, Hole D, McMurray JJ. Longterm cardiovascular consequences of obesity: 20-year follow-up of more than 15000 middle-aged men and women (the Renfrew-Paisley study). Eur Heart J. 2006;27(1):96-106.

5. Unger $\mathrm{RH}$, Orci L. Diseases of liporegulation: new perspective on obesity and related disorders. FASEB J. 2001;15(2):312-21.

6. Zhou YT, Grayburn P, Karim A, Shimabukuro M, Higa M, Baetens D, Orci $\mathrm{L}$, Unger $\mathrm{RH}$. Lipotoxic heart disease in obese rats: implications for human obesity. Proceedings of the National Academy of Sciences of the United States of America. 2000;97(4):1784-9.

7. Yagyu H, Chen G, Yokoyama M, Hirata K, Augustus A, Kako Y, Seo T, Hu Y, Lutz EP, Merkel M, Bensadoun A, Homma S, Goldberg IJ. Lipoprotein lipase (LpL) on the surface of cardiomyocytes increases lipid uptake and produces a cardiomyopathy. J Clin Invest. 2003;111(3):419-26.

8. Chiu HC, Kovacs A, Blanton RM, Han X, Courtois M, Weinheimer CJ, Yamada KA, Brunet S, Xu H, Nerbonne JM, Welch MJ, Fettig NM, Sharp TL, Sambandam N, Olson KM, Ory DS, Schaffer JE. Transgenic expression of fatty acid transport protein 1 in the heart causes lipotoxic cardiomyopathy. Circ Res. 2005;96(2):225-33.

9. Chiu HC, Kovacs A, Ford DA, Hsu FF, Garcia R, Herrero P, Saffitz JE, Schaffer JE. A novel mouse model of lipotoxic cardiomyopathy. J Clin Invest. 2001;107(7):813-22.

10. Cheng L, Ding G, Qin Q, Huang Y, Lewis W, He N, Evans RM, Schneider MD, Brako FA, Xiao Y, Chen YE, Yang Q. Cardiomyocyte-restricted peroxisome proliferator-activated receptor-delta deletion perturbs myocardial fatty acid oxidation and leads to cardiomyopathy. Nat Med. 2004;10(11):1245-50.

11. Nielsen LB, Bartels ED, Bollano E. Overexpression of apolipoprotein B in the heart impedes cardiac triglyceride accumulation and development of cardiac dysfunction in diabetic mice. J Biol Chem. 2002;277(30):27014-20.

12. Szczepaniak LS, Babcock EE, Schick F, Dobbins RL, Garg A, Burns DK, McGarry JD, Stein DT. Measurement of intracellular triglyceride stores by $\mathrm{H}$ 
spectroscopy: validation in vivo. Am J Physiol. 1999;276(5 Pt 1):E977-89.

13. van der Meer RW, Doornbos J, Kozerke S, Schar M, Bax JJ, Hammer S, Smit JW, Romijn JA, Diamant M, Rijzewijk LJ, de Roos A, Lamb HJ. Metabolic imaging of myocardial triglyceride content: reproducibility of ${ }^{1} \mathrm{H}$ MR spectroscopy with respiratory navigator gating in volunteers. Radiology. 2007;245(1):251-7.

14. Kankaanpaa M, Lehto HR, Parkka JP, Komu M, Viljanen A, Ferrannini E, Knuuti J, Nuutila P, Parkkola R, Iozzo P. Myocardial triglyceride content and epicardial fat mass in human obesity: relationship to left ventricular function and serum free fatty acid levels. J Clin Endocrinol Metab. 2006;91(11):468995.

15. van der Meer RW, Hammer S, Smit JW, Frolich M, Bax JJ, Diamant M, Rijzewijk LJ, de Roos A, Romijn JA, Lamb HJ. Short-term caloric restriction induces accumulation of myocardial triglycerides and decreases left ventricular diastolic function in healthy subjects. Diabetes. 2007;56(12):2849-53.

16. Reingold JS, McGavock JM, Kaka S, Tillery T, Victor RG, Szczepaniak LS. Determination of triglyceride in the human myocardium by magnetic resonance spectroscopy: reproducibility and sensitivity of the method. Am J Physiol Endocrinol Metab. 2005;289(5):E935-9.

17. Scheuermann-Freestone M, Madsen PL, Manners D, Blamire AM, Buckingham RE, Styles P, Radda GK, Neubauer S, Clarke K. Abnormal cardiac and skeletal muscle energy metabolism in patients with type 2 diabetes. Circulation. 2003;107(24):3040-6.

18. Neubauer S. The failing heart--an engine out of fuel. $\mathrm{N}$ Engl J Med. 2007;356(11):1140-51.

19. Schrauwen P, Hesselink MK, Vaartjes I, Kornips E, Saris WH, Giacobino JP, Russell A. Effect of acute exercise on uncoupling protein 3 is a fat metabolismmediated effect. Am J Physiol Endocrinol Metab. 2002;282(1):E11-7.

20. Schrauwen-Hinderling VB, van Loon LJ, Koopman R, Nicolay K, Saris $\mathrm{WH}$, Kooi ME. Intramyocellular lipid content is increased after exercise in nonexercising human skeletal muscle. J Appl Physiol. 2003;95(6):2328-32.

21. Schrauwen-Hinderling VB, Hesselink MK, Meex R, van der Made S, Schar M, Lamb H, Wildberger JE, Glatz J, Snoep G, Kooi ME, Schrauwen P. Improved ejection fraction after exercise training in obesity is accompanied by reduced cardiac lipid content. J Clin Endocrinol Metab. 2010;95(4):19328.

22. Kuipers H, Verstappen FT, Keizer HA, Geurten P, van Kranenburg G. Variability of aerobic performance in the laboratory and its physiologic correlates. Int J Sports Med. 1985;6(4):197-201.

23. Siri WE. The gross composition of the body. Adv Biol Med Phys. 1956;4:23980.

24. Kozerke S, Schar M, Lamb HJ, Boesiger P. Volume tracking cardiac ${ }^{31} \mathrm{P}$ 
spectroscopy. Magn Reson Med. 2002;48(2):380-4.

25. Vanhamme L, van den Boogaart A, Van Huffel S. Improved method for accurate and efficient quantification of MRS data with use of prior knowledge. J Magn Reson. 1997;129(1):35-43.

26. Naressi A, Couturier C, Devos JM, Janssen M, Mangeat C, de Beer R, Graveron-Demilly D. Java-based graphical user interface for the MRUI quantitation package. Magma. 2001;12(2-3):141-52.

27. Lamb HJ, Doornbos J, den Hollander JA, Luyten PR, Beyerbacht HP, van der Wall EE, de Roos A. Reproducibility of human cardiac ${ }^{31} \mathrm{P}-\mathrm{NMR}$ spectroscopy. NMR Biomed. 1996;9(5):217-27.

28. Hansch A, Rzanny R, Heyne JP, Leder U, Reichenbach JR, Kaiser WA. Noninvasive measurements of cardiac high-energy phosphate metabolites in dilated cardiomyopathy by using ${ }^{31} \mathrm{P}$ spectroscopic chemical shift imaging. European radiology. 2005;15(2):319-23.

29. Sharma S, Adrogue JV, Golfman L, Uray I, Lemm J, Youker K, Noon GP, Frazier $\mathrm{OH}$, Taegtmeyer $\mathrm{H}$. Intramyocardial lipid accumulation in the failing human heart resembles the lipotoxic rat heart. Faseb J. 2004;18(14):1692700 .

30. Szczepaniak LS, Dobbins RL, Metzger GJ, Sartoni-D’Ambrosia G, Arbique D, Vongpatanasin W, Unger R, Victor RG. Myocardial triglycerides and systolic function in humans: in vivo evaluation by localized proton spectroscopy and cardiac imaging. Magn Reson Med. 2003;49(3):417-23.

31. Schwarzer M, Britton SL, Koch LG, Wisloff U, Doenst T. Low intrinsic aerobic exercise capacity and systemic insulin resistance are not associated with changes in myocardial substrate oxidation or insulin sensitivity. Basic Res Cardiol. 2010;105(3):357-64.

32. Rijzewijk LJ, Jonker JT, van der Meer RW, Lubberink M, de Jong HW, Romijn JA, Bax JJ, de Roos A, Heine RJ, Twisk JW, Windhorst AD, Lammertsma AA, Smit JW, Diamant M, Lamb HJ. Effects of hepatic triglyceride content on myocardial metabolism in type 2 diabetes. J Am Coll Cardiol. 2010;56(3):225-33.

33. Murray AJ, Anderson RE, Watson GC, Radda GK, Clarke K. Uncoupling proteins in human heart. Lancet. 2004;364(9447):1786-8.

34. Shen W, Asai K, Uechi M, Mathier MA, Shannon RP, Vatner SF, Ingwall JS. Progressive loss of myocardial ATP due to a loss of total purines during the development of heart failure in dogs: a compensatory role for the parallel loss of creatine. Circulation. 1999;100(20):2113-8.

35. Nakae I, Mitsunami K, Omura T, Yabe T, Tsutamoto T, Matsuo S, Takahashi M, Morikawa S, Inubushi T, Nakamura Y, Kinoshita M, Horie M. Proton magnetic resonance spectroscopy can detect creatine depletion associated with the progression of heart failure in cardiomyopathy. J Am Coll Cardiol. 2003;42(9):1587-93. 
36. Nakae I, Mitsunami K, Yoshino T, Omura T, Tsutamoto T, Matsumoto T, Morikawa S, Inubushi T, Horie M. Clinical features of myocardial triglyceride in different types of cardiomyopathy assessed by proton magnetic resonance spectroscopy: comparison with myocardial creatine. J Card Fail. 2010;16(10):812-22. 
L.Bilet, B. Brouwers, P.A. van Ewijk, M.K.C. Hesselink, M.E. Kooi, P. Schrauwen, V.B. Schrauwen-Hinderling

Scientific Reports 2015 Apr 13;5:9709 


\section{CHAPTER}

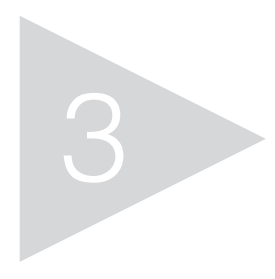

Acute exercise does not

decrease liver fat in men with

overweight or NAFLD 


\section{ABSTRACT}

Elevated hepatic lipid content (IntraHepatic Lipid, IHL) increases the risk of metabolic complications. Although prolonged exercise training lowers $\mathrm{IHL}$, it is unknown if acute exercise has the same effect. Furthermore, hepatic ATP content may be related to insulin resistance and IHL. We aimed to investigate if acute exercise leads to changes in $\mathrm{IHL}$ and whether this is accompanied by changes in hepatic ATP. Twenty-one men (age $54.8 \pm 7.2$ years, BMI $29.7 \pm 2.2 \mathrm{~kg} / \mathrm{m}^{2}$ ) performed a $2 \mathrm{~h}$ cycling protocol, once while staying fasted and once while ingesting glucose. $\mathrm{IHL}$ was determined at baseline, $30 \mathrm{~min}$ post-exercise and $4 \mathrm{~h}$ post-exercise. Additionally ATP/Total P ratio was measured at baseline and $4 \mathrm{~h}$ post-exercise. Compared with baseline values we did not observe any statistically significant changes in $\mathrm{HL}$ within 30 min post-exercise in neither the fasted nor the glucose-supplemented condition. However, $\mathrm{IHL}$ was elevated $4 \mathrm{~h}$ post-exercise compared with baseline in the fasted condition (from $8.3 \pm 1.8 \%$ to $8.7 \pm 1.8 \%, p=0.010$ ), an effect that was blunted by glucose supplementation (from $8.3 \pm 1.9$ to $8.3 \pm 1.9 \%, p=0.789$ ). Acute exercise does not decrease liver fat in overweight middle-aged men. Moreover, $\mathrm{IHL}$ increased $4 \mathrm{~h}$ post-exercise in the fasted condition, an increase that was absent in the glucose-supplemented condition. These data suggest that a single bout of exercise may not be able to lower IHL. 


\section{INTRODUCTION}

Regular exercise has beneficial effects on metabolic risk factors associated with type 2 diabetes [1, 2]. Recent studies have suggested that prolonged exercise training reduces liver fat content and may thereby contribute to the beneficial effects of exercise on metabolic risk [3-6]. Results from exercise training studies in animals revealed that the effect of exercise on hepatic lipid content (IntraHepatic Lipid, $\mathrm{IHL}$ ) strongly depends on the diet and that exercise is more effective in reducing $\mathrm{IHL}$ under conditions that favor liver fat accretion, such as when animals are fed a high-fat diet [7]. Interestingly, human data also revealed that exercise training appears to be more potent in reducing $\mathrm{HH}$ in subjects with increased baseline $\mathrm{IHL}$. Thus, the exercise-mediated reduction in $\mathrm{HL}$ is more pronounced in subjects with Non-alcoholic fatty liver disease (NAFLD), type 2 diabetes, or in elderly [8] than in healthy normal weight and young subjects. Furthermore, like with exercise training, acute bouts of exercise also improve insulin sensitivity [9-11]. The acute effects of exercise on IHL, however, have not yet been intensively studied. As yet, only three studies have examined the effect of acute exercise on IHL. However, all three of these studies were performed in lean young healthy volunteers in which liver fat is usually rather low [12-14], which would complicate detecting exercise-mediated reductions in IHL. To circumvent this, one study [12] let the male subjects consume a high-fat diet or a mixed diet for $67 \mathrm{~h}$ before exercise. Subsequently IHL was measured (with ${ }^{1} \mathrm{H}-\mathrm{MRS}$ ) before and after 90 minutes of moderate intensity cycling. No statistically significant decrease was found directly after exercise, irrespective of the dietary condition. Hence it was concluded that acute exercise does not lower liver fat in young healthy men. In the other two studies, one study including male subjects with an average age of 28.9 years old [13] and one study including male and female subjects with a slightly older age of 37.6 years old [14], subjects also consumed a high-fat diet 3 days prior to the exercise trial. Here IHL (measured with ${ }^{1} \mathrm{H}-\mathrm{MRS}$ ) was increased rather than decreases after a 2 hours exercise bout (50$60 \%$ of $\mathrm{VO}_{2}$ max), and it was speculated that the increase in IHL upon exercise was due to increased free fatty acid (FFA) availability during exercise. A clinically more relevant question, however, would be if acute exercise lowers liver fat in a middleaged overweight subject population who are prone to the development of fatty liver or may already have elevated IHL (NAFLD), but such information is presently lacking.

As mentioned above, a potentially biasing complication when measuring IHL postexercise is the increase in plasma FFA that goes along with exercise in the fasted 
state (originating from exercise-mediated increase in adipose tissue lipolysis) [1516]. Plasma FFA is an important source for hepatic triglyceride [17], and therefore high levels of plasma FFA during exercise might mask a potential exercise-lowering effect. To circumvent this bias, we here investigated the effect of acute exercise on $\mathrm{IHL}$ in middle-aged overweight sedentary subjects with a wide range of liver fat content under conditions with high and low plasma FFA concentrations.

Next to IHL, hepatic ATP concentrations, a measure for liver energy status, have also been suggested to be related to insulin resistance and hepatic lipid accumulation [18]. Therefore, we also studied if changes in $\mathrm{HL}$ are accompanied by changes in hepatic ATP concentration. To this end, we employed ${ }^{1} \mathrm{H}-\mathrm{MRS}$ to determine $\mathrm{IHL}$ before and after exercise performed with and without glucose ingestion to suppress plasma FFA levels, as well as $4 \mathrm{~h}$ post exercise. ${ }^{31} \mathrm{P}-\mathrm{MRS}$ was employed before exercise and $4 \mathrm{~h}$ post exercise to determine hepatic ATP concentrations.

\section{METHODS}

\section{SUBJECTS}

Twenty-one middle-aged overweight men with a wide range of liver fat content participated in this study. None of the subjects participated in competitive sports and subjects with unstable body weight ( $>3 \mathrm{~kg}$ change in preceding six months) were excluded from the study. The study protocol conforms to the ethical guidelines of the 1975 Declaration of Helsinki as reflected in a priori approval by the institution's human research committee and written informed consent was obtained from all participants.

\section{STUDY PROTOCOL}

Before the start of the study, body composition and maximal aerobic capacity were determined in all subjects. The experimental trial comprised two separate test days separated by at least one week and performed in random order. Subjects refrained from physical activity two days prior to the test days. Furthermore, subjects were instructed to consume a standardized meal the evening prior to the test days and stayed fasted from $10 \mathrm{pm}$ onwards. On the test days, subjects reported to the laboratory (Maastricht University Medical Center+) at 7:00 am after an overnight 
fast. IHL was investigated by proton magnetic resonance spectroscopy ( $\left.{ }^{1} \mathrm{H}-\mathrm{MRS}\right)$. After this, a Teflon cannula was inserted into an antecubital forearm vein for sampling of blood and subjects rested for 30 minutes. Immediately after drawing the first blood sample, subjects ingested either $1.4 \mathrm{~g} / \mathrm{kg}$ body weight of glucose (dissolved in water to a $20 \%$ solution and flavoured with $1 \mathrm{ml}$ lemon juice) or the same amount of water. After this, subjects started exercising ( $t=0$ minute) on a stationary bike at $50 \%$ of their pre-determined maximal power output (Wmax) for two hours. During exercise, blood samples were drawn and substrate oxidation was measured by indirect calorimetry (Omnical, Maastricht University, Maastricht, The Netherlands) every 30 minutes (at $t=30,60,90$ and 120 minutes) while heart rate was constantly measured. Immediately after cessation of exercise ( $\mathrm{t}=120$ minute), subjects were transferred to the MR facility for a second ${ }^{1} \mathrm{H}$-MRS measurement. Importantly, due to the transfer time and the preparation steps of the ${ }^{1} \mathrm{H}$-MRS measurement itself, $\mathrm{IHL}$ could only be measured within 30 min after cessation of exercise. Subsequently, subjects bed-rested for three hours, followed by a third ${ }^{1} \mathrm{H}-\mathrm{MRS}$ scan four hours post exercise. Additionally, in a subgroup of eight subjects, ATP/Total P ratio was measured by phosphorous magnetic resonance spectroscopy ( $\left.{ }^{31} \mathrm{P}-\mathrm{MRS}\right)$ at baseline as well as four hours post exercise. During the 4-hour post exercise period, blood samples were drawn and substrate oxidation was measured for 15 minutes every hour (at $\mathrm{t}=180,240,300$ and 360 minutes) in all subjects. The experimental design is depicted in figure 1.

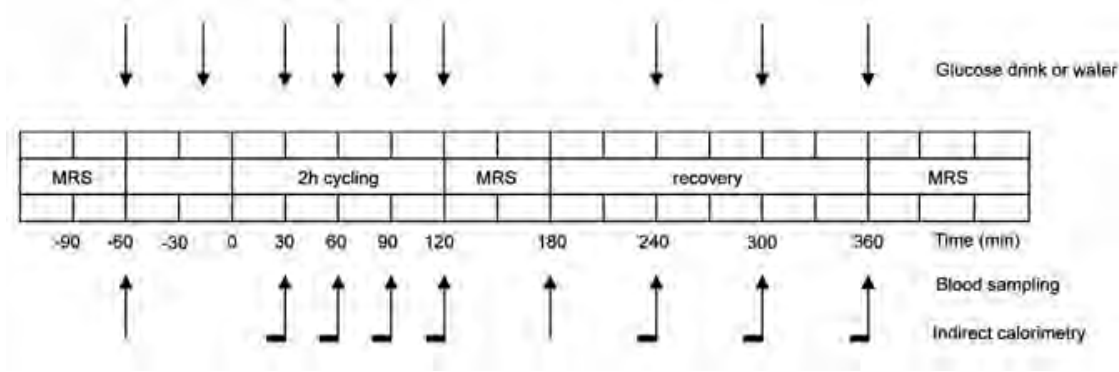

Figure 1 Experimental design of the study. All subjects performed the protocol two times, one time in the fasted state consuming water and one time with glucose supplementation. MRS hepatic magnetic resonance spectroscopy. 


\section{MEASUREMENTS PRIOR TO TEST DAYS}

A routine incremental cycling test on a stationary bike was used to determine maximal exercise capacity as described previously [25] and a hydrostatic weighing with simultaneous measurement of lung volume was used to determine body composition. The equation of Siri [26] was used to calculate fat percentage, fat mass and fat-free mass.

\section{BLOOD SAMPLE ANALYSES}

Blood samples were collected in EDTA-containing tubes and immediately spun at high speed and frozen in liquid nitrogen and subsequently stored at $-80^{\circ} \mathrm{C}$ until assayed. Plasma free fatty acids, triglycerides, and glucose were measured with enzymatic assays automated on a Cobas Fara/Mira (FA: Wako Nefa C test kit; Wako Chemicals, Neuss, Germany) (glucose: hexokinase method; Roche, Basel, Switzerland) (triglycerides: ABX Pentra CP reagents, Horiba ABX Diagnostics, Montpellier, France) (glycerol: Enzytec ${ }^{\mathrm{TM}}$ glycerol kit, R-Biopharm, Germany). The liver enzymes Gamma-GT, ASAT and ALAT were routinely measured during the screening visit and analysed in the clinical chemistry department in the hospital.

\section{${ }^{1} \mathrm{H}-\mathrm{MRS}$}

$\mathrm{IHL}$ was determined in vivo by ${ }^{1} \mathrm{H}-\mathrm{MRS}$. Measurements were performed on a whole body scanner (1.5T, Intera, Philips Healthcare, Best, The Netherlands) as reported previously [27]. An $18 \mathrm{~cm}^{3}$ Volume of Interest (VOI) was placed within the lower right hepatic lobe (point resolved spectroscopy (PRESS), repetition time $(T R)=4 \mathrm{~s}$, Echo time $(\mathrm{TE})=23 \mathrm{~ms}$, bandwidth $(\mathrm{BW})=1000 \mathrm{~Hz}, \mathrm{n}=1024$ points, number of signal averages $(\mathrm{NSA})=64)$. To minimize motion artifacts, subjects were asked to breathe in the rhythm of the measurement and to be at end-expiration during acquisition of spectra. Water signal was suppressed using frequency-selective prepulses. Spectra without water suppression were acquired with identical settings (NSA=16) and all spectra were fitted with AMARES [28] in the jMRUI software [29]. The T2corrected ratios of the $\mathrm{CH}_{2}$ peak, relative to the unsuppressed T2-corrected water resonance was calculated and converted to a tissue fat percentage (weight/weight) by assuming a water content of $71.1 \%, \mathrm{a} \mathrm{CH}_{2}$-proton density of triglycerides of 60.2 $\mathrm{mol}^{-1}$, a proton density of water of $2 \mathrm{~mol}^{-1}$, a molecular weight of triglycerides and 
water of $860 \mathrm{~g} / \mathrm{mol}$ and $18 \mathrm{~g} / \mathrm{mol}$, respectively. Three subjects had to be excluded from the IHL analysis due to poor quality of spectra.

\section{${ }^{31}$ P-MRS}

In a subgroup of eight subjects ATP content was determined at baseline and four hours post exercise in both the fasted and the glucose-supplemented condition. Subjects were positioned in supine position with a 10-cm diameter transmit/receive surface coil positioned at the level of the liver. MRI scout images were acquired during a breath hold and one-dimensional spectroscopic imaging (SI) was performed with 8 phase-encoding steps and SI slice thickness of $30 \mathrm{~mm}$ (TR= $4 \mathrm{~s}, \mathrm{n}=512$ points, $\mathrm{BW}=4000 \mathrm{~Hz}, \mathrm{NSA}=16$ ). At least one slice was planned to be exclusively in liver tissue. To minimize motion artifacts, subjects were asked to breathe in the rhythm of the measurement and to be at end-expiration during acquisition of spectra. All spectra were fitted with the AMARES algorithm [28] in the jMRUI software package [29]. The $\mathrm{Y}$-ATP resonance was quantified and expressed as ratio of the $\mathrm{Y}$-ATP to total phosphorus signal in the -25 to 25 ppm frequency region, expressed as ATP/ Total $\mathrm{P}$ ratio in the current paper.

\section{STATISTICS}

Data are presented as means \pm SE. Hepatic lipid content was not normally distributed and therefore a non-parametric Friedman test was performed to test if there was an overall effect on $\mathrm{HHL}$. Thereafter a pairwise comparison was performed with a Bonferroni correction for multiple comparisons. A two-way repeated measures ANOVA was performed to compare the mean differences between conditions for ATP, substrate oxidation and plasma values of FA, triglycerides, and glucose. All statistics were performed using SPSS 16.0 (IBM Corporation, Armonk, NY, USA) for Mac and $\mathrm{P}<0.05$ was considered statistically significant.

\section{RESULTS}

\section{BASIC CHARACTERISTICS}

Twenty-one middle-aged overweight men participated in this study. The subject 
characteristics of the entire group are shown in Table 1. The subjects had a wide variety of liver fat content (see figure 2 for basal liver fat content per subject). Of these subjects, eleven subjects met the clinical criteria for NAFLD (> 5.6\% liver fat) [19], while in ten subjects hepatic fat content was within the normal physiological range (<5.6\% liver fat). There were no significant differences in body weight, BMI, whole body fat percentage and fasting plasma glucose levels between subjects that would qualify as NAFLD and subjects with a normal liver fat content, but the NAFLD subjects were somewhat younger than the subjects with normal liver fat content $(51.7 \pm 5.4$ years vs $58.2 \pm 7.7$ years, $p=0.036)$ and had a higher diastolic blood pressure $(p=0.011)$. As expected, clinical parameters that associate with fatty liver, such as plasma levels of TG and the liver enzymes gamma-GT, ASAT and ALAT were all significantly higher in subjects with a high (> 5.6\%) liver fat content compared to the subjects with normal liver fat content $(p<0.05)$. However, despite these clinical differences, liver fat content responded similarly in subjects with low and high liver fat content and hence all subjects are treated as one group in the data presented below.

Table 1 Subjects' characteristics

\begin{tabular}{|c|c|c|c|}
\hline Mean \pm SE & Liver fat $<5.6 \%$ & Liver fat $>5.6 \%$ & All subjects (pooled) \\
\hline Age, yr & $58.2 \pm 7.7$ & $51.7 \pm 5.4^{*}$ & $54.8 \pm 7.2$ \\
\hline Height, m & $1.79 \pm 0.05$ & $1.79 \pm 0.03$ & $1.79 \pm 0.04$ \\
\hline Weight, kg & $92.6 \pm 9.1$ & $97.5 \pm 8.6$ & $95.2 \pm 9.0$ \\
\hline BMI, kg/m² & $28.7 \pm 1.8$ & $30.4 \pm 2.3$ & $29.6 \pm 2.2$ \\
\hline Fat, \% & $27.5 \pm 6.2$ & $28.5 \pm 3.1$ & $27.9 \pm 4.9$ \\
\hline $\mathrm{VO}_{2} \max / \mathrm{kg}, \mathrm{ml} \times \min ^{-1} \times \mathrm{kg}^{-1}$ & $30.3 \pm 5.7$ & $29.1 \pm 6.1$ & $29.7 \pm 5.8$ \\
\hline $\mathrm{SBP}, \mathrm{mmHg}$ & $135.7 \pm 16.5$ & $144.7 \pm 12.6$ & $140.4 \pm 15.0$ \\
\hline $\mathrm{DBP}, \mathrm{mmHg}$ & $83.3 \pm 12.0$ & $95.1 \pm 6.7^{*}$ & $89.5 \pm 11.1$ \\
\hline Glucose, mmol/L & $5.3 \pm 0.8$ & $5.6 \pm 0.4$ & $5.4 \pm 0.6$ \\
\hline Gamma-GT, U/L & $27.6 \pm 9.4$ & $55.5 \pm 26.2^{*}$ & $42.2 \pm 24.2$ \\
\hline ASAT, U/L & $18.0 \pm 4.5$ & $25.9 \pm 6.6^{*}$ & $22.1 \pm 6.9$ \\
\hline ALAT, U/L & $25.4 \pm 8.8$ & $44.6 \pm 11.0^{*}$ & $35.5 \pm 13.9$ \\
\hline Triglycerides, $\mathrm{mmol} / \mathrm{L}$ & $1.1 \pm 0.3$ & $2.0 \pm 0.5^{*}$ & $1.5 \pm 0.6$ \\
\hline Liver fat, \% & $2.7 \pm 1.5$ & $13.1 \pm 6.7^{*}$ & $8.1 \pm 7.2$ \\
\hline
\end{tabular}

Data are means \pm SD. BMI Body Mass Index, SBP Systolic Blood Pressure, DBP Diastolic Blood Pressure.

${ }^{*} \mathrm{P}<0.05$ compared with subjects having less than $5.6 \%$ liver fat. 


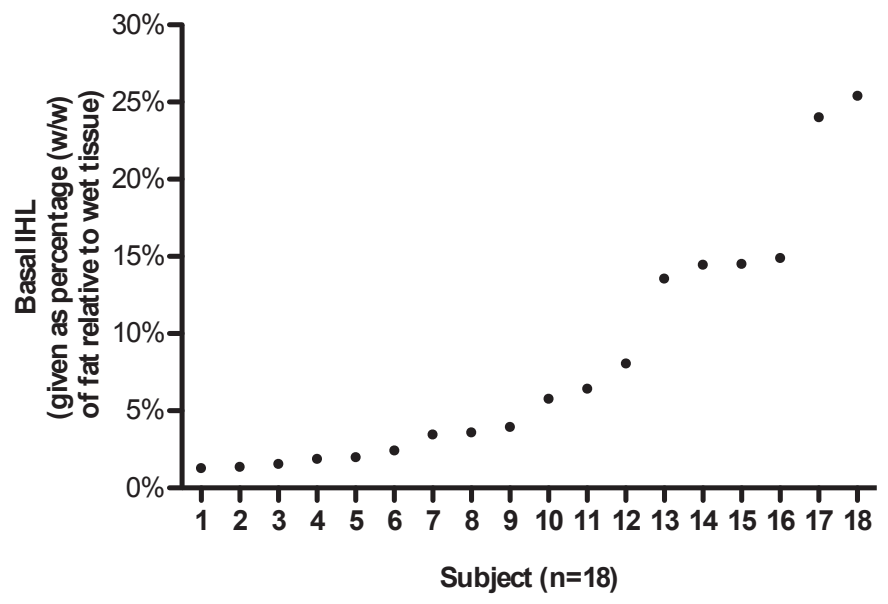

Figure 2 Hepatic lipid content at baseline for each individual subject given as percentage (w/w) of fat relative to wet tissue, $\mathrm{n}=18$.

\section{ENERGY EXPENDITURE AND SUBSTRATE OXIDATION}

No significant differences in energy expenditure between the glucose-supplemented and the fasted state were found at baseline, during exercise or post exercise (see table 2). During exercise, there was a significant time $(p<0.001)$ and treatment $(p<0.001)$ effect, without a time ${ }^{*}$ treatment interaction $(p<0.132)$ effect for respiratory quotient $(R Q)$. RQ was significantly lower at every time point, except for baseline, in the fasted state compared with the glucose-supplemented state $(p<0.01)$ (see figure $3 a)$, reflecting a lower carbohydrate oxidation in the fasted state compared with the glucose-supplemented state $(p<0.01)$ and a higher fat oxidation in the fasted state compared with the glucose-supplemented state (see table 2 for whole body glucose- and fat oxidation). $R Q$ dropped between $t=30$ and $t=120$ min $(p<0.001)$ in both conditions. In the post-exercise period, a significant treatment effect $(p<0.001)$ was observed, with $R Q$ remaining significantly lower in the fasted state compared with the glucose-supplemented state at every time point $(p<0.001)$. Data presented above is acquired from 17 subjects, data from four subjects had to be excluded from the analysis due to missing or poor quality of data. 
Table 2 Energy expenditure and fat and carbohydrate oxidation during and after exercise in glucose-supplemented and fasted state.

\begin{tabular}{|c|c|c|c|c|c|c|c|}
\hline & \multirow[b]{2}{*}{$\begin{array}{c}\text { Time, } \\
\min \end{array}$} & \multicolumn{3}{|c|}{ Glucose-supplemented } & \multicolumn{3}{|c|}{ Fasted } \\
\hline & & $\begin{array}{c}\mathrm{EE}, \\
\mathrm{kJ} / \mathrm{min}\end{array}$ & $\begin{array}{c}\text { Fat } \\
\text { oxidation, } \\
\text { mg/min }\end{array}$ & $\begin{array}{c}\mathrm{CHO} \\
\text { oxidation, } \\
\mathrm{mg} / \mathrm{min}\end{array}$ & $\begin{array}{c}\mathrm{EE}, \\
\mathrm{kJ} / \mathrm{min}\end{array}$ & $\begin{array}{c}\text { Fat } \\
\text { oxidation, } \\
\text { mg/min }\end{array}$ & $\begin{array}{c}\text { CHO } \\
\text { oxidation, } \\
\text { mg/min }\end{array}$ \\
\hline \multirow{4}{*}{ Exercise } & 30 & $36 \pm 4$ & $342 \pm 108$ & $1442 \pm 273$ & $36 \pm 5$ & $457 \pm 139^{\#}$ & $1125 \pm 337^{\#}$ \\
\hline & 60 & $37 \pm 4$ & $512 \pm 133$ & $1077 \pm 362$ & $37 \pm 5$ & $592 \pm 162^{\#}$ & $854 \pm 396^{\#}$ \\
\hline & 90 & $36 \pm 5$ & $534 \pm 114$ & $942 \pm 326$ & $36 \pm 5$ & $646 \pm 174^{\#}$ & $666 \pm 424^{\#}$ \\
\hline & 120 & $35 \pm 4$ & $548 \pm 135$ & $891 \pm 329$ & $36 \pm 6$ & $672 \pm 164^{\#}$ & $600 \pm 438^{\#}$ \\
\hline \multirow{3}{*}{$\begin{array}{l}\text { Post- } \\
\text { exercise }\end{array}$} & 240 & $5 \pm 1$ & $54 \pm 43$ & $231 \pm 107$ & $6 \pm 1$ & $107 \pm 21^{\#}$ & $79 \pm 45^{\#}$ \\
\hline & 300 & $5 \pm 1$ & $45 \pm 20$ & $238 \pm 54$ & $5 \pm 1$ & $108 \pm 22^{\#}$ & $72 \pm 45^{\#}$ \\
\hline & 360 & $5 \pm 1$ & $45 \pm 18$ & $240 \pm 45$ & $6 \pm 1$ & $114 \pm 21^{\#}$ & $70 \pm 45^{\#}$ \\
\hline
\end{tabular}

Data are means $\pm \mathrm{SE}, \mathrm{n}=17$. EE energy expenditure, $\mathrm{CHO}$ carbohydrate. $\# \mathrm{P}<0.01$ compared with glucose-supplemented condition.

\section{PLASMA CONCENTRATIONS}

There was a significant time $(p<0.0001)$, treatment $(p<0.0001)$ and time*treatment interaction $(p<0.0001)$ effect for plasma FFA concentrations. Plasma FFA concentrations increased with time during exercise and recovery from exercise in the fasted state, with a significant higher plasma FFA concentration at the end of exercise $(t=120)$ and 4 hours post-exercise $(t=360)$ compared with before exercise $(t=-60)(p<0.0001)$, whereas plasma FFA concentrations decreased over time in the glucose-fed state $(p=0.002)$. Furthermore, plasma FFA concentrations were substantially higher at the end of 2 hours of exercise and 4 hours post-exercise in the fasted state $(p<0.0001)$ compared with the glucose-fed state (Fig $3 b)$.

Plasma glucose concentrations showed a significant time $(p<0.0001)$, treatment $(p<0.0001)$ and time*treatment interaction $(p<0.0001)$ effect. Thus, plasma glucose concentrations increased with time during exercise and recovery from exercise in the glucose-supplemented state, with a significant higher plasma glucose concentration at the end of exercise $(t=120)$ and 4 hours post-exercise $(t=360)$ compared with before exercise $(t=-60)(p=0.0001)$, whereas plasma glucose concentrations decreased over time in the fasted state $(p=0.0001)$. Moreover, plasma glucose concentrations were lower at the end of 2 hours of exercise and 4 hours post-exercise in the state $(p<0.0001)$ compared with the glucosesupplemented state (Fig 3c).

Plasma triglyceride concentrations showed a significant time $(p<0.0001)$ and 
time ${ }^{*}$ treatment interaction $(p<0.0001)$ effect in the fasted condition (Fig $\left.3 d\right)$. Plasma triglyceride concentrations decreased with time from baseline $(\mathrm{t}=-60)$ to post-recovery $(\mathrm{t}=360)$ in the fasted state, whereas it did not change when glucose supplementation was given.

a

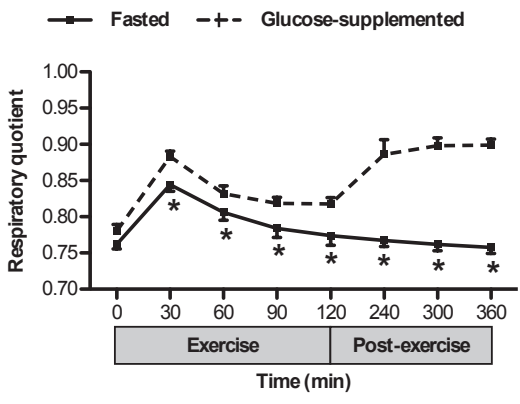

b

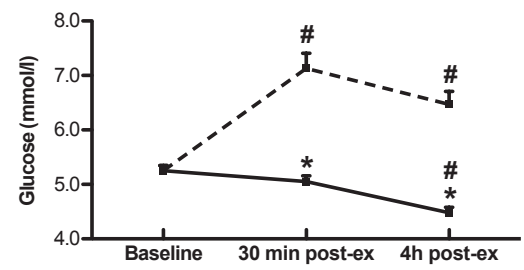

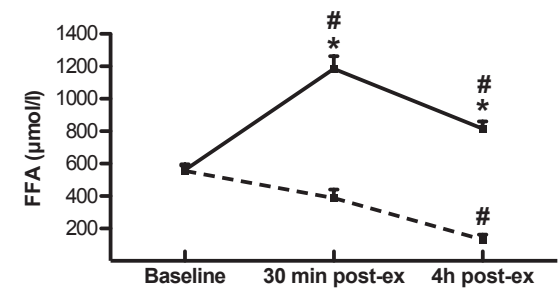

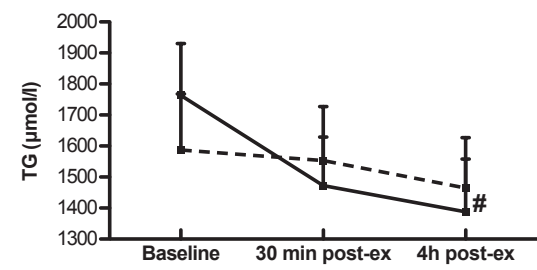

Figure 3 (a) Respiratory quotient during and after $2 \mathrm{~h}$ of cycling at $50 \%$ of maximal power output (Wmax) ( $n=17)$ and plasma concentrations of (b) plasma free fatty acids (FFA), (c) glucose, (d) and triglycerides (TG), with (dotted line) and without (solid line) glucose supplementation. ${ }^{*} P<0.05$ compared with glucose-supplemented condition. ${ }^{\#} \mathrm{P}<0.05$ compared with baseline $(\mathrm{t}=-60)$. Data are means $\pm \mathrm{SE}$.

\section{HEPATIC LIPID CONTENT}

Hepatic lipid content was investigated, by the means of ${ }^{1} \mathrm{H}-\mathrm{MRS}$, before, within 30 min after cessation of exercise and $4 \mathrm{~h}$ post-exercise. IHL did not change significantly with acute exercise neither in the fasted nor in the glucose-supplemented condition, with $\mathrm{IHL}$ after cessation of exercise $(\mathrm{t}=120)$ being $8.3 \pm 1.9 \%$ of the water resonance in the fasted condition $(p=0.154)$ and $8.4 \pm 1.8 \%$ in the glucose-supplemented condition $(p=0.181)$. However, IHL was increased 4 h post-exercise in the fasted condition compared with before exercise $(8.3 \pm 1.8 \%$ of the water resonance before exercise to $8.7 \pm 1.8 \%$ of the water resonance 4 h post-exercise, $(p=0.010))$; this increase in $\mathrm{IHL}$ post-exercise was absent in the glucose-supplemented condition (from $8.3 \pm 1.9 \%$ to $8.3 \pm 1.9 \%$ of the water resonance, $(p=0.789)$ (Fig $4 a)$. 
When dividing subjects with low $(<5.6 \%)$ and high $(>5.6 \%)$ liver fat content, similar effects are found, with no significant changes in $\mathrm{IHL}$ within 30 min after cessation of exercise in both conditions and slightly increased $4 \mathrm{~h}$ post-exercise in the fasted condition. Furthermore, the increase in $\mathrm{IHL}$ 4h post-exercise was similar for both groups ( $p=0.630$ ) (see delta increase in figure $4 b$ ).

a

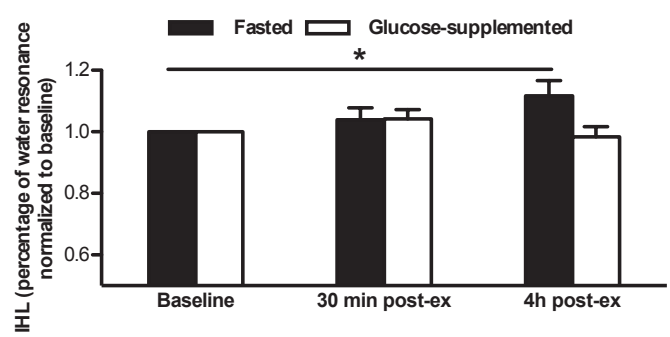

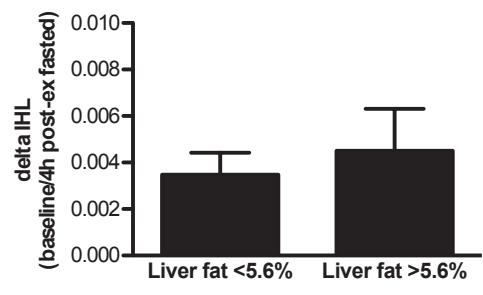

Figure 4 (a) hepatic lipid content within 30 min after cessation of exercise (30 min post-exercise) and $4 \mathrm{~h}$ post-exercise, (because the subjects had a wide variety of liver fat content data was normalized to baseline values), $\mathrm{n}=18$, and (b) delta $(\Delta) \mathrm{lHL}$ between baseline and $4 \mathrm{~h}$ post-exercise in the fasted condition in subjects with low $(<5.6 \%)$ and high $(>5.6 \%)$ liver fat content ${ }^{*} P<0.05$. Data are means \pm SE.

\section{HEPATIC ATP/TOTAL P RATIO}

ATP/Total $\mathrm{P}$ ratio was not statistically significant different from baseline $4 \mathrm{~h}$ postexercise in neither the fasted $(p=0.086)$ nor the glucose-supplemented $(p=0.582)$ condition (Fig 5a). However, although not statistically significant, we observed a tendency to a decrease in ATP/Total P ratio in the fasted condition. In six out of eight subjects ATP/Total $P$ ratio decreased with $16.9 \pm 3.3 \%$ four hours postexercise, whereas we did not observe a decrease in ATP/Total $P$ ratio when glucose supplementation was given (See individual data in figure $5 \mathrm{~b}$ and $\mathrm{c}$ ). No correlation was found between IHL and hepatic ATP content in this subgroup of eight subjects. 


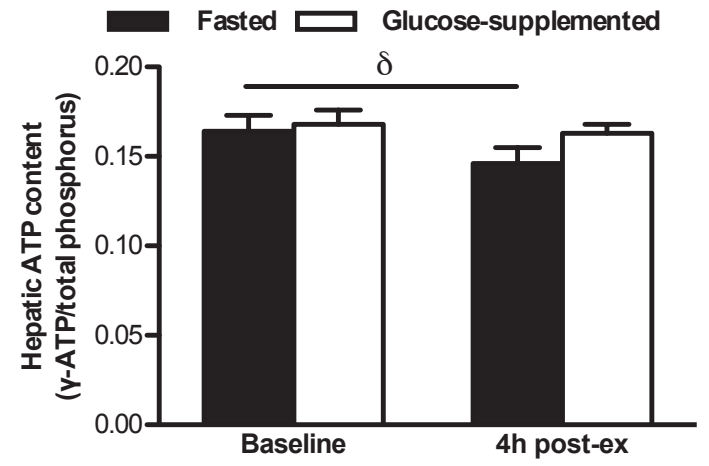

b

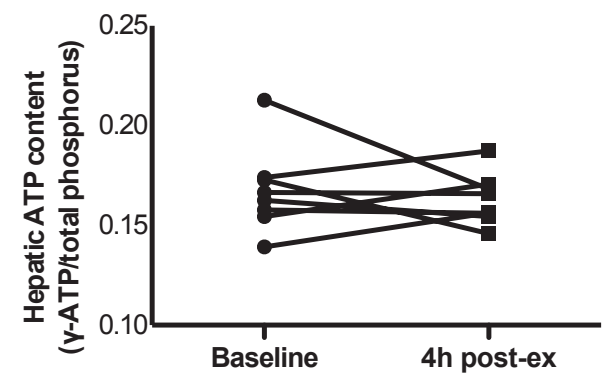

C

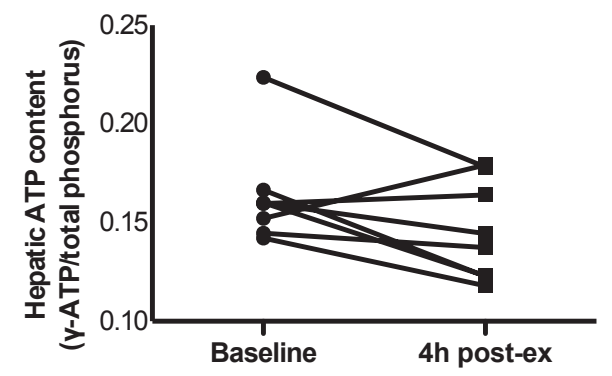

Figure 5 Hepatic ATP/Total $P$ ratio (the relative amount of total phosphorous in the liver) at baseline and $4 \mathrm{~h}$ postexercise as (a) group average and individual data with

(b) and without (c) glucose supplementation. In the fasted condition (without glucosesupplementation) it was a trend to a lower hepatic ATP/Total P ratio $4 \mathrm{~h}$ post-exercise compared with baseline. ${ }^{\delta} \mathrm{P}<0.10$.

\section{DISCUSSION}

Recent evidence suggests that prolonged exercise training might have a lowering effect on IHL [3-6]. Here, we examined the effect of an acute bout of exercise on the $\mathrm{IHL}$ in middle-aged overweight men with a wide range of liver fat content and we did not observe a decreased $\mathrm{IHL}$ in this population. Moreover, in the recovery 
phase after exercise, IHL was increased at $4 \mathrm{~h}$ post-exercise in the fasted condition; this increase in IHL was absent when subjects consumed glucose during and after exercise. During and after exercise, circulatory FFA levels are profoundly increased, which may deliver FFA to the liver with increased IHL as a consequence. Of note, glucose supplementation blunts the exercise-induced increase in plasma FFA levels. Therefore, the results of the present study indicate that in spite of strongly stimulated whole body fat oxidation during exercise, an acute bout of exercise is not enough to decrease IHL in this population.

There is an increasing prevalence of obesity worldwide, and obesity is associated with excessive storage of lipids (triglycerides) not only in adipose tissue, but also in non-adipose tissues, such as skeletal muscle and liver. Excessive lipid accumulation in the liver is associated with insulin resistance and type 2 diabetes. Lifestyle interventions like exercise training revealed that hepatic fat can be lowered by prolonged exercise training, hence preventing complications associated with hepatic fat accumulation [3-6], with patients with high liver fat content showing the greatest reduction following physical activity training. Until now there are no studies investigating the acute effects of exercise on hepatic fat accumulation in an overweight middle-aged population at risk of developing fatty liver or with NAFLD already being present. We show here that an acute bout of exercise did not lead to a detectable decrease $\mathrm{IHL}$, neither in a fasted nor in a glucose-supplemented condition. To our knowledge this is the first study to show this in overweight middleaged men, which suggests that the long term effects of physical activity training cannot simply be explained by an additive effect of acute exercise bouts.

Whereas $\mathrm{IHL}$ did not significantly change within 30 min after cessation of exercise, it was slightly increased $4 \mathrm{~h}$ post-exercise in the fasted condition. This finding is consistent with recent reports in young, healthy subjects, in which one exercise session also lead to an increase in IHL after exercise [13-14]. The authors suggested that increased FFA availability during exercise [15-16] might be responsible for the increase in IHL. We therefore also examined if exercise would have similar effects on $\mathrm{IHL}$ when performed with glucose supplementation during and after exercise. We have previously shown that glucose supplementation during/after exercise markedly blunts the exercise-induced increase in FFA. Consistently, the increase in $\mathrm{IHL}$ observed $4 \mathrm{~h}$ post exercise was absent in the glucose-supplemented condition. Next to reducing FFA levels, glucose supplementation also increases plasma glucose levels and - although not measured - possibly also insulin levels [20], and 
both glucose and insulin are able to stimulate de novo lipogenesis [21], which is an important factor in hepatic fat accumulation [22]. However, since enhanced de novo lipogenesis would result in increased IHL, the absence of an exercise effect on $\mathrm{IHL}$ in the glucose fed condition is most likely due to the reduction in plasma FFA levels, suggesting that indeed FFA availability during and after exercise may be an important factor in determining post-exercise $\mathrm{IHL}$ content. However, studies directly measuring FFA fluxes into liver are needed to confirm this hypothesis.

Next to measuring the IHL content, ATP/Total $P$ ratio was determined at baseline and $4 \mathrm{~h}$ post-exercise in a subgroup of eight subjects. Although, ATP/Total P ratio did not significantly change $4 \mathrm{~h}$ post-exercise in neither the fasted nor the glucosesupplemented condition, ATP/Total P ratio had a tendency to be decreased in six out of eight subjects $4 \mathrm{~h}$ post-exercise in the fasted condition. It has been suggested that hepatic ATP levels are decreased in conditions such as insulin resistance and type 2 diabetes mellitus [18-23], and that hepatocellular ATP levels are negatively correlating with liver fat in human subjects, suggesting lipotoxicity. In agreement with these data the current study reports a trend to decreased ATP levels along with increased IHL, although no correlation between hepatic lipid content and hepatic ATP levels was found. Interestingly, a recent study investigating the energy charge in the liver of mice after one single bout of exercise found a clear increase of AMP and a strong decrease of ATP in the liver [24], suggesting that the reduction in ATP levels after exercise is a direct consequence of exercise. In the current study we did observe a non-significant decrease in ATP/Total $P$ ratio after exercise in the fasted condition, whereas no decrease in ATP/Total $P$ ratio was observed after exercise in the glucose-supplemented condition. This suggests that the elevation of IHL upon exercise instead of exercise per se - may be responsible for the reduced hepatic energy status of the liver. However, investigation of larger subject groups will have to determine to what extent the decrease in ATP/Total $\mathrm{P}$ ratio is related to increase in $\mathrm{IHL}$.

In summary, we did not observe a decrease in liver fat after acute exercise in overweight middle-aged men. Moreover, IHL was increased post-exercise in the fasted state, an effect that is most likely due to the exercise-induced increase in plasma FFA levels. These data suggest that acute exercise is not responsible for the exercise-lowering effects on liver fat, and that a single bout of exercise may not be able to lower IHL, not even in a population with elevated IHL. 


\section{ACKNOWLEDGEMENTS}

Funding: The project is supported by the Dutch Diabetes Research Foundation (2009.60.003) and a $\mathrm{VICl}$ (grant 918.96.618) for innovative research from the Netherlands Organization for Scientific Research (NWO). V.B. SchrauwenHinderling is supported by a VENI (grant 91611136) for innovative research from the Netherlands Organization for Scientific Research (NWO). M. E. Kooi is supported by Aspasia Grant 015.008.047 from the Netherlands Organization for Scientific Research. This research was performed within the framework of CTMM, the Center for Translational Molecular Medicine (www.ctmm.nl), project PREDICCt (grant 01C-104), and supported by the Dutch Heart Foundation, Dutch Diabetes research Foundation and Dutch Kidney Foundation. 


\section{REFERENCES}

1. Dela F. Other adaptations to training/inactivity in type 2 diabetics and other groups with insulin resistance: emphasis on prevention of CHD. Applied physiology, nutrition, and metabolism = Physiologie appliquee, nutrition et metabolisme. 2007;32(3):602-6.

2. Gordon BA, Benson AC, Bird SR, Fraser SF. Resistance training improves metabolic health in type 2 diabetes: a systematic review. Diabetes research and clinical practice. 2009;83(2):157-75.

3. Sullivan S, Kirk EP, Mittendorfer B, Patterson BW, Klein S. Randomized trial of exercise effect on intrahepatic triglyceride content and lipid kinetics in nonalcoholic fatty liver disease. Hepatology (Baltimore, Md. 2012;55(6):1738-45.

4. Hallsworth K, Fattakhova G, Hollingsworth KG, Thoma C, Moore S, Taylor R, Day CP, Trenell MI. Resistance exercise reduces liver fat and its mediators in non-alcoholic fatty liver disease independent of weight loss. Gut. 2011;60(9):1278-83.

5. Finucane FM, Sharp SJ, Purslow LR, Horton K, Horton J, Savage DB, Brage S, Besson H, De Lucia Rolfe E, Sleigh A, Martin HJ, Aihie Sayer A, Cooper C, Ekelund U, Griffin SJ, Wareham NJ. The effects of aerobic exercise on metabolic risk, insulin sensitivity and intrahepatic lipid in healthy older people from the Hertfordshire Cohort Study: a randomised controlled trial. Diabetologia. 2010;53(4):624-31.

6. Chen SM, Liu CY, Li SR, Huang HT, Tsai CY, Jou HJ. Effects of therapeutic lifestyle program on ultrasound-diagnosed nonalcoholic fatty liver disease. J Chin Med Assoc. 2008;71(11):551-8.

7. Magkos F. Putative factors that may modulate the effect of exercise on liver fat: insights from animal studies. Journal of nutrition and metabolism. 2012;2012:827417.

8. Magkos F. Exercise and fat accumulation in the human liver. Current opinion in lipidology. 2010;21(6):507-17.

9. Rogers MA. Acute effects of exercise on glucose tolerance in non-insulindependent diabetes. Medicine and science in sports and exercise. 1989;21(4):362-8.

10. Frank P, Katz A, Andersson E, Sahlin K. Acute exercise reverses starvationmediated insulin resistance in humans. American journal of physiology. 2013;304(4):E436-43.

11. Mackenzie R, Maxwell N, Castle P, Elliott B, Brickley G, Watt P. Intermittent exercise with and without hypoxia improves insulin sensitivity in individuals with type 2 diabetes. The Journal of clinical endocrinology and metabolism. 2012;97(4):E546-55.

12. Johnson NA, van Overbeek D, Chapman PG, Thompson MW, Sachinwalla 
T, George J. Effect of prolonged exercise and pre-exercise dietary manipulation on hepatic triglycerides in trained men. European journal of applied physiology. 2011;112(5):1817-25.

13. Bucher J, Krusi M, Zueger T, Ith M, Stettler C, Diem P, Boesch C, Kreis R, Christ $\mathrm{E}$. The effect of a single $2 \mathrm{~h}$ bout of aerobic exercise on ectopic lipids in skeletal muscle, liver and the myocardium. Diabetologia. 2014.

14. Schrauwen P, Hesselink MK, Vaartjes I, Kornips E, Saris WH, Giacobino JP, Russell A. Effect of acute exercise on uncoupling protein 3 is a fat metabolismmediated effect. American journal of physiology. 2002;282(1):E11-7.

15. Bilet L, van de Weijer T, Hesselink MK, Glatz JF, Lamb HJ, Wildberger J, Kooi ME, Schrauwen P, Schrauwen-Hinderling VB. Exercise-induced modulation of cardiac lipid content in healthy lean young men. Basic research in cardiology. 2010;106(2):307-15.

16. Donnelly KL, Smith Cl, Schwarzenberg SJ, Jessurun J, Boldt MD, Parks EJ. Sources of fatty acids stored in liver and secreted via lipoproteins in patients with nonalcoholic fatty liver disease. The Journal of clinical investigation. 2005;115(5):1343-51.

17. Szendroedi J, Chmelik M, Schmid AI, Nowotny P, Brehm A, Krssak M, Moser E, Roden M. Abnormal hepatic energy homeostasis in type 2 diabetes. Hepatology (Baltimore, Md. 2009;50(4):1079-86.

18. Kuipers H, Verstappen FT, Keizer HA, Geurten P, van Kranenburg G. Variability of aerobic performance in the laboratory and its physiologic correlates. International journal of sports medicine. 1985;6(4):197-201.

19. Siri WE. The gross composition of the body. Advances in biological and medical physics. 1956;4:239-80.

20. van Herpen NA, Schrauwen-Hinderling VB, Schaart G, Mensink RP, Schrauwen P. Three weeks on a high-fat diet increases intrahepatic lipid accumulation and decreases metabolic flexibility in healthy overweight men. The Journal of clinical endocrinology and metabolism. 2011;96(4):E691-5.

21. Vanhamme L, van den Boogaart A, Van Huffel S. Improved method for accurate and efficient quantification of MRS data with use of prior knowledge. J Magn Reson. 1997;129(1):35-43.

22. Naressi A, Couturier C, Devos JM, Janssen M, Mangeat C, de Beer R, Graveron-Demilly D. Java-based graphical user interface for the MRUI quantitation package. Magma (New York, NY. 2001;12(2-3):141-52.

23. Szczepaniak LS, Nurenberg P, Leonard D, Browning JD, Reingold JS, Grundy S, Hobbs HH, Dobbins RL. Magnetic resonance spectroscopy to measure hepatic triglyceride content: prevalence of hepatic steatosis in the general population. American journal of physiology. 2005;288(2):E462-8.

24. Stellingwerff T, Boon H, Gijsen AP, Stegen JH, Kuipers H, van Loon LJ. Carbohydrate supplementation during prolonged cycling exercise spares muscle glycogen but does not affect intramyocellular lipid use. Pflugers 
Archiv : European journal of physiology. 2007;454(4):635-47.

25. Hellerstein MK. De novo lipogenesis in humans: metabolic and regulatory aspects. European journal of clinical nutrition. 1999;53 Suppl 1:S53-65.

26. Ferre P, Foufelle F. Hepatic steatosis: a role for de novo lipogenesis and the transcription factor SREBP-1c. Diabetes, obesity \& metabolism. 2010;12 Suppl 2:83-92.

27. Schmid Al, Szendroedi J, Chmelik M, Krssak M, Moser E, Roden M. Liver ATP synthesis is lower and relates to insulin sensitivity in patients with type 2 diabetes. Diabetes care. 2011;34(2):448-53.

28. Camacho RC, Donahue EP, James FD, Berglund ED, Wasserman DH. Energy state of the liver during short-term and exhaustive exercise in C57BL/6J mice. American journal of physiology. 2006;290(3):E405-8. 
L.Bilet, E. Phielix, E. Moonen-Kornips, V.B. Schrauwen-Hinderling, M.K.C. Hesselink, P. Schrauwen

In preparation 


\section{CHAPTER}

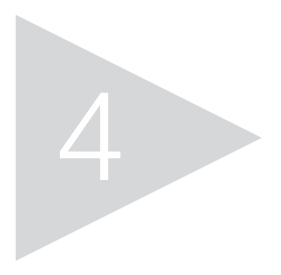

Differential effects of exercise on IMCL content in the fasted and fed state 


\section{ABSTRACT}

Studies have been inconsistent in showing the effect of exercise on IMCL content. We here hypothesize that skeletal muscle is taking up FFAs when the availability is high, thereby facilitating increased storage of muscle fat after exercise. Further, we hypothesize that when the exercise-induced increase in FFA is blunted (by consuming glucose drinks), muscle fat content will decrease upon exercise. To test this hypothesis, we manipulated plasma FFA levels, by means of a fasted vs. glucose-supplemented exercise and recovery protocol, and monitored skeletal muscle lipid content. Nine healthy lean young men (age 23.2 \pm 2.2 years, BMI 22.7 $\pm 1.8 \mathrm{~kg} / \mathrm{m}^{2}$ ) performed a $2 \mathrm{~h}$ cycling protocol, once while staying fasted and once while ingesting glucose. IMCL was measured by Oil-red-O staining at baseline, directly after exercise and again $4 \mathrm{~h}$ post-exercise. Plasma FFA concentrations were substantially higher at the end of 2 hours of exercise and 4 hours post-exercise in the fasted condition $(p<0.001)$ compared with the glucose-supplemented condition, reflecting a higher fat oxidation rate $(p<0.05)$ in the fasted condition compared with the glucose-supplemented condition. In mixed muscle total IMCL content was higher directly after exercise $(p=0.026)$ and 4 h post-exercise $(p=0.007)$ in the fasted condition compared with the glucose-supplemented condition. An acute bout of exercise leads to different effects on IMCL depending on whether exercise is performed in a fasted or in a glucose-supplemented condition. Performing exercise in a fasted condition leads to an increase in IMCL, probably due to elevated plasma FFA levels, whereas performing exercise in a glucose-supplemented condition leads to a decrease in IMCL in exercising muscle. This suggests that the muscle has capacity to take up and re-esterify FFA and that it takes up FFA when the availability is high. 


\section{INTRODUCTION}

One of the earliest hallmarks of type 2 diabetes is resistance of the peripheral tissues liver and muscle to the action of insulin, which is generally referred to as insulin resistance. Development of insulin resistance is strongly promoted by obesity. In fact obesity is the major risk factor for insulin resistance, and $80 \%$ of all type 2 diabetic patients are overweight or obese. Whereas obesity is by definition characterized by an excessive accumulation of fat in the body, it is specifically the accumulation of fat within non-adipose tissue (called steatosis or ectopic fat accumulation), which is associated with the development of insulin resistance. Indeed, type 2 diabetic patients and their first-degree relatives are characterized by excessive accumulation of fat in skeletal muscle [1]. Despite the well-known detrimental effects of ectopic fat accumulation, it is not completely understood why fat accumulates in the muscle.

Human studies using ${ }^{1} \mathrm{H}-\mathrm{MRS}$ have reported that intramyocellular lipid content (IntraMyoCellular Lipid, IMCL) is associated with obesity, insulin resistance and type 2 diabetes [2, 3]. It has been shown that a period of prolonged fasting (60 hours) increased IMCL dramatically [4]. Furthermore, results in skeletal muscle show that elevation of FFA levels by lipid infusion result in increased lipid content after 4 hours [5]. Similarly, we showed that skeletal muscle lipid content is increased in the inactive arm muscle directly after prolonged cycling exercise in the fasted state, where FFA typically increase to up to $1450 \mathrm{mmol}$ [6]. These results suggest that high circulatory FFA levels lead to unrestrained uptake of these FA in skeletal muscle, independent of oxidative needs.

Next to this, intramyocellular lipids are also an important source of energy for the mitochondria, and can be used during exercise, as we showed previously [7]. However, if exercise reduces IMCL is still under debate, with studies reporting conflicting results [7-12]. A confounding factor here may be that exercise promotes adipose tissue lipolysis and hence elevates plasma FFA levels, which could lead to increased muscle fat accumulation. In that context, we have previously shown that lipid content in other ectopic stores is increased $4 \mathrm{~h}$ post exercise in the fasted condition, accompanied by increased FFA levels, both in the heart [6] and in the liver [13]. However, when blunting the exercise-induced increase in lipolysis by giving glucose supplementation before exercise, during exercise and during recovery from exercise, liver and cardiac lipid content did not increase. Whether or 
not the same holds true for skeletal muscle is presently unknown.

We here hypothesize that skeletal muscle is passively taking up FFAs when the availability is high, thereby promoting fat storage in muscle post-exercise. Further, we hypothesize that when this increase in FFA levels is blunted, by consuming glucose drinks, exercise will result in a decreased muscle lipid content. To test this hypothesis, we manipulated FFA levels, by means of a fasted vs. glucosesupplemented exercise and recovery protocol, and monitored skeletal muscle lipid content.

\section{MATERIALS AND METHODS}

\section{SUBJECTS}

Nine healthy lean young men participated in this study. None of the subjects participated in competitive sports and subjects with unstable body weight ( $>3 \mathrm{~kg}$ change in preceding six months) were excluded from the study. The institutional medical ethics committee approved the study, and all participants gave their informed written consent.

Table 1 Subjects' characteristics

\begin{tabular}{lc}
\hline Subjects' characteristics & Mean \pm SE \\
\hline Age, $\mathrm{yr}$ & $23.2 \pm 2.2$ \\
Height, $\mathrm{m}$ & $1.85 \pm 0.09$ \\
Weight, $\mathrm{kg}$ & $77.9 \pm 9.5$ \\
$\mathrm{BMI}, \mathrm{kg} / \mathrm{m}^{2}$ & $22.7 \pm 1.8$ \\
Fat $\%$ & $14.4 \pm 5.5$ \\
$\mathrm{VO}_{2} \mathrm{max} / \mathrm{kg}, \mathrm{ml} \times \mathrm{min}^{-1} \times \mathrm{kg}^{-1}$ & $38.5 \pm 15.6$ \\
\hline
\end{tabular}

Data are means \pm SD. BMI Body mass index.

\section{STUDY PROTOCOL}

At the beginning of the study, body composition and maximal aerobic capacity were determined in all subjects. The experimental trial comprised two separate test days separated by at least one week and performed in random order. Subjects refrained from physical activity two days prior to the test days. Furthermore, subjects were 
instructed to consume a standardized meal the evening prior to the test days. On the test days, subjects reported to the laboratory after an overnight fast no food consumption after $10 \mathrm{pm}$ the preceding day). A muscle biopsy from the vastus lateralis muscle was taken and immediately frozen in tissue tek/melting isopentane and stored at -80 degree for later analysis of intramyocellular lipid content. Thereafter, a teflon canula was inserted into an antecubital forearm vein for sampling of blood and subjects rested for 30 minutes. Immediately after drawing the first blood sample, subjects ingested either $1.4 \mathrm{~g} / \mathrm{kg}$ body weight of glucose (dissolved in water to a $20 \%$ solution and flavoured with $1 \mathrm{ml}$ lemon juice) or the same amount of water. After this, subjects started exercising on a stationary bike at $50 \%$ of their pre-determined maximal power output (Wmax) ( $t=0$ minute) for two hours. During exercise, blood samples were drawn and substrate oxidation was measured by indirect calorimetry (Omnical, Maastricht, The Netherlands) every 30 minutes (at $t=30,60,90$ and 120 minutes) while heart rate was constantly measured. Immediately after cessation of exercise, a second muscle biopsy was taken. Subsequently, subjects bed-rested for four hours, followed by a third muscle biopsy four hours post exercise. During the 4-hour post exercise period, blood samples were drawn and substrate oxidation was measured for 15 minutes every hour (at $t=180,240,300$ and 360 minutes) in all subjects. The experimental design is depicted in Fig. 1.

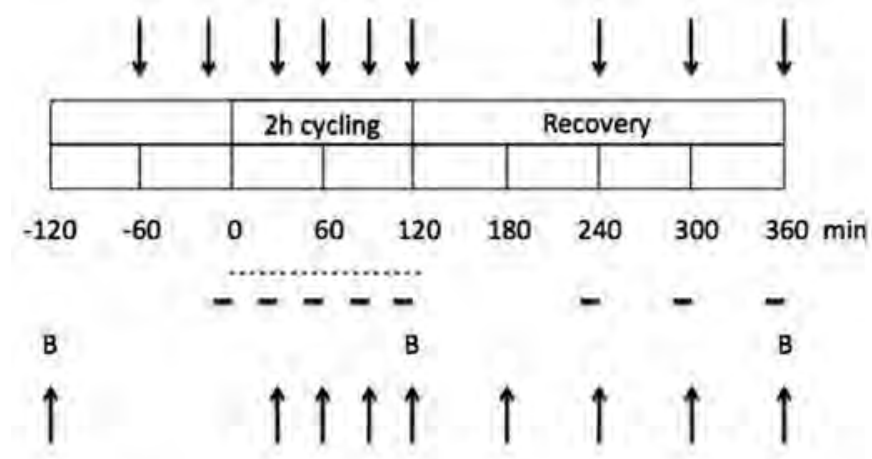

Figure 1 The experimental design of the study. All subjects performed the protocol twice, one time in the fasted state consuming water and one time with glucose supplementation.

\footnotetext{
B Muscle biopsy

Glucose or water supplementation

- Heart rate monitoring

- Indirect calorimetry

$\uparrow$ Blood sampling
} 


\section{MEASUREMENTS PRIOR TO TEST DAYS}

A routine incremental cycling test on a stationary bike was used to determine maximal exercise capacity as described previously [14] and a hydrostatic weighing with simultaneous measurement of lung volume was used to determine body composition. The equation of Siri [15] was used to calculate fat percentage, fat mass and fat-free mass.

\section{BLOOD SAMPLE ANALYSES}

Blood samples were collected in EDTA-containing tubes and immediately spun at high speed, frozen in liquid nitrogen and stored at $-80^{\circ} \mathrm{C}$. Plasma free fatty acids, triglycerides, and glucose were measured with enzymatic assays automated on a ABX Pentra 400 (Horiba diagnostics, Montpellier, France). Glycerol was measured with a EnzytecTM glycerol kit, R-Biopharm, Germany.

\section{MUSCLE BIOPSIES AND ANALYSES}

Muscle biopsies were taken from the $\mathrm{m}$. vastus lateralis, prior to the clamp under local anaesthesia (2\% lidocaine), according to the Bergstrom technique [16]. In the muscle tissue obtained, lipid accumulation was assessed histochemically in crosssections using a modified Oil-red-O staining for fluorescence microscopy [17].

\section{STATISTICS}

Data are reported as mean \pm SE. Statistical analyses were performed using SPSS version 20.0.0 for Mac OS X (SPSS Inc., NC, USA). A two-way repeated measures ANOVA was performed to compare the mean differences between conditions for Intramyocellular lipid content, substrate oxidation and plasma values of FA, triglycerides, and glucose. Thereafter a pairwise comparison was performed with a Bonferroni correction for multiple comparisons. Statistical significance was set a priori at $\mathrm{p}<0.05$. 


\section{RESULTS}

\section{ENERGY EXPENDITURE AND SUBSTRATE OXIDATION}

Energy expenditure was significantly lower in the fasted state compared with the glucose-supplemented state during exercise $(p=0.014)$, whereas in the post-exercise period the energy expenditure was similar between the two states $(p=0.386)$ (see table 2). During exercise, there was a significant time $(p=0.005)$ and treatment $(p<0.026)$ effect, without a time*treatment interaction $(p<0.099)$ effect for respiratory quotient $(R Q)$. $R Q$ was significantly lower from $t=60$ onwards in the fasted state compared with the glucose-supplemented state $(p<0.05)$ (see fig. 2a), reflecting a lower carbohydrate oxidation in the fasted state compared with the glucose-supplemented state $(p<0.05)$ and a higher fat oxidation in the fasted state compared with the glucose-supplemented state $(p<0.05)$ (see table 2 for whole body glucose- and fat oxidation). $R Q$ dropped between $t=30$ and $t=120$ $\min (p<0.05)$ in both conditions. In the post-exercise period, a significant treatment effect ( $p=0.002$ ) was observed, with $R Q$ remaining significantly lower in the fasted state compared with the glucose-supplemented state at all time points $(p<0.01)$. In the post-exercise period two subjects had to be excluded from the analysis due to missing data.

Table 2 Energy expenditure and fat and carbohydrate oxidation during and after exercise in glucose-supplemented and fasted state.

\begin{tabular}{|c|c|c|c|c|c|c|c|}
\hline & \multirow[b]{2}{*}{$\begin{array}{c}\text { Time, } \\
\text { min }\end{array}$} & \multicolumn{3}{|c|}{ Glucose-supplemented } & \multicolumn{3}{|c|}{ Fasted } \\
\hline & & $\begin{array}{c}\mathrm{EE}, \\
\mathrm{kJ} / \mathrm{min}\end{array}$ & $\begin{array}{c}\text { Fat } \\
\text { oxidation, } \\
\text { mg/min }\end{array}$ & $\begin{array}{c}\text { CHO } \\
\text { oxidation, } \\
\text { mg/min }\end{array}$ & $\begin{array}{c}\mathrm{EE}, \\
\mathrm{kJ} / \mathrm{min}\end{array}$ & $\begin{array}{c}\text { Fat } \\
\text { oxidation, } \\
\text { mg/min }\end{array}$ & $\begin{array}{c}\text { CHO } \\
\text { oxidation, } \\
\text { mg/min }\end{array}$ \\
\hline \multirow{4}{*}{ Exercise } & 30 & $51 \pm 3$ & $253 \pm 85$ & $2594 \pm 292$ & $45 \pm 3^{*}$ & $458 \pm 123$ & $1703 \pm 307^{*}$ \\
\hline & 60 & $52 \pm 3$ & $274 \pm 87$ & $2600 \pm 291$ & $46 \pm 3^{*}$ & $552 \pm 127^{*}$ & $1538 \pm 299^{*}$ \\
\hline & 90 & $52 \pm 3$ & $325 \pm 85$ & $2431 \pm 270$ & $46 \pm 3^{*}$ & $583 \pm 127^{*}$ & $1430 \pm 257^{*}$ \\
\hline & 120 & $51 \pm 4$ & $367 \pm 83$ & $2079 \pm 351$ & $44 \pm 3^{*}$ & $655 \pm 116^{*}$ & $1161 \pm 233^{*}$ \\
\hline \multirow{4}{*}{$\begin{array}{l}\text { Post- } \\
\text { exercise }\end{array}$} & 180 & $7 \pm 0.4$ & $56 \pm 15$ & $324 \pm 46$ & $7 \pm 0.3$ & $154 \pm 17^{*}$ & $48 \pm 30^{*}$ \\
\hline & 240 & $7 \pm 0.3$ & $53 \pm 11$ & $327 \pm 35$ & $7 \pm 0.4$ & $157 \pm 17^{*}$ & $43 \pm 35^{*}$ \\
\hline & 300 & $7 \pm 0.4$ & $48 \pm 15$ & $359 \pm 40$ & $7 \pm 0.4$ & $146 \pm 14^{*}$ & $68 \pm 26^{*}$ \\
\hline & 360 & $7 \pm 0.4$ & $44 \pm 14$ & $321 \pm 49$ & $7 \pm 0.5$ & $160 \pm 17^{*}$ & $39 \pm 23^{*}$ \\
\hline
\end{tabular}

Data are means $\pm \mathrm{SE}, \mathrm{n}=9$ during exercise, $\mathrm{n}=7$ during recovery from exercise. $E E$ energy expenditure; $\mathrm{CHO}$ carbohydrate. ${ }^{*} \mathrm{P}<0.05$ compared with glucose-supplemented condition. 


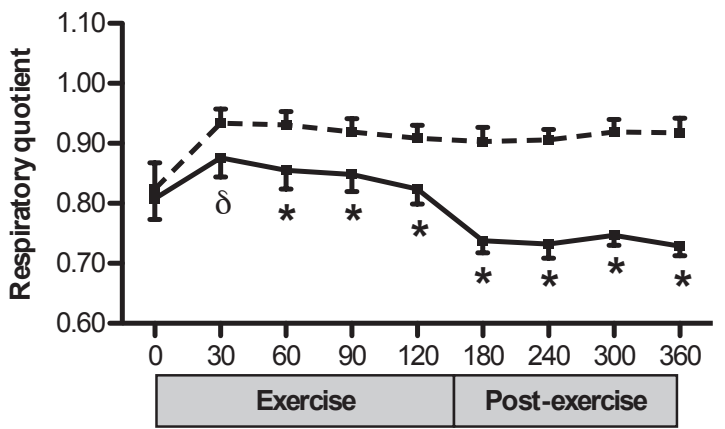

Time (min)

b

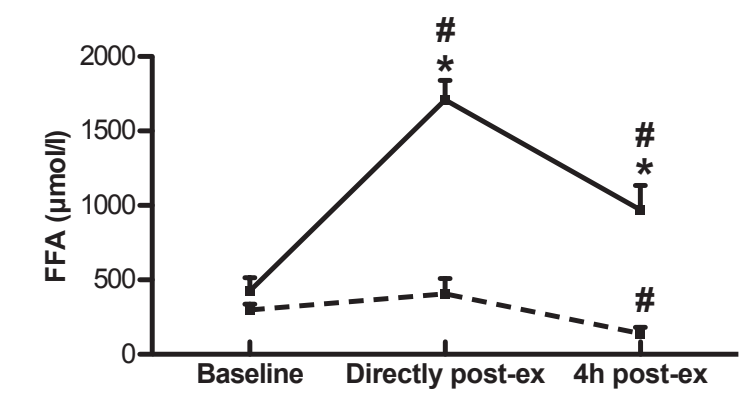

c

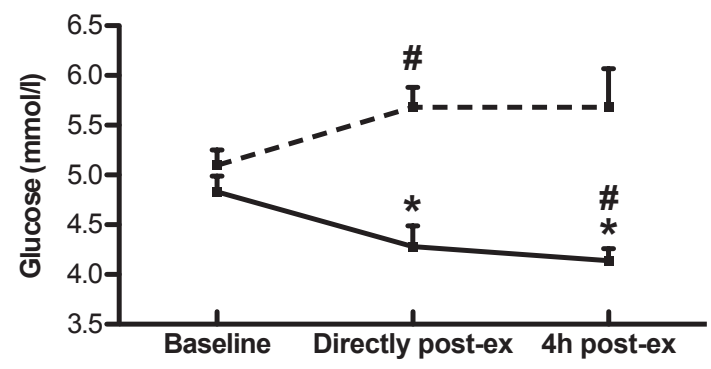

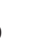

Figure 2 (a) Respiratory quotient (RQ), (b) Plasma Free Fatty Acids (FFA) and (c) plasma glucose before, during and post-exercise with (dotted line) and without (solid line) glucose supplementation. * $\mathrm{P}<0.05$ compared with glucosesupplemented condition. ${ }^{*} \mathrm{P}<0.05$ compared with baseline $(t=-60)$. Data are means \pm SE.

\section{PLASMA CONCENTRATIONS}

There was a significant time $(p<0.0001)$, treatment $(p<0.0001)$ and time $e^{*}$ treatment interaction $(p<0.0001)$ effect for plasma FFA concentrations. Plasma FFA concentrations were substantially higher at the end of 2 hours of exercise and 4 hours post-exercise in the fasted state $(p<0.001)$ compared with the glucose- 
supplemented state (Fig. 2b). Moreover, plasma FFA concentrations were increased at the end of exercise $(t=120)$ and $4 \mathrm{~h}$ post-exercise $(t=360)$ in the fasted state compared with baseline $(t=-60)(p<0.05)$, whereas plasma FFA concentrations were decreased $4 \mathrm{~h}$ post-exercise $(\mathrm{t}=360)$ in the glucose-supplemented state compared with baseline $(p=0.047)$.

Plasma glucose concentrations showed a significant treatment $(p<0.002)$ and time*treatment interaction $(p<0.021)$ effect, without any time effect $(p<0.971)$. Thus, plasma glucose concentrations were lower at the end of 2 hours of exercise and $4 \mathrm{~h}$ post-exercise in the fasted state $(\mathrm{p}<0.05)$ compared with the glucosesupplemented state (Fig. 2c). Moreover, plasma glucose concentrations were increased at the end of exercise $(t=120)$ compared with baseline $(t=-60)(p=0.029)$, whereas plasma glucose concentrations were decreased $4 \mathrm{~h}$ post-exercise in the fasted state compared with baseline $(p=0.003)$.

\section{INTRAMYOCELLULAR LIPID CONTENT}

Intramyocellular lipid content was investigated with Oil-red-O staining in muscle tissue from $\mathrm{m}$. vastus lateralis before, directly after exercise and $4 \mathrm{~h}$ post-exercise in 8 subjects. For total intramyocellular lipid content there was a treatment $(p=0.027)$ and treatment*time interaction $(p=0.024)$ effect, without a time effect $(p=0.416)$. Thus, the effect of acute exercise on lipid content was depended on whether the subjects were fasted or received glucose during and after exercise. In the fasted condition the IMCL content increased over time whereas in the glucosesupplemented condition the IMCL decreased over time, resulting in a significant difference in total IMCL content between the two conditions directly after exercise $(p=0.026)$ and 4 h post-exercise $(p=0.007)$ (see Fig. 3).

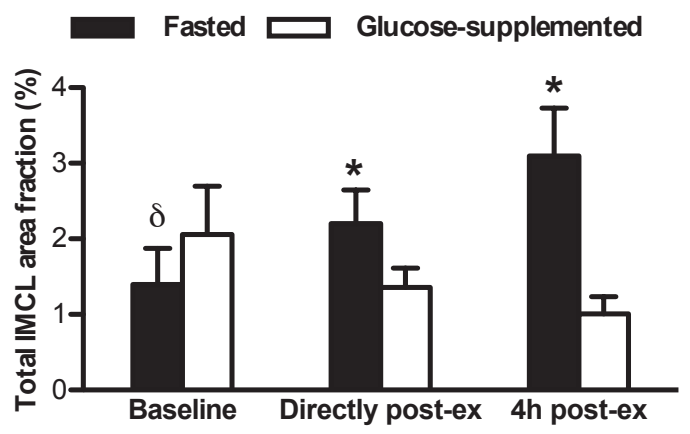

Figure 3 Total Intramyocellular lipid content (IMCL) in mixed muscle before exercise, directly post-exercise and 4h post-exercise, $\mathrm{n}=8 .{ }^{*} \mathrm{P}<$ 0.05 compared with glucosesupplemented condition. ${ }^{\circ} \mathrm{P}<$ 0.10 compared with glucosesupplemented condition. Data are means $\pm \mathrm{SE}$. 


\section{DISCUSSION}

Here, we examined the effect of an acute bout of exercise on the intramyocellular lipid content in healthy lean young men. The data show that the effect of an acute bout of exercise on IMCL is depending on whether the subjects were fasted or received glucose during exercise and during recovery from exercise. In the fasted condition IMCL is increasing over time, whereas in the glucose-supplemented condition IMCL is decreasing over time, resulting in a higher IMCL content directly after exercise and $4 \mathrm{~h}$ post-exercise in the fasted condition compared with the glucose-supplemented condition. In the fasted condition, circulatory FFA levels are profoundly increased during and after exercise (in contrast to the glucosesupplemented condition). The present study indicates that the strong increase in plasma FFA levels in the fasted condition leads to FFA delivery to skeletal muscle, and in spite of strongly elevated fat oxidation during prolonged exercise, it still leads to increased IMCL in the active muscle post-exercise.

The finding that IMCL is increasing in muscle during exercise is surprising and in contrast to previous findings by us [7] and others [9, 10, 18-20], where it was reported that IMCL is decreasing during exercise, due to the oxidation of IMCL in contracting muscle [7]. However, it has been previously shown that FFA can be reesterified also in exercising muscle [21]. When this re-esterification is stronger than the hydrolysis of triglycerides during exercise it might result in a turnover of IMCL with a net increase in IMCL content in exercising muscle and explain the findings in the current study. In support, when the exercise-induced increase in plasma FFA is blunted by glucose supplementation, we did confirm the previously reported decrease in IMCL during exercise, further supporting the notion that the elevated FFA is the underlying reason for net IMCL storage. The discrepancy found between the current study and previous studies might be explained by difference in duration and intensity of exercise, but also on diet modifications and therefore plasma FFA levels during and prior to testing. In our previous study [7] FFA concentrations were approximately 4-fold lower during exercise than in the fasted condition in the current study, probably due to the fact that subjects were not fasted at the beginning of the cycling test and furthermore, glucose-supplementation during exercise that was given to facilitate completion of a 3-h exercise bout. Similarly lower levels of plasma FFA (almost 2-fold lower) were found in the studies of Bucher et al. [9] and Egger et al. [10], where a high-fat diet was given to replete IMCL levels prior to testing. Additionally, a light meal or a breakfast was given on the day of testing, whereas in 
the current study subjects were performing exercise after an overnight fast receiving only water or glucose during exercise. These studies are therefore more similar to the glucose-supplemented condition in the current study, where it is also found that IMCL is decreasing during exercise. Thus, elevated plasma FFA levels during exercise in the fasted condition might explain a higher re-esterification of IMCL in the current study, resulting in an increase in IMCL after exercise. Furthermore, it is suggested that pre-exercise IMCL levels determine the degree of IMCL depletion after exercise [12, 22], thus giving a high-fat diet to replete IMCL levels prior to testing might lead to a higher decrease of IMCL during exercise. In contrast to these studies, in the study of Johnson et al. [19] and Krssak et al. [20], where highly trained men were tested, plasma FFA levels were comparable to plasma concentrations in the current study, but did not seem to affect the decrease in IMCL during exercise. The reason for this discrepancy is unknown, although it could be that the effects of exercise on IMCL metabolism may be different between trained and untrained subjects.

Interestingly, in agreement with the current study we have previously shown that lipid content is increased both in the heart [6] and in the liver (chapter 3 in this thesis) [13] $4 \mathrm{~h}$ post-exercise in the fasted condition, accompanied with increased FFA levels. Consistent with the current data set, when given glucose supplementation before, during exercise and during recovery from exercise, the increase in ectopic lipid content in heart and liver was not observed. These results suggest that, elevation of FFA in a physiological manner during exercise and recovery from exercise, leads to accumulation of ectopic lipid stores in organs like the heart, liver and muscle, together contributing to the clearance of FFA from the plasma.

In summary, an acute bout of exercise leads to different effects on IMCL depending on whether exercise is performed in a fasted or in a glucose-supplemented condition. Performing exercise in a fasted condition leads to an increase in IMCL, probably due to elevated plasma FFA levels, whereas performing exercise in a glucose-supplemented condition leads to a decrease in IMCL in working muscle. This suggests that the working muscle has capacity to take up and re-esterify FFA and that it takes up FFA unrestricted when the availability is high. 


\section{REFERENCES}

1. Perseghin G, Scifo P, De Cobelli F, Pagliato E, Battezzati A, Arcelloni C, Vanzulli A, Testolin G, Pozza G, Del Maschio A, Luzi L. Intramyocellular triglyceride content is a determinant of in vivo insulin resistance in humans: a ${ }^{1} \mathrm{H}-{ }^{13} \mathrm{C}$ nuclear magnetic resonance spectroscopy assessment in offspring of type 2 diabetic parents. Diabetes. 1999;48(8):1600-6.

2. Krssak M, Falk Petersen K, Dresner A, DiPietro L, Vogel SM, Rothman $\mathrm{DL}$, Roden M, Shulman Gl. Intramyocellular lipid concentrations are correlated with insulin sensitivity in humans: a ${ }^{1} \mathrm{H}$ NMR spectroscopy study. Diabetologia. 1999;42(1):113-6.

3. Kelley DE, Goodpaster BH, Storlien L. Muscle triglyceride and insulin resistance. Annual review of nutrition. 2002;22:325-46.

4. Hoeks J, van Herpen NA, Mensink M, Moonen-Kornips E, van Beurden D, Hesselink MK, Schrauwen P. Prolonged fasting identifies skeletal muscle mitochondrial dysfunction as consequence rather than cause of human insulin resistance. Diabetes. 2010;59(9):2117-25.

5. Schrauwen-Hinderling VB, van Loon LJ, Koopman R, Nicolay K, Saris $\mathrm{WH}$, Kooi ME. Intramyocellular lipid content is increased after exercise in nonexercising human skeletal muscle. Journal of applied physiology. 2003;95(6):2328-32.

6. Bilet L, van de Weijer T, Hesselink MK, Glatz JF, Lamb HJ, Wildberger J, Kooi ME, Schrauwen P, Schrauwen-Hinderling VB. Exercise-induced modulation of cardiac lipid content in healthy lean young men. Basic research in cardiology. 2011;106(2):307-15.

7. Schrauwen-Hinderling VB, Schrauwen P, Hesselink MK, van Engelshoven JM, Nicolay K, Saris WH, Kessels AG, Kooi ME. The increase in intramyocellular lipid content is a very early response to training. The Journal of clinical endocrinology and metabolism. 2003;88(4):1610-6.

8. Brechtel K, Niess AM, Machann J, Rett K, Schick F, Claussen CD, Dickhuth $\mathrm{HH}$, Haering $\mathrm{HU}$, Jacob S. Utilisation of intramyocellular lipids (IMCLs) during exercise as assessed by proton magnetic resonance spectroscopy ( $\left.{ }^{1} \mathrm{H}-\mathrm{MRS}\right)$. Hormone and metabolic research $=$ Hormon- und Stoffwechselforschung = Hormones et metabolisme. 2001;33(2):63-6.

9. Bucher J, Krusi M, Zueger T, Ith M, Stettler C, Diem P, Boesch C, Kreis R, Christ $\mathrm{E}$. The effect of a single $2 \mathrm{~h}$ bout of aerobic exercise on ectopic lipids in skeletal muscle, liver and the myocardium. Diabetologia. 2014;57(5):10015.

10. Egger A, Kreis R, Allemann S, Stettler C, Diem P, Buehler T, Boesch C, Christ ER. The effect of aerobic exercise on intrahepatocellular and intramyocellular lipids in healthy subjects. PloS one. 2013;8(8):e70865.

11. Rico-Sanz J, Hajnal JV, Thomas EL, Mierisova S, Ala-Korpela M, Bell JD. 
Intracellular and extracellular skeletal muscle triglyceride metabolism during alternating intensity exercise in humans. The Journal of physiology. 1998;510 ( Pt 2):615-22.

12. Vermathen P, Saillen P, Boss A, Zehnder M, Boesch C. Skeletal muscle (1) $\mathrm{H}$ MRSI before and after prolonged exercise. I. muscle specific depletion of intramyocellular lipids. Magnetic resonance in medicine : official journal of the Society of Magnetic Resonance in Medicine / Society of Magnetic Resonance in Medicine. 2012;68(5):1357-67.

13. Bilet L, Brouwers BMW, van Ewijk PA, Hesselink MKC, Kooi ME, SchrauwenHinderling VB, Schrauwen P. Acute exercise does not decrease liver fat in men with overweight or NAFLD. Scientific Reports 2015; 5:9709.

14. Kuipers H, Verstappen FT, Keizer HA, Geurten P, van Kranenburg G. Variability of aerobic performance in the laboratory and its physiologic correlates. International journal of sports medicine. 1985;6(4):197-201.

15. Siri WE. The gross composition of the body. Advances in biological and medical physics. 1956;4:239-80.

16. Bergstrom J, Hermansen L, Hultman E, Saltin B. Diet, muscle glycogen and physical performance. Acta physiologica Scandinavica. 1967;71(2):140-50.

17. Koopman R, Schaart G, Hesselink MK. Optimisation of oil red O staining permits combination with immunofluorescence and automated quantification of lipids. Histochemistry and cell biology. 2001;116(1):63-8.

18. White LJ, Ferguson MA, McCoy SC, Kim H. Intramyocellular lipid changes in men and women during aerobic exercise: a (1)H-magnetic resonance spectroscopy study. The Journal of clinical endocrinology and metabolism. 2003;88(12):5638-43.

19. Johnson NA, Stannard SR, Mehalski K, Trenell MI, Sachinwalla T, Thompson $\mathrm{CH}$, Thompson MW. Intramyocellular triacylglycerol in prolonged cycling with high- and low-carbohydrate availability. Journal of applied physiology. 2003;94(4):1365-72.

20. Krssak M, Petersen KF, Bergeron R, Price T, Laurent D, Rothman DL, Roden M, Shulman GI. Intramuscular glycogen and intramyocellular lipid utilization during prolonged exercise and recovery in man: $a{ }^{13} \mathrm{C}$ and ${ }^{1} \mathrm{H}$ nuclear magnetic resonance spectroscopy study. The Journal of clinical endocrinology and metabolism. 2000;85(2):748-54.

21. Sacchetti M, Saltin B, Osada T, van Hall G. Intramuscular fatty acid metabolism in contracting and non-contracting human skeletal muscle. The Journal of physiology. 2002;540(Pt 1):387-95.

22. Zehnder M, Christ ER, Ith M, Acheson KJ, Pouteau E, Kreis R, Trepp R, Diem P, Boesch C, Decombaz J. Intramyocellular lipid stores increase markedly in athletes after 1.5 days lipid supplementation and are utilized during exercise in proportion to their content. European journal of applied physiology. 2006;98(4):341-54. 
L.Bilet, T. van de Weijer, E. Phielix, A. Laufs, R. Livingstone, P. Nowotny, L.M. Sparks, S. Paglialunga, J. Szendroedi, J.H. Hwang, V.B. Schrauwen-Hinderling, M.K.C. Hesselink, M. Roden, P. Schrauwen

A part of this chapter is published in Diabetes 2015 Apr;64(4):1193-201 (Evidence for a direct effect of the NAD+ precursor Acipimox on muscle mitochondrial function in humans) 


\section{CHAPTER}

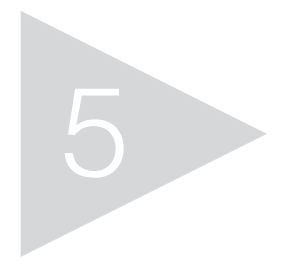

Treatment with Acipimox fails to improve insulin sensitivity and may impair cardiac function in non-insulin dependent type 2 diabetes mellitus 


\section{ABSTRACT}

We tested the hypothesis that treatment with the nicotinic acid derivative Acipimox results in a persistent reduction in free fatty acid (FFA) concentrations, which would improve cardiac function and insulin sensitivity via a reduction in myocardial and skeletal muscle fat accumulation. In a multi-center randomized cross-over trial, 21 patients with type 2 diabetes (age $57.7 \pm 1.1$ years, body mass index, BMI, $33.4 \pm 0.8 \mathrm{~kg} / \mathrm{m}^{2}$ ) were included. Patients received daily 3 times either $250 \mathrm{mg}$ placebo or Acipimox, each for 2 weeks. We also included 10 age- and BMImatched non-diabetic subjects $\left(56.0 \pm 2.7\right.$ years, $\left.31.4 \pm 0.8 \mathrm{~kg} / \mathrm{m}^{2}\right)$ who did not receive treatment, as a reference group. Insulin sensitivity was measured with a hyperinsulinemic-euglycemic clamp and a muscle biopsy was taken to assess ex vivo muscle mitochondrial function and lipid accumulation. In a subgroup of participants magnetic resonance spectroscopy was used to measure cardiac lipid content $(n=10)$ and cardiac energy status $(n=10)$, whereas liver fat content and in vivo mitochondrial function was measured in all subjects. Cardiac function was measured with echocardiography $(n=10)$. Unexpectedly, after 2-weeks of Acipimox treatment, plasma FFA almost doubled $(759 \pm 44$ vs. $1135 \pm 97 \mu \mathrm{mol} / \mathrm{L}, \mathrm{p}<0.01$ for placebo vs. Acipimox). This was paralleled by an increase in skeletal muscle lipid content and a decrease in in vivo mitochondrial function and insulin sensitivity. Hepatic lipid content remained unchanged, whereas ex vivo mitochondrial function tended to increase. Surprisingly, despite unaltered cardiac lipid content and energy status, cardiac function tended to decrease (Ejection Fraction (EF) $59.9 \pm 2.7$ vs. $56.6 \pm 2.0 \%, p=0.08$ for placebo vs. Acipimox). Treating type 2 diabetic patients with Acipimox leads to a rebound rise in plasma FFA, which further deteriorates insulin sensitivity and cardiac function. The decrease in insulin sensitivity is likely to be mediated through enhanced lipid accumulation and impaired in vivo mitochondrial function in skeletal muscle. However, Acipimox did seem to upregulate mitochondrial function ex vivo, indicating that in the absence of elevated plasma FFA concentrations, Acipimox might have a direct positive effect on the mitochondria. Still, treating hyperlipidemia in insulin resistant patients with nicotinic acid derivatives should be done with care, and further research is needed to assess the safety and efficacy of this drug class. 


\section{INTRODUCTION}

The risk of cardiovascular diseases is markedly elevated in patients with type 2 diabetes (T2D), leading to an increased morbidity and mortality rate in T2D patients compared to the general population [1]. Prevention and treatment of the complications of diabetes mellitus have the potential to improve quality of life and life expectancy $[2,3]$. Hence, early diagnosis and treatment of hyperlipidemia in T2D is important to reduce morbidity and mortality rates in T2D patients. First choice for treatment of hyperlipidemia in T2D is treatment with statins, as these are known for their potent effect on lowering of cholesterol concentrations. However, statins only have a minor effect on triglycerides. Here, nicotinic acid analogues are far more potent, as these drugs form a class of lipid lowering drugs, which inhibit adenylyl-cyclase, resulting in lowering of hormone sensitive lipase (HSL) in adipose tissue [4,5]. Lowering of HSL results in a diminished release of free fatty acids (FFA) from adipose tissue and increases lipoprotein lipase (LPL) activity in adipose tissue, thereby increasing the uptake and breakdown of very-low density lipoproteins (VLDL).

Acipimox is a nicotinic acid analogue frequently used to treat hyperlipidemia [6-8]. Besides its effects on cholesterol and triglycerides, Acipimox has been described to reduce plasma FFA concentrations by 46-57\% [9-11], which may lower ectopic fat accumulation in T2D [9-11]. Excessive fat accumulation in skeletal muscle, liver and heart has been linked to the development of T2D and its co-morbidities [12]. A surplus of circulating FFA, as well as increased storage in skeletal muscle, result in the formation of toxic lipids intermediates known to impede with insulin signaling [2, 13-15]. Moreover, lipid accumulation in skeletal muscle as well as in liver and heart has been associated with the development of non-alcoholic fatty liver disease [16] and the development of diabetic cardiomyopathy [17, 18]. Hence, a better understanding of the underlying mechanisms leading to diseases associated with ectopic fat accumulation in T2D is needed. In that context, a role for mitochondrial oxidative capacity has been suggested. Some studies show that mitochondrial oxidative capacity is impaired in both patients with type 2 diabetes [19-22] as well as in pre-type 2 diabetic first-degree relatives [19, 23]. Therefore, it is tempting to suggest that a reduction in mitochondrial oxidative capacity will contribute to the ectopic accumulation of insulin signalling-desensitizing lipid intermediates promoting insulin resistance. Indeed, increased skeletal muscle lipid accumulation previously has been shown to be associated with a decreased ATP production [23, 
However, alternatively it has been suggested that elevated plasma FFA concentrations may also result in a deterioration of mitochondrial function (for review see Schrauwen et al. BBA, 201025). This mechanism has not been confirmed yet, as studies assessing the acute effects of elevated plasma FFA concentrations did not show any effects on ATP production [26]. Therefore, a prolonged sustained lowering of circulating FFA concentrations might be beneficial to unravel these mechanisms. We hypothesized that Acipimox, as a lipid-lowering agent, would exert a sustained suppression of adipose tissue lipolysis, resulting in a lower accumulation of ectopic fat, improved mitochondrial function and increased insulin sensitivity. As a consequence, we predict that this might improve cardiac function, skeletal muscle mitochondrial function and hepatic steatosis and reduce co-morbidities of type 2 diabetes. The effects of Acipimox on skeletal muscle lipid accumulation and insulin sensitivity have been investigated before, though, these studies investigated only short acute effects (within 1-2 hours) [27, 28]. Here, we investigate prolonged sustained effects of Acipimox administration. Noteworthy, studies investigating the prolonged effects of Acipimox [9, 27, 29-31], administered the last dose shortly before the metabolic measurement of interest, and results obtained may therefore reflect the acute effect of the last dose. Therefore, in the present study patients with T2D were administered Acipimox 2-3 times upon each meal daily, according to international clinical standards. We were interested in the sustained and not the acute effects of the last dose of Acipimox administration, and therefore administration of Acipimox directly before the test days was omitted. Hence, in the present study we aimed to investigate whether the effects of 2 weeks of chronic reduction of circulating FFA via administration of Acipimox, would lower ectopic fat accumulation and improve the metabolic profile of T2D.

\section{MATERIALS AND METHODS}

\section{STUDY DESIGN}

In the present multi-centre, randomised, double-blind, placebo-controlled crossover trial, 21 patients with T2D and 10 control participants were included (10 T2D patients and 10 control subjects in the Maastricht University Medical Center+ and 11 T2D patients in the German Diabetes Center in Düsseldorf). T2D patients were 
randomly assigned to either placebo or Acipimox (250 mg 3dd) treatment for 2 weeks. During these 2 weeks of intervention, diabetic patients were asked to stop their oral glucose lowering medication. Patients were provided with a standardised meal the day prior to the clamp and were advised to refrain from physical exercise 3 days before and during the entire study. At the end of the 2-weeks Acipimox or placebo treatment, measurements were performed to assess cardiac and mitochondrial function, ectopic lipid accumulation and insulin sensitivity. Between interventions, a 4-week washout period was maintained. A control group with similar $\mathrm{BMI}$ and age served as a reference group, but did not undergo the intervention.

\section{SUBJECTS}

Both male and post-menopausal female humans were included (see table 1). Before inclusion, participants underwent physical examination and anthropometric measurements and completed a medical history questionnaire, including history of cardiovascular, renal and pulmonary disease, cancer and duration of diabetes. Also routine medical laboratory tests including haematology, and a maximal aerobic capacity test with concurrent ECG were performed as previously described [32]. Body composition was determined using hydrostatic weighing in Maastricht according to Siri et al. [33]. In Dusseldorf body composition was measured with a DEXA scan. Control participants had no family history of T2D and had normal fasting plasma glucose concentrations. T2D patients had well-controlled diabetes $(\mathrm{HbA} 1 \mathrm{C} 7.08 \pm 0.16 \%)$ and were either on monotherapy with metformin, or on metformin combined with sulfonylurea. Patients were included when diagnosed with T2D for at least one year. None of the participants included followed a weight-loss dietary program and had a stable body weight for the last 6 months. The Maastricht University Medical Ethical Committee (The Netherlands) and the Medical Association North Rhine in Düsseldorf (Germany), approved the study, and written informed consent was obtained from all participants prior to screening. The study was performed according to the principles expressed in the Declaration of Helsinki.

\section{HYPERINSULINEMIC-EUGLYCEMIC CLAMP}

All participants underwent a 2-step 6-h hyperinsulinemic-euglycemic clamp (10 and $40 \mathrm{mU} / \mathrm{m}^{2} / \mathrm{min}$ ) [34]. After an overnight fast, participants received a primed- 
continuous infusion of $\left\{6,6-{ }^{2} \mathrm{H}_{2}\right\}$ glucose $(0.04 \mathrm{mg} / \mathrm{kg} / \mathrm{min})$ to determine rates of endogenous glucose production (EGP) and whole body glucose disposal rates (WGD) as previously described [35]. After 180 minutes, low insulin infusion was started (10 mU $/ \mathrm{m}^{2} / \mathrm{min}$ ) with co-infusion of $0.1 \mu \mathrm{g} / \mathrm{kg} / \mathrm{min}$ of somatostatin [24] for 3.5 hours until a steady state was reached, after which blood sampling and indirect calorimetry was performed during 30 minutes. Thereafter, high insulin infusion was started $\left(40 \mathrm{mU} / \mathrm{m}^{2} / \mathrm{min}\right)$ with co-infusion of $0.1 \mu \mathrm{g} / \mathrm{kg} / \mathrm{min}$ somatostatin for 1.5 hours, after which steady state was reached and blood sampling and indirect calorimetry were repeated.

\section{INDIRECT CALORIMETRY}

During the clamp, oxygen consumption and carbon dioxide production were measured with a daily-calibrated automated respiratory gas analyzer using a ventilated hood system (Omnical, IDEE, Maastricht, The Netherlands; Vmax Encore 29n, SensorMedix, Cardinal Health Germany, Hoechberg, Germany). Whole body glucose and fat oxidation rates were calculated using stoichiometric equations based on measured oxygen consumption and carbon dioxide concentrations [36] with the assumption that protein oxidation was negligible.

\section{MUSCLE BIOPSY}

Muscle biopsies were taken from the $\mathrm{m}$. vastus lateralis, prior to the clamp under local anesthesia (2\% lidocaine), according to the Bergstrom technique [37]. In the muscle tissue obtained, lipid accumulation was assessed histochemically in crosssections using a modified Oil-red-O staining for fluorescence microscopy [38]. In addition, $\sim 30 \mathrm{mg}$ of the muscle tissue was used for high-resolution respirometry to determine ex vivo mitochondrial function.

\section{PERMEABILIZATION OF MUSCLE FIBERS}

A small portion of the muscle biopsy sample ( 30 mg) was immediately placed in ice-cold biopsy containing preservation medium (BIOPS; OROBOROS Instruments, Innsbruck, Austria). Muscle fibres were permeabilized with saponin according to the technique of Veksler et al. [39]. After completion of the permeabilization protocol, muscle fibres were transferred into ice-cold mitochondrial respiration buffer 
(MiRO5; OROBOROS Instruments, Innsbruck, Austria). Subsequently, the muscle fibres were transferred to the oxygraph to perform high-resolution respirometry as previously described [40], and were corrected for wet weight.

\section{HIGH-RESOLUTION RESPIROMETRY}

Mitochondrial function ex vivo was determined by measuring oxygen consumption polarographically using a two-chamber Oxygraph (OROBOROS Instruments). Oxygen consumption, or oxygen flux, reflects the first derivative of the oxygen concentration $(\mathrm{nmol} / \mathrm{ml})$ in the respiration chambers, expressed as $\left(\mathrm{pmol} /\left(\mathrm{s}^{\star} \mathrm{mg}\right)\right.$ ), corrected for wet weight muscle tissue (2-5 mg). To evaluate mitochondrial oxidative capacity, different substrate protocols were applied. In every protocol, $4.0 \mathrm{mmol} / \mathrm{l}$ malate was added to obtain state 2 respiration followed by addition of $8.0 \mathrm{mmol} / \mathrm{l}$ glutamate as a substrate for complex I, which was combined with or without 40.0 $\mathrm{mmol} / /$ palmitoyl-carnitine. In addition, an excess of $1.6 \mathrm{mmol} / \mathrm{l}$ ADP was added to evaluate state 3 respiration of complex I (state 3 respiration reflects substrate oxidation coupled to energy production). Then $8.0 \mathrm{mmol} / \mathrm{l}$ succinate was added to obtain state 3 respiration from complex I and II. Finally, titrations (in steps of $0.5 \mu \mathrm{l}$ of $1.0 \mathrm{mmol} / \mathrm{l}$ ) of the chemical uncoupler fluoro-carbonyl cyanide phenylhydrazone (FCCP) were added to evaluate maximal respiratory capacity, state $U$.

\section{MEASURES OF MITOCHONDRIAL DENSITY}

Mitochondrial DNA (mtDNA) copy number was determined as a marker for mitochondrial density using quantitative real-time PCR, based on the TaqMan probe method. mtDNA copy number was calculated from the ratio of $\mathrm{NADH}$ dehydrogenase subunit 1 (ND1) to lipoprotein lipase (LPL) (mtDNA/nuclear DNA), as described previously [19].

\section{HEPATIC LIPID CONTENT BY ${ }^{1} H-M R S$}

${ }^{1} \mathrm{H}-\mathrm{MRS}$ was used to quantify $\mathrm{IHL}$ in all subjects on a $3 \mathrm{~T}$ whole-body scanner (Achieva, Philips Healthcare, Best, The Netherlands) using a two or five-element coil as previously described [41] with a repetition time of $4000 \mathrm{~ms}$, echo time of $32.5 \mathrm{~ms}$, and number of averages of 64 . To minimize motion artifacts, participants were asked to breathe in the rhythm of the measurement and to be at end-expiration during the 
acquisition of the spectra. To determine the intensity of the lipid peak, the water signal was suppressed using frequency-selective pre-pulses. The unsuppressed water resonance was used as internal reference (number of averages $=64$ ), and spectra were fitted with AMARES [42] in the jMRUI software [43]. Values are given as T2-corrected ratios (according to Hamilton et al., 2011 [44]) of the $\mathrm{CH}_{2}$-peak, relative to the unsuppressed water resonance (as percentage).

\section{CARDIAC LIPID CONTENT BY ${ }^{1} \mathrm{H}-M R S$}

Cardiac lipid content was determined at the Maastricht University Medical center+ (10 diabetic subjects and 10 controls) only, using in vivo ${ }^{1} \mathrm{H}-\mathrm{MRS}$ [45]. Respiratory gating and tracking was performed with a pencil beam navigator placed on the diaphragm [46]. Chemical shift selective water suppression was performed to acquire spectra of the lipid metabolites using a series of 32 spectra (NSA=2 each), resulting in a total of 64 acquisitions. To acquire a reference spectrum of the unsuppressed water peak in the same volume of interest, the acquisition was repeated, with the water suppression pulse off resonance, using a series of 12 spectra (NSA=2 each), resulting in a total of 24 acquisitions. From 10 diabetic subjects, 1 had to be excluded from the cardiac lipid content analysis due to poor quality of spectra.

Post-processing of the spectra was performed with the jMRUI software [47]. Manual phase correction was performed, and subsequently, all spectra with water suppression and without were averaged, resulting in one water-suppressed lipid spectrum originating from 128 averages and a non-suppressed spectrum from 24 averages for quantification of water resonance. Myocardial lipid peaks were fitted in the time domain by using the Advanced magnetic resonance (AMARES) fitting algorithm [48] within the jMRUI software [43] as reported [46]. Cardiac lipid content is given as the percentage of the $\mathrm{CH}_{2}$-peak compared to water resonance and without correction for $\mathrm{T} 1$ and $\mathrm{T} 2$ relaxation.

\section{CARDIAC ENERGY STATUS BY ${ }^{31}$ P-MRS}

Cardiac energy status was determined in vivo with ${ }^{31} \mathrm{P}-\mathrm{MRS}$, as reported previously [49], only in the subjects included at the Maastricht University Medical Center+. Single voxel cardiac ${ }^{31} \mathrm{P}-\mathrm{MRS}$ spectra were obtained from the left ventricle with subjects in the supine position [50]. A 10-cm coil was fixed on the chest, at the 
position of the myocardium. Manual tuning and matching of the ${ }^{31} \mathrm{P}$-surface coil was performed to adjust for different coil loadings. ECG-triggered ISIS (Image-selected in vivo spectroscopy) was used for localization to the left ventricle (TR=3.6s, $n=192$ ). Spectroscopy and shimming volumes were planned on the transverse and sagittal scout images to include the entire left ventricle, while avoiding chest wall muscle and diaphragm muscle. A rest slab was placed over the chest muscle to minimize contamination from skeletal muscle. From the 10 T2D subjects, 3 subjects had to be excluded due to a poor quality of the spectra. Likewise, 2 out of 10 controls subjects had to be excluded as well.

${ }^{31}$ P-MRS was quantified in the time domain with the AMARES algorithm [48] in jMRUI software. Six Gaussian peaks were fitted using prior knowledge defining chemical shift. The ATP concentration assessed with ${ }^{31} \mathrm{P}-\mathrm{MRS}$ was corrected for the ATP contribution from blood and T1-corrected [51].

\section{PCR-RECOVERY BY ${ }^{31}$ P-MRS}

PCr-recovery was measured in all participants using ${ }^{31} \mathrm{P}-\mathrm{MRS}$ to determine in vivo mitochondrial function as previously described [22]. The test was performed one day prior to the clamp test. A knee-extension protocol was performed on a custombuilt magnetic resonance compatible ergometer with a pulley system in a 1.5 and $3 \mathrm{~T}$ whole-body MRI scanner (Intera; Philips Medical Systems, Best, the Netherlands). The knee extension exercise was performed for 5 min with weight corresponding to $50-60 \%$ of the subject's pre-determined maximal knee-extension capacity. Postexercise PCr kinetics were computed as previously described [22].

\section{PLASMA ASSAYS}

Blood collected in tubes containing EDTA was immediately centrifuged and plasma stored at $-80^{\circ} \mathrm{C}$ until assayed. Plasma free fatty acids (FFAs) and glucose were measured with enzymatic assays on a Cobas Fara/Mira (FFA: Wako Nefa C test kit; Wako Chemicals, Neuss, Germany; Glucose: hexokinase method; Roche, Basel, Switzerland). Insulin concentration was determined using a radioimmunoassay (Linco Reseach, St. Charles, MO). Cholesterol, LDL and triglycerides were measured colorimetrically (Roche, Vienna, Austria). 


\section{GAS CHROMATOGRAPHY-MASS SPECTROMETRY}

Determination of atom percent enrichement (APE) of ${ }^{2} \mathrm{H}$ was done as previously described (Stingle krssak, krebs, Diabetologia 2001:44:48-54) after deproteinization. Briefly, $100 \mu \mathrm{KF}$-EDTA plasma was diluted with an equal amount of water and deproteinized after adding $300 \mu \mathrm{l}$ of $0.3 \mathrm{~N} \mathrm{ZnSO}_{4}$ solution followed by $300 \mu \mathrm{l}$ of $0.3 \mathrm{~N} \mathrm{Ba}(\mathrm{OH})_{2}$ solution. After vortexing for 20 minutes, samples were centrifugated (21.000 g, room temperature). Then, $400 \mu$ were evaporated under a stream of nitrogen 5.0 at $37^{\circ} \mathrm{C}$ and both endogenous and infused $\left\{6,6-^{2} \mathrm{H}_{2}\right\}$ glucose were dericatized with $\mathrm{HOX}\left(100 \mu \mathrm{l}\right.$ of $2 \%$ solution in pyridine, 60 min $90^{\circ} \mathrm{C}$, cooling for $5 \mathrm{~min})$ and acetic anhydride $\left(200 \mu \mathrm{l}, 60 \mathrm{~min}\right.$ at $90^{\circ} \mathrm{C}$, cooling for $\left.5 \mathrm{~min}\right)$ to the aldonitrile-pentaacetate. The analyses were performed on a Hewlet-Packard 6890 gas chromatograph equipped with a 25-m CPSil5CB capillary column (0.2 mm i.d., $0.12 \mu \mathrm{m}$ film thickness; Chrompack/Varian, Middelburg, Netherlands) and interfaced to a Hewlett Packard 5975 mass selective detector. Selected ion monitoring was used to determine enrichments of the fragments C3 to C6 with the average mass units 187 for the endogenous glucose and 189 for the $\left\{6,6-{ }^{2} \mathrm{H}_{2}\right\}$ glucose. Intra-and inter assay CVs were $0.6 \%$ and 1.0 .

\section{CALCULATIONS}

Steele's single-pool non-steady-state equations were used to calculate WGD and EGP [52]. Volume of distribution was assumed to be $0.160 \mathrm{l} / \mathrm{kg}$ for glucose. Nonoxidative glucose disposal (NOGD) was calculated as WGD minus carbohydrate oxidation.

\section{STATISTICS}

Data are reported as means \pm SE. Statistical analyses were performed using SPSS version 16.0.2 for Mac OS X (SPSS Inc., NC, USA). Differences between the interventions were analyzed with a 2-tailed, paired student t-test. Differences between T2D patients and obese control subjects were tested with a 2-tailed, unpaired student t-test. Statistical significance was set a priori at $p<0.05$. 
Table 1 Subjects' characteristics

\begin{tabular}{|c|c|c|c|}
\hline Mean \pm SD & Controls & Type 2 diabetics & Significance \\
\hline male/female & $n=9 / 1$ & $n=18 / 3$ & \\
\hline Age, yr & $56.0 \pm 2.7$ & $57.7 \pm 1.1^{*}$ & \\
\hline Weight, kg & $96.0 \pm 4.4$ & $100.5 \pm 2.9$ & \\
\hline BMI, $\mathrm{kg} / \mathrm{m}^{2}$ & $31.4 \pm 0.8$ & $33.4 \pm 0.8^{*}$ & \\
\hline Fat mass, $\%$ & $35.3 \pm 2.4$ & $35.1 \pm 1.2$ & \\
\hline $\mathrm{VO}_{2} \max / \mathrm{kg}, \mathrm{ml} \times \min ^{-1} \times \mathrm{kg}^{-1}$ & $27.1 \pm 1.5$ & $24.0 \pm 1.2$ & \\
\hline Systolic blood pressure, $\mathrm{mmHg}$ & $144.6 \pm 3.9$ & $148.9 \pm 2.6$ & \\
\hline Diastolic blood pressure, $\mathrm{mmHg}$ & $92.8 \pm 1.9$ & $92.8 \pm 1.9$ & \\
\hline Fasting plasma glucose, $\mathrm{mmol} / \mathrm{L}$ & $5.5 \pm 0.1$ & $7.4 \pm 0.2$ & ** \\
\hline $\mathrm{HbA} 1 \mathrm{c}, \%$ & $5.6 \pm 0.1$ & $7.1 \pm 0.2$ & ** \\
\hline ASAT, U/L & $20.1 \pm 1.4$ & $23.7 \pm 1.7$ & \\
\hline ALAT, U/L & $31.3 \pm 3.5$ & $35.9 \pm 3.2$ & \\
\hline Gamma-GT, U/L & $28.1 \pm 3.3$ & $41.6 \pm 3.5$ & * \\
\hline Total cholesterol, $\mathrm{mmol} / \mathrm{L}$ & $5.3 \pm 0.4$ & $8.4 \pm 3.5$ & \\
\hline $\mathrm{HDL}, \mathrm{mmol} / \mathrm{L}$ & $1.6 \pm 0.5$ & $1.2 \pm 0.1$ & \\
\hline LDL, mmol/L & $3.3 \pm 0.3$ & $2.6 \pm 0.2$ & \\
\hline Triglycerides, $\mathrm{mmol} / \mathrm{L}$ & $1.1 \pm 0.1$ & $2.0 \pm 0.2$ & * \\
\hline $\mathrm{FFA}, \mu \mathrm{mol} / \mathrm{L}$ & $773 \pm 184$ & $672 \pm 70$ & \\
\hline
\end{tabular}

Significance between the groups are indicated by * for $p<0.05$ and ${ }^{* *}$ for $p<0.01$

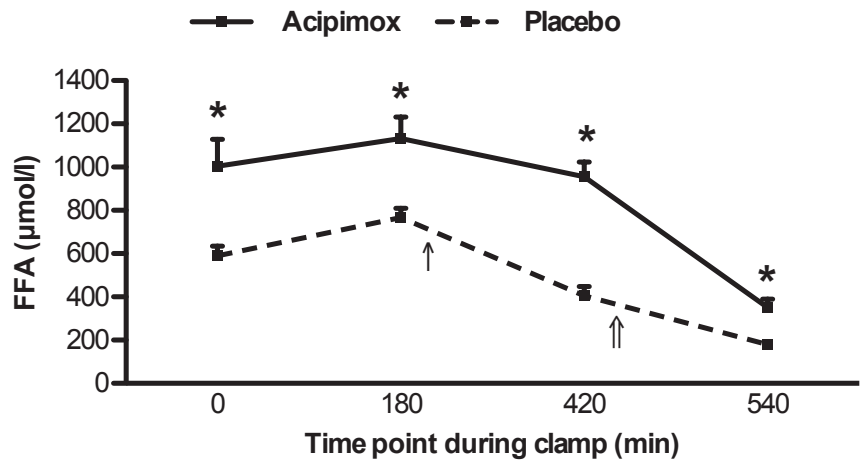

Figure 1 Plasma FFA concentrations in T2D subjects during the clamp. Acipimox treatment resulted in elevated plasma FFA concentrations, and remained significantly elevated throughout the clamp. Indicated with the first solid arrow is the start of $10 \mathrm{mU} / \mathrm{m} 2 / \mathrm{min}$ infusion of insulin, and indicated with the double lined arrow is the start of $40 \mathrm{mU} / \mathrm{m} 2 / \mathrm{min}$ infusion of insulin. Significant differences $p<0.05$ are indicated by *. 


\section{RESULTS}

\section{BASIC CHARACTERISTICS}

An overview of the patient characteristics is given in table 1. Control subjects and T2D patients had similar weight, BMl, fat percentage and $\mathrm{VO}_{2} \max$. By design, plasma glucose was elevated in T2D patients $(5.5 \pm 0.1$ vs. $7.4 \pm 0.2 \mathrm{mmol} / \mathrm{L}$, $p<0.01$, for controls and T2D patients). g-GT was elevated in the T2D patients compared to controls $(28.1 \pm 3.3$ vs. $41.6 \pm 3.5 \mathrm{U} / \mathrm{L}, \mathrm{p}<0.05$, for controls and T2D patients), though the other liver enzymes were similar and within normal range. Baseline cholesterol and plasma FFA were similar between groups, but plasma triglycerides were elevated in the T2D patients $(1.12 \pm 0.14 \mathrm{vs} .1 .98 \pm 0.21 \mathrm{mmol} / \mathrm{L}$, $\mathrm{p}<0.05$, for controls and T2D patients).

\section{EFFECT OF ACIPIMOX ON PLASMA METABOLITE CONCENTRATIONS}

In contrast to our expectations, we observed that plasma FFA increased rather than decreased upon Acipimox treatment. Fasting plasma FFA concentrations increased from $0.77 \pm 0.05 \mathrm{mmol} / \mathrm{L}$ in placebo condition, to $1.13 \pm 0.10 \mathrm{mmol} / \mathrm{L}$ in Acipimox treated condition ( $p<0.01$, see figure 1a). This observation of elevated FFA concentrations under basic conditions was also observed during the clamp; FFA concentrations remained significantly elevated throughout the insulin-stimulated period of the clamp (figure 1). While plasma FFA were elevated, cholesterol and triglyceride concentrations tended to decrease upon Acipimox treatment, indicating that administration of Acipimox was effective in our patients (Total cholesterol; 5.63 \pm 0.28 vs. $5.05 \pm 0.28 \mathrm{mmol} / \mathrm{L}, \mathrm{p}=0.08$, and TG; $2.60 \pm 0.41$ vs. $1.68 \pm 0.27 \mathrm{mmol} / \mathrm{L}$, $\mathrm{p}=0.08$, for placebo vs. Acipimox).

Acipimox did not affect plasma glucose concentrations $(9.0 \pm 0.8$ vs. $9.2 \pm 0.5$ $\mathrm{mmol} / \mathrm{L}, \mathrm{p}=0.90$, for placebo vs. Acipimox). Fasting plasma insulin concentrations increased upon Acipimox treatment $(21.4 \pm 2.5$ vs. $26.9 \pm 3.3, p<0.05$, for placebo vs. Acipimox). 
Table 2 Results of the hyperinsulinemic-euglycemic clamp

\begin{tabular}{|c|c|c|c|c|}
\hline Measurement & Condition & Controls & Type 2 diabetics & Significance \\
\hline \multirow[t]{3}{*}{ Glucose (mmol/l) } & Basal & $6.3 \pm 0.4$ & $9.1 \pm 0.8$ & * \\
\hline & $10 \mathrm{mU}$ Insulin & $5.6 \pm 0.1$ & $6.5 \pm 0.3$ & \\
\hline & $40 \mathrm{mU}$ Insulin & $5.5 \pm 0.1$ & $5.3 \pm 0.1$ & \\
\hline \multirow[t]{3}{*}{$\operatorname{NEFA}(\mu \mathrm{mol} / \mathrm{l})$} & Basal & $692 \pm 51$ & $759 \pm 44$ & \\
\hline & $10 \mathrm{mU}$ Insulin & $278 \pm 35$ & $401 \pm 44$ & \\
\hline & $40 \mathrm{mU}$ Insulin & $133 \pm 19$ & $179 \pm 20$ & \\
\hline \multirow[t]{3}{*}{ Insulin (mU/L) } & Basal & $22.1 \pm 4.5$ & $21.4 \pm 2.5$ & \\
\hline & $10 \mathrm{mU}$ Insulin & $28.0 \pm 1.2$ & $27.1 \pm 1.7$ & \\
\hline & $40 \mathrm{mU}$ Insulin & $111.0 \pm 5.3$ & $120.6 \pm 16.7$ & \\
\hline \multirow[t]{3}{*}{$\mathrm{EE}(\mathrm{kJ} / \mathrm{min})$} & Basal & $1.73 \pm 0.11$ & $2.05 \pm 0.06$ & * \\
\hline & $10 \mathrm{mU}$ Insulin & $1.77 \pm 0.13$ & $1.97 \pm 0.06$ & \\
\hline & $40 \mathrm{mU}$ Insulin & $1.84 \pm 0.09$ & $1.99 \pm 0.07$ & \\
\hline \multirow[t]{5}{*}{$\mathrm{RQ}$} & Basal & $0.81 \pm 0.02$ & $0.78 \pm 0.01$ & \\
\hline & $10 \mathrm{mU}$ Insulin & $0.85 \pm 0.02$ & $0.82 \pm 0.01$ & \\
\hline & Delta Basal-10mU & $0.03 \pm 0.00$ & $0.04 \pm 0.00$ & \\
\hline & 40mU Insulin & $0.91 \pm 0.04$ & $0.85 \pm 0.02$ & \# \\
\hline & Delta Basal-40mU & $0.10 \pm 0.02$ & $0.07 \pm 0.01$ & * \\
\hline \multirow[t]{3}{*}{ Glucose oxidation $(\mu \mathrm{mol} / \mathrm{kg} / \mathrm{min})$} & Basal & $6.7 \pm 1.2$ & $5.0 \pm 0.5$ & \\
\hline & $10 \mathrm{mU}$ Insulin & $8.7 \pm 2.0$ & $7.3 \pm 0.7$ & \\
\hline & 40mU Insulin & $9.9 \pm 2.2$ & $9.7 \pm 1.4$ & \\
\hline \multirow[t]{3}{*}{ Lipid oxidation $(\mu \mathrm{mol} / \mathrm{kg} / \mathrm{min})$} & Basal & $2.7 \pm 0.4$ & $3.5 \pm 0.2$ & \# \\
\hline & $10 \mathrm{mU}$ Insulin & $2.0 \pm 0.2$ & $2.6 \pm 0.2$ & $\#$ \\
\hline & $40 \mathrm{mU}$ Insulin & $1.2 \pm 0.4$ & $2.1 \pm 0.2$ & \# \\
\hline \multirow[t]{5}{*}{$\operatorname{EGP}(\mu \mathrm{mol} / \mathrm{kg} / \mathrm{min})$} & Basal & $6.08 \pm 0.75$ & $9.78 \pm 0.90$ & * \\
\hline & 10mU Insulin & $2.7 \pm 0.9$ & $4.9 \pm 0.7$ & \# \\
\hline & $\%$ supp B-10mU & $-59.8 \pm 12.4$ & $-44.9 \pm 9.9$ & \\
\hline & 40mU Insulin & $1.1 \pm 1.6$ & $1.7 \pm 0.8$ & \\
\hline & $\%$ supp BI-40mU & $-103 \pm 22$ & $-80.4 \pm 13.1$ & \\
\hline \multirow[t]{5}{*}{ WGD $(\mu \mathrm{mol} / \mathrm{kg} / \mathrm{min})$} & Basal & $6.5 \pm 0.8$ & $10.2 \pm 0.9$ & * \\
\hline & $10 \mathrm{mU}$ Insulin & $11.1 \pm 1.4$ & $7.6 \pm 0.7$ & * \\
\hline & Stim B-10mU & $4.6 \pm 1.7$ & $-2.6 \pm 1.1$ & * \\
\hline & $40 \mathrm{mU}$ Insulin & $31.9 \pm 5.0$ & $20.0 \pm 2.6$ & * \\
\hline & Stim B-40mU & $25.4 \pm 5.1$ & $9.7 \pm 2.7$ & * \\
\hline \multirow[t]{5}{*}{ NOGD $(\mu \mathrm{mol} / \mathrm{kg} / \mathrm{min})$} & Basal & $0.1 \pm 0.8$ & $4.8 \pm 1.0$ & * \\
\hline & $10 \mathrm{mU}$ Insulin & $2.6 \pm 1.5$ & $0.1 \pm 0.7$ & * \\
\hline & $\%$ stim B-10mU & $2.5 \pm 0.6$ & $-4.7 \pm 1.2$ & * \\
\hline & 40mU Insulin & $14.3 \pm 3.5$ & $9.9 \pm 2.6$ & \\
\hline & Stim B-40mU & $14.2 \pm 2.6$ & $5.1 \pm 3.0$ & * \\
\hline
\end{tabular}

$\#=p<0.10$ between type 2 diabetics and controls, ${ }^{*}=p<0.05$ between type 2 diabetics and controls 


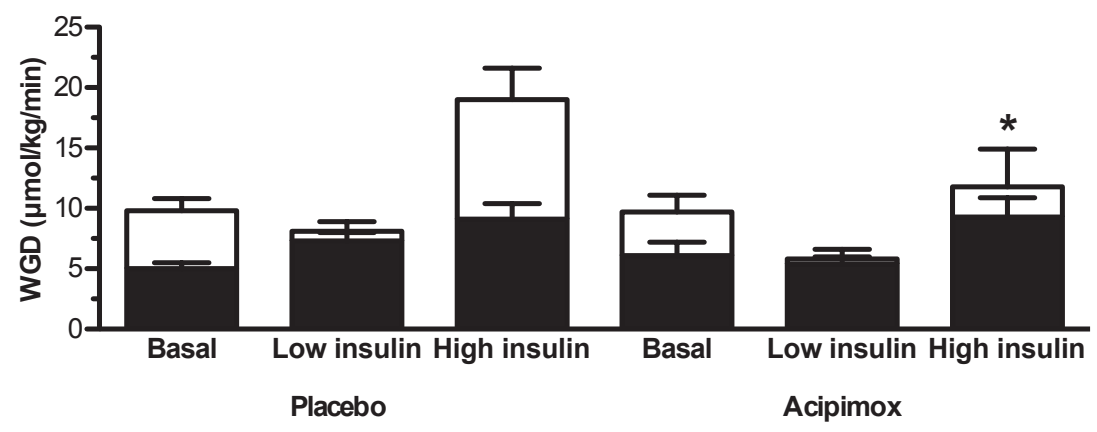

b

Acipimox $\square$ Placebo

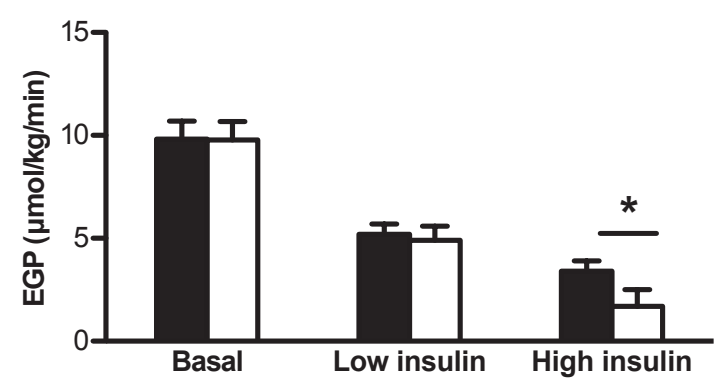

Figure 2 (a) whole body glucose disposal rates (WGD) for placebo versus Acipimox treatment in T2D patients. In black oxidative and in white non-oxidative glucose disposal (NOGD) rates. (b) Endogenous glucose production for both placebo and acipimox treated T2D patients. Significant differences $p<0.05$ are indicated by *.

\section{INSULIN SENSITIVITY}

By design, T2D patients were insulin resistant. Both whole body glucose disposal (WGD) and non-oxidative glucose disposal (NOGD) were higher in T2D and suppression of endogenous glucose production (EGP) was significantly lower in T2D patients compared to controls (see table 2). Furthermore, T2D patients were metabolically less flexible, as the change in $R Q$ upon insulin stimulation was significantly lower (see table 2).

Upon Acipimox treatment, non-insulin stimulated and at low insulin concentrations, there were no significant differences in insulin sensitivity and metabolic flexibility 


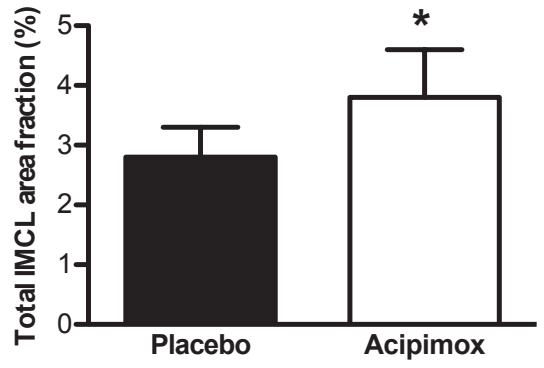

b

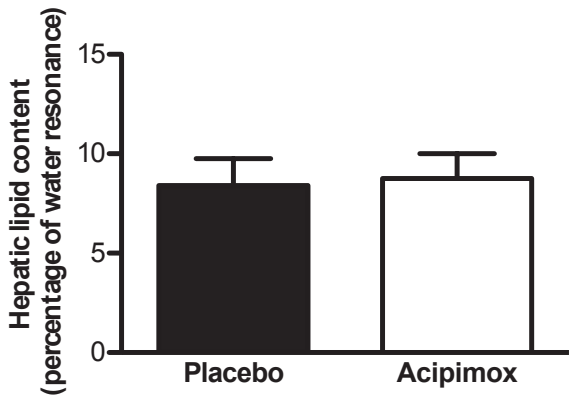

c

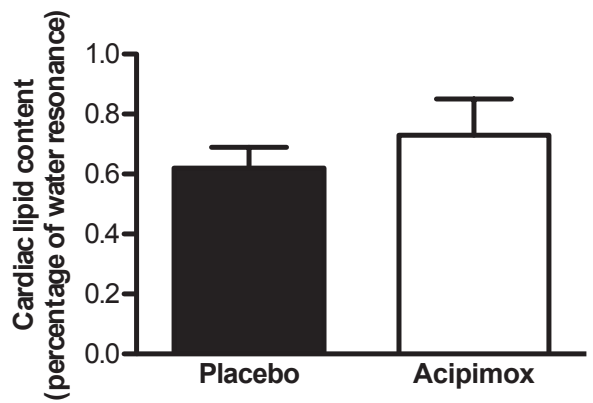

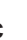
.
Placebo$$
\text { Acipimox }
$$

Figure 3 Lipid content measured in T2D patients after either placebo or acipimox treatment. (a) Lipid content of skeletal muscle, as measured by ORO staining in m. vastus lateralis. (b) lipid content of liver, as measured by ${ }^{1} \mathrm{H}-\mathrm{MRS}$. (c) lipid content of heart as measured in 10 subjects with ${ }^{1} \mathrm{H}-\mathrm{MRS}$. Significant differences $\mathrm{p}<0.05$ are indicated by *. 


\section{ECTOPIC LIPID CONTENT}

T2D patients had higher hepatic lipid content compared to control subjects (3.12 \pm $0.01 \%$ vs. $8.40 \pm 0.01 \%, p=0.03$, in controls vs. T2D patients). Two out of 10 control subjects and 13 out of $21 \mathrm{~T} 2 \mathrm{D}$ subjects had a fatty liver. There was no difference in cardiac lipid content between T2D patients and controls (data not shown).

a

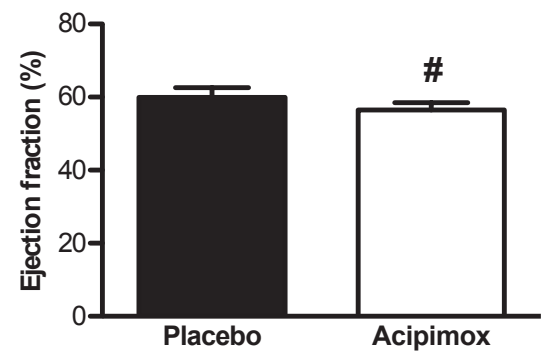

b

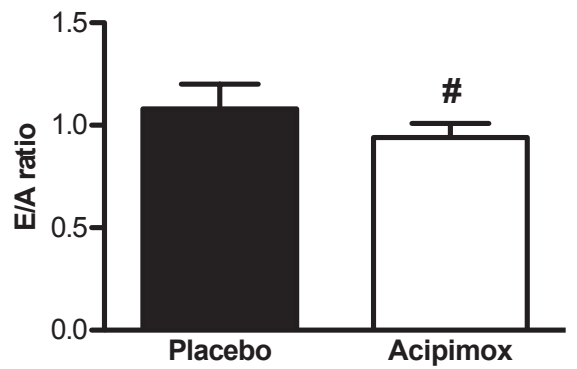

C

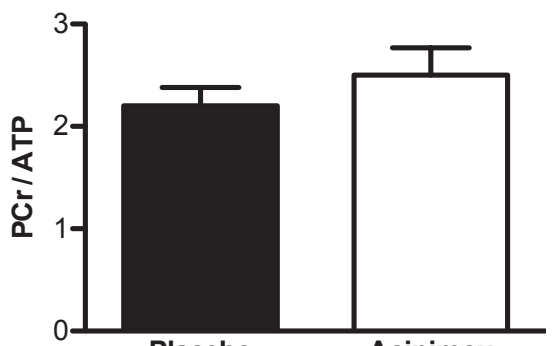

Placebo
Figure 4 Cardiac function and cardiac energy status measured in $10 \mathrm{~T} 2 \mathrm{D}$ subjects. (a) Systolic function expressed by Ejection fraction measured by Ultrasound (b) diastolic function expressed by E/A ratios as measured by Ultrasound (c) cardiac energy status expressed as PCr/ATP ratio, as measured by ${ }^{31} \mathrm{P}-\mathrm{MRS}$. $\mathrm{p}<0.10$ is indicated by \#. 
Upon Acipimox treatment, skeletal muscle lipid content significantly increased from $2.8 \pm 0.5 \%$ to $3.8 \pm 0.8 \%$ of total fibre area, $p<0.05$ (figure 3a). However, Acipimox treatment did not alter hepatic lipid accumulation ( $8.40 \pm 0.01 \%$, vs. $8.77 \pm 0.01 \%$, $\mathrm{p}=0.42$, in placebo vs. Acipimox, figure $3 \mathrm{~b}$ ). In a subgroup of the T2DM patients $(n=10)$, also cardiac lipid content was measured. Here, Acipimox did not have an effect on cardiac lipid accumulation (0.62 \pm 0.07 vs. $0.73 \pm 0.12 \% \mathrm{CH}_{2} /$ water resonance, $p=0.38$, for placebo vs. Acipimox, figure $3 c$ ).

\section{CARDIAC FUNCTION AND ENERGY STATUS}

Ejection fraction (EF), Early filling over Atrial filling phase (E/A) ratio and cardiac energy status were not different between T2D subjects and controls. These data indicate that T2D patients in this study had normal cardiac function. Surprisingly, upon Acipimox treatment both systolic and diastolic function tended to decrease in our T2D subjects (EF $59.9 \pm 2.7$ vs. $56.5 \pm 2.0 \%, p=0.08$ and $E / A 1.08 \pm 0.12$ vs $0.94 \pm 0.07, p=0.08$ for placebo vs. Acipimox, figure $4 a$ and b). However, Acipimox treatment did not affect cardiac energy status $(2.20 \pm 0.18$ vs. $2.50 \pm 0.27, p=0.52$, in placebo vs. Acipimox, figure 4c).

\section{MITOCHONDRIAL CAPACITY}

All data for PCr-recovery were measured at similar depletion and post-exercise $\mathrm{pH}$ levels. T2D patients $(n=21)$ tended to have a longer PCr-recovery half-time than controls, indicating reduced in vivo mitochondrial capacity (PCr-t1/2: $22.2 \pm 1.8$ sec vs. $27.4 \pm 2.6 \mathrm{sec}, \mathrm{p}=0.08)$, Upon Acipimox treatment, PCr-recovery half-time increased, suggesting a reduction in in vivo mitochondrial capacity $(27.4 \pm 2.6 \mathrm{sec}$ vs. $30.2 \pm 2.6 \mathrm{sec}$ in placebo vs. Acipimox, $p=0.008$, figure $5 a$ ).

Mitochondrial density as determined by mtDNA copy number, was lower in T2D patients compared to obese control subjects $(3555 \pm 435 \mathrm{AU}$ vs. $2305 \pm 218 \mathrm{AU}$, $\mathrm{p}=0.001$ ). However, mtDNA copy number was unaffected by Acipimox treatment $(2305 \pm 218 \mathrm{AU}$ vs. $2353 \pm 202 \mathrm{AU}, \mathrm{p}=0.84$, in placebo vs. Acipimox).

Ex vivo mitochondrial function measured as respiration in permeabilized muscle fibers was lower in T2D patients, compared to controls (data not shown). After correction of the mitochondrial respiration for mtDNA content, all differences between T2D patients and controls disappeared (data not shown). In contrast to in 
a

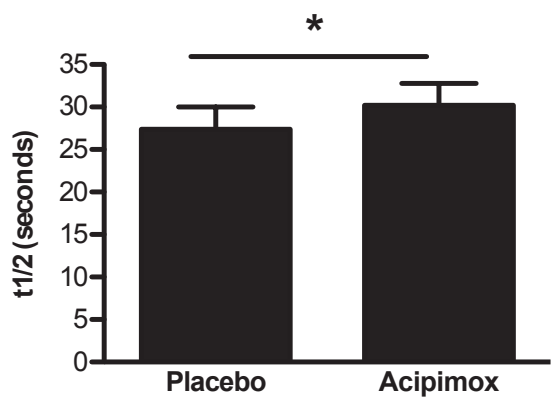

b

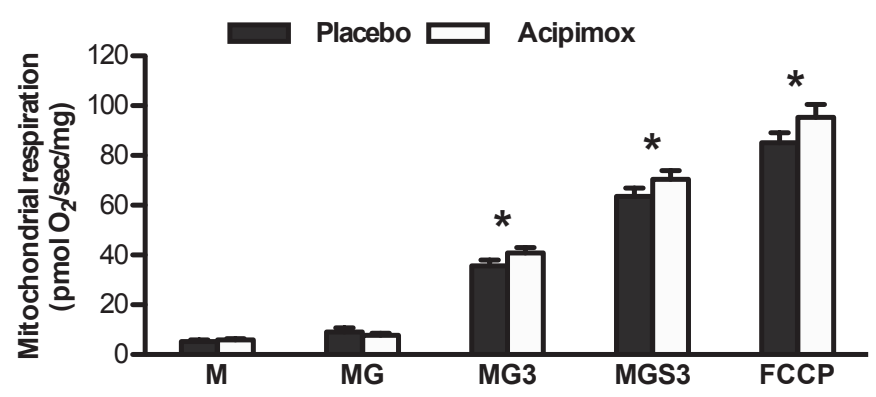

C

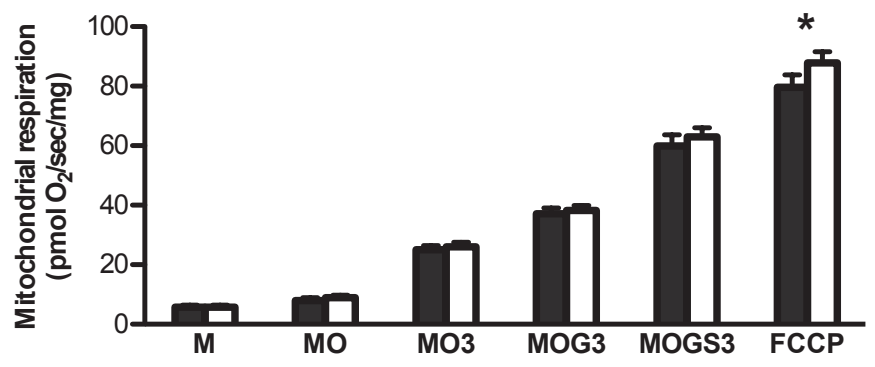

Figure $\mathbf{5}$ (a) in vivo mitochodondrial function as PCr-recovery rate, (b) ex vivo mitochondrial function was measured in permeabilized fibers, upon addition of complex I and II substrates uncorrected for mtDNA, in (c) the same measurement is repeated, only after adding octanoyl-carnitine as a substrate uncorrected for mtDNA, M=malate, $\mathrm{G}=$ glutamate, $\mathrm{S}=$ succinate, $\mathrm{O}=$ octanoyl-carnitin, $3=$ state 3 after addition of $\mathrm{ADP}, \mathrm{cytC}=$ cytochrome $\mathrm{C} \mathrm{FCCP}=$ maximal respiration upon chemical uncoupling with $\mathrm{FCCP}$. Significant differences with $p<0.05$ are indicated by *.

vivo findings, ex vivo respiration of mitochondria increased upon Acipimox treatment both for state 3 and for maximal uncoupled respiration on malate/succinate (see figure 5B). Upon addition of octanoyl-carnitine only maximal uncoupled respiration was significantly higher in the Acipimox treated condition (see figure $5 \mathrm{C}$ ). As mtDNA 
content was not different between the interventions, after correction of mitochondrial respiration for mtDNA content a similar trend with an increased mitochondrial respiration upon Acipimox treatment was observed (data not shown).

\section{DISCUSSION}

The standard clinical dosage of Acipimox only gradually lowered plasma cholesterol and triglyceride concentrations and caused a rebound effect in fasting plasma FFA concentrations, rising up to 2-fold, after 2 weeks of treatment. This elevation of plasma FFA concentration was paralleled by reduced insulin sensitivity, an increase in skeletal muscle lipid accumulation and decreased in vivo, but not ex vivo mitochondrial function. Furthermore, the elevation of plasma FFA concentration by Acipimox tended to decrease cardiac function in T2D patients.

The observation of elevated FFA levels and impaired insulin action is in contrast to some other studies that did show a long-term reduction of plasma FFA concentrations by Acipimox [9, 29, 53]. There are 2 major differences between these studies and our study. First, we administered Acipimox 3 times a day, after every meal, according to clinical and medicinal guidelines, whereas other studies used a 4 times daily dosing. Second, in all the previous studies, the last dose of Acipimox was given on the test-day directly prior to blood sampling and analysis. Of note, Acipimox treatment can lead to a rebound effect with plasma FFA rising in the morning, even with a 4 times daily dosage [54]. Saloranta et al. [54, 55] showed that the administration of Acipimox resulted in a sustained daytime rise in plasma FFA, and did not change plasma FFA concentrations over a 24 hour period. It was suggested that this compensatory free fatty acid rise may be necessary to maintain energy production. This notion is of interest, as it is known that mainly nocturnal concentrations of plasma fatty acids are elevated in T2D individuals [56], with insulin resistance being more pronounced in the morning than in the afternoon [57, 58]. Hence, the increase in plasma FFA concentrations upon Acipimox administration is most likely a reflection of a noctural rebound effect, which in our study became apparent due to lack of Acipimox administration in the morning of the experimental test days. Thus, it is likely that previous reports on the effect of Acipimox on plasma FFA concentrations and insulin sensitivity actually reflect the remnant effect of the last dose of Acipimox taken, rather than being a reflection of prolonged Acipimox treatment. 
In addition to the absence of a FFA-lowering effect of Acipimox, our study revealed some other interesting findings. The Acipimox-induced elevation of plasma FFA induced lipid accumulation and insulin resistance, and tended to compromise cardiac function in patients with type 2 diabetes. However, cardiac lipid content was not increased, suggesting that plasma FFA concentrations may have a direct, detrimental effect on cardiac function, which is independent of cardiac fat accumulation. Consistently in the study of Letho et al. [30], changes in lipid supply rather than in lipid accumulation seemed to determine cardiac function and workload. These data suggest that the heart is more susceptible for changes in substrate supply rather than changes in cardiac lipid content itself. Furthermore, our data suggest that one should be cautious when treating hyperlipidemia with Acipimox in T2D patients. Future studies should be performed to assess safety and efficacy of Acipimox treatment in T2D patients.

The rebound rise in plasma FFA also provided a model to study the effects of elevated plasma FFA on cardiac, liver and skeletal muscle lipid accumulation and function, without directly altering energy balance, which is the case in lipid infusion or highfat diet models used to examine the effect of FFA elevation on insulin sensitivity and related parameters. It is thus of interest to note that, in accordance with the lipid infusion paradigms, Acipimox-induced elevation of plasma FFA concentrations also resulted in accumulation of fat in skeletal muscle and insulin resistance. However, in our study, elevated plasma FFA concentrations did not increase liver fat content but did impair hepatic insulin sensitivity. Consistently, a study with Acipimox that resulted in reducing plasma fatty acids found unchanged hepatic fat content, whilst hepatic glucose output was improved [31]. These data together suggest that circulating fatty acids may play a dominant role in regulating hepatic insulin sensitivity independent of hepatic fat content.

We, and others, have previously shown that acute elevation of plasma FFA may decrease mitochondrial biogenesis and function [24, 26, 59-61]. Rather interestingly, we observed that elevated plasma FFA concentrations decreased in vivo mitochondrial function, but increased ex vivo mitochondrial function. The reduction in in vivo mitochondrial function is consistent with previous findings that elevation of FFA concentrations can reduce mitochondrial metabolism [59-62]. However, it should be noted that in vivo mitochondrial function - as determined by $\mathrm{PCr}$ recovery halftime - is determined not only by intrinsic mitochondrial function, but also by mitochondrial density and perfusion. Therefore, ex vivo mitochondrial function is 
a more direct measure of skeletal muscle mitochondrial oxidative capacity. As we previously showed that high FFA concentrations - induced by prolonged fasting resulted in reduction (rather than an improvement) in mitochondrial function [61], the present results are surprising. Most likely, these findings can be explained by a direct effect of Acipimox on skeletal muscle mitochondrial function. Acipimox is a nicotinic acid analogue, and may thereby increase intracellular NAD+ concentrations in skeletal muscle. Recent reports show that stimulation of the NAD+ biosynthesis pathway, for example by nicotinamide riboside, has beneficial effects on mitochondrial function [63]. Thus, although Acipimox did not have beneficial effects on in vivo mitochondrial function, probably due to negative effects of high FFA concentrations on muscle perfusion or substrate delivery, our results suggest that other compounds that may stimulate NAD+ metabolism without increasing plasma FFA concentrations may be very interesting targets for the treatment of mitochondrial dysfunction that is associated with type 2 diabetes.

In conclusion, a two-week intervention with clinical dosages of Acipimox led to a rebound rise in plasma FFA, which negatively impacts insulin sensitivity and cardiac function. The decrease in insulin sensitivity was probably mediated through an increase in skeletal muscle lipid accumulation and a decreased in vivo mitochondrial function. Future research is needed to investigate the safety and efficacy of Acipimox treatment for hyperlipidemia in T2D patients. 


\section{REFERENCES}

1. Krolewski AS, Czyzyk A, Janeczko D, Kopczynski J. Mortality from cardiovascular diseases among diabetics. Diabetologia. 1977;13(4):34550 .

2. Roden M, Price TB, Perseghin G, Petersen KF, Rothman DL, Cline GW, Shulman GI. Mechanism of free fatty acid-induced insulin resistance in humans. J Clin Invest. 1996;97(12):2859-65.

3. Panzram G. Mortality and survival in type 2 (non-insulin-dependent) diabetes mellitus. Diabetologia. 1987;30(3):123-31.

4. Tunaru S, Kero J, Schaub A, Wufka C, Blaukat A, Pfeffer K, Offermanns S. PUMA-G and HM74 are receptors for nicotinic acid and mediate its antilipolytic effect. Nat Med. 2003;9(3):352-5.

5. Vaag A, Skott P, Damsbo P, Gall MA, Richter EA, Beck-Nielsen H. Effect of the antilipolytic nicotinic acid analogue acipimox on whole-body and skeletal muscle glucose metabolism in patients with non-insulin-dependent diabetes mellitus. J Clin Invest. 1991;88(4):1282-90.

6. Sirtori CR, Gianfranceschi G, Sirtori M, Bernini F, Descovich G, Montaguti U, Fuccella LM, Musatti L. Reduced triglyceridemia and increased high density lipoprotein cholesterol levels after treatment with acipimox, a new inhibitor of lipolysis. Atherosclerosis. 1981;38(3-4):267-71.

7. Jung W, Kohlmeier M, Nikolaus T, Schlierf G. Effects of Acipimox on plasma lipids and biliary lipids in healthy subjects. Research in experimental medicine. 1985;185(6):457-68.

8. Taskinen MR, Nikkila EA. Effects of acipimox on serum lipids, lipoproteins and lipolytic enzymes in hypertriglyceridemia. Atherosclerosis. 1988;69(23):249-55.

9. Bajaj M, Suraamornkul S, Romanelli A, Cline GW, Mandarino LJ, Shulman GI, DeFronzo RA. Effect of a sustained reduction in plasma free fatty acid concentration on intramuscular long-chain fatty Acyl-CoAs and insulin action in type 2 diabetic patients. Diabetes. 2005;54(11):3148-53.

10. Bajaj M, Medina-Navarro R, Suraamornkul S, Meyer C, DeFronzo RA, Mandarino LJ. Paradoxical changes in muscle gene expression in insulinresistant subjects after sustained reduction in plasma free fatty acid concentration. Diabetes. 2007;56(3):743-52.

11. van Loon LJ, Manders RJ, Koopman R, Kaastra B, Stegen JH, Gijsen AP, Saris WH, Keizer HA. Inhibition of adipose tissue lipolysis increases intramuscular lipid use in type 2 diabetic patients. Diabetologia. 2005;48(10):2097-107.

12. van Herpen NA, Schrauwen-Hinderling VB. Lipid accumulation in nonadipose tissue and lipotoxicity. Physiol Behav. 2008;94(2):231-41.

13. Roden M, Krssak M, Stingl H, Gruber S, Hofer A, Furnsinn C, Moser E, Waldhausl W. Rapid impairment of skeletal muscle glucose transport/ 
phosphorylation by free fatty acids in humans. Diabetes. 1999;48(2):35864.

14. Krebs M, Krssak M, Nowotny P, Weghuber D, Gruber S, Mlynarik V, Bischof M, Stingl H, Furnsinn C, Waldhausl W, Roden M. Free fatty acids inhibit the glucose-stimulated increase of intramuscular glucose-6-phosphate concentration in humans. J Clin Endocrinol Metab. 2001;86(5):2153-60.

15. Shulman GI. Cellular mechanisms of insulin resistance. J Clin Invest. 2000;106(2):171-6.

16. Cusi K. Role of insulin resistance and lipotoxicity in non-alcoholic steatohepatitis. Clin Liver Dis. 2009;13(4):545-63.

17. Boudina S, Abel ED. Diabetic cardiomyopathy revisited. Circulation. 2007;115(25):3213-23.

18. van de Weijer T, Schrauwen-Hinderling VB, Schrauwen P. Lipotoxicity in type 2 diabetic cardiomyopathy. Cardiovasc Res. 2011;92(1):10-8.

19. Phielix E, Schrauwen-Hinderling VB, Mensink M, Lenaers E, Meex R, Hoeks J, Kooi ME, Moonen-Kornips E, Sels JP, Hesselink MK, Schrauwen P. Lower intrinsic ADP-stimulated mitochondrial respiration underlies in vivo mitochondrial dysfunction in muscle of male type 2 diabetic patients. Diabetes. 2008;57(11):2943-9.

20. Kelley DE, He J, Menshikova EV, Ritov VB. Dysfunction of mitochondria in human skeletal muscle in type 2 diabetes. Diabetes. 2002;51(10):2944-50.

21. He J, Watkins S, Kelley DE. Skeletal muscle lipid content and oxidative enzyme activity in relation to muscle fiber type in type 2 diabetes and obesity. Diabetes. 2001;50(4):817-23.

22. Schrauwen-Hinderling VB, Kooi ME, Hesselink MK, Jeneson JA, Backes WH, van Echteld CJ, van Engelshoven JM, Mensink M, Schrauwen P. Impaired in vivo mitochondrial function but similar intramyocellular lipid content in patients with type 2 diabetes mellitus and BMI-matched control subjects. Diabetologia. 2007;50(1):113-20.

23. Petersen KF, Dufour S, Befroy D, Garcia R, Shulman GI. Impaired mitochondrial activity in the insulin-resistant offspring of patients with type 2 diabetes. N Engl J Med. 2004;350(7):664-71.

24. Brehm A, Krssak M, Schmid Al, Nowotny P, Waldhausl W, Roden M. Increased lipid availability impairs insulin-stimulated ATP synthesis in human skeletal muscle. Diabetes. 2006;55(1):136-40.

25. Schrauwen P, Schrauwen-Hinderling V, Hoeks J, Hesselink MK. Mitochondrial dysfunction and lipotoxicity. Biochim Biophys Acta. 2010;1801(3):266-71.

26. Brehm A, Krssak M, Schmid Al, Nowotny P, Waldhausl W, Roden M. Acute elevation of plasma lipids does not affect ATP synthesis in human skeletal muscle. Am J Physiol Endocrinol Metab. 2010;299(1):E33-8.

27. Lim EL, Hollingsworth KG, Smith FE, Thelwall PE, Taylor R. Inhibition of lipolysis in Type 2 diabetes normalizes glucose disposal without change in 
muscle glycogen synthesis rates. Clin Sci (Lond). 2011;121(4):169-77.

28. Serlie MJ, Meijer AJ, Groener JE, Duran M, Endert E, Fliers E, Aerts JM, Sauerwein HP. Short-term manipulation of plasma free fatty acids does not change skeletal muscle concentrations of ceramide and glucosylceramide in lean and overweight subjects. J Clin Endocrinol Metab. 2007;92(4):15249.

29. Bajaj M, Suraamornkul S, Kashyap S, Cusi K, Mandarino L, DeFronzo RA. Sustained reduction in plasma free fatty acid concentration improves insulin action without altering plasma adipocytokine levels in subjects with strong family history of type 2 diabetes. J Clin Endocrinol Metab. 2004;89(9):464955.

30. Lehto HR, Parkka J, Borra R, Tuunanen H, Lepomaki V, Parkkola R, Knuuti J, Nuutila P, Iozzo P. Effects of acute and one-week fatty acid lowering on cardiac function and insulin sensitivity in relation with myocardial and muscle fat and adiponectin levels. J Clin Endocrinol Metab. 2012;97(9):3277-84.

31. Rigazio S, Lehto HR, Tuunanen H, Nagren K, Kankaanpaa M, Simi C, Borra R, Naum AG, Parkkola R, Knuuti J, Nuutila P, lozzo P. The lowering of hepatic fatty acid uptake improves liver function and insulin sensitivity without affecting hepatic fat content in humans. Am J Physiol Endocrinol Metab. 2008;295(2):E413-9.

32. Kuipers H, Verstappen FT, Keizer HA, Geurten P, van Kranenburg G. Variability of aerobic performance in the laboratory and its physiologic correlates. Int J Sports Med. 1985;6(4):197-201.

33. Siri WE. The gross composition of the body. Adv Biol Med Phys. 1956;4:23980.

34. DeFronzo RA, Tobin JD, Andres R. Glucose clamp technique: a method for quantifying insulin secretion and resistance. Am J Physiol. 1979;237(3):E21423.

35. Mensink M, Blaak EE, van Baak MA, Wagenmakers AJ, Saris WH. Plasma free Fatty Acid uptake and oxidation are already diminished in subjects at high risk for developing type 2 diabetes. Diabetes. 2001;50(11):2548-54.

36. Frayn $\mathrm{KN}$. Calculation of substrate oxidation rates in vivo from gaseous exchange. J Appl Physiol. 1983;55(2):628-34.

37. Bergstrom J, Hermansen L, Hultman E, Saltin B. Diet, muscle glycogen and physical performance. Acta Physiol Scand. 1967;71(2):140-50.

38. Koopman R, Schaart G, Hesselink MK. Optimisation of oil red O staining permits combination with immunofluorescence and automated quantification of lipids. Histochem Cell Biol. 2001;116(1):63-8.

39. Veksler VI, Kuznetsov AV, Sharov VG, Kapelko VI, Saks VA. Mitochondrial respiratory parameters in cardiac tissue: a novel method of assessment by using saponin-skinned fibers. Biochim Biophys Acta. 1987;892(2):191-6.

40. Phielix E, Meex R, Ouwens DM, Sparks L, Hoeks J, Schaart G, Moonen- 
Kornips E, Hesselink MK, Schrauwen P. High oxidative capacity due to chronic exercise training attenuates lipid-induced insulin resistance. Diabetes. 2012;61(10):2472-8.

41. Timmers S, Konings E, Bilet L, Houtkooper RH, van de Weijer T, Goossens GH, Hoeks J, van der Krieken S, Ryu D, Kersten S, Moonen-Kornips E, Hesselink MK, Kunz I, Schrauwen-Hinderling VB, Blaak EE, Auwerx J, Schrauwen P. Calorie restriction-like effects of 30 days of resveratrol supplementation on energy metabolism and metabolic profile in obese humans. Cell Metab. 2012;14(5):612-22.

42. Vanhamme L, van den Boogaart A, Van Huffel S. Improved method for accurate and efficient quantification of MRS data with use of prior knowledge. J Magn Reson. 1997;129(1):35-43.

43. Naressi A, Couturier C, Devos JM, Janssen M, Mangeat C, de Beer R, Graveron-Demilly D. Java-based graphical user interface for the MRUI quantitation package. Magma. 2001;12(2-3):141-52.

44. Hamilton G, Yokoo T, Bydder M, Cruite I, Schroeder ME, Sirlin CB, Middleton MS. In vivo characterization of the liver fat (1)H MR spectrum. NMR Biomed. 2011;24(7):784-90.

45. Schrauwen-Hinderling VB, Hesselink MK, Meex R, van der Made S, Schar M, Lamb H, Wildberger JE, Glatz J, Snoep G, Kooi ME, Schrauwen P. Improved ejection fraction after exercise training in obesity is accompanied by reduced cardiac lipid content. J Clin Endocrinol Metab. 2010;95(4):19328.

46. van der Meer RW, Doornbos J, Kozerke S, Schar M, Bax JJ, Hammer S, Smit JW, Romijn JA, Diamant M, Rijzewijk LJ, de Roos A, Lamb HJ. Metabolic imaging of myocardial triglyceride content: reproducibility of ${ }^{1} \mathrm{H}$ MR spectroscopy with respiratory navigator gating in volunteers. Radiology. 2007;245(1):251-7.

47. Kozerke S, Schar M, Lamb HJ, Boesiger P. Volume tracking cardiac ${ }^{31} \mathrm{P}$ spectroscopy. Magn Reson Med. 2002;48(2):380-4.

48. Yagyu H, Chen G, Yokoyama M, Hirata K, Augustus A, Kako Y, Seo T, Hu Y, Lutz EP, Merkel M, Bensadoun A, Homma S, Goldberg IJ. Lipoprotein lipase $(\mathrm{LpL})$ on the surface of cardiomyocytes increases lipid uptake and produces a cardiomyopathy. J Clin Invest. 2003;111(3):419-26.

49. Bilet L, van de Weijer T, Hesselink MK, Glatz JF, Lamb HJ, Wildberger $J$, Kooi ME, Schrauwen P, Schrauwen-Hinderling VB. Exercise-induced modulation of cardiac lipid content in healthy lean young men. Basic Res Cardiol. 2011;106(2):307-15.

50. Lamb HJ, Doornbos J, den Hollander JA, Luyten PR, Beyerbacht HP, van der Wall EE, de Roos A. Reproducibility of human cardiac ${ }^{31} \mathrm{P}-\mathrm{NMR}$ spectroscopy. NMR Biomed. 1996;9(5):217-27.

51. Hansch A, Rzanny R, Heyne JP, Leder U, Reichenbach JR, Kaiser WA. 
Noninvasive measurements of cardiac high-energy phosphate metabolites in dilated cardiomyopathy by using ${ }^{31} \mathrm{P}$ spectroscopic chemical shift imaging. Eur Radiol. 2005;15(2):319-23.

52. Steele R. Influences of glucose loading and of injected insulin on hepatic glucose output. Ann N Y Acad Sci. 1959;82:420-30.

53. Worm D, Henriksen JE, Vaag A, Thye-Ronn P, Melander A, Beck-Nielsen $\mathrm{H}$. Pronounced blood glucose-lowering effect of the antilipolytic drug acipimox in noninsulin-dependent diabetes mellitus patients during a 3-day intensified treatment period. J Clin Endocrinol Metab. 1994;78(3):717-21.

54. Saloranta C, Taskinen MR, Widen E, Harkonen M, Melander A, Groop L. Metabolic consequences of sustained suppression of free fatty acids by acipimox in patients with NIDDM. Diabetes. 1993;42(11):1559-66.

55. Saloranta C, Groop L, Ekstrand A, Franssila-Kallunki A, Eriksson J, Taskinen MR. Different acute and chronic effects of acipimox treatment on glucose and lipid metabolism in patients with type 2 diabetes. Diabet Med. 1993;10(10):950-7.

56. Reaven GM, Hollenbeck C, Jeng CY, Wu MS, Chen YD. Measurement of plasma glucose, free fatty acid, lactate, and insulin for $24 \mathrm{~h}$ in patients with NIDDM. Diabetes. 1988;37(8):1020-4.

57. Bolli GB. The dawn phenomenon: its origin and contribution to early morning hyperglycemia in diabetes mellitus. Diabete \& metabolisme. 1988;14(6):675-86.

58. Shapiro ET, Polonsky KS, Copinschi G, Bosson D, Tillil H, Blackman J, Lewis G, Van Cauter E. Nocturnal elevation of glucose levels during fasting in noninsulin-dependent diabetes. J Clin Endocrinol Metab. 1991;72(2):44454.

59. Hoeks J, Hesselink MK, Russell AP, Mensink M, Saris WH, Mensink RP, Schrauwen P. Peroxisome proliferator-activated receptor-gamma coactivator-1 and insulin resistance: acute effect of fatty acids. Diabetologia. 2006;49(10):2419-26.

60. Groop LC, Bonadonna RC, Shank M, Petrides AS, DeFronzo RA. Role of free fatty acids and insulin in determining free fatty acid and lipid oxidation in man. J Clin Invest. 1991;87(1):83-9.

61. Hoeks J, van Herpen NA, Mensink M, Moonen-Kornips E, van Beurden D, Hesselink MK, Schrauwen P. Prolonged fasting identifies skeletal muscle mitochondrial dysfunction as consequence rather than cause of human insulin resistance. Diabetes. 2010;59(9):2117-25.

62. Chavez AO, Kamath S, Jani R, Sharma LK, Monroy A, Abdul-Ghani MA, Centonze VE, Sathyanarayana P, Coletta DK, Jenkinson CP, Bai Y, Folli F, Defronzo RA, Tripathy D. Effect of short-term free Fatty acids elevation on mitochondrial function in skeletal muscle of healthy individuals. J Clin Endocrinol Metab. 2010;95(1):422-9. 
63. Canto C, Houtkooper RH, Pirinen E, Youn DY, Oosterveer MH, Cen $\mathrm{Y}$, Fernandez-Marcos PJ, Yamamoto $\mathrm{H}$, Andreux PA, Cettour-Rose P, Gademann K, Rinsch C, Schoonjans K, Sauve AA, Auwerx J. The NAD(+) precursor nicotinamide riboside enhances oxidative metabolism and protects against high-fat diet-induced obesity. Cell Metab. 2012;15(6):83847. 
L.Bilet, T. van de Weijer, E. Phielix, A. Gemmink, M. Bosma, E. Moonen-Kornips, J. Jorgensen, K. Meijer, M. Hopman, M.K.C. Hesselink, M. Ouwens, V.B. Schrauwen-Hinderling, P. Schrauwen

In progress 


\section{CHAPTER}

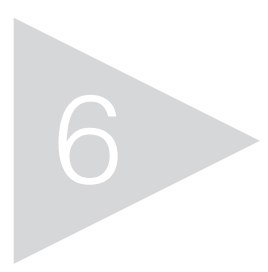

The effect of one-legged

lowered physical activity on insulin sensitivity and lipid and glucose metabolism 


\section{ABSTRACT}

Physical inactivity and associated decline in mitochondrial function, increased myocellular fat deposition and reduced insulin sensitivity are common denominators in chronic metabolic disorders like obesity and T2DM. Here we examined the direct effect of inactivity-induced declined mitochondrial function on muscle fat content and insulin sensitivity. Ten male subjects (age $22.4 \pm 4.2$ years, BMI $21.3 \pm 2.0$ $\mathrm{kg} / \mathrm{m}^{2}$ ) underwent a 12 days unilateral lower limb suspension to investigate the effect of one-legged physical inactivity on skeletal muscle mitochondrial function $\left({ }^{31} \mathrm{P}-\mathrm{NMRS}\right.$ ), lipid and glucose metabolism (ex vivo ${ }^{14} \mathrm{C}$ lipid and glucose oxidation), intramyocellular lipid content (IMCL by ${ }^{1} \mathrm{H}-\mathrm{NMRS}$ and histology) and insulin sensitivity (markers of insulin signalling upon an acute intravenous insulin bolus). The contralateral leg served as an active internal control. In vivo mitochondrial function was lower upon inactivity, as revealed by a significantly longer PCrrecovery half-time compared to the active leg (PCr-t1/2: $21.4 \pm 2.3 \mathrm{sec}$ vs. 16.7 $\pm 1.8 \mathrm{sec}, \mathrm{p}=0.02)$. In skeletal muscle biopsies, palmitate oxidation to ${ }^{14} \mathrm{CO}_{2}$ was significantly lower in the immobilized leg compared to the active leg $(0.14 \pm 0.03$ $\mathrm{nmol} / \mathrm{mg}$ vs. $0.18 \pm 0.03 \mathrm{nmol} / \mathrm{mg}, \mathrm{p}=0.013)$ accompanied by a higher ${ }^{14} \mathrm{C}$-palmitate incorporation into TAG in the immobilized leg (ex vivo assays, $0.019 \pm 0.005 \mathrm{nmol} /$ $\mathrm{mg}$ vs. $0.010 \pm 0.002 \mathrm{nmol} / \mathrm{mg}$ ), $\mathrm{p}=0.075)$. Further, IMCL in both $\mathrm{m}$. tibialis anterior $(0.312 \pm 0.045 \%$ vs $0.239 \pm 0.041, p=0.003)$ and in $\mathrm{m}$. vastus lateralis $(2.09 \pm$ $0.47 \%$ lipid fraction vs $0.91 \pm 0.27 \%$ lipid fraction, $p=0.008$ ) was higher in the immobilized leg compared with the active leg. Finally, blunting of insulin action upon lipid infusion was more pronounced in the immobilized leg compared with the active leg, suggesting compromised insulin sensitivity upon inactivity $(p<0.05)$. Inactivity blunts in vivo mitochondrial function and reduces fat oxidative capacity while promoting incorporation of fat into intramyocellular triacylglycerol stores ex vivo. Accordingly, IMCL content in the inactive leg was higher and blunting of insulin signalling upon lipid infusion more pronounced than in the active leg. Thus, we demonstrate that a physical inactivity-mediated decline in mitochondrial function directly impacts insulin sensitivity under high lipid conditions. 


\section{INTRODUCTION}

Physical inactivity is a major determinant of the current epidemic of chronic metabolic disorders like obesity and type 2 diabetes mellitus (T2DM) [1, 2]. The imbalance between substrate uptake and oxidation in obesity possess to accumulation of excessive fat in non-adipose tissues such as liver, heart and skeletal muscle (ectopic fat accumulation). Ectopic fat accumulation in skeletal muscle of sedentary humans is strongly associated with insulin resistance [3]. Likewise, type 2 diabetic patients [4] as well as their first-degree relatives [5, 6] are characterized by excessive accumulation of fat in skeletal muscle and insulin resistance.

Endurance training is a powerful way to prevent and treat type 2 diabetes. However, intramyocellular lipid (IMCL) content is also increased in highly insulin sensitive endurance trained subjects (known as the athlete's paradox) [4, 7], suggesting that IMCL per se is not causative in skeletal muscle insulin resistance. In fact, the increased IMCL storage following endurance training serves to match the traininginduced increase in oxidative capacity and reliance on fat as a substrate during exercise [7]. In obesogenic/diabetogenic conditions, however, the ectopic fat accumulation is not paralleled by compromised rather than improved mitochondrial function. These findings indicate that the dysbalance between skeletal muscle fat accumulation and mitochondrial oxidative capacity, rather than the IMCL content per se determines the development of insulin resistance. Likewise, we have recently shown that a high-oxidative capacity (partly) protects against the development of lipid-induced insulin resistance [8]. From a prevention perspective, it is, however, also of relevance to examine if physical inactivity and associated decline in mitochondrial function renders people sensitive to the development of human skeletal muscle insulin resistance.

To examine this is not trivial in humans. Exercise training as well as physical inactivity (bed rest) studies have shown that multiple systemic effects contribute to the effect of the (in)activity on outcome parameters related to insulin sensitivity, hence results remain associative. In the current study, we therefore used a model in which muscle mitochondrial function was manipulated in only one leg, leaving the other leg unaffected, thus allowing the comparison - within one individual - of the local effect of altered mitochondrial function on muscle lipid metabolism and insulin sensitivity. We achieved this by using the model of unilateral lower limb suspension (ULLS), mimicking inactivity in one leg of a subject, while using the other leg of 
the same individual as an active control. The model of ULLS, originally described by Berg et al. [9] induces deconditioning of the muscle [9, 10] and markers of compromised mitochondrial function as a consequence of ULLS have previously been described $[11,12]$.

Here we used unilateral limb suspension to determine the relationship between mitochondrial function, IMCL content and insulin sensitivity. We hypothesized that introducing physical inactivity unilaterally would result in compromised mitochondrial function, increased intramyocellular lipid content and augmentation of lipid-induced insulin resistance.

\section{MATERIALS AND METHODS}

\section{SUBJECTS}

Ten healthy lean young men participated in this study. Subjects' characteristics are shown in Table 1. None of the subjects participated in competitive sports. Subjects with unstable body weight ( $>3 \mathrm{~kg}$ change in preceding six months) were excluded. The institutional medical ethics committee approved the study, and all participants gave their informed written consent.

Table 1 Subjects' characteristics

\begin{tabular}{lc}
\hline Subjects' characteristics & Mean $\pm \mathrm{SE}$ \\
\hline Age, $\mathrm{yr}$ & $22.4 \pm 4.2$ \\
$\mathrm{BMI}, \mathrm{kg} / \mathrm{m}^{2}$ & $21.3 \pm 2.0$ \\
Fat $\%$ & $14.6 \pm 3.9$ \\
Systolic blood pressure, $\mathrm{mmHg}$ & $115 \pm 12$ \\
Diastolic blood pressure, $\mathrm{mmHg}$ & $74 \pm 11$ \\
\hline Plasma glucose, $\mathrm{mmol} / \mathrm{L}$ & $4.9 \pm 0.3$ \\
\hline Plasma triglyceride, $\mathrm{mmol} / \mathrm{L}$ & $1.0 \pm 0.4$ \\
\hline Plasma free fatty acids, $\mathrm{mmol} / \mathrm{L}$ & $0.4 \pm 0.2$ \\
\hline VO ${ }_{2} \mathrm{max} / \mathrm{kg}, \mathrm{ml} \times \mathrm{min}^{-1} \times \mathrm{kg}{ }^{-1}$ & $48 \pm 10$ \\
\hline Data are means $\pm \mathrm{SD} . \mathrm{BMI}$ Body mass index.
\end{tabular}

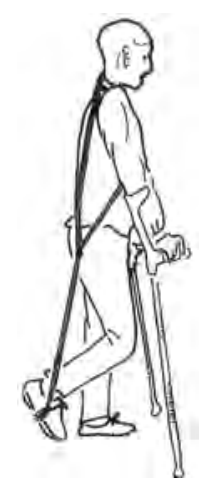

Figure 2 Unilateral lower limb suspension set up. 


\section{STUDY DESIGN}

We examined the effects of one-legged lowered physical activity on skeletal muscle mitochondrial function, ex vivo glucose and lipid metabolism, lipid content and insulin signalling. Volunteers were subjected to 12 days of unilateral lower limb suspension (ULLS) randomized to either their dominant or non-dominant leg. All outcome measurements were performed in the active and the inactivated leg and outcome parameters were compared within one individual in a paired design. See study design in fig. 1.

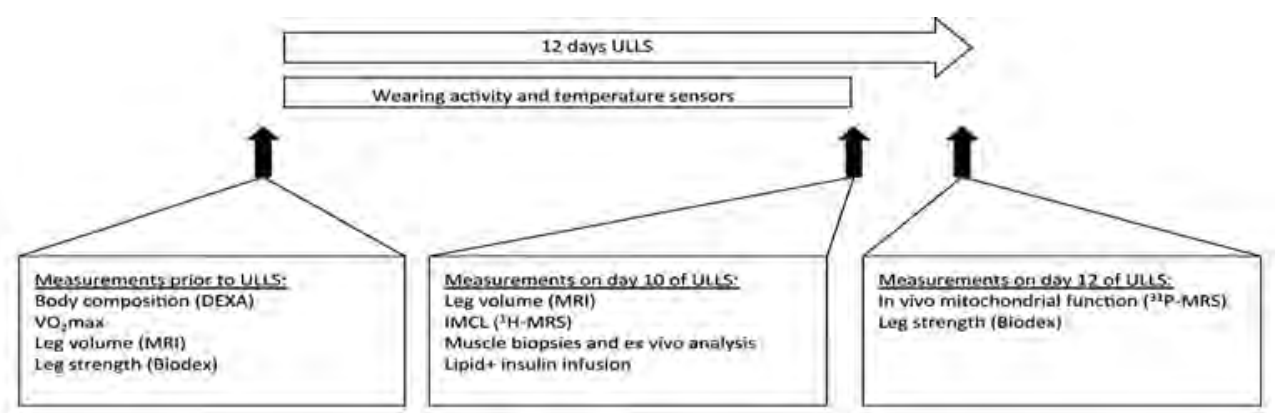

Figure 1 Study design. ULLS Unilateral lower limb suspension, ${ }^{1} \mathrm{H}-M R S$ proton magnetic resonance spectroscopy, ${ }^{31} \mathrm{P}-M R S$ phosphorous magnetic resonance spectroscopy.

Within 1 week of the start of the experimental period, a basal blood sample was obtained after an overnight fast. Furthermore, resting blood pressure, body composition and maximal aerobic capacity was determined in all subjects. Subjects were exposed to a lower limb suspension for 12 days as previously described [13]. Leg suspension was randomized to either the dominant or the non-dominant leg. Suspension was achieved by attachment of a sling to a non-rigid ankle brace and to a harness on the upper body, thus the suspended leg was unloaded from all weight bearing (see fig. 2 for illustration). The knee was slightly flexed at an angle of $130^{\circ}$, while the hip and the ankle maintained full mobility. The sling was worn during all locomotor activity. Subjects were provided with crutches to support daily life mobility. During the night, the sling was taken off. Also during periods of prolonged sitting and showering the sling was temporarily removed and subjects were instructed to minimize activity of the suspended leg during sitting and showering. To monitor compliance and physical activity level, subjects 1) kept a diary of their daily activities, 2) wore temperature sensors (ibuttons) and 3) wore leg specific accelerometers at all day times, except for when showering/bathing. 
After nine days of ULLS, subjects reported to the laboratory after an overnight fast. Upper leg muscle volume and intramyocellular lipid content in the muscle tibialis were determined by MRI and ${ }^{1} \mathrm{H}-\mathrm{MRS}$, respectively. Thereafter a basal muscle biopsy was taken from vastus lateralis muscle of both legs for ex vivo analysis of lipid metabolism, determination of IMCL and incorporation of ${ }^{14} \mathrm{C}$ labelled palmitate into DAG and TAG. Subsequently, a five-hour lipid infusion was initiated to elevate plasma FFA concentrations to levels previously shown to compromise insulin sensitivity. After 4.5 hour of lipid infusion a short-term hyperinsulinemic euglycemic clamp was performed with simultaneous infusions of insulin and glucose. A second muscle biopsy was taken immediately after 30 minutes of insulin infusion for analysis of insulin action. After these tests, subjects continued the ULLS for another two days to prevent any carry-over effects of the clamp procedure on subsequent functional assays. Hence, on day 12 of ULLS in vivo mitochondrial function (PCr recovery), and isometric leg strength was measured in both legs using ${ }^{31} \mathrm{P}$ MRS and Biodex respectively.

\section{MEASUREMENTS}

\section{MAXIMAL PERFORMANCE AND BODY COMPOSITION}

A routine incremental cycling test on a stationary bike to exhaustion was used to assess maximal exercise capacity as described previously [14] and a dual energy x-ray absorptiometry (DEXA) scan was used to determine body composition.

\section{COMPLIANCE}

Activity monitors (CAM system developed by Maastricht Instruments, Maastricht, the Netherlands) were attached to the upper part of suspended and unsuspended limb, just above the knee using customized pouches. The CAM contained a triaxial piezoresistive accelerometer and had a sample rate of $25 \mathrm{~Hz}$. Matlab(c) software and algorithms were used to calculate movement intensity [15, 16]. Next to monitoring activity by accelerometry, skin temperature of the quadriceps and gastrocnemius muscle was monitored by using iButtons [17] (type DS192 ${ }^{1} \mathrm{H}$; Maxim/ Dallas Semiconductor Corp., USA) throughout the whole ULLS period as a marker. 


\section{MUSCLE VOLUME AND STRENGTH}

As muscle mass is a determinant of insulin sensitivity we aimed to design the intervention such that muscle mass did not differ between the legs as a consequence of the immobilization. Hence, we examined the muscle volume of the upper leg by serial T2 weighted MRI images along with measurements of knee flexion and extension strength. Images to assess muscle volume were acquired using a body coil (Achieva Tx, Philips Healthcare, Best, The Netherlands) and a turbo spin echo sequence (TSE factor $=21$ ). Twenty contiguous slices of $10 \mathrm{~mm}$ thickness were acquired $(F O V=200 \times 400 \times 200 \mathrm{~mm}, \mathrm{TE}=100 \mathrm{~ms}, \mathrm{TR}=5351 \mathrm{~ms}$, flip angle $=$ $90 \mathrm{deg}$, scan duration $=4 \mathrm{~min} 30 \mathrm{sec}$ ). The most distal slice was positioned on the patella and all slices up to the hip were used for analysis. The MR images (plane resolution $0.78 \times 0.78 \mathrm{~mm}$ ) were segmented into muscle tissue and non-muscle tissue upon automated grayscale based binning using a home-written script in MATLAB. The muscle area upon segmentation was computed for every single slice and multiplied by slice thickness to compute muscle volume.

Isometric knee extending and flexing strength at 5 different knee angles (70, 80, 90, 100, 110 degrees) was measured using a Biodex III dynamometer [18]. Subjects seated upright in a chair and tightly fixed using straps. Subsequently, the knee was brought into position and subjects were asked to conduct maximal knee extension (3 seconds) followed by maximal knee flexion (3 seconds), while the force traces were recorded on a PC. This procedure was repeated once for each evaluated joint angle. Subjects were allowed two minutes rest between contractions.

\section{LIPID INFUSION + CLAMP}

In the morning after 9 days of immobilization participants reported to the laboratory after an overnight fast. After taking basal muscle biopsies from both legs ( $\mathrm{m}$. vastus lateralis), a teflon cannula was inserted into an antecubital vein for the heparinised (0.2 $\left.U^{*} \mathrm{~kg}^{-1 *} \mathrm{~min}^{-1}\right)$ infusion of long-chain triacylglycerols $(1.35 \mathrm{ml} / \mathrm{min}$ intralipid; Intralipid, Fresenius-Kabi, The Netherlands) for 5 hours. Blood was sampled from a second cannula, inserted retrogradely into a superficial dorsal hand vein, for later analysis of plasma glucose and FFAs. This venous blood was arterialized by placing the hand into a hot box that emits warm air $\left(\sim 65^{\circ} \mathrm{C}\right)$. After 4.5 hours a third cannula was inserted into an antecubital vein of the contralateral arm for simultaneous infusion of insulin (40mU/m²/min, Actrapid, Novo Nordisk) and glucose. During a $30 \mathrm{~min}$ 
hyperinsulinemic-euglycemic clamp plasma glucose levels were clamped at $\sim 5$ $\mathrm{mmol} / \mathrm{L}$ by variable co-infusion of $20 \%$ glucose. Thirty minutes after the start of the insulin infusion, a second muscle biopsy was taken from the vastus lateralis of both legs.

\section{MAGNETIC RESONANCE SPECTROSCOPY MEASUREMENTS}

In vivo mitochondrial function was determined by ${ }^{31} \mathrm{P}-\mathrm{MRS}$ in the afternoon after 12 days of immobilization as previously described [19]. Briefly, a knee-extension protocol was performed on a custom-built magnetic resonance compatible ergometer with a pulley system in a 3T whole-body MRI scanner (Achieva, 3Tx; Philips Medical Systems, Best, the Netherlands), for 5 min with weight corresponding to $50-60 \%$ of the subject's pre-determined maximal knee-extension capacity. A transmit/receive surface coil ( $5 \mathrm{~cm}$ diameter) was positioned on the vastus lateralis muscle and a time series of ${ }^{31} \mathrm{P}-\mathrm{MR}$ spectra (Free Induction Decays) were acquired with a repetition time of 4 seconds. Post-exercise PCr kinetics was computed as previously described [19].

In vivo IMCL content in $\mathrm{m}$. tibialis was assessed by ${ }^{1} \mathrm{H}-\mathrm{MRS}$ on a $3.0 \mathrm{~T}$ whole body MR system (Achieva 3Tx, Philips Healthcare, Best, The Netherlands). as described previously [20]. T2-weighted images were acquired for accurate positioning of the voxel $14 \times 14 \times 40 \mathrm{~mm}^{3}$ in the tibialis anterior muscle. Point Resolved Spectroscopy (PRESS) was used with the following acquisition parameters: TR $=2000 \mathrm{~ms}$, TE $=38 \mathrm{~ms}$, NSA $=128$ and 2048 sample points. Water suppression was performed using a selective excitation pulse followed by dephasing gradients. A second nonwater suppressed spectrum was acquired subsequently from the same volume, which enabled us to use the water signal as an internal reference $(N S A=8)$.

${ }^{1} \mathrm{H}$ MR spectra obtained, were analyzed and fitted in the time domain by using the non-linear least-squares AMARES algorithm in the jMRUI software package $[21,22]$ as described earlier [20]. IMCL is given as percentage of the $\mathrm{CH}_{2}$ peak compared to the water resonance, based upon assumptions published before [23, 24] and corrected for $\mathrm{T} 1$ and $\mathrm{T} 2$ relaxation time. 


\section{MUSCLE BIOPSIES AND ANALYSES}

Muscle biopsies were taken from the $\mathrm{m}$. vastus lateralis of both legs after 9 days of ULLS, under local anaesthesia (2\% lidocaine), according to the Bergstrom technique [25] and instantaneously processed for ex vivo 14C oxidation assays. The remainder of the muscle tissue was stored at $-80^{\circ} \mathrm{C}$ for later analysis of intramyocellular lipid content by histology and markers of insulin action.

${ }^{14} \mathrm{C}$ oxidation assays were performed as previously described [26, 27]. Briefly, palmitate oxidation was determined by measuring production of ${ }^{14} \mathrm{CO}_{2}$ and acidsoluble metabolites $\left({ }^{14} \mathrm{C}\right.$-ASMs) in skeletal muscle homogenates containing 250 $\mathrm{mmol} / \mathrm{L}$ sucrose, $10 \mathrm{mmol} / \mathrm{L}$ Tris- $\mathrm{HCl}, 1 \mathrm{mmol} / \mathrm{L}$ EDTA, and $2 \mathrm{mmol} / \mathrm{L}$ ATP in a modified 48-well trapping device. Reactions were initiated with a buffer containing $0.2 \mathrm{mmol} / \mathrm{L}$ palmitate, $1 \mu \mathrm{Ci} / \mathrm{ml}\left[1-{ }^{14} \mathrm{C}\right]$-palmitate, $125 \mathrm{mM}$ sucrose, $25 \mathrm{mM}$ potassium phosphate, $200 \mathrm{mM}$ potassium chloride, $2.5 \mathrm{mM}$ magnesium chloride, $2.5 \mathrm{mM}$ L-Carnitine, 0.25 mM malic acid, 20 mM Tris-HCl, 2.5 mM DTT, 0.25 mM NAD+, 4 mM ATP and 0.125 $\mathrm{mM}$ Coenzyme A. Reactions were terminated with $70 \%$ perchloric acid and $\mathrm{CO}_{2}$ was trapped in $1 \mathrm{~N} \mathrm{NaOH}$ in adjacent wells. ${ }^{14} \mathrm{C}$-ASMs were stored overnight at $4{ }^{\circ} \mathrm{C}$, spun down and supernatant was analysed for ASMs. To measure lipid incorporation into DAG and TAG lipids were extracted from the remaining pellet according to the Folch extraction [28]. Glucose oxidation to $\mathrm{CO}_{2}$ was determined by replacing 0.2 $\mathrm{mmol} / \mathrm{L}$ palmitate and $1 \mu \mathrm{Ci} / \mathrm{ml}\left[1-{ }^{14} \mathrm{C}\right]$-palmitate with $10 \mathrm{mmol} / \mathrm{L}$ glucose and $1 \mu \mathrm{Ci} /$ $\mathrm{ml}\left[\mathrm{U}-{ }^{14} \mathrm{C}\right]$-glucose respectively.

Intramyocellular lipid content was assessed in muscle cross-sections using a modified Oil-red-O staining for fluorescence microscopy [29]. Freezing artefacts in sections of 4 subjects prevented valid histological quantification of the intramyocellular lipid content and were hence excluded.

Insulin action. Muscle biopsies were prepared for analysis of the expression and phosphorylation of components of the insulin signalling pathway by Western blotting as described previously [8]. The blots were incubated with antibodies recognizing the insulin receptor beta-subunit and pyruvate dehydrogenase 4 (PDK4) (both from Santa Cruz Biotechnology, Santa Cruz, CA), phosphorylated insulin receptor substrate 1 (IRS1-Ser1101), Akt-Thr308, Akt-Ser473, glycogen synthase kinase 3beta (GSK3beta-Ser9), glycogen synthase (GS-Ser641), FOX01-Thr24/FOXO3aThr32, AMP-activated protein kinase (AMPK-Thr172), and acetyl CoA carboxylase (ACC-Ser79) (all from Cell Signaling Technology, Beverly, MA). Bound antibodies 
were detected by incubation with the appropriate secondary HRP-conjugated antibodies (Promega, Mannheim, Germany), and visualized by enhanced chemiluminescence on a VersaDoc 4000 MP (Bio-Rad) workstation. Signals were quantified using ImageLab software (version 4.0, Bio-Rad), and normalized for abundance of beta-actin, GAPDH and alpha-tubulin.

\section{BLOOD SAMPLE ANALYSES}

Blood samples were collected in EDTA-containing tubes and immediately spun at high speed, frozen in liquid nitrogen and stored at $-80^{\circ} \mathrm{C}$. Plasma free fatty acids, triglycerides, and glucose were measured with enzymatic assays automated on a ABX Pentra 400 (Horiba diagnostics, Montpellier, France). Glycerol was measured with a EnzytecTM glycerol kit, R-Biopharm, Germany.

\section{STATISTICS}

Data are presented as mean \pm SE. All statistics were performed using SPSS 16.0 for Mac and $\mathrm{P}<0.05$ was considered statistically significant. For most parameters, differences between the immobilized and the active leg were analyzed with a 2-tailed, paired Student's t-test. The non-normally distributed data on insulin action were tested for differences using a non-parametric Wilcoxon signed rank test for related-samples. Statistical significance was set a priori at $p<0.05$.

\section{RESULTS}

\section{COMPLIANCE}

Compliance to the immobilization was confirmed by accelerometery data and data on skin temperature; activity counts in the immobilized leg were lower in all subjects than in the active leg (48826 \pm 73524 counts/day vs. $65969 \pm 10101$ counts/day, respectively (see fig. 3a). In line with lower activity, also skin temperature was lower in the inactive leg than in the active leg (lower leg: $31.5 \pm 0.03^{\circ} \mathrm{C}$ vs. $33.0 \pm 0.02$ ${ }^{\circ} \mathrm{C}$; upper leg: $32.2 \pm 0.02{ }^{\circ} \mathrm{C}$ vs. $33.0 \pm 0.04{ }^{\circ} \mathrm{C}$ for the immobilized and active leg respectively, $\mathrm{p}<0.05$, see fig. $3 \mathrm{~b}$ ). 
active $\square$ immo

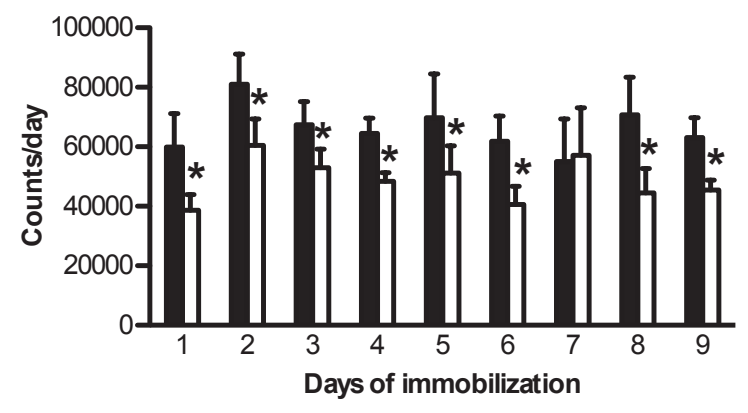

b

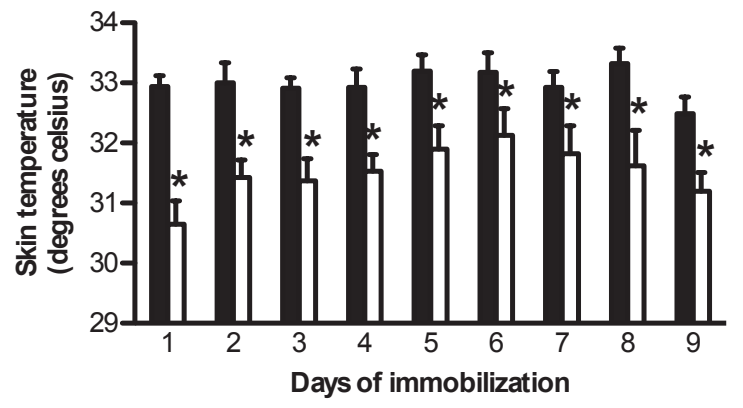

Figure 3 Subject's compliance to the intervention measured with activity monitors (accelerometers) and temperature sensors.

\section{MUSCLE VOLUME AND STRENGTH}

There was no difference in upper leg muscle volume $\left(2794 \pm 182 \mathrm{~cm}^{3}\right.$ in the immobilized leg vs. $2766 \pm 173 \mathrm{~cm}^{3}$ in the active leg, $(p=0.33)$ and maximal isometric strength of the knee extensors and flexors was $170 \pm 21 \mathrm{Nm}$ for the immobilized leg vs. $178 \pm 20 \mathrm{Nm}$ for the active leg, $(p=0.6)$ and $95 \pm 9 \mathrm{Nm}$ for the immobilized leg vs. $95 \pm 9 \mathrm{Nm}$ for the active leg, $(p=0.95)$, respectively.

\section{EFFECT OF IMMOBILIZATION ON MITOCHONDRIAL FUNCTION, OXIDATIVE CAPACITY AND INTRAMYOCELLULAR LIPID CONTENT}

In vivo mitochondrial function was lower in the immobilized leg, as revealed by a significant longer PCr-recovery half-time compared to the active leg after 12 days of immobilization (PCr-t1/2: $21.4 \pm 2.3 \mathrm{sec}$ vs. $16.7 \pm 1.8 \mathrm{sec}$ in immobilized and active leg respectively, $p=0.02$, fig. $4 a$ ). 
In skeletal muscle biopsies, palmitate oxidation to ${ }^{14} \mathrm{CO}_{2}$ ("complete oxidation") was significantly lower in the immobilized leg compared to the active leg after nine days of immobilization $(0.14 \pm 0.03 \mathrm{nmol} / 2 \mathrm{~h} / \mathrm{mg}$ vs. $0.18 \pm 0.03 \mathrm{nmol} / 2 \mathrm{~h} / \mathrm{mg}$ in the immobilized vs active leg resp, $p=0.013, n=9$, fig. 4b). Acid-soluble metabolites (ASMs; reflecting incomplete oxidation) tended to be lower in the immobilized leg compared with the active leg $(1.15 \pm 0.07 \mathrm{nmol} / 2 \mathrm{~h} / \mathrm{mg}$ vs. $1.29 \pm 0.10 \mathrm{nmol} / 2 \mathrm{~h} / \mathrm{mg}$ respectively, $p=0.065, n=9$, fig. $4 c$ ).

a

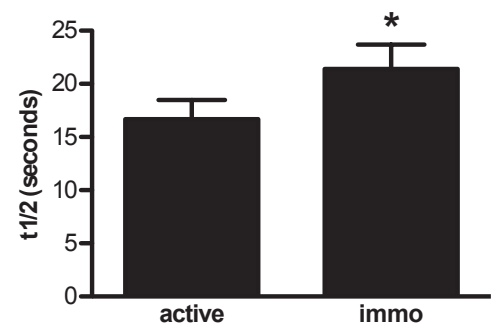

C

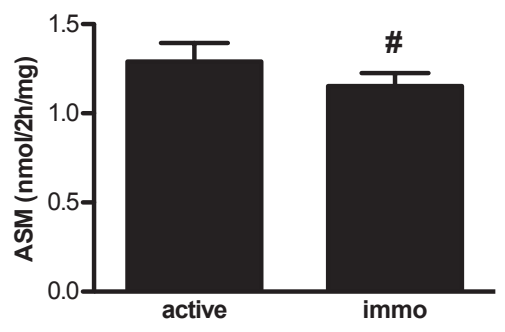

e

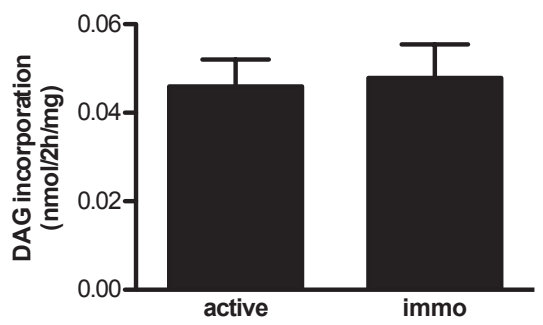

b

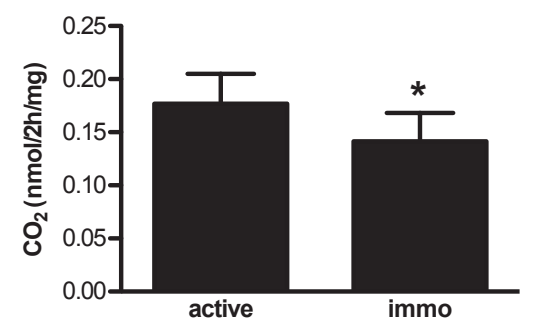

d

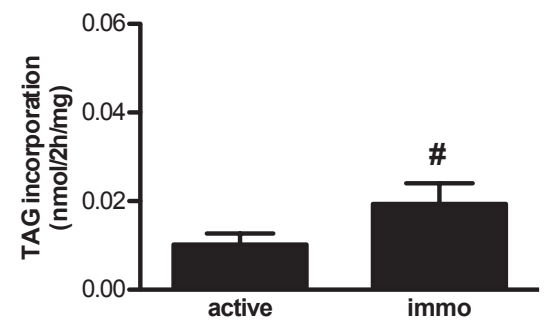

Figure 4 (a) In vivo mitochondrial function, expressed as phosphocreatine recovery half-time and Ex vivo ${ }^{14} \mathrm{C}$-palmitate metabolism $(\mathrm{n}=9)$; (b) ${ }^{14} \mathrm{C}$-palmitate oxidation to $\mathrm{CO}_{2}$, (c) ex vivo ${ }^{14} \mathrm{C}$-palmitate oxidation to ASMs, (d) ${ }^{14} \mathrm{C}$-palmitate incorporation into TAG, (e) ${ }^{14} \mathrm{C}$-palmitate incorporation into DAG, in the active vs. the immobilized leg post immobilization. ${ }^{*} \mathrm{P}<0.05$ compared with active leg, $\# \mathrm{P}<0.10$ compared with active leg. Data are means \pm SE. 
Incorporation of ${ }^{14} \mathrm{C}$-palmitate into triacylglycerol TAG tended to be higher in the immobilized leg compared to the active leg $(0.019 \pm 0.005 \mathrm{nmol} / 2 \mathrm{~h} / \mathrm{mg}$ vs. 0.010 $\pm 0.002 \mathrm{nmol} / 2 \mathrm{~h} / \mathrm{mg}$ in the immobilized vs active leg resp, $\mathrm{p}=0.075, \mathrm{n}=9$, fig. $4 \mathrm{~d}$ ) whereas ${ }^{14} \mathrm{C}$-palmitate incorporation into DAG was not different between the two legs $(0.048 \pm 0.008 \mathrm{nmol} / 2 \mathrm{~h} / \mathrm{mg}$ vs. $0.046 \pm 0.006 \mathrm{nmol} / 2 \mathrm{~h} / \mathrm{mg}$ in the immobilized vs the active leg respectively, $p=0.822$, fig. $4 e$ ), This indicates that inactivity makes the muscle prone to storage and retaining lipids in the TAG pool.

In contrast to the palmitate oxidation, there were no significant differences in complete glucose oxidation rates between the immobilized- and the active leg $(0.429 \pm 0.125 \mathrm{nmol} / 2 \mathrm{~h} / \mathrm{mg}$ in the immobilized leg vs. $0.567 \pm 0.167 \mathrm{nmol} / 2 \mathrm{~h} / \mathrm{mg}$ in the active leg, $p=0.461, n=9$ ).

In vivo IMCL in $\mathrm{m}$. tibialis anterior (measured with ${ }^{1} \mathrm{H}-\mathrm{MRS}$ ) was $23.4 \%$ higher in the immobilized leg compared with the active leg $(0.312 \pm 0.045 \%$ vs $0.239 \pm 0.041$, $\mathrm{p}=0.003, \mathrm{n}=8$, fig. $5 \mathrm{a}$ ). Ex vivo IMCL in $\mathrm{m}$. vastus lateralis (measured with Oil-red-O

a

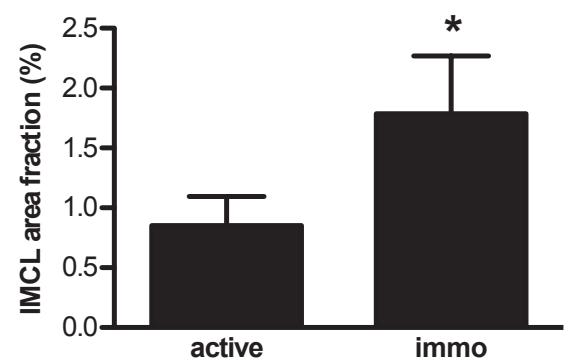

Figure $\mathbf{5}$ (a) Ex vivo IMCL in $\mathrm{m}$. tibialis anterior measured with Oilred-O staining $(\mathrm{n}=6)$ and $(\mathbf{b})$ in vivo IMCL in $\mathrm{m}$. vastus lateralis measured by ${ }^{1} \mathrm{H}-\mathrm{MRS}(\mathrm{n}=9)$ in the active vs. the immobilized leg post immobilization. ${ }^{*} \mathrm{P}<0.05$ compared with active leg. Data are means \pm SE.

b

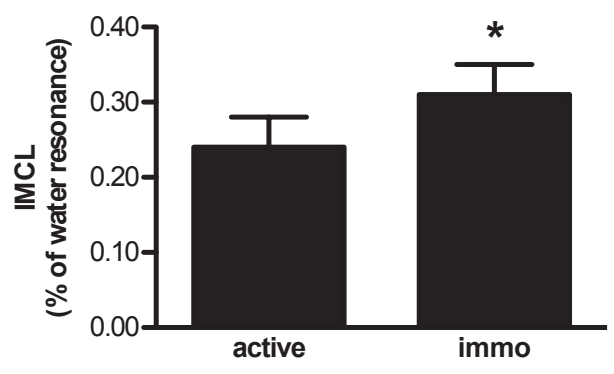


staining) was 52\% higher in the immobilized leg compared with the active leg (1.79 $\pm 0.48 \%$ lipid fraction vs $0.85 \pm 0.24 \%, p=0.021, n=6$, fig. $5 b)$.

Jointly, these data indicate that adherence to the unilateral limb suspension protocol was good. Importantly, ULLS resulted in compromised mitochondrial function, increased muscle fat content while muscle mass and strength were maintained. Thus, we created the required situation to examine the effect of compromised mitochondrial function on insulin action.

\section{PLASMA CONCENTRATIONS DURING LIPID AND INSULIN INFUSION}

During the entire 5-hour lipid infusion, plasma FFA concentrations increased compared with baseline. Plasma FFA concentrations increased from $492 \pm 95$ $\mu \mathrm{mol} / \mathrm{L}$ at baseline, to $1759 \pm 111 \mu \mathrm{mol} / \mathrm{L}$ one hour after start of lipid infusion and remained elevated over the 5 -hour lipid infusion period $(p<0.0001)$, fig. $6 a$.

a

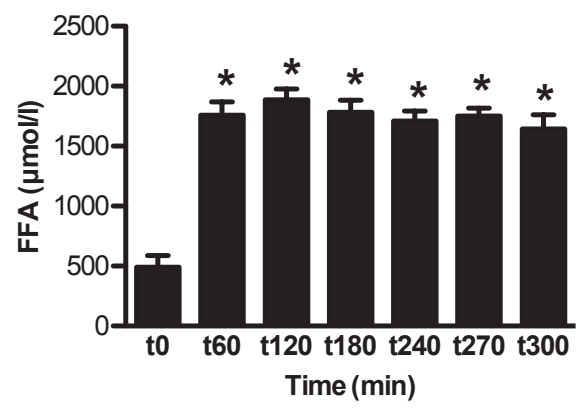

Figure 6 Plasma concentrations of (a) free fatty acids and (b) glucose during the lipid + insulin infusion. * $\mathrm{P}<0.05$ compared with baseline (t0). Data are means \pm SE.

b

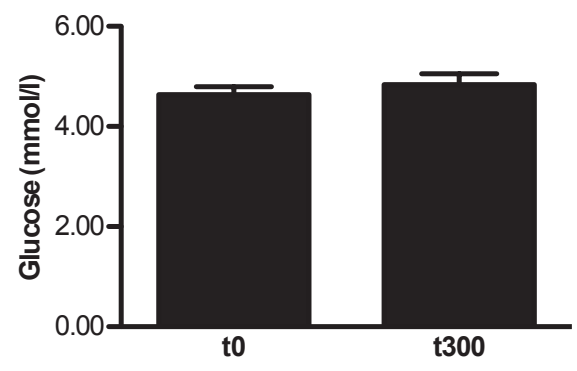


a

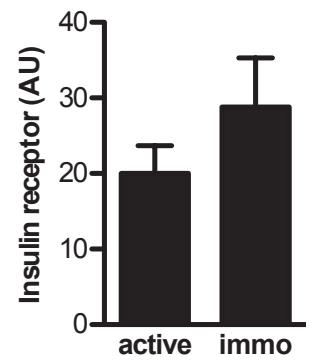

d

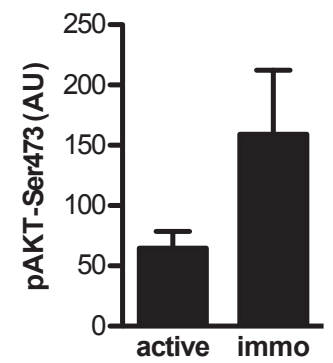

g

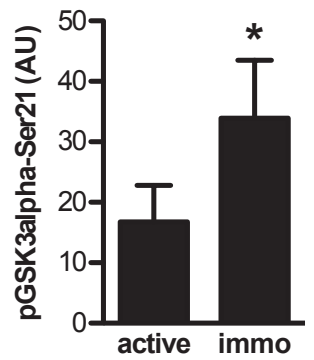

j

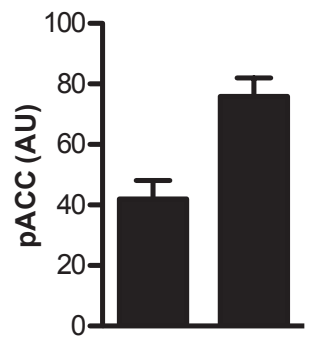

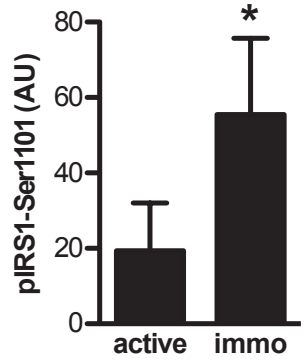

e

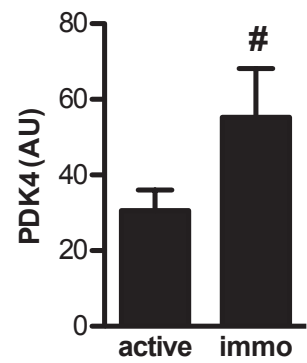

h
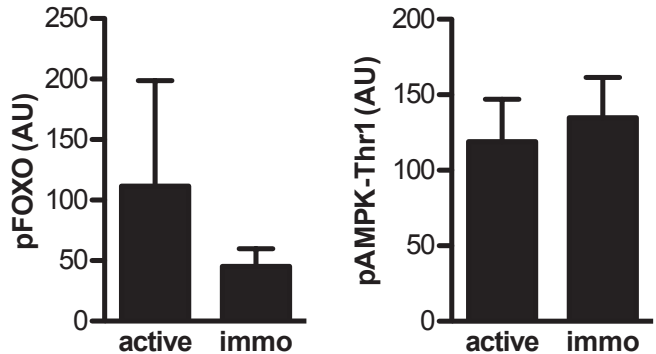

f

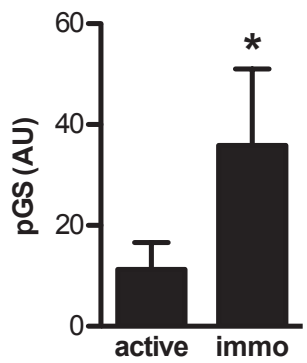

i

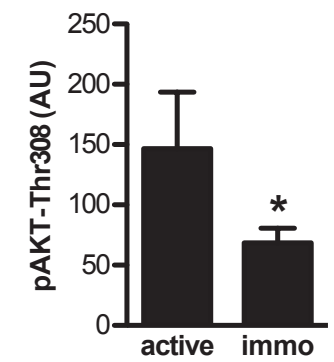

c 
As targeted, plasma glucose concentrations were stable and did not change significantly after lipid and insulin infusion $(4.6 \pm 0.2 \mu \mathrm{mol} / \mathrm{L}$ at baseline and $4.8 \pm$ $0.2 \mu \mathrm{mol} / \mathrm{L}$ after 5 hours of lipid infusion, $\mathrm{p}=0.46$, fig. $6 \mathrm{~b}$ ).

\section{INSULIN SIGNALING IN SKELETAL MUSCLE BIOPSIES UPON LIPID AND INSULIN INFUSION}

Insulin-induced activation of insulin signaling was determined in muscle biopsies of the immobilized vs. active leg upon a $5 \mathrm{~h}$ lipid infusion. As anticipated the expression level of insulin receptor between the immobilized and the active leg after lipid infusion was unaffected ( $p=0.161$, fig. $7 a)$. It has been shown that lipidinduced insulin resistance is accompanied by phosphorylation of IRS1 at Ser1101. Consistent with reduced insulin sensitivity in the immobilized leg, a significantly higher phosphorylation of IRS1 at Ser1101 was found in the immobilized leg compared with the active leg ( $p=0.018$, fig. $7 b)$. Ser1101 phosphorylation of IRS1 is expected to result in an inactivation of AKT via dephosphorylation at Thr308- and Ser473 residues; indeed phosphorylation of AKT (pAKT) at Thr308 was significantly reduced in the immobilized leg compared with in the inactive leg (fig. $7 c, p=0.036$ ). Remarkably, however, phosphorylation of AKT at Ser473 was not significantly different between legs but if anything was higher instead of lower in he inactive leg (fig. $7 d, p=0.263$ ).

Insulin resistance is also associated with disturbed glucose oxidation and glycogen storage in skeletal muscle. PDK4 is a key factor in regulating glucose oxidation, and elevated levels are associated with reduced glucose oxidation. Consistently, the expression of PDK4 tended to be higher in the immobilized leg upon lipid infusion compared with the active leg ( $p=0.058$, fig. 7e). Furthermore, a higher phosphorylation of GS ( $p G S$ ) in the immobilized leg compared with the active leg was observed ( $p=0.050$, fig. $7 f$ ); increased phosphorylation of glycogen synthase (GS) would result in a deactivation of the enzyme, consequently leading to blunted insulin-stimulated glycogen storage, thus reflecting increased insulin resistance, Remarkably, however, phosphorylation of GSK3beta at alpha-Ser21 (pGSK3beta), inhibiting GSK3beta activity, was significantly higher in the immobilized leg compared to the active leg upon lipid infusion ( $p=0.036$, fig. $7 \mathrm{~g}$ ). The downstream effect of enhanced phosphorylation of GSK3beta is normally a lower phosphorylation of GS, which is contradictory to what we observed in the present study. 
Finally, the phosphorylation of fork-head box class 01 ( $p F O X 01, p=0.889$, fig. $7 \mathrm{~h}$ ), AMPK (pAMPK) at Thr172 ( $p=0.208$, fig. 7i) and ACC (pACC) $(p=0.183$, fig. 7j) were not different across legs.

\section{DISCUSSION}

Physical inactivity has been considered as a major determinant of the current epidemic of chronic metabolic diseases such as obesity and T2DM [1, 2]. Physical inactivity is suggested to reduce skeletal muscle mitochondrial function, and thereby contribute to muscle fat accumulation and skeletal muscle insulin resistance [30, 31]. However, the direct relationship between these variables is difficult to examine in humans, since physical inactivity will have many systemic effects that may contribute to insulin resistance as well. In the current study, we investigated the effect of one-legged physical inactivity on mitochondrial function, lipid content and insulin sensitivity, leaving the contralateral leg as an active control. We observed that inactivity indeed leads to a lowering of in vivo mitochondrial function as well as a reduced fat oxidative capacity. In parallel, inactivity lead to a marked increase in skeletal muscle IMCL content. Most importantly, physical inactivity resulted in a blunted decline in insulin action upon lipid infusion. Together these data demonstrate the impact of physical inactivity on skeletal muscle insulin resistance and suggest that a reduced mitochondrial function may underlie this effect.

To investigate the local effects of physical inactivity independent of systemic effects we used a unique human model for inactivity; unilateral lower limb suspension (ULLS). During the ULLS period leg skin temperature and overall activity level was lower in the suspended leg compared with the active leg, showing good compliance to the intervention. With such an unloading model, muscle mass can be lost at a rate of $0.4 \%$ per day [32]. However, in the current study we observed no changes in leg muscle volume after ULLS, which indicates that no atrophy occurred in the thigh of neither the active nor the immobilize leg during ULLS. Furthermore, previous studies have shown that the greatest rate of unloading occurs during the first seven days of intervention and that one week of unloading leads to a loss of $70 \%$ of the isometric strength detected with two weeks of unloading [28]. Again, in the current study, we did not observe any difference in strength between the immobilized and active leg. The absence of an effect of ULLS on muscle volume and strength indicate that muscle mass was unaffected by the intervention. This is of importance in the 
present study as muscle mass is an important determinant of glucose disposal. Moreover, the lack of an effect on muscle volume and strength indicate that the level of physical inactivity in our model was relatively mild, especially when compared to previously used models like bed rest and hence most likely better mimics the real life situation in which a modest drop in physical activity may result in the development of chronic metabolic diseases in the long run.

Interestingly, despite the lack of reduction in muscle volume and strength, in vivo mitochondrial function and skeletal muscle fat oxidative capacity were both $\sim 20$ percentage lower in the immobilized leg than in the active leg. This result indicates that despite the relatively mild inactivity induced by ULLS, mitochondrial function and fat oxidative capacity are reduced to an extent that is also observed in type 2 diabetic patients, illustrating the importance of physical activity in maintaining skeletal muscle mitochondrial function. In addition to lower fat oxidation in the immobilized leg there was also a tendency to higher ${ }^{14} \mathrm{C}$-palmitate incorporation into TAG. In line with this, we observed that intramyocellular lipid content was higher in the immobilized leg than in the active leg after the intervention period. Several bed-rest studies have shown similar effects with reduction in fat oxidation favouring incorporation of dietary saturated FA (palmitate) into intramyocellular lipids [33]. Since intramyocellular triglycerides are considered to be relatively harmless when compared to the more toxic intermediates like diacylglycerol (DAG) and ceramides [34-38], such increased incorporation into TG may be a protective mechanism to prevent insulin resistance when mitochondrial function is reduced like for example by physical inactivity. Indeed, in the current study we do not see any difference in ${ }^{14} \mathrm{C}$-palmitate incorporation into DAG, suggesting that indeed the inactive muscle may try to efficiently store excessive fatty acids into inert TG. Unfortunately, we have not yet been able to determine the level of other lipid intermediates.

A high-fat diet and low physical activity often coexist in individuals at risk for obesity and insulin resistance. Although the immobilized leg showed an increased basal capacity to incorporate fatty acids into inert TG, we hypothesized that during a lipid challenge test, with high circulating FFA, the reduced mitochondrial function might even more so results in differences in insulin sensitivity. Indeed, we found significantly higher p-IRS1-Ser1101, lower pAKT-308 and pGS in the immobilized leg, all indicative of a more pronounced compromised insulin action in the immobilized leg than in the active leg. Phosphorylation of IRS1-Ser1101 inhibits AKT, leading to reduced cellular glucose uptake. Phosphorylation of GS inactivates GS and results 
in lower glycogen production, which is suggesting lower insulin sensitivity in the immobilized leg. Also an increase in PDK4 would be consistent with reduced insulin sensitivity in the inactive leg. Overall these data are supportive that the immobilized leg is more insulin resistant than the active leg when challenged by lipids, suggesting a protective effect of physical activity on lipid-induced insulin resistance. This finding is consistent with a previous study in which we showed that endurance trained athletes are (partly) protected against lipid-induced insulin resistance [8]. However, not all insulin-signalling data was consistent with decreased insulin sensitivity in the immobilized leg; thus, phosphorylation of AKT-SER473 was in fact not decreased, and if anything higher, in the inactive leg, as was the phosphorylation of GKS3beta. Phosphorylation of GSK3 normally activates GS by dephosphorylating it, but in the current study the effects are contradictory. An discordant phosphorylation of AKT at serine473 and tyrosine-308 was recently reported by Yung et al. [39], who showed that ER stress increases serine phosphorylation of AKT, while decreasing tyrosine phosphorylation, and that the ratio Ser/Thr phosphorylation of AKT was positively related to the severity of ER stress. In that context it is interesting to note that a previous study, in which whole-body bed rest was used to introduce physical inactivity, also revealed that ER stress might be involved in the inactivity-induced insulin resistance [40]. Further studies are needed to investigate if ER stress is indeed involved in the induction of insulin resistance in inactivity-induced insulin resistance.

In summary, inactivity compromises in vivo mitochondrial function along with reduced fat oxidative capacity. This reduction in fatty acid oxidation was accompanied by a higher incorporation of fatty acids into inert TAG, which translated into a higher content of IMCL and a blunted decline in insulin action upon lipid-induced insulin resistance. Together these data demonstrate the impact of physical inactivity on skeletal muscle insulin resistance and suggest that a reduced mitochondrial function may underlie this effect. 


\section{REFERENCES}

1. Short KR, Vittone JL, Bigelow ML, Proctor DN, Rizza RA, Coenen-Schimke JM, Nair KS. Impact of aerobic exercise training on age-related changes in insulin sensitivity and muscle oxidative capacity. Diabetes. 2003;52(8):188896.

2. Rimbert V, Boirie Y, Bedu M, Hocquette JF, Ritz P, Morio B. Muscle fat oxidative capacity is not impaired by age but by physical inactivity: association with insulin sensitivity. FASEB journal : official publication of the Federation of American Societies for Experimental Biology. 2004;18(6):7379.

3. McGarry JD. Banting lecture 2001: dysregulation of fatty acid metabolism in the etiology of type 2 diabetes. Diabetes. 2002;51(1):7-18.

4. Goodpaster BH, He J, Watkins S, Kelley DE. Skeletal muscle lipid content and insulin resistance: evidence for a paradox in endurance-trained athletes. J Clin Endocrinol Metab. 2001;86(12):5755-61.

5. Perseghin G, Scifo P, De Cobelli F, Pagliato E, Battezzati A, Arcelloni C, Vanzulli A, Testolin G, Pozza G, Del Maschio A, Luzi L. Intramyocellular triglyceride content is a determinant of in vivo insulin resistance in humans: a ${ }^{1} \mathrm{H}-13 \mathrm{C}$ nuclear magnetic resonance spectroscopy assessment in offspring of type 2 diabetic parents. Diabetes. 1999;48(8):1600-6.

6. Jacob S, Machann J, Rett K, Brechtel K, Volk A, Renn W, Maerker E, Matthaei S, Schick F, Claussen CD, Haring HU. Association of increased intramyocellular lipid content with insulin resistance in lean nondiabetic offspring of type 2 diabetic subjects. Diabetes. 1999;48(5):1113-9.

7. Schrauwen-Hinderling VB, Hesselink MK, Schrauwen P, Kooi ME. Intramyocellular lipid content in human skeletal muscle. Obesity (Silver Spring, Md. 2006;14(3):357-67.

8. Phielix E, Meex R, Ouwens DM, Sparks L, Hoeks J, Schaart G, MoonenKornips E, Hesselink MK, Schrauwen P. High oxidative capacity due to chronic exercise training attenuates lipid-induced insulin resistance. Diabetes. 2012;61(10):2472-8.

9. Berg HE, Dudley GA, Haggmark T, Ohlsen H, Tesch PA. Effects of lower limb unloading on skeletal muscle mass and function in humans. J Appl Physiol. 1991;70(4):1882-5.

10. Dudley GA, Duvoisin MR, Adams GR, Meyer RA, Belew AH, Buchanan P. Adaptations to unilateral lower limb suspension in humans. Aviation, space, and environmental medicine. 1992;63(8):678-83.

11. Abadi A, Glover El, Isfort RJ, Raha S, Safdar A, Yasuda N, Kaczor JJ, Melov S, Hubbard A, Qu X, Phillips SM, Tarnopolsky M. Limb immobilization induces a coordinate down-regulation of mitochondrial and other metabolic pathways in men and women. PloS one. 2009;4(8):e6518. 
12. Blakemore SJ, Rickhuss PK, Watt PW, Rennie MJ, Hundal HS. Effects of limb immobilization on cytochrome c oxidase activity and GLUT4 and GLUT5 protein expression in human skeletal muscle. Clin Sci (Lond). 1996;91(5):591-9.

13. Bleeker MW, De Groot PC, Poelkens F, Rongen GA, Smits P, Hopman MT. Vascular adaptation to $4 \mathrm{wk}$ of deconditioning by unilateral lower limb suspension. American journal of physiology. 2005;288(4):H1747-55.

14. Kuipers H, Verstappen FT, Keizer HA, Geurten P, van Kranenburg G. Variability of aerobic performance in the laboratory and its physiologic correlates. International journal of sports medicine. 1985;6(4):197-201.

15. Annegarn J, Spruit MA, Uszko-Lencer NH, Vanbelle S, Savelberg HH, Schols AM, Wouters EF, Meijer K. Objective physical activity assessment in patients with chronic organ failure: a validation study of a new singleunit activity monitor. Archives of physical medicine and rehabilitation. 2011;92(11):1852-7 e1.

16. Preece SJ, Goulermas JY, Kenney LP, Howard D, Meijer K, Crompton R. Activity identification using body-mounted sensors--a review of classification techniques. Physiological measurement. 2009;30(4):R1-33.

17. van Marken Lichtenbelt WD, Daanen HA, Wouters L, Fronczek R, Raymann RJ, Severens NM, Van Someren EJ. Evaluation of wireless determination of skin temperature using iButtons. Physiology \& behavior. 2006;88(4-5):48997.

18. Savelberg $\mathrm{HH}$, Meijer $\mathrm{K}$. The effect of age and joint angle on the proportionality of extensor and flexor strength at the knee joint. The journals of gerontology. 2004;59(11):1120-8.

19. Schrauwen-Hinderling VB, Kooi ME, Hesselink MK, Jeneson JA, Backes $\mathrm{WH}$, van Echteld CJ, van Engelshoven JM, Mensink M, Schrauwen P. Impaired in vivo mitochondrial function but similar intramyocellular lipid content in patients with type 2 diabetes mellitus and BMI-matched control subjects. Diabetologia. 2007;50(1):113-20.

20. Lindeboom L, Nabuurs C, Hesselink M, Wildeberger J, Schrauwen P, Schrauwen-Hinderling V. Proton magnetic resonance spectroscopy reveals increased hepatic lipid content after a single high-fat meal with no additional modulation by added protein. Am J Clin Nutr. 2015:

21. Vanhamme L, van den Boogaart A, Van Huffel S. Improved method for accurate and efficient quantification of MRS data with use of prior knowledge. Journal of magnetic resonance. 1997;129(1):35-43.

22. Krssak M, Mlynarik V, Meyerspeer M, Moser E, Roden M. ${ }^{1} \mathrm{H}$ NMR relaxation times of skeletal muscle metabolites at 3 T. Magma. 2004;16(4):155-9.

23. Szczepaniak LS, Babcock EE, Schick F, Dobbins RL, Garg A, Burns DK, McGarry JD, Stein DT. Measurement of intracellular triglyceride stores by 
$\mathrm{H}$ spectroscopy: validation in vivo. The American journal of physiology. 1999;276(5 Pt 1):E977-89.

24. Boesch C, Machann J, Vermathen P, Schick F. Role of proton MR for the study of muscle lipid metabolism. NMR in biomedicine. 2006;19(7):968-88.

25. Bergstrom J, Hermansen L, Hultman E, Saltin B. Diet, muscle glycogen and physical performance. Acta Physiol Scand. 1967;71:140-50.

26. Kim JY, Koves TR, Yu GS, Gulick T, Cortright RN, Dohm GL, Muoio DM. Evidence of a malonyl-CoA-insensitive carnitine palmitoyltransferase I activity in red skeletal muscle. American journal of physiology Endocrinology and metabolism. 2002;282(5):E1014-22.

27. Sparks LM, Johannsen NM, Church TS, Earnest CP, Moonen-Kornips E, Moro C, Hesselink MK, Smith SR, Schrauwen P. Nine months of combined training improves ex vivo skeletal muscle metabolism in individuals with type 2 diabetes. The Journal of clinical endocrinology and metabolism. 2013;98(4):1694-702.

28. Koopman R, Schaart G, Hesselink MK. Optimisation of oil red O staining permits combination with immunofluorescenceand automated quantification of lipids. Histochemistry and cell biology. 2001;116(1):63-8.

29. Kelley DE, He J, Menshikova EV, Ritov VB. Dysfunction of mitochondria in human skeletal muscle in type 2 diabetes. Diabetes. 2002;51(10):2944-50.

30. Lowell BB, Shulman Gl. Mitochondrial dysfunction and type 2 diabetes. Science. 2005;307(5708):384-7.

31. de Boer MD, Maganaris CN, Seynnes OR, Rennie MJ, Narici MV. Time course of muscular, neural and tendinous adaptations to 23 day unilateral lower-limb suspension in young men. The Journal of physiology. 2007;583(Pt 3):1079-91.

32. Deschenes MR, Holdren AN, McCoy RW. Adaptations to short-term muscle unloading in young and aged men. Medicine and science in sports and exercise. 2008;40(5):856-63.

33. Bergouignan A, Trudel G, Simon C, Chopard A, Schoeller DA, Momken I, Votruba SB, Desage M, Burdge GC, Gauquelin-Koch G, Normand S, Blanc S. Physical inactivity differentially alters dietary oleate and palmitate trafficking. Diabetes. 2009;58(2):367-76.

34. Adams JM, 2nd, Pratipanawatr T, Berria R, Wang E, DeFronzo RA, Sullards $\mathrm{MC}$, Mandarino LJ. Ceramide content is increased in skeletal muscle from obese insulin-resistant humans. Diabetes. 2004;53(1):25-31.

35. Samuel VT, Petersen KF, Shulman Gl. Lipid-induced insulin resistance: unravelling the mechanism. Lancet. 2010;375(9733):2267-77.

36. Itani SI, Ruderman NB, Schmieder F, Boden G. Lipid-induced insulin resistance in human muscle is associated with changes in diacylglycerol, protein kinase C, and IkappaB-alpha. Diabetes. 2002;51(7):2005-11.

37. Timmers S, de Vogel-van den Bosch J, Hesselink MK, van Beurden D, 
Schaart G, Ferraz MJ, Losen M, Martinez-Martinez P, De Baets MH, Aerts JM, Schrauwen P. Paradoxical increase in TAG and DAG content parallel the insulin sensitizing effect of unilateral DGAT1 overexpression in rat skeletal muscle. PloS one. 2011;6(1):e14503.

38. Liu L, Shi X, Choi CS, Shulman GI, Klaus K, Nair KS, Schwartz GJ, Zhang Y, Goldberg IJ, Yu YH. Paradoxical coupling of triglyceride synthesis and fatty acid oxidation in skeletal muscle overexpressing DGAT1. Diabetes. 2009;58(11):2516-24.

39. Yung HW, Charnock-Jones DS, Burton GJ. Regulation of AKT phosphorylation at Ser473 and Thr308 by endoplasmic reticulum stress modulates substrate specificity in a severity dependent manner. PloS one. 2011;6(3):e17894.

40. Alibegovic AC, Sonne MP, Hojbjerre L, Bork-Jensen J, Jacobsen S, Nilsson E, Faerch K, Hiscock N, Mortensen B, Friedrichsen M, Stallknecht B, Dela F, Vaag A. Insulin resistance induced by physical inactivity is associated with multiple transcriptional changes in skeletal muscle in young men. American journal of physiology Endocrinology and metabolism. 2010;299(5):E75263. 
L.Bilet, V.B. Schrauwen-Hinderling, N.A. van Herpen, R.C. Meex, E. Phielix, J.A. Bakker, P. Schrauwen, M.K,C. Hesselink

Submitted 


\section{CHAPTER}

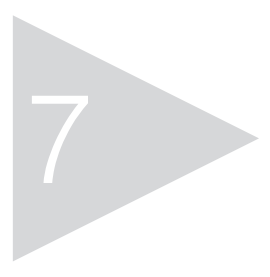

The novel biomarker for insulin resistance alpha-hydroxybutyrate is not responsive to lifestyle changes affecting liver fat or insulin sensitivity 


\section{ABSTRACT}

Recently, alpha-hydroxybutyrate has been positioned as a novel biomarker for progressive insulin resistance and glucose intolerance. However, its responsiveness to changes in insulin sensitivity is currently unknown. We measured alpha-hydroxybutyrate in groups with progressive insulin resistance (ranging from insulin sensitive lean subjects to patients with overt type 2 diabetes (T2D)) and examined the correlation with peripheral and hepatic insulin resistance. To examine if alpha-hydroxybutyrate could be a useful marker to detect early changes in insulin sensitivity, we measured alpha-hydroxybutyrate levels before and after lifestyle interventions modulating liver fat or insulin sensitivity. As anticipated, alphahydroxybutyrate levels progressively increased in groups with increased insulin resistance (lean $4.7 \pm 0.3 \mu \mathrm{g} / \mathrm{ml}$, obese $6.0 \pm 1.5 \mu \mathrm{g} / \mathrm{ml}$, T2D $8.5 \pm 0.4 \mu \mathrm{g} / \mathrm{ml}$ ). Furthermore, alpha-hydroxybutyrate correlated negatively with basal- $\left(R^{2}=0.146\right.$, $\mathrm{p}=0.002)$ and insulin-stimulated $\left(R^{2}=0.235, p=<0.0001\right)$ whole body glucose disposal (WGD) and, although weakly, positively with basal endogenous glucose production (EGP) $\left(R^{2}=0.091, p=0.04\right)$. However, alpha-hydroxybutyrate did not respond to a 3-week high fat diet in obese subjects $(5.2 \pm 0.3 \mu \mathrm{g} / \mathrm{ml}$ vs. $5.8 \pm 0.4$ $\mu \mathrm{g} / \mathrm{ml}, \mathrm{p}=0.13$ ) and was unaffected by a 12-weeks exercise training intervention in insulin resistant obese subjects $(6.5 \pm 0.35$ vs. $6.3 \pm 0.38 \mu \mathrm{g} / \mathrm{ml}, p=0.551)$. Stepwise linear regression analysis showed that although alpha-hydroxybutyrate is a significant predictor for basal- and insulin-stimulated WGD and delta EPG, alphahydroxybutyrate was not a very powerful predictor (beta of- 0.294 for basal WGD, -0.275 for insulin stimulated WGD and -0.279 for delta WGD) compared with other predictors. alpha-hydroxybutyrate is a marker of insulin resistance, even in subjects with normoglycemia. However, alleviation of insulin resistance by exercise training does not necessitate a decline in alpha-hydroxybutyrate and we observed little added value of using alpha-hydroxybutyrate as a predictive marker for insulin resistance relative to conventional markers like fasting insulin and glucose levels. 


\section{INTRODUCTION}

Clinically overt type 2 diabetes is preceded by a prolonged period of insulin resistance during which glucose homeostasis starts to derail. Impaired glucose tolerance and fasting glycaemia and modest hyperinsulinaemia are a reflection of attenuated peripheral insulin sensitivity and could be considered predictive for the development of type 2 diabetes. Overt type 2 diabetes is diagnosed by increased fasting glucose levels, while disturbed glycaemic control is classically monitored by the percentage of glycosylated haemoglobin ( $\mathrm{HbA1c})$. These well-established markers have proven diagnostic value; however, they only poorly reflect changes in glycaemic control upon lifestyle or drug interventions. Therefore, there is need for identification of novel biomarkers, which not only indicate a state of insulin resistance and identifies subjects at risk of developing full-blown type 2 diabetes, but ideally also are responsive to interventions modulating (risk factors for) insulin resistance. Recently, alpha-hydroxybutyrate has been positioned as a novel biomarker of insulin resistance and glucose intolerance [1]. alpha-hydroxybutyrate is an organic acid derived from alpha-ketobutyrate, which in turn is produced by amino acid catabolism (from threonine and methionine) or glutathione anabolism (via cysteine formation). Alpha-hydroxybutyrate is progressively higher across quartiles of insulin resistance and in individuals with impaired glucose tolerance or type 2 diabetes [2]. Moreover, it has been shown that glucose tolerance in those with the higher levels of alpha-hydroxybutyrate deteriorates over a 3-year follow-up period, whereas in subjects with low alpha-hydroxybutyrate levels glucose tolerance remained stable [2].

To examine if alpha-hydroxybutyrate is an early marker of insulin resistance, we studied alpha-hydroxybutyrate levels in normoglycemic lean subjects, in normoglycemic obese subjects and in obese patients with type 2 diabetes of similar age and BMI compared with normoglycemic obese subjects. Moreover, we examined if alpha-hydroxybutyrate correlates with recognised markers of insulin sensitivity over a wide range of insulin resistance in normoglycemic subjects.

Increased liver fat content associates with insulin resistance [3,4] and it has been suggested that elevated liver fat contributes to elevations in the liver metabolite alphahydroxybutyrate. We hence also examined the response of alpha-hydroxybutyrate in an experimental setting designed to augment liver fat content by consumption of a high-fat diet. Finally, we examined if alpha-hydroxybutyrate is a useful and early 
marker for improved insulin sensitivity by examining its response to 12-week insulin sensitizing training intervention.

Here we show that alpha-hydroxybutyrate increases progressively in groups with decreased insulin sensitivity. Even in normoglycemic subjects, insulin sensitivity measured under hyperinsulinemic euglycemic clamp conditions scaled negatively with plasma levels of alpha-hydroxybutyrate, indicating that indeed alphahydroxybutyrate could be used as an early marker for insulin resistance. Alphahydroxybutyrate was not increased upon a high-fat diet-mediated increase in liver fat content neither did alpha-hydroxybutyrate drop when insulin sensitivity improved after a 12-week exercise training intervention. Hence, alpha-hydroxybutyrate appears not to be a useful marker to monitor changes in insulin sensitivity.

\section{MATERIALS AND METHODS}

\section{SUBJECTS}

In the present study we used samples obtained from a variety of studies in well phenotyped subjects who all underwent a hyperinsulinemic-euglycemic clamp to measure insulin sensitivity [5-8]. The subjects were grouped in a group lean, young normoglycemic subjects (BMI $21.9 \pm 1.8 \mathrm{~kg} / \mathrm{m}^{2}$; age $22.6 \pm 2.8$ years; fasting glucose $5.1 \pm 0.3 \mathrm{mmol} / \mathrm{l})$, a group obese, middle aged normoglycemic subjects (BMI $29.6 \pm 3.1 \mathrm{~kg} / \mathrm{m}^{2}$; age $58.3 \pm 5.3$ years; fasting glucose $5.8 \pm 0.5 \mathrm{mmol} / \mathrm{l}$ ) and a group obese, middle-aged patients with type 2 diabetes (BMI $30.0 \pm 3.5 \mathrm{~kg} / \mathrm{m}^{2}$; $59.4 \pm 4.6$ years; fasting glucose $9.0 \pm 1.7 \mathrm{mmol} / \mathrm{l})$. These groups will be referred to as Lean (L), Obese (Ob) and type 2 diabetes patients (T2D). A 2-hour oral glucose tolerance test was performed in obese normoglycemic subjects according to the WHO criteria to dissect between obese insulin resistant subjects and patients with type 2 diabetes. Patients with type 2 diabetes had well-controlled type 2 diabetes and were on oral medication (metformin or metformin and sulfonylureas, none of the type 2 diabetes patients were on insulin). Blood glucose lowering medication was withdrawn 3-5 days prior to the clamp. Subject data are presented in Table 1. Fat free mass was obtained via hydrostatic weighing [9], $\mathrm{VO}_{2}$ max was measured using open circuit spirometry during a graded exercise test on a stationary bike until exhaustion [10]. Subjects reported to the lab on the day of the hyperinsulinemic euglycemic clamp after an over-night fast and a fasting blood sample was drawn 
from an indwelling catheter in an antecubital vein. The institutional medical ethical committee of Maastricht University Medical Center+ approved the studies and written informed consent was obtained from all participants.

Table 1 Subjects' characteristics

\begin{tabular}{|c|c|c|c|}
\hline Mean $\pm S D$ & $L(n=10)$ & Ob $(n=48)$ & T2D (n=18) \\
\hline Age, yr & $22.6 \pm 2.8$ & $58.3 \pm 5.3^{*}$ & $59.4 \pm 4.6^{*}$ \\
\hline $\mathrm{BMI}, \mathrm{kg} / \mathrm{m}^{2}$ & $21.9 \pm 1.8$ & $29.6 \pm 3.1^{*}$ & $30.0 \pm 3.5^{*}$ \\
\hline $\mathrm{FM}, \mathrm{kg}$ & $11.5 \pm 5.1$ & $30.1 \pm 6.1^{*}$ & $31.1 \pm 5.8^{*}$ \\
\hline FFM, kg & $60.1 \pm 6.8$ & $65.2 \pm 7.5^{*}$ & $64.3 \pm 6.9^{\delta}$ \\
\hline $\mathrm{VO}_{2} \max / \mathrm{kg}, \mathrm{ml} \times \mathrm{min}^{-1} \times \mathrm{kg}^{-1}$ & $51.4 \pm 10.3$ & $31.1 \pm 6.0^{*}$ & $27.5 \pm 5.2^{\text {*\# }}$ \\
\hline Alpha-hydroksybutyrate, $\mu \mathrm{l} / \mathrm{ml}$ & $4.7 \pm 1.4$ & $6.0 \pm 1.5^{\star}$ & $8.5 \pm 1.7^{\text {*\# }}$ \\
\hline FFA, $\mu \mathrm{mol} / \mathrm{I}$ & $407 \pm 86$ & $427 \pm 140$ & $519 \pm 107^{\star \#}$ \\
\hline Glucose, mmol/l & $5.1 \pm 0.3$ & $5.8 \pm 0.5^{*}$ & $9.0 \pm 1.7^{\text {*\# }}$ \\
\hline Insulin, mmol// & $10.0 \pm 3.7$ & $16.1 \pm 7.2^{*}$ & $14.6 \pm 3.2^{*}$ \\
\hline $\mathrm{HbA} 1 \mathrm{c}^{\Phi}$ & - & $5.8 \pm 0.3$ & $7.2 \pm 0.8^{\#}$ \\
\hline
\end{tabular}

Data are means \pm SD. L, Lean; Ob, Obese; T2D, type 2 diabetics; BMI, Body Mass Index; SBP, Systolic Blood Pressure; $D B P$, Diastolic Blood Pressure. * $\mathrm{P}<0.05$ compared with lean, ${ }^{\#} \mathrm{P}<0.05$ compared with obese. ${ }^{\delta} \mathrm{P}<0.10$ compared with lean. ${ }^{\Phi} \mathrm{HbA} 1 \mathrm{c}$ was not measured in the lean group and only in $\mathrm{n}=18$ in the obese group.

\section{HIGH-FAT DIET INTERVENTION}

Of the obese group, 10 overweight men were subjected to a dietary intervention. All subjects followed a 3-week low fat run-in diet matched to their daily life energy expenditure (15\% energy (En\%) as protein, 65 En\% as carbohydrates, 20 En\% as fat). After this run-in diet basal measurements of plasma parameters and insulin sensitivity (hyperinsulinemic euglycemic clamp) and liver fat content ( ${ }^{1} \mathrm{H}-\mathrm{NMR}$ spectroscopy) were performed. Subsequently, subjects switched towards an isocaloric high-fat diet (15 En\% protein, $30 \mathrm{En \%}$ carbohydrates, $55 \mathrm{En} \%$ fat) for another three weeks, followed again by measurements of intrahepatic liver fat content and insulin sensitivity [6].

\section{EXERCISE TRAINING PROTOCOL}

All patients with type 2 diabetes ( $n=18)$ and $20 \mathrm{BMl}$ and age matched normoglycemic controls, none of whom had participated in the dietary intervention study, were 
subjected to a tightly controlled progressive exercise training program for 12 weeks. The training program comprised a combination of aerobic and resistance exercise. Aerobic exercise was carried out on a cycling ergometer twice a week for 30 minutes at 55\% of a previously determined maximal workload. Resistance exercise was performed once a week and comprised one series of 8 repetitions at $55 \%$ of their previously determined maximal voluntary contraction and two series of 8 repetitions at $75 \%$ MVC, focussing on large muscle groups. Basal subject characteristics and plasma parameters were assessed after an overnight fast at the day of the hyperinsulinemic euglycemic clamp. Insulin sensitivity was measured by a hyperinsulinemic euglycemic clamp before and after the training period within 48-72 hours after the final exercise session [5].

\section{HYPERINSULINEMIC EUGLYCEMIC CLAMP}

In all subjects a 3-h hyperinsulinemic euglycemic (40 $\mathrm{mU} / \mathrm{m}^{2} / \mathrm{min}$ ) clamp was performed according to De Fronzo [11]. After an overnight fast, subjects were primed with an infusion of $\left[6,6-{ }^{2} \mathrm{H}_{2}\right]$ glucose $(0.04 \mathrm{mg} / \mathrm{kg} / \mathrm{min})$ to determine rates of glucose appearance (Ra, or endogenous glucose production, EGP) and disposal (Rd, or whole body glucose disposal, WGD) [12]. Steele's single-pool non-steady state equations were used to calculate glucose, endogenous glucose production (EGP) and whole body glucose disposal (WGD) [13]. Volume of distribution was assumed to be $0.160 \mathrm{l} / \mathrm{kg}$ for glucose. Basal and insulin-stimulated measurements were performed (see table 2 for clamp data).

Table 2 Hyperinsulinemic-euglycemic clamp

\begin{tabular}{|c|c|c|c|}
\hline Mean \pm SE & $L(n=10)$ & $\mathrm{Ob}(\mathrm{n}=48)$ & T2D $(n=18)$ \\
\hline \multicolumn{4}{|l|}{$\mathrm{EGP}(\mu \mathrm{mol} / \mathrm{kg} / \mathrm{min})$} \\
\hline Basal & $15.3 \pm 2.8$ & $9.6 \pm 2.3^{*}$ & $10.3 \pm 2.6^{*}$ \\
\hline Insulin stimulated & $-0.7 \pm 3.0$ & $1.6 \pm 3.2^{*}$ & $2.9 \pm 2.1^{*}$ \\
\hline \multicolumn{4}{|l|}{ WGP $(\mu \mathrm{mol} / \mathrm{kg} / \mathrm{min})$} \\
\hline Basal & $15.6 \pm 2.8$ & $9.8 \pm 2.9^{*}$ & $11.6 \pm 2.7^{\star \#}$ \\
\hline Insulin stimulated & $55.9 \pm 9.0$ & $27.5 \pm 9.1^{*}$ & $18.4 \pm 5.3^{\star \#}$ \\
\hline
\end{tabular}

Data are means \pm SE. L, Lean; Ob, Obese; T2D, type 2 diabetics. ${ }^{*} \mathrm{P}<0.05$ compared with $\mathrm{L}$ and ${ }^{\#} \mathrm{P}<$ 0.05 compared with $\mathrm{Ob}$. 


\section{BLOOD SAMPLE ANALYSES}

Blood samples were collected in EDTA-containing tubes and immediately spun at high speed and frozen in liquid nitrogen and subsequently stored at $-80^{\circ} \mathrm{C}$ until assayed. Plasma fatty acids and glucose were measured with enzymatic assays automated on a CobasFara/Mira (FA: Wako Nefa C test kit; Wako Chemicals, Neuss, Germany) (glucose: hexokinase method; Roche, Basel, Switzerland) (triglycerides: ABX Pentra CP reagens, Horiba ABX Diagnostics, Montpellier, France) (glycerol: EnzytecTM glycerol kit, R-Biopharm, Germany). Alpha-hydroxybutyrate was measured by liquid chromatography electrospray ionization tandem mass spectrometry. Briefly 30ul sample was mixed with $30 \mu \mathrm{l}$ d3-2-hydroxy-butyric acid and extracted with $600 \mu \mathrm{l}$ 0.5\%-TFA/ethylacetate. The supernatant was evaporated to dryness and the residue dissolved in 0.05\% formic acid. 2-HBA was separated using a $0.05 \%$ formic acid - 50\% acetonitrile gradient. 2-HBA was quantified using negative electrospray ionization, MRM transition m/z $103 \rightarrow 57$ for 2-HBA and m/z $106 \rightarrow 59$ for d3-2-HBA respectively. Reference values: 8 - $80 \mu \mathrm{mol} / \mathrm{l}$.

\section{STATISTICS}

Data are presented as mean \pm SE. Statistical analyses were performed using SPSS version 16.0.2 for Mac OS X (SPSS Inc., NC, USA). Differences between groups were analysed by one-way ANOVA. Since all variables were normally distributed, correlations were performed in a pair-wise fashion using the Pearson product moment statistics. To investigate the relationship among alpha-hydroxybutyrate and insulin sensitivity with other related parameters, we performed stepwise linear regression analyses. Dependent variables were selected based on simple regression analyses and biological importance in the linear regression analysis. Statistical significance was set a priori at $\mathrm{p}<0.05$.

\section{RESULTS}

\section{GROUP COMPARISONS}

Comparing type 2 diabetic patients with BMI- and age-matched normoglycemic controls revealed that alpha-hydroxybutyrate levels progressively increased in groups with increased insulin resistance (see figure 1). The lowest alpha- 
hydroxybutyrate levels were observed in $L(4.7 \pm 0.3 \mu \mathrm{g} / \mathrm{ml})$, with intermediate levels in $\mathrm{Ob} 6.0 \pm 1.5 \mu \mathrm{g} / \mathrm{ml}$ and highest levels in T2D $(8.5 \pm 0.4 \mu \mathrm{g} / \mathrm{ml})$. All differences between groups were statistically significant (see figure 1).

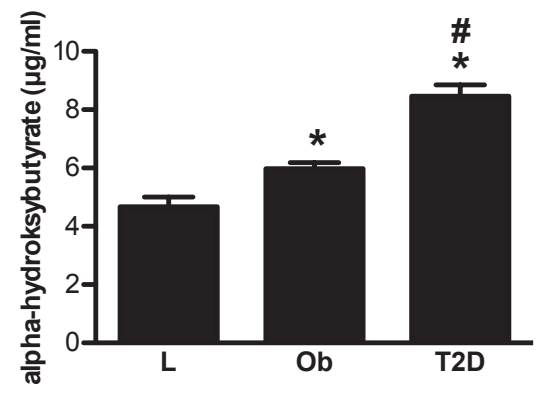

Figure 1 Plasma alpha-hydroxybutyrate in lean $(\mathrm{L})$, Obese $(\mathrm{Ob})$ and type 2 diabetic patients (T2D). ${ }^{*} \mathrm{P}<0.05$ compared with lean. ${ }^{\#} P<0.05$ compared with obese. Data are means \pm SE.

As alpha-hydroxybutyrate is considered an early biomarker for insulin resistance, we performed simple bivariate correlation analysis between alpha-hydroxybutyrate and markers of peripheral insulin sensitivity in normoglycemic (not type 2 diabetic) subjects under basal non-insulin stimulated conditions (basal whole body glucose disposal, basalWGD) as well as under insulin stimulated conditions (insulin stimulated WGD). Moreover, we examined if a correlation exists between alpha-hydroxybutyrate and insulin mediated suppression of endogenous glucose production (EGP), a reflection of liver insulin sensitivity. In line with previous observations, we observed a negative correlation between alpha-hydroxybutyrate levels and both basal (see figure $2 a, R^{2}=0.146, p=0.002$ ) as well as insulin stimulated (see figure $2 b R^{2}=0.235$, $\mathrm{p}<0.0001$ ) whole body glucose disposal. Interestingly, we also observed a weak, but significant positive correlation between alpha-hydroxybutyrate levels and hepatic insulin resistance (as measured as insulin mediated suppression of EGP, hence a small negative delta indicates hepatic insulin resistance, see figure 2c, EGP $\left.R^{2}=0.091, p=0.04\right)$. These correlations indeed suggest that alpha-hydroxybutyrate is a marker of peripheral as well as hepatic insulin resistance.

\section{HEPATIC FAT CONTENT AND ALPHA-HYDROXYBUTYRATE}

As alpha-hydroxybutyrate correlates with hepatic insulin resistance and hepatic fat content is an early marker of peripheral insulin resistance we hypothesised that augmenting hepatic fat content would go along with increases in plasma alphahydroxybutyrate. As previously reported, hepatic fat content increased significantly 


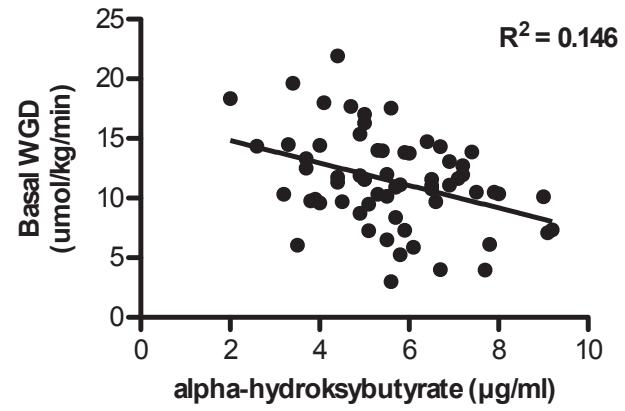

b

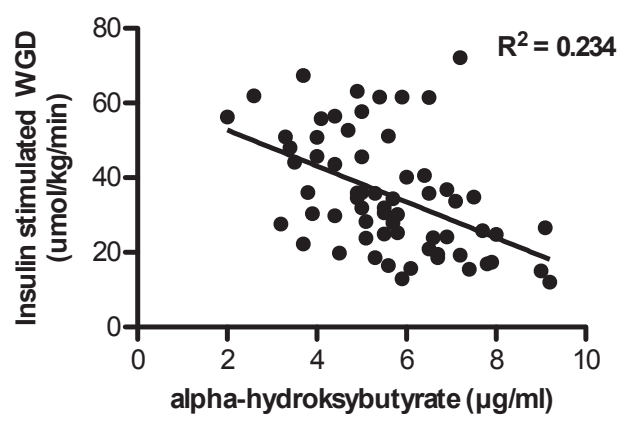

c

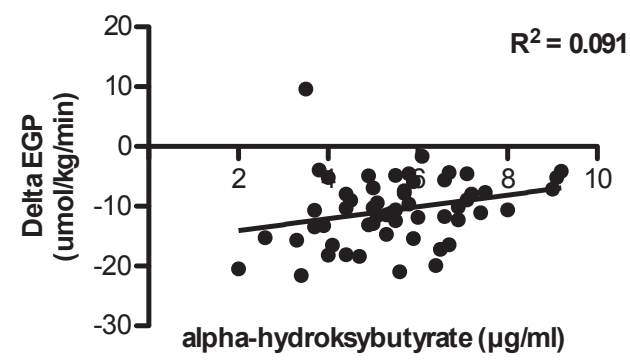

by $17 \%$ upon a 3-week high fat diet [6]. The increase in liver fat, however, was not parallelled by a significant change in alpha-hydroxybutyrate $(5.2 \pm 0.3 \mu \mathrm{g} / \mathrm{ml}$ after the run in diet and $5.8 \pm 0.4 \mu \mathrm{g} / \mathrm{ml}$ after consumption of the high fat diet, $p=0.13$, see figure 3a). In this dietary intervention, however, hepatic insulin sensitivity (measured as suppression of hepatic glucose output) was not affected [6]. Thus, while we can conclude that a diet-induced increase in liver fat does not result in increased alphahydroxybutyrate levels, we cannot conclude if alpha-hydroxybutyrate is a useful biomarker to reflect changes in insulin sensitivity. 


\section{EXERCISE TRAINING AND ALPHA-HYDROXYBUTYRATE}

To further explore the usefulness of alpha-hydroxybutyrate as a biomarker for changes in insulin sensitivity, we examined alpha-hydroxybutyrate before and after exercise training in obese insulin resistant normoglycemic and in BMI- and age-matched type 2 diabetic patients. As anticipated, exercise training improved markers of insulin sensitivity [5]. In insulin resistant obese subjects, fasting insulin dropped from $18.1 \pm 2.4$ to $16.1 \pm 2.1 \mathrm{mU} / \mathrm{l}$, insulin stimulated whole body glucose disposal increased from $25.8 \pm 2.3$ to $26.7 \pm 2.3 \mu \mathrm{mol} / \mathrm{kg} / \mathrm{min}$ and endogenous glucose production under insulin stimulated conditions dropped from $2.8 \pm 0.8$ to $1.0 \pm 1.0 \mu \mathrm{mol} / \mathrm{kg} / \mathrm{min}$, before and after training respectively. In patients with type 2 diabetes fasting insulin dropped from $16.4 \pm 1.2$ to $14.6 \pm 0.8 \mathrm{mU} / \mathrm{l}$, insulin stimulated whole body glucose disposal increased from $18.4 \pm 1.4$ to $21.0 \pm 1.4 \mu \mathrm{mol} / \mathrm{kg} / \mathrm{min}$ and endogenous glucose production under insulin stimulated conditions dropped from $2.9 \pm 0.5$ to $1.4 \pm 0.3 \mu \mathrm{mol} / \mathrm{kg} / \mathrm{min}$, before and after training respectively [5]. In contrast to what was anticipated based upon the observed improvement in markers of insulin sensitivity, alpha-hydroxybutyrate was unaffected in the insulin resistant obese group $(6.5 \pm 0.35$ vs. $6.3 \pm 0.38 \mu \mathrm{g} / \mathrm{ml}, \mathrm{p}=0.551)$ and if anything tended to increase rather than decrease $(8.1 \pm 0.33 \mathrm{vs} .8 .9 \pm 0.55 \mu \mathrm{g} / \mathrm{ml}, \mathrm{p}=0.068)$ after exercise training (see figure $3 \mathrm{~b}$ ). This has led us to conclude that alphahydroxybutyrate is not a useful marker to monitor changes in insulin sensitivity following a relatively short-term intervention (12 weeks of exercise training).

\section{ALPHA-HYDROXYBUTYRATE AS PREDICTOR OF INSULIN RESISTANCE}

The lack of response of alpha-hydroxybutyrate to insulin sensitizing interventions debates the usefulness of alpha-hydroxybutyrate as a biomarker of early changes in insulin sensitivity. Despite the absence of a clear intervention effect on alphahydroxybutyrate, we did observe that measuring plasma alpha-hydroxybutyrate clearly identifies groups with progressive levels of insulin resistance. This is in line with previous papers $[1,2]$. Moreover, we and others, report positive correlations between alpha-hydroxybutyrate levels and markers of insulin resistance. Thus the question arises if measuring alpha-hydroxybutyrate is of added (predictive) value to measuring more conventional predictors of insulin resistance like plasma free fatty acids, glucose, insulin or maximal exercise capacity $\left(\mathrm{VO}_{2} \mathrm{max}\right)$. This was investigated by performing step-wise linear regression analyses (see table 3) with basal glucose disposal, insulin stimulated glucose disposal and delta endogenous 
a

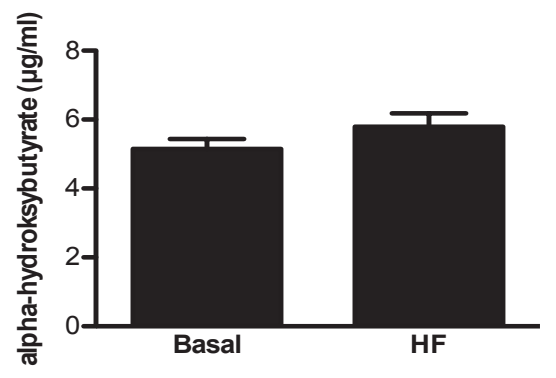

b

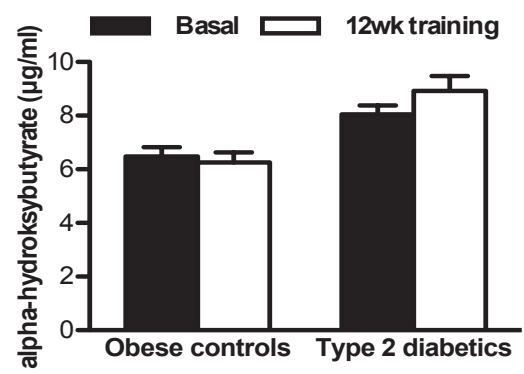

Figure 3 Comparison of plasma alpha-hydroxybutyrate concentrations (a) before and after a high fat diet-induced increase in hepatic lipid content and (b) before and after 12 weeks of exercise training. alpha-hydroxybutyrate tended to increase in type 2 diabetics upon 12 weeks of exercise training. Data are means $\pm \mathrm{SE}$.

Table 3 Stepwise Linear regression analysis

\begin{tabular}{|c|c|c|c|c|c|}
\hline Dependent variable & Parameters & Significant predictors & Beta & $\mathrm{R}^{2}$ & P-value \\
\hline \multirow{5}{*}{ Basal WGD } & Plasma alpha-HB & Plasma insulin & -0.423 & 0.318 & $p<0.05$ \\
\hline & Plasma FFA & alpha-HB & -0.294 & & \\
\hline & Plasma glucose & & & & \\
\hline & Plasma insulin & & & & \\
\hline & $\mathrm{VO}_{2} \max / \mathrm{kg}$ & & & & \\
\hline \multirow{5}{*}{$\begin{array}{l}\text { Insulin stimulated } \\
\text { WGD }\end{array}$} & Plasma alpha-HB & Plasma glucose & -0.259 & 0.585 & $p<0.05$ \\
\hline & Plasma FFA & Plasma insulin & -0.373 & & \\
\hline & Plasma glucose & alpha-HB & -0.275 & & \\
\hline & Plasma insulin & $\mathrm{VO}_{2} \max / \mathrm{kg}$ & 0.274 & & \\
\hline & $\mathrm{VO}_{2} \max / \mathrm{kg}$ & & & & \\
\hline \multirow{5}{*}{ Delta EGP } & Plasma alpha-HB & Plasma glucose & -0.235 & 0.51 & $p<0.05$ \\
\hline & Plasma FFA & Plasma insulin & -0.277 & & \\
\hline & Plasma glucose & alpha-HB & -0.279 & & \\
\hline & Plasma insulin & $\mathrm{VO}_{2} \max / \mathrm{kg}$ & 0.322 & & \\
\hline & $\mathrm{VO}_{2} \max / \mathrm{kg}$ & & & & \\
\hline
\end{tabular}

Results of the stepwise regression analyses. Indicated in the 'Parameters' column are all variables included in the model, and in the 'Significant predictors' column are all variables that were significant after stepwise regression. In the 'Beta' column, the beta value for each (significant) predictor in the model is given and in ' $\mathrm{R}^{2}$ ' column are the values for the entire model. $\mathrm{P}<0.05$ was considered statistically significant. alpha-HB, alpha-hydroksybutyrate. 
glucose production as dependent variables. For all these dependent variables, alpha-hydroxybutyrate significantly $(\mathrm{p}<0.001)$ contributed to the prediction model $\left(R^{2}=0.318, R^{2}=0.585\right.$ and $R^{2}=0.510$, respectively, table 3$)$. For basal WGD alphahydroxybutyrate contributed with explaining an additional $8 \%$ of the variation $\left(R^{2}=0.318\right)$ on top of the $24 \%$ already predicted for by plasma insulin alone as the strongest predictor $\left(R^{2}=0.235\right)$. For insulin stimulated WGD plasma glucose and insulin were the strongest predictors, explaining $49 \%$ of the variation $\left(R^{2}=0.486\right)$. Alpha-hydroxybutyrate contributed with another $4 \%\left(R^{2}=0.529\right)$. Also the beta -derived from stepwise regression analyses-, show that alpha-hydroxybutyrate was, however, not a very powerful predictor (beta of -0.294 for basal WGD, -0.275 for insulin stimulated WGD and -0.279 for delta WGD, table 3). Compared to the more conventional marker fasting plasma insulin levels (beta of -0.423 for basal WGD, -0.373 for insulin stimulated WGD and -0.277 for delta WGD, table 3) the added value of alpha-hydroxybutyrate as a biomarker for insulin resistance was limited.

\section{DISCUSSION}

Using unbiased metabolomics approaches alpha-hydroxybutyrate has recently been suggested as a novel biomarker of progressive insulin resistance [1, 2]. Here, we investigated alpha-hydroxybutyrate levels in groups with progressive insulin resistance (ranging from insulin sensitive lean subjects to patients with overt type 2 diabetes) and examined the correlation with peripheral and hepatic insulin resistance. To examine if alpha-hydroxybutyrate could be a useful marker to detect early changes in insulin sensitivity, we measured alpha-hydroxybutyrate levels before and after lifestyle interventions modulating liver fat or insulin sensitivity.

The main finding of the present paper is that despite a stepwise increase in alphahydroxybutyrate in groups with progressive insulin resistance and its negative correlation with markers of insulin sensitivity, alpha-hydroxybutyrate did not respond to changes in interventions that affect hepatic fat content and/or insulin sensitivity.

The observation that alpha-hydroxybutyrate increases in a stepwise manner when comparing lean normoglycemic subjects with obese normoglycemic subjects and patients with type 2 diabetes is in line with previous reports [1, 2, 14]. Interestingly, we observed that even within normoglycemic groups, alpha-hydroxybutyrate correlated with insulin sensitivity. Both whole body glucose disposal under basal, non-insulin 
stimulated, as well as whole body glucose uptake under insulin stimulated conditions scaled negatively with increasing levels of alpha-hydroxybutyrate, indicating that alpha-hydroxybutyrate is a reflection of insulin mediated glucose uptake in skeletal muscle. This is an interesting observation as compromised skeletal muscle glucose uptake is one of the earliest hallmarks in the pathogenesis of type 2 diabetes [15]. These data are therefore in line with the observation that progression towards overt type 2 diabetes occurred at higher rates in subjects at the higher quartile of alphahydroxybutyrate than those in the lower quartiles [2]. Using tracer methodology in the clamps studies we were able to discern liver insulin resistance from peripheral insulin resistance. The prevailing notion is that hepatic insulin resistance (blunted inhibitory effect of insulin on endogenous glucose production by the liver) is the cause of elevated fasting plasma glucose levels in patients with type 2 diabetes. In that respect it is of relevance to note that we not only observed correlations of alpha-hydroxybutyrate with peripheral insulin resistance, but also with hepatic insulin resistance.

Most of the conventional biomarkers for insulin resistance (elevated fasting glucose and insulin levels and $\mathrm{HbA} 1 \mathrm{c}$ ) respond poorly or slowly to interventions modulating markers of insulin resistance. Thus, we examined if alpha-hydroxybutyrate responded to interventions that are associated with the development or prevention of diabetes (increasing hepatic fat content upon a high-fat diet vs physical exercise training). As alpha-hydroxybutyrate is a liver derived organic acid [16] and alphahydroxybutyrate scaled negatively with hepatic insulin sensitivity, and hepatic fat content is a strong predictor of insulin resistance, we hypothesized alphahydroxybutyrate to increase upon a high-fat diet mediated increase in liver fat. In contrast to this hypothesis we observed no change in alpha-hydroxybutyrate despite a significant increase in liver fat. Thus, while a three-week dietary intervention suffices to augment liver fat content, it failed to significantly increase circulatory levels of alpha-hydroxybutyrate.

Based upon the reported correlation between alpha-hydroxybutyrate and whole body glucose disposal, we hypothesised alpha-hydroxybutyrate levels to drop following a twelve-week exercise training intervention. In this training study, both peripheral as hepatic insulin resistance was significantly alleviated. However, we failed to detect a significant drop in alpha-hydroxybutyrate within the duration of the study. Jointly, these intervention study based data do not indicate that alphahydroxybutyrate is biomarker, which is sensitive to lifestyle mediates changes in 
insulin sensitivity.

Despite the notion that alpha-hydroxybutyrate appears to be a useful marker of peripheral and hepatic insulin resistance, in normoglycemic as well as in type 2 diabetic conditions, it does not respond more rapidly to relatively short-term insulin sensitivity modulating interventions than any of the more conventional markers tested. Although the present study was not designed to elucidate why alphahydroxybutyrate is elevated in insulin resistant conditions, the poor responsiveness of alpha-hydroxybutyrate to insulin sensitizing may indicate that the correlation between alpha-hydroxybutyrate and insulin resistance is unlikely to be direct.

A recent paper showed that alpha-hydroxybutyrate could predict elevations in 1-hr glucose levels and early phase beta-cell dysfunction following an oral glucose tolerance test [17] and positioned alpha-hydroxybutyrate as tool to detect subclinical stages of hyperglycaemia, insulin resistance and beta-cell dysfunction. To explore the usefulness and added value of alpha-hydroxybutyrate as a biomarker for insulin resistance we performed stepwise regression analysis on our data set. This revealed that alpha-hydroxybutyrate (next to fasting glucose and insulin levels) is one of the significant predictors of basal whole body glucose uptake as well as insulin stimulated glucose uptake. The contribution of alpha-hydroxybutyrate as a marker however was modest and did not, or only barely, exceeded the predictive value of more conventional (and cheaper) plasma markers of disturbed insulin sensitivity like fasting glucose or insulin levels.

Thus, we conclude that alpha-hydroxybutyrate is a marker of insulin resistance, even in subjects with normoglycemia. Although alpha-hydroxybutyrate scales with insulin resistance, alleviation of insulin resistance by exercise training does not necessitate a decline in alpha-hydroxybutyrate. While stepwise regression analysis identified alpha-hydroxybutyrate as a significant predictor for insulin resistance, it is of little added value to the conventionally used and rather cheap markers like fasting glucose and insulin. 


\section{REFERENCES}

1. Gall WE, Beebe K, Lawton KA, Adam KP, Mitchell MW, Nakhle PJ, Ryals JA, Milburn MV, Nannipieri M, Camastra S, Natali A, Ferrannini E, Group RS. alpha-hydroxybutyrate is an early biomarker of insulin resistance and glucose intolerance in a nondiabetic population. PloS one. 2010;5(5):e10883.

2. Ferrannini E, Natali A, Camastra S, Nannipieri M, Mari A, Adam KP, Milburn MV, Kastenmuller G, Adamski J, Tuomi T, Lyssenko V, Groop L, Gall WE. Early metabolic markers of the development of dysglycemia and type 2 diabetes and their physiological significance. Diabetes. 2013;62(5):1730-7.

3. Marchesini G, Brizi M, Morselli-Labate AM, Bianchi G, Bugianesi E, McCullough AJ, Forlani G, Melchionda N. Association of nonalcoholic fatty liver disease with insulin resistance. The American journal of medicine. 1999;107(5):450-5.

4. Seppala-Lindroos A, Vehkavaara S, Hakkinen AM, Goto T, Westerbacka J, Sovijarvi A, Halavaara J, Yki-Jarvinen H. Fat accumulation in the liver is associated with defects in insulin suppression of glucose production and serum free fatty acids independent of obesity in normal men. The Journal of clinical endocrinology and metabolism. 2002;87(7):3023-8.

5. Meex RC, Schrauwen-Hinderling VB, Moonen-Kornips E, Schaart G, Mensink M, Phielix E, van de Weijer T, Sels JP, Schrauwen P, Hesselink MK. Restoration of muscle mitochondrial function and metabolic flexibility in type 2 diabetes by exercise training is paralleled by increased myocellular fat storage and improved insulin sensitivity. Diabetes. 2010;59(3):572-9.

6. van Herpen NA, Schrauwen-Hinderling VB, Schaart G, Mensink RP, Schrauwen P. Three weeks on a high-fat diet increases intrahepatic lipid accumulation and decreases metabolic flexibility in healthy overweight men. The Journal of clinical endocrinology and metabolism. 2011;96(4):E691-5.

7. Phielix E, Meex R, Ouwens DM, Sparks L, Hoeks J, Schaart G, MoonenKornips E, Hesselink MK, Schrauwen P. High oxidative capacity due to chronic exercise training attenuates lipid-induced insulin resistance. Diabetes. 2012;61(10):2472-8.

8. Phielix E, Schrauwen-Hinderling VB, Mensink M, Lenaers E, Meex R, Hoeks J, Kooi ME, Moonen-Kornips E, Sels JP, Hesselink MK, Schrauwen P. Lower intrinsic ADP-stimulated mitochondrial respiration underlies in vivo mitochondrial dysfunction in muscle of male type 2 diabetic patients. Diabetes. 2008;57(11):2943-9.

9. Siri WE. The gross composition of the body. Advances in biological and medical physics. 1956;4:239-80.

10. Kuipers H, Verstappen FT, Keizer HA, Geurten P, van Kranenburg G. Variability of aerobic performance in the laboratory and its physiologic correlates. International journal of sports medicine. 1985;6(4):197-201. 
11. DeFronzo RA, Tobin JD, Andres R. Glucose clamp technique: a method for quantifying insulin secretion and resistance. The American journal of physiology. 1979;237(3):E214-23.

12. Mensink M, Blaak EE, van Baak MA, Wagenmakers AJ, Saris WH. Plasma free Fatty Acid uptake and oxidation are already diminished in subjects at high risk for developing type 2 diabetes. Diabetes. 2001;50(11):2548-54.

13. Steele R. Influences of glucose loading and of injected insulin on hepatic glucose output. Annals of the New York Academy of Sciences. 1959;82:42030.

14. Xu F, Tavintharan S, Sum CF, Woon K, Lim SC, Ong CN. Metabolic signature shift in type 2 diabetes mellitus revealed by mass spectrometry-based metabolomics. The Journal of clinical endocrinology and metabolism. 2013;98(6):E1060-5.

15. DeFronzo RA. Pathogenesis of type 2 diabetes mellitus. The Medical clinics of North America. 2004;88(4):787-835, ix.

16. Landaas $\mathrm{S}$. The formation of 2-hydroxybutyric acid in experimental animals. Clinica chimica acta; international journal of clinical chemistry. 1975;58(1):23-32.

17. Varvel SA, Pottala JV, Thiselton DL, Caffrey R, Dall T, Sasinowski M, McConnell JP, Warnick GR, Voros S, Graham TE. Serum alphahydroxybutyrate (alpha-HB) predicts elevated $1 \mathrm{~h}$ glucose levels and earlyphase beta-cell dysfunction during OGTT. BMJ open diabetes research \& care. 2014;2(1):e000038. 
L.Bilet 
CHAPTER

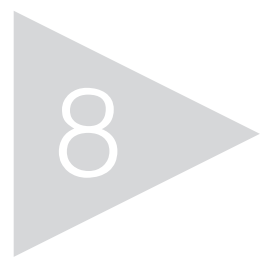

General discussion 
Worldwide there is an obesity epidemic [1, 2], which in turn is linked to an epidemic of chronic disorders such as type 2 diabetes and cardiovascular disease. Ectopic fat accumulation is suggested to be the link between obesity and such chronic metabolic disorders [3]. Why in obesity fat accumulates in ectopic tissues is not completely understood. Increased flux of fatty acids into ectopic tissue has been suggested to lead to disturbances in tissue function, a phenomenon known as lipotoxicity [4-7]. In this thesis, we investigated the role of plasma free fatty acids (FFA) in lipid accumulation in skeletal muscle, liver and heart and how such ectopic fat accumulation is linked to lipotoxic effects in these tissues.

\section{LIPID ACCUMULATION IN NON-ADIPOSE TISSUES}

\section{WHY LIPIDS ACCUMULATE IN NON-ADIPOSE TISSUES}

The ability to store energy, mainly in the form of triglycerides (TG) in adipose tissue, is a biological adaptation with great evolutionary advantage [8]. Adipose tissue can expand either by increasing the number (hyperplasia) or size (hypertrophy) of individual adipocytes [9]. This basic life function was present already in unicellular organisms in order to provide energy during periods when energy demands exceed caloric intake [10]. Further, it is postulated that the adipose tissue acts to "buffer" the influx of dietary fat into the circulation [11, 12]. Thus, by storing excessive dietary fat it prevents "overflow" to other organs. However, in obesity there is an excessive growth of adipose tissue depots arising from a long-term mismatch between energy intake and energy expenditure. As a result the adipose tissue eventually fails to expand, [13] impairing its storage capacity, and consequently redirects the increased flux of fatty acids away from rather than into adipose tissues. This results in an inappropriate storage of lipids in non-adipose tissues, such as skeletal muscle, liver and heart (also called ectopic lipid accumulation) [3, 14, 15].

There are three ways in which ectopic lipid accumulation can occur; 1) increased uptake of fatty acids (FA) into peripheral tissues, such as skeletal muscle, liver and heart, 2) increased de novo lipogenesis- or 3) reduced FA oxidation within the tissue involved [16]. Each of these factors contributes differently to ectopic lipid accumulation depending on the type of tissue and its physiological state.

In skeletal muscle, lipid droplets are localized close to the mitochondria, suggesting 
that lipids inside the muscle are used as fuel for muscular activity [6]. Indeed, the physiological role of intramyocellular lipids (IMCL) as substrate during physical activity is well established and the increase of IMCL with training, seen in highly trained athletes [17], is a healthy physiological response [6]. Interestingly, while endurance training increases IMCL due to an increased demand of intramyocellular substrate, physical inactivity seems to result in a high IMCL content due to decreased oxidative capacity of lipids within the muscle tissue (chapter 6). This fit with the generally accepted athlete's paradox, which describes that endurance trained athletes have increased insulin sensitivity [18, 19] despite having high IMCL, whereas high IMCL in obesity is associated with insulin resistance and type 2 diabetes [17]. It is therefore suggested that muscle oxidative capacity is an important mediator of the association between excess muscle lipid accumulation and insulin resistance [17]. The results of chapter 6 , in which a lower oxidative capacity of fat in the immobilized leg lead to elevated IMCL, suggests that the excessive accumulation of IMCL in obesity may also be caused by physical inactivity (and thereby reduced demand of IMCL for oxidation). However, not only increased or decreased intracellular demand, but also high availability of plasma FFAs can result in high IMCL content (chapters 4 and 5). Elevated levels of plasma FFA are typically observed in people at risk for type 2 diabetes [20], in whom IMCL correlates with insulin resistance $[20,21]$, and is considered to be a risk factor for disease development. Interestingly, also acute elevations of plasma FFA can result in increased IMCL [22]. Indeed, in chapter 4 we show that in spite of an increased cellular demand of FA during exercise, fat accumulates in skeletal muscle when plasma FFAs are high. Likewise, in type 2 diabetic patients, increased plasma FFAs, due to a rebound effect of Acipimox, also led to increased IMCL (chapter 5). This suggests that plasma FFAs are important determinants of IMCL and that skeletal muscle takes up plasma FFA unrestricted when the availability is high, independent of cellular needs.

Together these findings suggest that a tight balance between FA availability, uptake into skeletal muscle and subsequent oxidation (lipid turnover) is important to maintain an appropriate level of IMCL [23].

In contrast to what has been observed in skeletal muscle, the liver does not accumulate fat as an energy store under conditions of high cellular demand such as exercise training. However, with the current obesity epidemic up to one third of all people with overweight and obesity have elevated lipid content in the liver 
(intrahepatic lipid (IHL) content) [24, 25]. Fatty acids entering the liver originate from several different sources; dietary fat, FA released from adipose tissue and from de novo hepatic lipogenesis [6]. An increased lipid accumulation in the liver reflects an imbalance between hepatic TG synthesis and utilization [26]. In this thesis we found that exercise-induced elevations of plasma FFAs triggered uptake into the liver resulting in increased intrahepatic lipid accumulation (chapter 3). In the liver, TG may accumulate either as small or large lipid deposits, histologically classified as micro- or macrovesicular steatosis [27], respectively. Non-alcoholic fatty liver disease (NAFLD) is one of the main causes for macrovesicular steatosis, with its prevalence increasing with increasing obesity [26].

As with skeletal muscle and liver, we managed to detect TGs in the myocardium of lean healthy humans (chapter 2). Myocardial fat has been found to be higher in obese than in lean subjects, correlating with plasma FFA levels [28]. In line with this, we also found myocardial fat to increase when plasma FFA levels were elevated by means of exercise (chapter 2).

Together, these results suggest that plasma FFAs are important determinants of ectopic fat accumulation, but the exact role will be discussed in more detail below.

\section{THE ROLE OF FFAS IN ECTOPIC LIPID ACCUMULATION}

Already in the 1950s Robert Gordon demonstrated the origin of plasma FFAs from adipose tissue and their use by other tissues [29, 30]. FFAs circulate in the plasma bound to plasma albumin. In a normal situation FFAs are one of the most important nutrients involved in the regulation of energy metabolism [31] and as oxidative fuel for skeletal muscle, liver and heart [32]. Plasma FFAs arises from two main sources; in the fasted state hydrolysis of TG in adipose tissue contributes most to the plasma FFA pool, whereas in the postprandial state "spillover" of dietary fat contributes up to $40-50 \%$ of the plasma FFA pool [33]. In healthy humans, the dynamic amount of FA storage and its release into the blood circulation is tightly coordinated based on metabolic demands [31]. Until recently, it was believed that obese people had a higher fasting and postprandial FFA concentration [34, 35] due to an expanded fat mass [36], however new data show that plasma FFA concentrations do not necessary increase in proportion to fat mass; instead as adipose tissue expands, FFA release per kilogram adipose tissue is downregulated, which in many individuals can even lead to normalization of plasma 
FFA concentrations [37]. Indeed, recent studies show little difference in systemic FFA concentrations between obese and lean [33, 37]. Interestingly, however, independent of BMI, people with type 2 diabetes [38, 39] and fatty liver [40] are characterized by increased plasma FFA concentrations. As already pointed out in chapter 1, these elevated circulating plasma FFAs have been suggested to be responsible for the ectopic lipid accumulation seen in these patients. Therefore, in this thesis we manipulated plasma FFA concentrations both physiologically with exercise (chapters 2, 3 and 4) and pharmacologically with Acipimox (in chapter 5 ) to investigate the role of plasma FFA on ectopic fat accumulation in heart, liver and skeletal muscle. In all three tissues, exercise-induced elevation of plasma FFA concentrations resulted in an increased accumulation of ectopic fat (chapters 2-4). Our data therefore suggests that plasma FFA concentrations are important determinants of ectopic fat accumulation, which in turn suggests that the uptake of FFAs into the ectopic tissues largely depends on FFA availability. By taking up excessive FFA from the circulation, the heart (chapter 2), the liver (chapter 3) and skeletal muscle (chapter 4 ) together act as a buffer contributing to the clearance of FFA from the plasma. In line with this, it has previously been shown that there is a net accumulation of IMCL content in non-exercising muscle during exercise in the fasted state, due to increased plasma FFA availability [41]. However, in the same study, intramyocellular lipid content was reduced in the exercising muscles of the leg, suggesting that in this active muscle, FFA delivery was customized to FA oxidation. In that respect, it is surprising that in cardiac muscle, which heavily relies on FA for oxidation during exercise, the elevation of plasma FA lead to an increase rather than a decrease in cardiac lipid content. This suggests that the uptake of FA in cardiac muscle is less well-tuned to the oxidative needs compared to skeletal muscle and that even under conditions of increased cardiac work, FA entering the heart are shuttled towards storage rather than to oxidation. In the liver, a high flux of plasma FFAs into the tissue may exceed the capacity of the tissue to oxidize and/or export FFAs and therefore subsequently results in an accumulation of triglycerides.

The plasma FFA-induced elevation of ectopic lipid accumulation seen in this thesis is in agreement with other studies pointing at the importance of high FA concentrations as determinants of ectopic fat accumulation [42, 43]. Fasting for more than 48 hours [28] or very low caloric diet for more than three days [44], which both are characterized by elevated plasma FA concentrations, also resulted in increased cardiac lipid content. Likewise, lipid infusion increases both plasma TG and IMCL content in lean young men [22]. 
Given that plasma FFA levels are an important determinant of ectopic fat accumulation, we attempted to lower ectopic fat stores in type 2 diabetic patients, by lowering plasma FFA concentrations with the anti-lipolytic agent Acipimox. However, as described in chapter 5, instead of lowering plasma FFA concentrations, a 2 weeks administration of Acipimox induced a rebound effect, causing a raise in circulating plasma FFAs. Consistent with a role for FFA in fat accumulation in muscle, also in this study elevated plasma FFA levels lead to increased IMCL. Interestingly, however, the acipimox-induced elevation of plasma FFAs did not lead to the same alterations in the lipid content of the heart and the liver as observed with exercise-induced elevation of plasma FFAs. The discrepancy between these results might be explained by the magnitude of elevation of plasma FFA, and by the difference in energy demand in these two study designs. Exercise increases fatty acid oxidation rates, while administration of Acipimox does not lead to changes in energy demand. This may suggest that changes in plasma FFA concentrations alone might not be able to alter fat accumulation in the heart and the liver, but that also an increased demand of FA for subsequent oxidation is an important trigger for uptake of FA in liver and heart and thereby ectopic fat accumulation in the heart and the liver.

\section{EXERCISE AND ECTOPIC LIPID ACCUMULATION}

As discussed above, increased ectopic lipid accumulation can be both beneficial and harmful, depending on the physiological state of the tissue. In the obesogenic/ diabetogenic state harmful effects of excessive lipid accumulation are seen in ectopic tissues, such as skeletal muscle, liver and heart. Exercise training has been shown to have a lowering effect on lipid content in both heart [45] and liver [46-49], suggested to contribute to the beneficial effects of exercise training on metabolic risk [46-49]. In contrast, however, in skeletal muscle, increased lipid content is observed upon exercise training, also in obese and diabetic patients, and this increase is suggested to be a beneficial adaptation to increased energy demand [50]. Like with exercise training, acute bouts of exercise also appear to have beneficial effects, e.g. by improving insulin sensitivity [51-53]. However, in this thesis we show that an acute bout of exercise does not result in a lowering of ectopic fat accumulation in neither the heart (chapter 2) nor in the liver (chapter 3). Instead, the cardiac- and hepatic lipid content increased rather than decreased post-exercise when exercise was performed in the fasting state. As already discussed, circulatory FA levels are profoundly increased during and after exercise in the fasted state (in contrast to the 
glucose-supplemented state), and this increase in plasma FA levels in the fasted state may deliver fatty acids to the heart and the liver, with increased cardiac- and hepatic lipid accumulation as a consequence. This indicates that in spite of strongly stimulated whole body fat oxidation during exercise, an acute bout of exercise is not enough to decrease cardiac- and hepatic lipid content. However, in skeletal muscle fat accumulation is reported to serve as important fuel during exercise [45], resulting in a decrease in IMCL during exercise [54] [55-59], due to the oxidation of IMCL in contracting muscle [54]. Surprisingly, and in contrast to these previous findings, our studies revealed that IMCL does not necessarily decrease with acute exercise (chapter 4). Thus, when exercise was performed in the fasted state, IMCL was increasing over time, whereas in the glucose-supplemented condition IMCL was decreasing over time. This suggests that during exercise in the fasted state the re-esterification of FFA is stronger than the hydrolysis of triglycerides resulting in a turnover of IMCL with a net increase in IMCL in exercising muscle.

Taken together, acute exercise might be able to decrease ectopic fat accumulation. However, this exercise-induced lowering effect is dependent on the individual's nutritional status during exercise. The exercise-induced elevation of plasma FFAs, blunts the potential exercise-lowering effect on ectopic fat accumulation, even leading to an increased storage of fat in non-adipose tissue post-exercise.

\section{LIPOTOXIC EFFECTS}

Lipotoxicity, which is defined as the accumulation of excess lipids in non-adipose tissues leading to cell dysfunction and cell death, may play an important role in the pathogenesis of diabetes and heart failure in humans [5]. The toxic consequences of lipid overload and ectopic fat accumulation vary between different tissues and depend on the degree and the duration of the imbalance between fatty acid influx and oxidation in these tissues. As will be discussed in more detail below, lipotoxicity may display as insulin resistance, hepatic steatosis [60] and cardiac dysfunction [61] in skeletal muscle, liver and heart respectively. 


\section{CARDIAC LIPID ACCUMULATION AND CARDIAC DYSFUNCTION}

In type 2 diabetes elevated levels of cardiac lipids have been linked to cardiac dysfunction [5, 62-64] and lowered cardiac energy status [65, 66]. The latter is suggested to result from impaired mitochondrial function due to elevated cardiac lipid content or an increased fatty acid supply [5]. In support of this view, we observed that cardiac energy status, expressed as PCr/ATP ratio, was decreased in parallel with increased cardiac lipid content upon exercise in the fasted state (chapter 2). Surprisingly, however, systolic cardiac function improved rather than decreased upon exercise-induced changes in cardiac lipid content in the same study. This indicates that fat accumulation per se is not necessarily detrimental to organ function, at least not on the short term. Furthermore, it shows that at least in this population, PCr/ATP ratio is not a good marker of cardiac function under acute conditions of elevated plasma FFAs. Another explanation might be that, despite being decreased, the observed PCr/ATP ratio is well within a normal physiological range and therefore does not have consequences for cardiac function. In agreement with this it has previously been shown that only a PCr/ATP ratio lower than 1.6 is associated with poor prognosis in patients with heart failure [67]. Thus, even though the lower PCr/ATP ratio is in line with a lipotoxic action of cardiac lipids, it might not be low enough to affect cardiac function. Likewise, in chapter 5, where plasma FFAs were increased due to a rebound-effect of Acipimox-administration, cardiac lipid content and cardiac energy status were unchanged, despite a tendency to decreased cardiac function. Also other recent studies indicate that interventions that would potentially improve lipotoxic conditions, such as weight loss in patients undergoing bariatric surgery, can improve cardiac function without changes in cardiac lipid content. [68, 69]. Furthermore, Acipimox-lowering of plasma FFA in young healthy volunteers did not affect cardiac lipid content, but still resulted in a decrease in cardiac function [70]. Taken together, these data reveal that cardiac lipid content is not causally related to cardiac function and that changes in plasma FFA and cardiac lipid content not always predict changes in cardiac function.

\section{HEPATIC LIPID CONTENT AND ENERGY STATUS}

Excessive fat accumulation in the liver exceeding $5.56 \%$, measured by proton magnetic resonance spectroscopy $\left({ }^{1} \mathrm{H}-\mathrm{MRS}\right)$ is considered as pathological [71] and is referred to as Non- Alcoholic Fatty Liver Disease (NAFLD). NAFLD has frequently been observed in obese individuals and compromises a spectrum of 
conditions extending from simple hepatic steatosis to end-stage liver disease [72-74]. Furthermore, NAFLD is also linked to insulin resistance [75-77] and type 2 diabetes. Interestingly, it has been suggested that hepatic ATP levels are decreased in conditions such as insulin resistance and type 2 diabetes [78, 79], and that hepatocellular ATP correlates negatively with liver fat in human subjects, indicative of lipotoxicity. In chapter 3 we therefore investigated the relationship between hepatic ATP and hepatic lipid content in overweight and obese subjects with a wide variety of hepatic lipid content. We observed that an exercise-induced elevation of plasma FFAs resulted in an increase in hepatic lipid content, and a trend towards decreased ATP levels. It could be argued that the decrease in ATP is a consequence of exercise. Indeed, a recent study investigating the energy charge in the liver of mice after one single bout of exercise found a clear increase of AMP and a strong decrease of ATP in the liver [80], suggesting that the reduction in ATP levels after exercise is a direct consequence of exercise. In contrast we did not observe a decrease in ATP after exercise in the glucose-supplemented condition. This suggests that an elevation of $\mathrm{IHL}$ upon exercise interventions instead of exercise per se - might be responsible for the reduced hepatic energy status seen in the fasted condition. Thus, this may suggest a role of hepatic lipid accumulation in impairing hepatic energy status. However, in a study comparing hepatic energy status in metabolic well-controlled type 2 diabetics with BMI- and age matched controls and lean young subjects, ATP and Pi concentrations were reduced in type 2 diabetics even when correcting for hepatocellular lipid volume. This indicates that reduced energy status is independent of liver fat content and that impaired hepatic energy status and hepatic insulin resistance could precede the development of steatosis in patients with type 2 diabetes [81].

Together, hepatic lipid accumulation and decreased levels of hepatic ATP are both associated with insulin resistance, however to what extent the decrease in ATP is related to the increase in hepatic lipid content still needs to be determined.

\section{ALTERATIONS IN INTRAMYOCELLULAR LIPID CONTENT AND ITS EFFECTS ON INSULIN SENSITIVITY}

Although the presence of intramyocellular triglycerides was already described in 1967 [82], its association with insulin resistance was not demonstrated in humans before the early 1990s [83]. In the years following, it was shown that intramyocellular lipid (IMCL) content was increased in obesity and type 2 diabetes [84-86], and 
studies using fasting [87], lipid infusion [88-90] or high fat diets [91-93] confirmed a relationship between IMCL content and insulin resistance. In agreement, in chapter 5 the acipimox-induced increase in fatty acid supply was paralleled by increased skeletal muscle lipid content and insulin resistance. Thus, fatty acid overload and lipid accumulation in skeletal muscle in combination with unadjusted fat oxidation rates can induce insulin resistance. Nowadays, however, it is well known that lipid accumulation in skeletal muscle not necessarily causes insulin resistance; IMCL is also found to be elevated in highly insulin-sensitive athletes, a phenomenon refereed to as the athletes' paradox [17]. Likewise, exercise training has been shown to improve insulin sensitivity and fat oxidative capacity, despite an increase in skeletal muscle fat content, also in obese and type 2 diabetics [50]. Increased IMCL storage following endurance training serves to match the training-induced increase in oxidative capacity and reliance on fat as substrate during exercise [94], whereas obesity- and diabetes-induced accumulation of IMCL is not matched by improved oxidative capacity. Because physical inactivity has been considered as a major determinant of the current epidemic of chronic disease, such as obesity and type 2 diabetes [95, 96], it is suggested to reduce skeletal muscle mitochondrial function, and thereby contribute to muscle fat accumulation and skeletal muscle insulin resistance $[97,98]$. In chapter 6 we therefore used a model in which muscle mitochondrial function was manipulated in one leg, leaving the other leg unaffected, thus allowing the comparison - within one individual - of the local effect of altered mitochondrial function on muscle lipid metabolism and insulin sensitivity [97, 98]. We observed that inactivity indeed leads to a lowering of in vivo mitochondrial function as well as a reduced fat oxidative capacity. In parallel, inactivity markedly increased skeletal muscle IMCL content. Interestingly, the immobilized leg was more insulin resistant than the active leg upon the infusion of lipids. These data suggest that physical inactivity renders skeletal muscle more prone to lipid-induced insulin resistance. This finding is consistent with a previous study in which it was shown that endurance trained athletes are (partly) protected against lipid-induced insulin resistance [89]. These studies suggest that both physical inactivity and physical activity (exercise training) increase IMCL content, but that the reduced mitochondrial function observed upon physical inactivity - and not the IMCL per se - may underlie the compromised insulin action. In line, it is generally accepted that it are not the intramyocellular triglycerides that induce cellular insulin resistance, but rather lipid intermediates, such as diacylglycerol (DAG) and ceramide, which in high concentrations can affect cellular insulin signaling. These intermediates of fatty acid metabolism may indeed accumulate if a dysbalance between lipid supply and 
lipid oxidation exists. Taken together, the results of the present thesis do not rule out a role for lipid accumulation in the development of insulin resistance. However, the balance between IMCL and fat oxidative capacity may be a more important determinant for the observed associations between muscle fat content and insulin resistance than IMCL content per se.

\section{CONCLUDING REMARKS AND FUTURE PERSPECTIVES}

The studies described in this thesis provide insight into the role of plasma free fatty acids (FFA) in lipid accumulation in skeletal muscle, liver and heart and how ectopic fat accumulation is linked to lipotoxic effects in these tissues. We have shown that plasma FFA concentrations are important determinants of ectopic fat accumulation and that the uptake of FFAs into the ectopic tissue largely depends on FFA availability. By taking up excessive FFA from the circulation, the heart, the liver and the skeletal muscle together act as a buffer contributing to the clearance of FFA from the plasma.

Furthermore, excessive cardiac lipid accumulation is not causally related to cardiac function and changes in plasma FFA and cardiac lipid content do not consistently predict changes in cardiac function. However, increased lipid content in heart and liver were paralleled with a decreased energy status of these tissues; the clinical consequences of this need to be studied in future studies. For the skeletal muscle we show that not only elevated plasma FFA, but also decreased physical activity (induced by unilateral lower limb suspension is this thesis) goes along with increased intramyocellular lipid content together with decreased in vivo mitochondrial function and oxidative capacity. However, the interrelationship between these parameters is still unknown and should be explored in more detail in the future. If the sequence of events leading to organ dysfunction and insulin resistance could be revealed, specific therapeutic and preventive strategies could be applied in people at risk for developing type 2 diabetes. 


\section{REFERENCES}

1. Ng M, Fleming T, Robinson M, Thomson B, Graetz N, Margono C, Zhao Y, Zhou M, Zhu S, Lopez AD, Murray CJ, Gakidou E et al. Global, regional, and national prevalence of overweight and obesity in children and adults during 1980-2013: a systematic analysis for the Global Burden of Disease Study 2013. Lancet. 2014;384(9945):766-81.

2. Shulman Gl. Cellular mechanisms of insulin resistance. The Journal of clinical investigation. 2000;106(2):171-6.

3. Goodpaster BH, Wolf D. Skeletal muscle lipid accumulation in obesity, insulin resistance, and type 2 diabetes. Pediatric diabetes. 2004;5(4):21926.

4. Unger $\mathrm{RH}$, Orci L. Diseases of liporegulation: new perspective on obesity and related disorders. FASEB J. 2001;15(2):312-21.

5. Schaffer JE. Lipotoxicity: when tissues overeat. Curr Opin Lipidol. 2003;14(3):281-7.

6. van Herpen NA, Schrauwen-Hinderling VB. Lipid accumulation in nonadipose tissue and lipotoxicity. Physiol Behav. 2008;94(2):231-41.

7. Bays H, Mandarino L, DeFronzo RA. Role of the adipocyte, free fatty acids, and ectopic fat in pathogenesis of type 2 diabetes mellitus: peroxisomal proliferator-activated receptor agonists provide a rational therapeutic approach. J Clin Endocrinol Metab. 2004;89(2):463-78.

8. Hardy OT, Czech MP, Corvera S. What causes the insulin resistance underlying obesity? Current opinion in endocrinology, diabetes, and obesity. 2012;19(2):81-7.

9. Jo J, Gavrilova O, Pack S, Jou W, Mullen S, Sumner AE, Cushman SW, Periwal V. Hypertrophy and/or Hyperplasia: Dynamics of Adipose Tissue Growth. PLoS computational biology. 2009;5(3):e1000324.

10. Kadereit B, Kumar P, Wang WJ, Miranda D, Snapp EL, Severina N, Torregroza I, Evans T, Silver DL. Evolutionarily conserved gene family important for fat storage. Proceedings of the National Academy of Sciences of the United States of America. 2008;105(1):94-9.

11. Frayn KN. Adipose tissue as a buffer for daily lipid flux. Diabetologia. 2002;45(9):1201-10.

12. Lewis GF, Carpentier A, Adeli K, Giacca A. Disordered fat storage and mobilization in the pathogenesis of insulin resistance and type 2 diabetes. Endocr Rev. 2002;23(2):201-29.

13. Unger RH. Lipid overload and overflow: metabolic trauma and the metabolic syndrome. Trends Endocrinol Metab. 2003;14(9):398-403.

14. Le KA, Mahurkar S, Alderete TL, Hasson RE, Adam TC, Kim JS, Beale E, Xie C, Greenberg AS, Allayee H, Goran MI. Subcutaneous adipose tissue macrophage infiltration is associated with hepatic and visceral fat 
deposition, hyperinsulinemia, and stimulation of NF-kappaB stress pathway. Diabetes. 2011;60(11):2802-9.

15. Montani JP, Carroll JF, Dwyer TM, Antic V, Yang Z, Dulloo AG. Ectopic fat storage in heart, blood vessels and kidneys in the pathogenesis of cardiovascular diseases. International journal of obesity and related metabolic disorders : journal of the International Association for the Study of Obesity. 2004;28 Suppl 4:S58-65.

16. Goodpaster BH, He J, Watkins S, Kelley DE. Skeletal muscle lipid content and insulin resistance: evidence for a paradox in endurance-trained athletes. J Clin Endocrinol Metab. 2001;86(12):5755-61.

17. Ebeling P, Bourey R, Koranyi L, Tuominen JA, Groop LC, Henriksson J, Mueckler M, Sovijarvi A, Koivisto VA. Mechanism of enhanced insulin sensitivity in athletes. Increased blood flow, muscle glucose transport protein (GLUT-4) concentration, and glycogen synthase activity. The Journal of clinical investigation. 1993;92(4):1623-31.

18. Rodnick KJ, Haskell WL, Swislocki AL, Foley JE, Reaven GM. Improved insulin action in muscle, liver, and adipose tissue in physically trained human subjects. The American journal of physiology. 1987;253(5 Pt 1):E489-95.

19. Jacob S, Machann J, Rett K, Brechtel K, Volk A, Renn W, Maerker E, Matthaei S, Schick F, Claussen CD, Haring HU. Association of increased intramyocellular lipid content with insulin resistance in lean nondiabetic offspring of type 2 diabetic subjects. Diabetes. 1999;48(5):1113-9.

20. Krssak M, Falk Petersen K, Dresner A, DiPietro L, Vogel SM, Rothman DL, Roden M, Shulman Gl. Intramyocellular lipid concentrations are correlated with insulin sensitivity in humans: a ${ }^{1} \mathrm{H}$ NMR spectroscopy study. Diabetologia. 1999;42(1):113-6.

21. Itani SI, Ruderman NB, Schmieder F, Boden G. Lipid-induced insulin resistance in human muscle is associated with changes in diacylglycerol, protein kinase C, and IkappaB-alpha. Diabetes. 2002;51(7):2005-11.

22. Moro C, Bajpeyi S, Smith SR. Determinants of intramyocellular triglyceride turnover: implications for insulin sensitivity. American journal of physiology Endocrinology and metabolism. 2008;294(2):E203-13.

23. Browning JD, Szczepaniak LS, Dobbins R, Nuremberg P, Horton JD, Cohen JC, Grundy SM, Hobbs HH. Prevalence of hepatic steatosis in an urban population in the United States: impact of ethnicity. Hepatology. 2004;40(6):1387-95.

24. Jimba S, Nakagami T, Takahashi M, Wakamatsu T, Hirota Y, Iwamoto Y, Wasada T. Prevalence of non-alcoholic fatty liver disease and its association with impaired glucose metabolism in Japanese adults. Diabetic medicine : a journal of the British Diabetic Association. 2005;22(9):1141-5.

25. Yki-Jarvinen $\mathrm{H}$. Ectopic fat accumulation: an important cause of insulin resistance in humans. Journal of the Royal Society of Medicine. 2002;95 
Suppl 42:39-45.

26. Fong DG, Nehra V, Lindor KD, Buchman AL. Metabolic and nutritional considerations in nonalcoholic fatty liver. Hepatology. 2000;32(1):3-10.

27. Reingold JS, McGavock JM, Kaka S, Tillery T, Victor RG, Szczepaniak LS. Determination of triglyceride in the human myocardium by magnetic resonance spectroscopy: reproducibility and sensitivity of the method. American journal of physiology Endocrinology and metabolism. 2005;289(5):E935-9.

28. Gordon RS, Jr. Unesterified fatty acid in human blood plasma. II. The transport function of unesterified fatty acid. The Journal of clinical investigation. 1957;36(6 Part 1):810-5.

29. Gordon RS, Jr., Cherkes A. Unesterified fatty acid in human blood plasma. The Journal of clinical investigation. 1956;35(2):206-12.

30. Hafizi Abu Bakar M, Kian Kai C, Wan Hassan WN, Sarmidi MR, Yaakob H, Zaman Huri H. Mitochondrial dysfunction as a central event for mechanisms underlying insulin resistance: the roles of long chain fatty acids. Diabetes/ metabolism research and reviews. 2014.

31. Coppack SW, Jensen MD, Miles JM. In vivo regulation of lipolysis in humans. Journal of lipid research. 1994;35(2):177-93.

32. McQuaid SE, Hodson L, Neville MJ, Dennis AL, Cheeseman J, Humphreys SM, Ruge T, Gilbert M, Fielding BA, Frayn KN, Karpe F. Downregulation of adipose tissue fatty acid trafficking in obesity: a driver for ectopic fat deposition? Diabetes. 2011;60(1):47-55.

33. Coppack SW, Evans RD, Fisher RM, Frayn KN, Gibbons GF, Humphreys SM, Kirk ML, Potts JL, Hockaday TD. Adipose tissue metabolism in obesity: lipase action in vivo before and after a mixed meal. Metabolism: clinical and experimental. 1992;41(3):264-72.

34. Roust LR, Jensen MD. Postprandial free fatty acid kinetics are abnormal in upper body obesity. Diabetes. 1993;42(11):1567-73.

35. Flatt JP. Role of the increased adipose tissue mass in the apparent insulin insensitivity of obesity. The American journal of clinical nutrition. 1972;25(11):1189-92.

36. Karpe F, Dickmann JR, Frayn KN. Fatty acids, obesity, and insulin resistance: time for a reevaluation. Diabetes. 2011;60(10):2441-9.

37. Byrne CD, Wareham NJ, Brown DC, Clark PM, Cox LJ, Day NE, Palmer CR, Wang TW, Williams DR, Hales CN. Hypertriglyceridaemia in subjects with normal and abnormal glucose tolerance: relative contributions of insulin secretion, insulin resistance and suppression of plasma non-esterified fatty acids. Diabetologia. 1994;37(9):889-96.

38. Leahy JL. Pathogenesis of type 2 diabetes mellitus. Archives of medical research. 2005;36(3):197-209.

39. Holt HB, Wild SH, Wood PJ, Zhang J, Darekar AA, Dewbury K, Poole RB, 
Holt RI, Phillips DI, Byrne CD. Non-esterified fatty acid concentrations are independently associated with hepatic steatosis in obese subjects. Diabetologia. 2006;49(1):141-8.

40. Schrauwen-Hinderling VB, van Loon LJ, Koopman R, Nicolay K, Saris $\mathrm{WH}$, Kooi ME. Intramyocellular lipid content is increased after exercise in nonexercising human skeletal muscle. Journal of applied physiology. 2003;95(6):2328-32.

41. Kankaanpaa M, Lehto HR, Parkka JP, Komu M, Viljanen A, Ferrannini E, Knuuti J, Nuutila P, Parkkola R, lozzo P. Myocardial triglyceride content and epicardial fat mass in human obesity: relationship to left ventricular function and serum free fatty acid levels. The Journal of clinical endocrinology and metabolism. 2006;91(11):4689-95.

42. Koo SH. Nonalcoholic fatty liver disease: molecular mechanisms for the hepatic steatosis. Clinical and molecular hepatology. 2013;19(3):210-5.

43. van der Meer RW, Hammer S, Smit JW, Frolich M, Bax JJ, Diamant M, Rijzewijk LJ, de Roos A, Romijn JA, Lamb HJ. Short-term caloric restriction induces accumulation of myocardial triglycerides and decreases left ventricular diastolic function in healthy subjects. Diabetes. 2007;56(12):2849-53.

44. Schrauwen-Hinderling VB, Hesselink MK, Meex R, van der Made S, Schar M, Lamb H, Wildberger JE, Glatz J, Snoep G, Kooi ME, Schrauwen P. Improved ejection fraction after exercise training in obesity is accompanied by reduced cardiac lipid content. The Journal of clinical endocrinology and metabolism. 2010;95(4):1932-8.

45. Sullivan S, Kirk EP, Mittendorfer B, Patterson BW, Klein S. Randomized trial of exercise effect on intrahepatic triglyceride content and lipid kinetics in nonalcoholic fatty liver disease. Hepatology (Baltimore, Md. 2012;55(6):1738-45.

46. Hallsworth K, Fattakhova G, Hollingsworth KG, Thoma C, Moore S, Taylor R, Day CP, Trenell MI. Resistance exercise reduces liver fat and its mediators in non-alcoholic fatty liver disease independent of weight loss. Gut. 2011;60(9):1278-83.

47. Finucane FM, Sharp SJ, Purslow LR, Horton K, Horton J, Savage DB, Brage S, Besson H, De Lucia Rolfe E, Sleigh A, Martin HJ, Aihie Sayer A, Cooper C, Ekelund U, Griffin SJ, Wareham NJ. The effects of aerobic exercise on metabolic risk, insulin sensitivity and intrahepatic lipid in healthy older people from the Hertfordshire Cohort Study: a randomised controlled trial. Diabetologia. 2010;53(4):624-31.

48. Chen SM, Liu CY, Li SR, Huang HT, Tsai CY, Jou HJ. Effects of therapeutic lifestyle program on ultrasound-diagnosed nonalcoholic fatty liver disease. J Chin Med Assoc. 2008;71(11):551-8.

49. Meex RC, Schrauwen-Hinderling VB, Moonen-Kornips E, Schaart G, Mensink M, Phielix E, van de Weijer T, Sels JP, Schrauwen P, Hesselink 
MK. Restoration of muscle mitochondrial function and metabolic flexibility in type 2 diabetes by exercise training is paralleled by increased myocellular fat storage and improved insulin sensitivity. Diabetes. 2010;59(3):572-9.

50. Rogers MA. Acute effects of exercise on glucose tolerance in non-insulindependent diabetes. Medicine and science in sports and exercise. 1989;21(4):362-8.

51. Frank P, Katz A, Andersson E, Sahlin K. Acute exercise reverses starvationmediated insulin resistance in humans. American journal of physiology. 2013;304(4):E436-43.

52. Mackenzie R, Maxwell N, Castle P, Elliott B, Brickley G, Watt P. Intermittent exercise with and without hypoxia improves insulin sensitivity in individuals with type 2 diabetes. The Journal of clinical endocrinology and metabolism. 2012;97(4):E546-55.

53. Schrauwen-Hinderling VB, Schrauwen P, Hesselink MK, van Engelshoven JM, Nicolay K, Saris WH, Kessels AG, Kooi ME. The increase in intramyocellular lipid content is a very early response to training. The Journal of clinical endocrinology and metabolism. 2003;88(4):1610-6.

54. White LJ, Ferguson MA, McCoy SC, Kim H. Intramyocellular lipid changes in men and women during aerobic exercise: a (1)H-magnetic resonance spectroscopy study. The Journal of clinical endocrinology and metabolism. 2003;88(12):5638-43.

55. Egger A, Kreis R, Allemann S, Stettler C, Diem P, Buehler T, Boesch C, Christ ER. The effect of aerobic exercise on intrahepatocellular and intramyocellular lipids in healthy subjects. PloS one. 2013;8(8):e70865.

56. Johnson NA, Stannard SR, Mehalski K, Trenell MI, Sachinwalla T, Thompson $\mathrm{CH}$, Thompson MW. Intramyocellular triacylglycerol in prolonged cycling with high- and low-carbohydrate availability. Journal of applied physiology. 2003;94(4):1365-72.

57. Bucher J, Krusi M, Zueger T, Ith M, Stettler C, Diem P, Boesch C, Kreis R, Christ $\mathrm{E}$. The effect of a single $2 \mathrm{~h}$ bout of aerobic exercise on ectopic lipids in skeletal muscle, liver and the myocardium. Diabetologia. 2014;57(5):10015.

58. Krssak M, Petersen KF, Bergeron R, Price T, Laurent D, Rothman DL, Roden M, Shulman GI. Intramuscular glycogen and intramyocellular lipid utilization during prolonged exercise and recovery in man: a $13 \mathrm{C}$ and ${ }^{1} \mathrm{H}$ nuclear magnetic resonance spectroscopy study. The Journal of clinical endocrinology and metabolism. 2000;85(2):748-54.

59. Marceau P, Biron S, Hould FS, Marceau S, Simard S, Thung SN, Kral JG. Liver pathology and the metabolic syndrome $X$ in severe obesity. The Journal of clinical endocrinology and metabolism. 1999;84(5):1513-7.

60. Zhou YT, Grayburn P, Karim A, Shimabukuro M, Higa M, Baetens D, Orci $\mathrm{L}$, Unger $\mathrm{RH}$. Lipotoxic heart disease in obese rats: implications for human 
obesity. Proceedings of the National Academy of Sciences of the United States of America. 2000;97(4):1784-9.

61. Torffvit $\mathrm{O}$, Agardh $\mathrm{C}$. The prognosis for type 2 diabetic patients with heart disease. A 10-year observation study of 385 patients. Journal of diabetes and its complications. 2000;14(6):301-6.

62. Ernande L, Rietzschel ER, Bergerot C, De Buyzere ML, Schnell F, Groisne L, Ovize M, Croisille P, Moulin P, Gillebert TC, Derumeaux G. Impaired myocardial radial function in asymptomatic patients with type 2 diabetes mellitus: a speckle-tracking imaging study. Journal of the American Society of Echocardiography : official publication of the American Society of Echocardiography. 2010;23(12):1266-72.

63. Ng AC, Delgado V, Bertini M, van der Meer RW, Rijzewijk LJ, Shanks M, Nucifora G, Smit JW, Diamant M, Romijn JA, de Roos A, Leung DY, Lamb HJ, Bax JJ. Findings from left ventricular strain and strain rate imaging in asymptomatic patients with type 2 diabetes mellitus. The American journal of cardiology. 2009;104(10):1398-401.

64. Diamant M, Lamb HJ, Groeneveld Y, Endert EL, Smit JW, Bax JJ, Romijn JA, de Roos A, Radder JK. Diastolic dysfunction is associated with altered myocardial metabolism in asymptomatic normotensive patients with wellcontrolled type 2 diabetes mellitus. Journal of the American College of Cardiology. 2003;42(2):328-35.

65. Scheuermann-Freestone M, Madsen PL, Manners D, Blamire AM, Buckingham RE, Styles P, Radda GK, Neubauer S, Clarke K. Abnormal cardiac and skeletal muscle energy metabolism in patients with type 2 diabetes. Circulation. 2003;107(24):3040-6.

66. Neubauer S, Horn M, Cramer M, Harre K, Newell JB, Peters W, Pabst T, Ertl G, Hahn D, Ingwall JS, Kochsiek K. Myocardial phosphocreatine-toATP ratio is a predictor of mortality in patients with dilated cardiomyopathy. Circulation. 1997;96(7):2190-6.

67. Gaborit B, Jacquier A, Kober F, Abdesselam I, Cuisset T, Boullu-Ciocca $\mathrm{S}$, Emungania O, Alessi MC, Clement K, Bernard M, Dutour A. Effects of bariatric surgery on cardiac ectopic fat: lesser decrease in epicardial fat compared to visceral fat loss and no change in myocardial triglyceride content. Journal of the American College of Cardiology. 2012;60(15):13819 .

68. Vest AR, Heneghan HM, Agarwal S, Schauer PR, Young JB. Bariatric surgery and cardiovascular outcomes: a systematic review. Heart. 2012;98(24):1763-77.

69. Lehto HR, Parkka J, Borra R, Tuunanen H, Lepomaki V, Parkkola R, Knuuti J, Nuutila P, lozzo P. Effects of acute and one-week fatty acid lowering on cardiac function and insulin sensitivity in relation with myocardial and muscle fat and adiponectin levels. The Journal of clinical endocrinology 
and metabolism. 2012;97(9):3277-84.

70. Szczepaniak LS, Nurenberg P, Leonard D, Browning JD, Reingold JS, Grundy S, Hobbs HH, Dobbins RL. Magnetic resonance spectroscopy to measure hepatic triglyceride content: prevalence of hepatic steatosis in the general population. American journal of physiology Endocrinology and metabolism. 2005;288(2):E462-8.

71. Brunt EM, Janney CG, Di Bisceglie AM, Neuschwander-Tetri BA, Bacon BR. Nonalcoholic steatohepatitis: a proposal for grading and staging the histological lesions. The American journal of gastroenterology. 1999;94(9):2467-74.

72. Falck-Ytter Y, Younossi ZM, Marchesini G, McCullough AJ. Clinical features and natural history of nonalcoholic steatosis syndromes. Seminars in liver disease. 2001;21(1):17-26.

73. Matteoni CA, Younossi ZM, Gramlich T, Boparai N, Liu YC, McCullough AJ. Nonalcoholic fatty liver disease: a spectrum of clinical and pathological severity. Gastroenterology. 1999;116(6):1413-9.

74. Marchesini G, Brizi M, Morselli-Labate AM, Bianchi G, Bugianesi E, McCullough AJ, Forlani G, Melchionda N. Association of nonalcoholic fatty liver disease with insulin resistance. The American journal of medicine. 1999;107(5):450-5.

75. Tiikkainen M, Tamminen M, Hakkinen AM, Bergholm R, Vehkavaara S, Halavaara J, Teramo K, Rissanen A, Yki-Jarvinen H. Liver-fat accumulation and insulin resistance in obese women with previous gestational diabetes. Obesity research. 2002;10(9):859-67.

76. Seppala-Lindroos A, Vehkavaara S, Hakkinen AM, Goto T, Westerbacka J, Sovijarvi A, Halavaara J, Yki-Jarvinen H. Fat accumulation in the liver is associated with defects in insulin suppression of glucose production and serum free fatty acids independent of obesity in normal men. The Journal of clinical endocrinology and metabolism. 2002;87(7):3023-8.

77. Szendroedi J, Chmelik M, Schmid Al, Nowotny P, Brehm A, Krssak M, Moser E, Roden M. Abnormal hepatic energy homeostasis in type 2 diabetes. Hepatology (Baltimore, Md. 2009;50(4):1079-86.

78. Schmid Al, Szendroedi J, Chmelik M, Krssak M, Moser E, Roden M. Liver ATP synthesis is lower and relates to insulin sensitivity in patients with type 2 diabetes. Diabetes care. 2011;34(2):448-53.

79. Camacho RC, Donahue EP, James FD, Berglund ED, Wasserman DH. Energy state of the liver during short-term and exhaustive exercise in C57BL/6J mice. American journal of physiology. 2006;290(3):E405-8.

80. Koliaki C, Roden M. Hepatic energy metabolism in human diabetes mellitus, obesity and non-alcoholic fatty liver disease. Molecular and cellular endocrinology. 2013;379(1-2):35-42.

81. Denton RM, Randle PJ. Concentrations of glycerides and phospholipids 
in rat heart and gastrocnemius muscles. Effects of alloxan-diabetes and perfusion. The Biochemical journal. 1967;104(2):416-22.

82. Pan DA, Lillioja S, Milner MR, Kriketos AD, Baur LA, Bogardus C, Storlien LH. Skeletal muscle membrane lipid composition is related to adiposity and insulin action. The Journal of clinical investigation. 1995;96(6):2802-8.

83. Goodpaster BH, Theriault R, Watkins SC, Kelley DE. Intramuscular lipid content is increased in obesity and decreased by weight loss. Metabolism. 2000;49(4):467-72.

84. Toledo FG, Menshikova EV, Azuma K, Radikova Z, Kelley CA, Ritov VB, Kelley $D E$. Mitochondrial capacity in skeletal muscle is not stimulated by weight loss despite increases in insulin action and decreases in intramyocellular lipid content. Diabetes. 2008;57(4):987-94.

85. Bachmann OP, Dahl DB, Brechtel K, Machann J, Haap M, Maier T, Loviscach M, Stumvoll M, Claussen CD, Schick F, Haring HU, Jacob S. Effects of intravenous and dietary lipid challenge on intramyocellular lipid content and the relation with insulin sensitivity in humans. Diabetes. 2001;50(11):257984.

86. Rabol R, Boushel R, Dela F. Mitochondrial oxidative function and type 2 diabetes. Applied physiology, nutrition, and metabolism = Physiologie appliquee, nutrition et metabolisme. 2006;31(6):675-83.

87. Hoeks J, Hesselink MK, Russell AP, Mensink M, Saris WH, Mensink RP, Schrauwen P. Peroxisome proliferator-activated receptor-gamma coactivator-1 and insulin resistance: acute effect of fatty acids. Diabetologia. 2006;49(10):2419-26.

88. Phielix E, Meex R, Ouwens DM, Sparks L, Hoeks J, Schaart G, MoonenKornips E, Hesselink MK, Schrauwen P. High oxidative capacity due to chronic exercise training attenuates lipid-induced insulin resistance. Diabetes. 2012;61(10):2472-8.

89. Brands M, Hoeks J, Sauerwein HP, Ackermans MT, Ouwens M, Lammers NM, van der Plas MN, Schrauwen P, Groen AK, Serlie MJ. Short-term increase of plasma free fatty acids does not interfere with intrinsic mitochondrial function in healthy young men. Metabolism: clinical and experimental. 2011;60(10):1398-405.

90. Jans A, van Hees AM, Gjelstad IM, Sparks LM, Tierney AC, Riserus U, Drevon CA, Schrauwen P, Roche HM, Blaak EE. Impact of dietary fat quantity and quality on skeletal muscle fatty acid metabolism in subjects with the metabolic syndrome. Metabolism: clinical and experimental. 2012;61(11):1554-65.

91. Brons C, Jensen CB, Storgaard H, Hiscock NJ, White A, Appel JS, Jacobsen S, Nilsson E, Larsen CM, Astrup A, Quistorff B, Vaag A. Impact of short-term high-fat feeding on glucose and insulin metabolism in young healthy men. The Journal of physiology. 2009;587(Pt 10):2387-97. 
92. Samocha-Bonet D, Campbell LV, Mori TA, Croft KD, Greenfield JR, Turner N, Heilbronn LK. Overfeeding reduces insulin sensitivity and increases oxidative stress, without altering markers of mitochondrial content and function in humans. PloS one. 2012;7(5):e36320.

93. Schrauwen-Hinderling VB, Hesselink MK, Schrauwen P, Kooi ME. Intramyocellular lipid content in human skeletal muscle. Obesity. 2006;14(3):357-67.

94. Rimbert V, Boirie Y, Bedu M, Hocquette JF, Ritz P, Morio B. Muscle fat oxidative capacity is not impaired by age but by physical inactivity: association with insulin sensitivity. FASEB journal : official publication of the Federation of American Societies for Experimental Biology. 2004;18(6):7379.

95. Short KR, Vittone JL, Bigelow ML, Proctor DN, Rizza RA, Coenen-Schimke JM, Nair KS. Impact of aerobic exercise training on age-related changes in insulin sensitivity and muscle oxidative capacity. Diabetes. 2003;52(8):188896.

96. Kelley DE, He J, Menshikova EV, Ritov VB. Dysfunction of mitochondria in human skeletal muscle in type 2 diabetes. Diabetes. 2002;51(10):2944-50.

97. Lowell BB, Shulman Gl. Mitochondrial dysfunction and type 2 diabetes. Science. 2005;307(5708):384-7. 
L.Bilet 
CHAPTER

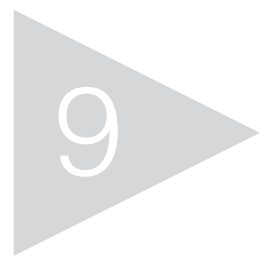

Appendices 


\section{SUMMARY}

An obesity epidemic exists worldwide, which in turn is linked to an epidemic of chronic disorders such as type 2 diabetes and cardiovascular disease. Obesity occurs as a result of an imbalance between calories consumed and calories expended resulting in an energy imbalance. This energy imbalance is further caused by overnutrition and physical inactivity. While obesity is characterized by an excessive accumulation of fat in the body, it is specifically the accumulation of fat within peripheral tissues, such as skeletal muscle, liver and heart (steatosis or ectopic fat accumulation) that is associated with the development of insulin resistance, making ectopic fat accumulation a possible link between obesity and chronic metabolic disorders. However, why fat accumulates in ectopic tissues is not completely understood. Increased flux of fatty acids into ectopic tissues has been suggested to lead to disturbances in tissue function, a phenomenon known as lipotoxicity. In this thesis, we investigated the role of plasma free fatty acids (FFA) in lipid accumulation in skeletal muscle, liver and heart.

In chapters 2-5 we manipulated plasma FFA levels physiologically with exercise or pharmacologically with the anti-lipolytic drug Acipimox. We demonstrated that an acute bout of exercise leads to different effects on IMCL depending on whether exercise is performed in a fasted or in a glucose-supplemented condition (chapter 4). In spite of an increased cellular demand of fatty acids during exercise, fat accumulates in skeletal muscle when plasma FFAs are high, whereas when performing exercise in a glucose-supplemented condition IMCL is decreasing in exercising muscle. Likewise, in type 2 diabetic patients, increased plasma FFAs, due to a rebound effect of Acipimox, also led to increased IMCL (chapter 5). This suggests that plasma FFAs are important determinants of IMCL and that skeletal muscle takes up plasma FFA unrestricted when the availability is high, independent of cellular needs.

In contrast to the skeletal muscle, the liver does not accumulate fat as an energy store under conditions of high cellular demand such as exercise training. However, with the current obesity epidemic up to one third of all people with overweight and obesity have elevated lipid content in the liver. In contrast to what is seen with exercise training, one acute bout of exercise was not able to lower hepatic lipid content in men with overweigh or NAFLD with the current protocol (chapter 3). Instead, similar to the skeletal muscle, exercise-induced elevations of plasma FFAs 
triggered uptake into the liver resulting in increased intrahepatic lipid accumulation four hours post-exercise. Furthermore, we also found a tendency to a lower energy status of the liver four hours post-exercise.

Previous studies have found that also cardiac lipid content correlates with plasma FFA levels, and in line with this, we also found myocardial fat to increase when plasma FFA levels were elevated by means of exercise in this thesis (chapter 2). In type 2 diabetes elevated levels of cardiac lipids have been linked to cardiac dysfunction and lowered cardiac energy status. In support of this, we observed that cardiac energy status, expressed as PCr/ATP ratio, was decreased in parallel with increased cardiac lipid content upon exercise in the fasted state. Surprisingly, however, systolic cardiac function improved rather than decreased upon exerciseinduced changes in cardiac lipid content in the same study. This indicates that fat accumulation per se is not necessarily detrimental to organ function, at least not on short term. Likewise, in chapter 5, where plasma FFAs were increased due to a rebound-effect of Acipimox-administration, cardiac lipid content and cardiac energy status were unchanged, despite a tendency to decreased cardiac function.

Although plasma FFA levels, as pointed out above, play an important role in ectopic lipid accumulation and the development of insulin resistance, mitochondrial dysfunction is also suggested to be an important determinant of ectopic lipid accumulation. Therefore, in chapter 6 , we tried to unravel the relationship between mitochondrial function, ectopic lipid accumulation and insulin resistance. We applied the model of unilateral lower limb suspension, mimicking inactivity in one leg of a subject, while using the other leg of the same individual as an active control. We revealed that inactivity blunts in vivo mitochondrial function and reduces fat oxidative capacity while promoting incorporation of fat into intramyocellular triglyceride stores ex vivo. Accordingly, intramyocellular lipid content in the inactive leg was higher and blunting of insulin signalling upon lipid infusion more pronounced than in the active leg. Thus, we demonstrated that a physical inactivity-mediated decline in mitochondrial function directly impacts insulin sensitivity under high lipid conditions.

Alpha-hydroxybutyrate has been recognized as a novel biomarker for progressive insulin resistance. In chapter 7 we used samples obtained from a variety of studies in well phenotyped subjects to examine if alpha-hydroxybutyrate could also be a useful marker to detect early changes in insulin sensitivity in future studies. We 
demonstrated that indeed alpha-hydroxybutyrate is a marker of insulin resistance. However, alleviation of insulin resistance by exercise training does not necessitate a decline in alpha-hydroxybutyrate and we observed little added value of using alpha-hydroxybutyrate as a predictive marker for insulin resistance relative to conventional markers like fasting insulin and glucose levels.

In conclusion, from the results obtained in this thesis we conclude that plasma FFA concentrations are important determinants of ectopic fat accumulation and that the uptake of FFAs into the ectopic tissue largely depends on FFA availability. By taking up excessive FFA from the circulation, the heart, the liver and the skeletal muscle together act as a buffer contributing to the clearance of FFA from the plasma. Furthermore, excessive cardiac lipid accumulation is not causally related to cardiac function, and changes in plasma FFA and cardiac lipid content do not consistently predict changes in cardiac function. However, increased lipid content in heart and liver were paralleled with a decreased energy status of these tissues; the clinical consequences of this need to be investigated in future studies. For the skeletal muscle, we show that not only elevated plasma FFA, but also decreased physical activity (induced by unilateral lower limb suspension is this thesis), goes along with increased intramyocellular lipid content together with decreased in vivo mitochondrial function and oxidative capacity. However, the interrelationship between these parameters is still unknown and should be explored in more detail in the future. 


\section{VALORIZATION ADDENDUM}

\section{SOCIAL RELEVANCE}

Obesity is today's most obvious visible health problem. Obesity is escalating and has become a global epidemic. The prevalence of obesity has more than doubled between 1980 and 2015, and without proper interventions, the prevalence of obesity-related conditions is likely to increase as obesity continues to rise in the next few decades. At present, at least 2.8 million people die prematurely each year as a result of being overweight or obese (WHO report March 2013). The health consequences of obesity are related to metabolic diseases, such as type 2 diabetes, cardiovascular disease, hypertension, stroke and certain types of cancer. Next to the metabolic complications, obesity also has social and psychological dimensions affecting essentially all ages and socioeconomic groups. Taken together, obesity and its complications can dramatically impair quality of life and have a big impact on health care costs. Therefore, it is important with immediate action to slow down or stop the global obesity epidemic and its complications. In this context a better understanding of the underlying cause of obesity related complications is needed and could result in the development of more specific therapeutic or preventive strategies for people at risk.

\section{TARGET GROUPS}

The obesity epidemic is a result of people consuming high caloric diets and being physically inactive. This results in an imbalance between calories consumed and calories expended, and hence a positive energy balance. This positive energy imbalance leads to an excessive accumulation of fat not only in adipose tissue, but also in non-adipose tissues (ectopic fat accumulation), such as skeletal muscle, liver and heart. In contrast to the fat stored in adipose tissues, the fat stored in the nonadipose tissue is associated with the development of insulin resistance and type 2 diabetes. Therefore, to slow down the development of obesity related complications, such as type 2 diabetes, it is essential to gain a better understanding of why lipids store in these tissues and what the consequences of ectopic fat storage are.

Because obesity affects millions of people worldwide and leads to exploding healthcare costs, the search for novel strategies to counteract obesity and its complications is important for the general public, and especially for those at risk 
of developing overweight- and obesity related complications. In this context, discovery of novel therapies and treatments might lead to an improvement of quality of life and long-term health, but also to saving health care costs by e.g. reduced hospitalization. Therefore it is important for obesity and diabetes management that the communication between researchers and health institutions, health care professionals and the general population, is good, so that knowledge can be shared.

\section{ACTIVITIES AND PRODUCTS}

The studies described in this thesis have been conducted at the department of Human Biology of Maastricht University Medical Center+. In order to investigate the causes and consequences of ectopic fat accumulation, some studies were done in collaboration with the department of Radiology of the University Hospital of Maastricht. This collaboration was essentially, as the current technique to measure ectopic fat in skeletal muscle, liver and heart non-invasively with Magnetic Resonance Spectroscopy (MRS) was only available in the hospital. All studies outlined in this thesis were conducted in human volunteers and different interventions were applied to manipulate e.g. plasma free fatty acid levels. Both in vivo and ex vivo state-ofthe-art techniques, such as MRS and high-resolution respirometry, were applied to unravel why fat is stored in non-adipose tissues and what the consequences are.

The results described in this thesis have been implemented in original research articles that have been published or submitted to scientific journals in the field of obesity and diabetes. These articles are to be found online and are accessible to other scientists. The present results have also been presented on international conferences and can be used for future studies.

\section{INNOVATION}

In obesity there is a failure in the capacity of appropriate adipose tissue expansion, which leads to an increased flux of free fatty acids away from rather than into adipose tissue resulting in an increased storage of fat in non-adipose tissues. This increased influx of free fatty acids is believed to be harmful to the tissues, contributing to insulin resistance and type 2 diabetes, a process referred to as lipotoxicity. Alternatively, impaired oxidative capacity of the mitochondria could also be an underlying factor for ectopic fat accumulation, interestingly, a low mitochondrial function has also been linked to insulin resistance. In this thesis, we mainly focused on the role of FFA in this 
ectopic fat accumulation and how this is linked to lipotoxicity, but also investigate mitochondrial function as a factor in lipotoxicity. We recruited human volunteers who underwent a combination of intervention studies, including manipulations of plasma FFA by acute exercise or administration of the antilipolytic-drug acipimox and manipulations of mitochondrial function and oxidative capacity by inactivity. Earlier, the heart and the liver were both inaccessible for human studies. However, due to a development of the non-invasive MRS technique and the implementation on clinical MRI scanners in recent years, we were able to intensively study the ectopic fat accumulation (with proton ( $\left.{ }^{1} \mathrm{H}\right) \mathrm{MRS}$ ) in skeletal muscle, liver and heart in both healthy volunteers and in people with type 2 diabetes. Additionally, applying phosphorous $\left({ }^{31} \mathrm{P}\right)$ MRS enabled us to investigate the energy status of the heart and the liver and the in vivo mitochondrial function of skeletal muscle. Another strength of this thesis therefore is that we were able to measure ectopic fat accumulation in more tissues enabling a comparison between tissues. The excellent facilities of our lab also enabled us to investigate subjects' substrate metabolism and insulin sensitivity in vivo by means of a ventilated hood and a 2-step hyperinsulinemic euglycemic clamp, respectively. Next to performing in vivo measurements, muscle biopsies were also withdrawn for ex vivo measurements of oxidative capacity, fatand glucose metabolism and insulin signalling analysis. Oxidative capacity was measured with high-resolution respirometry (Oroboros oxygraph), fat- and glucose metabolism by ${ }^{14} \mathrm{C}$ oxidation assays and insulin signaling by western blotting. The results provided us with valuable information on the role of FFA on ectopic fat accumulation and organ function. With the mentioned techniques we were able to show that plasma FFA levels are an important determinant for ectopic fat accumulation and that non-adipose tissues seem to take up plasma FFA from the circulation when the availability is high, independent of oxidative needs. However, we could not show that ectopic fat accumulation always leads to organ dysfunction and more research is necessary to answer this. The results of this thesis can be used for future studies focusing on the relevance of fat accumulation and lipotoxicity for the etiology of type 2 diabetes in humans.

\section{PLANNING AND REALIZATION}

In this thesis, human intervention studies have been used to study the role of free fatty acids in ectopic lipid accumulation. We demonstrated that plasma concentration of free fatty acids indeed is an important determinant for ectopic fat accumulation, but that an acute increase in ectopic fat depots did not necessarily lead to harmful 
effects disturbing organ function. Thus, more research is warranted to unravel the relationship between elevated ectopic fat accumulation and tissue dysfunction. In "The Diabetes and Metabolism Research Group" of Prof. dr. P. Schrauwen and Prof. dr. M. Hesselink, this relationship will further be explored by performing translational research. To this end high-end molecular and cellular biology tools and non-invasive and microscopically imaging and spectroscopy will be combined with state-of-theart metabolic phenotyping in a predominantly experimental human research setting. 


\section{LIST OF PUBLICATIONS}

L.Bilet, E. Phielix, E. Moonen-Kornips, V.B. Schrauwen-Hinderling, M.K.C. Hesselink, P. Schrauwen. Differential effects of exercise on IMCL content in the fasted and fed state. In preparation.

L.Bilet, T. van de Weijer, E. Phielix, A. Gemmink, M. Bosma, E. Moonen-Kornips, J. Jorgensen, K. Meijer, M. Hopman, M.K.C. Hesselink, M. Ouwens, V.B. SchrauwenHinderling, P. Schrauwen. The effect of one-legged lowered physical activity on insulin sensitivity and lipid and glucose metabolism. In preparation.

L. Bilet, V.B. Schrauwen-Hinderling, N. A. van Herpen, R.C. Meex, E. Phielix, P. Schrauwen, M.K.C. Hesselink. The novel biomarker for insulin resistance alphahydroksybutyrate is not responsive to lifestyle changes affecting liver fat or insulin sensitivity. Submitted.

L. Bilet, B.M.W. Brouwers, P.A. van Ewijk, M.K.C. Hesselink, M.E. Kooi, V.B. Schrauwen-Hinderling, P. Schrauwen. Acute exercise does not decrease liver fat in men with overweight or NAFLD. Scientific Reports 2015; 5:9709.

T. van de Weijer, E. Phielix, L. Bilet, E.G. Williams, E.R. Ropelle, A. Bierwagen, R. Livingstone, P. Nowotny, L.M. Sparks, S. Paglialunga, J. Szendroedi, B. Havekes, N. Moullan, E. Pirinen, Y.H. Hwang, V.B. Schrauwen-Hinderling, M.K.C. Hesselink, M. Roden, P. Schrauwen. Evidence for a direct effect of NAD+ precursor acipimox on muscle mitochondrial function in humans. Diabetes 2015; 64(4):1193-201.

L.M. Sparks, M. Bosma, B. Brouwers, T. van de Weijer, L. Bilet, G. Schaart, E. Moonen-Kornips, M.K.C. Hesselink, P. Schrauwen. Reduced incorporation of fatty acids into triacylglycerol in myotubes from obese individuals with type 2 diabetes. Diabetes 2014; 63(5): 1583-93.

T. van de Weijer, B. Havekes, L. Bilet, J. Hoeks, L. Sparks, M. Bosma, S. Paglialunga, J. Jorgensen, M.C. Janssen, G. Schaart, H. Sauerwein, J.L. Smeets, J. Wildberger, R. Zechner, V.B. Schrauwen-Hinderling, M.K. Hesselink, P. Schrauwen. Effects of bezafibrate treatment in a patient and a carrier with mutations in the PNPLA2 gene, causing neutral lipid storage disease with myopathy. Circulation Research 2013; 112(5):e51-4. 
S. Timmers, E. Konings, L.Bilet, R. H. Houtkooper, T. van de Weijer, G. H. Goossens, J. Hoeks, S. van der Krieken, D. Ryu, S. Kersten, E. Moonen-Kornips, M. K.C. Hesselink, I. Kunz, V. B. Schrauwen-Hinderling, E. E. Blaak, J. Auwerx, Patrick Schrauwen. Calorie restriction-like effects of 30 days of resveratrol supplementation on energy metabolism and metabolic profile in obese humans. Cell Metabolism 2011; 14(5), 612-622.

L. Bilet, T. van de Weijer, M.K.C. Hesselink, J.F.C. Glatz, H.J. Lamb, J. Wildberger, M.E. Kooi, P. Schrauwen, V.B. Schrauwen-Hinderling. Exercise-induced modulation of cardiac lipid content in healthy lean young men. Basic Research in Cardiology 2010; 106: 307-315. 


\section{CURRICULUM VITAE}

Lena Bilet was born in Moss, Norway, in 1982. She began her studies in Molecular Biology at the University of Oslo, Norway, in 2002. After obtaining her Bachelor in Science in 2005, her interest was more on nutrition and health and she continued specializing in Nutrition at the department of Nutrition, Faculty of Medicine, University of Oslo, Norway. During her Bachelor studies in nutrition she had a 5 months internship at the Faculty of Health Sciences, Stellenbosch University, South Africa, and during her Master studies in nutrition a 10 months research internship at the department of Human Biology, Maastricht University, the Netherlands, where she wrote her thesis entitled 'Effects of acute elevation of circulating fatty acids on cardiac lipid accumulation and cardiac function' under supervision of Prof. dr. Patrick Schrauwen and Dr. Vera Schrauwen-Hinderling. In August 2009 she obtained her Master degree in Nutrition.

In September 2009, Lena started working as a PhD student at the department of Human Biology, Maastricht University Medical Center+, the Netherlands, under supervision of Prof. dr. Schrauwen, Prof. dr. M.K.C. Hesselink and Dr. Vera Schrauwen-Hinderling. Her project encompassed human studies focusing on the role of plasma free fatty acids on ectopic fat accumulation and organ function in relation to obesity and type 2 diabetes.

In January 2015, Lena continued her work as a post-doctoral researcher at the department of Human Biology/Human Movement Sciences. She is carrying out clinical trials in collaboration with Unilever, looking into the effect of diet on health and wellbeing. 


\section{ACKNOWLEDGEMENTS}

Finally, I'm there! My book is finished! I'm writing the acknowledgements as the very last thing I have to do. This seemed like an easy task, but it felt like a project on its own.

Looking back at my PhD period, it all started back in 2008, when I was "grenzeloos verliefd" and was looking for a place to do my research internship in Maastricht. Luckily I could start in the research group of Prof. dr. Patrick Schrauwen and Prof. dr. Matthijs Hesselink. Both love and research did me well, so I continued as a PhD student. I only have good memories from my $\mathrm{PhD}$ period. I was a part of a great research team, where I also made friends for life. On a personal level it also meant being away from home, learning a new language and a new culture. This period would not have been the same without the supervision, support, help, love and friendship from many, who I would like to thank.

First of all I would like to express my deep gratitude to my promotors Prof. dr. Patrick Schrauwen and Prof. dr. Matthijs Hesselink and my co-promotor Dr. Vera Schrauwen-Hinderling. Thank you for believing in me and for giving me this great opportunity. Your patient guidance, enthusiastic encouragement and useful critiques were highly appreciated. I have really learned a lot and grown as a researcher. Thank you for that. The combination of Vera's helpfulness, Patrick's efficiency and Matthijs' final touch on the writing, made you a great team of supervisors.

Secondly, I would like to thank the members of the thesis assessment and defence committee, Prof. dr. ir. R.P. Mensink, Prof. dr. C. Schalkwijk, Prof. dr. ir. A. Kersten, Prof. dr. J. Eckel, Dr. G. Plasqui and Prof. dr. J. Plat, for finding the time to review my thesis and/or being present at the official dissertation.

I would also like to thank all (ex)SHOCkers, without help and support from many of you this thesis would not have been possible. Thank you for the good teamwork throughout the years. I have really been enjoying working with all of you. Esther, thank you for being a good support both at work and in private. You are someone I can always count on and I'm very lucky to have found such a true friend. It is so great that our children are growing up together; I'm looking forward to all the fun we are going to have. Thank you for being my paranimf on the big day. Tineke, starting in the SHOCk almost at the same time we have had the opportunity to work on many studies together. With your good mood, enthusiasm and practical jokes you were 
always fun to be around. Thank you for letting me be your paranimf as well, it was an honour. Bram, my roomy, you were always such a relaxed roommate. I don't know what I would have done without you sharing my love for working in a steamy hot environment. We also had the opportunity to perform a study together, which I think we did as a great team. I hope you will find your dream job and I wish you all the best for the future with Tatiana. Lauren, we hit it off right away and became good friends. Your knowledge and determination always impressed me. You were a great motivator at work and outside work you made me accomplish things I never thought I would, like running the 2010 Amsterdam marathon. I especially appreciated our late evenings (the time vacuum) with a glass (or two :-P) of wine talking about everything. Thank you for being my 'Lauren translator', my thesis reads a little bit better thanks to you! Heather, thank you for all the fun we had together. I wish you and Lauren all the best for the future together with your beautiful Finley. Eline, Anne and Madeleen, without your help and expertise many of my studies would not have been possible. Great teamwork pays off. Silvie and Sabina, we also had the opportunity to work together, which resulted in great publications. Joris, thank you for sharing your oxygraph expertise and for critically evaluating my data.

I would also like to extend my thanks to all my colleagues at the department of Human Biology and Human movement sciences for all their help and support. A special thanks goes to the technicians of the laboratory, Gert, Esther, Johanna and Jos, for running many of my analyses. Loek, Paul and Laurens, thank you for your technical support. To the secretaries, thank you for always being friendly and helpful. Ronald thank you for your statistical advises. It is good to have someone who knows some statistics in our department. Kenneth Meijer and Hans Essers, your help and advice with setting up my immobilization study were much appreciated. Bas Havekes, thank you for your professional advice on subject inclusion and for being the responsible doctor for many of my studies.

I would also like to thank the MRI technicians at the radiology department for always being friendly and helpful. At the radiology department I would also like to thank, Dr. Eline Kooi, for providing me with very valuable insight about MRS during our weekly spectro club meetings. Our collaboration also resulted in a couple of nice publications.

Thanks are also due to Prof. dr. Michael Roden and Prof. dr. Margriet Ouwens for nice collaborations, and Prof. dr. Maria Hopman for advise about my immobilization 
study and for letting us borrow your unilateral lower limb suspension equipment.

I would like to offer my special thanks to all volunteers, who participated in my studies, without your effort my studies would not have been possible. Also to all students who did their research internship with me, all your hard work was highly appreciated.

Finally, to all my friends and family, thank you for always being there for me.

Karen Eline, selv om vi ikke ser hverandre så ofte som vi kunne ønske setter jeg veldig pris på vennskapet vårt. Du betyr veldig mye for meg og jeg savner deg masse. Veldig morsomt at vi nå begge er småbarnsforeldre, tussen takk for at jeg får lov til å være fadder til Eric, det setter jeg veldig stor pris på. Malin, sammen med deg hadde jeg en kjempefin start på min tid som student. Tusen takk for all støtte du gav meg da jeg hadde det vanskelig. Fjellturer og backpacking gjennom Afrika er gode minner jeg alltid kommer til å ha med meg. Selv om livene våre bare blir mer og mer travle, håper jeg allikevel at vi vil klare å sette av litt tid til hverandre. Harald, Kristoffer og Jan Petter, gutta mine. Tusen takk for deres gode vennskap. Selv om det går litt tid mellom hver gang vi møtes, storkoser jeg meg alltid i deres selskap. Linda, Trine og Maria, selv om vi er spredt rundt i verden slipper vi ikke helt taket på hverandre. Jeg setter veldig pris på deres vennskap. Jenteturen vår til Barcelona var utrolig fin, det føltes som om vi var tilbake på barneskolen igjen. Jeg hadde det så moro med dere og jeg håper vi snart får sjansen til å dra på en slik tur igjen. Kristin, du er min første og eneste norske venninne her i Nederland. Det er godt å ha en man kan snakke norsk med og en man kan identifisere seg med. Du er en person med mange jern i ilden og du imponerer meg med alt du klarer å få til. Nederlandsk lærte du også utrolig fort (litt misunnelig der). Bart, as one of Stef's best friends, you were one of the first people I got to know here in the Netherlands. You have become a close friend to me as well. I'm very happy that you found such a great girl as Dominique. Dominique, it is so great that we live much closer to each other now. I am looking forward to more evenings of cooking and playing games! Samefko and Helen, Sander and Lisa, Guy and Maartje, I appreciate our friendship. Darius, as promised, you will also be acknowledged ;-) When I desperately needed a computer, your help was not far away. We have already made so many great memories together. You, Esther, Julius and Lennart have a special place in my heart. 
Beste schoonfamilie (Henk en Carla, Jacqueline en Ruud, Tim en Ayfa, Myrthe en Joep, Juliette en Wesley). Ik ben door jullie met open armen ontvangen en jullie hebben het gemis aan mijn eigen familie weten te verzachten. Ik had me geen betere schoonfamilie kunnen wensen. Beste Henk, om de week pas je op Sebastian, bedankt voor jouw behulpzaamheid. Ik geniet er van dat je zoveel plezier beleeft aan Sebastian. Lieve Jacqueline, altijd positief gestemd, je staat altijd voor me klaar. Ik hoefde maar te laten weten wanneer ik het druk had met mijn promotie, of je zat al in de auto. Ayfa, thank you for making this book so beautiful! I admire your creativity and your talent for realizing your ideas. You immediately had an idea for my book cover, and I never doubted the result. I would also like to thank you for all the tips and tricks you gave me while I was busy making the layout for this book. Without your help it wouldn't have been possible.

Kjære mamma og pappa. Takk for all deres kjærlighet, tillit og støtte. Dere har alltid vært der for meg og alltid stilt opp når jeg har trengt dere. Det har tatt sin tid, men nå tror jeg endelig jeg kan si at jeg er ferdig med studiene mine ;-). Mamma, takk for at du alltid er så snill og god. Pappa, takk for din generøsitet, dine bidrag opp gjennom årene har kommet godt med når kontoen nesten har vært tom. Sofie Elise, snuppa mi. Jeg husker som om det var i går hvor glad jeg var når du ble født - endelig en liten søster! Du var en morsom liten skrulle som imponerte med mange vittigheter og påfunn. Det var ikke lett å flytte til Nederland og måtte forlate deg. Jeg er veldig stolt av deg og du kommer alltid til å vær jenta mi. Glad i deg.

Stef, you are everything I need. Nothing of this would have been possible without you. Thank you for believing in me, when I did not believe in myself. There were times when I thought I would never manage to finish this thesis in time. Thank you for keeping up with me during these last months and for always supporting me. I promise you that it will be a little bit more time for your promotion now that I'm finished ;-). Thank you for always making me smile and for loving me. Thank you for giving me a great family. I have never regret following my heart and leaving everything behind for you. 'All of me, loves all of you!' - John Legend -

Sebastian, takk for at du lyser opp hverdagen min. Du er det vakreste jeg noen gang har laget, mamma er veldig glad i deg! 


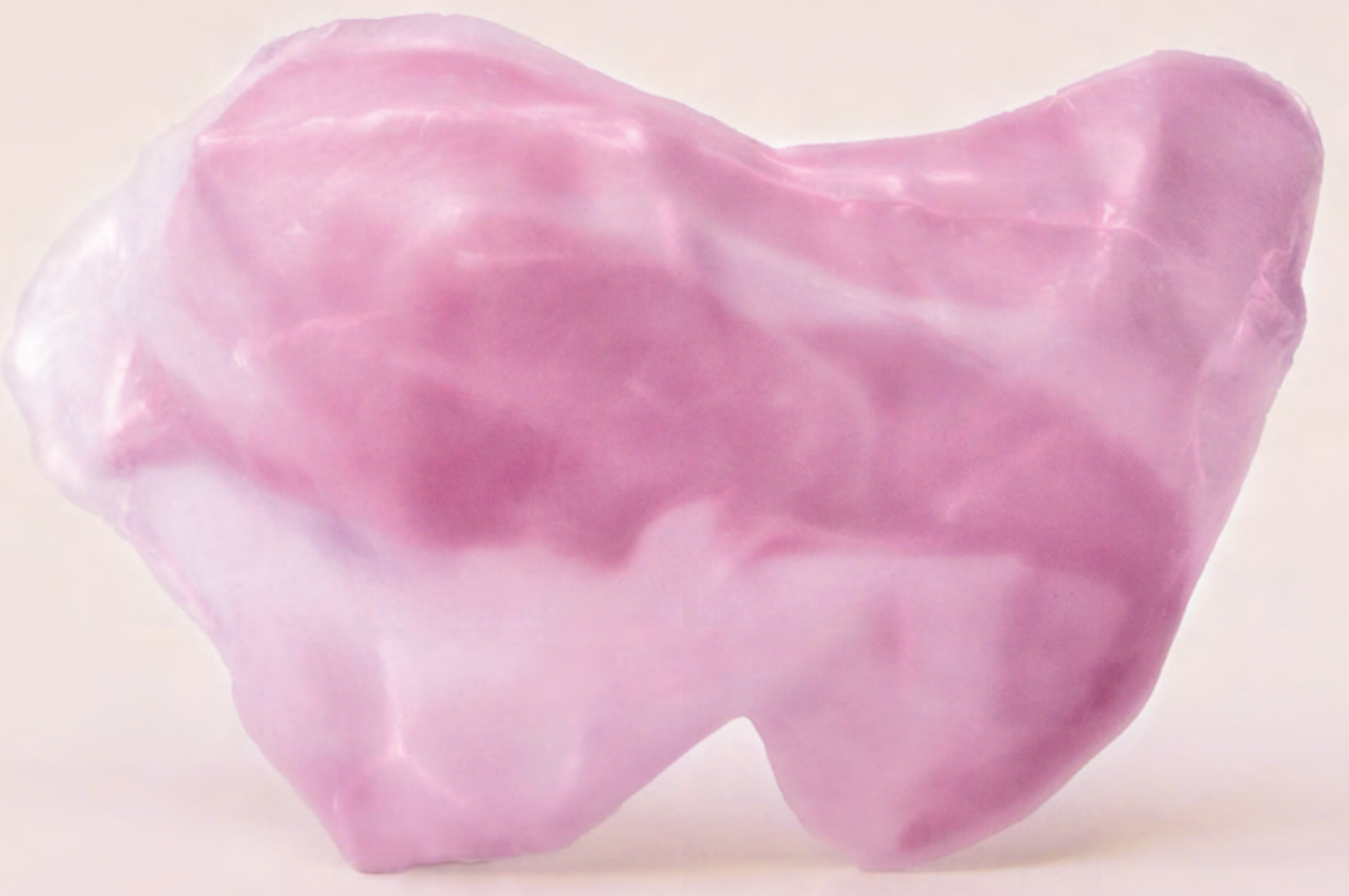

